\title{
CRISTIANA FURLAN CAPORRINO
}

CONFINAMENTO DADO POR LAJES E VIGAS MELHORANDO A RESISTÊNCIA DO PILAR QUE AS CRUZA

São Paulo

2007 


\section{CRISTIANA FURLAN CAPORRINO}

\section{CONFINAMENTO DADO POR LAJES E VIGAS MELHORANDO A RESISTENNCIA DO PILAR QUE AS CRUZA}

Dissertação apresentada à Escola

Politécnica da Universidade de São

Paulo para obtenção do Título de Mestre em Engenharia

Área de Concentração:

Engenharia de Estruturas

Orientador:

Prof. Doutor Fernando Rebouças Stucchi

São Paulo 
FICHA CATALOGRÁFICA

Caporrino, Cristiana Furlan

Confinamento dado por lajes e vigas melhorando a resistência do pilar que as cruza / C.F. Caporrino. -- São Paulo, 2007. $124 \mathrm{p}$.

Dissertação (Mestrado) - Escola Politécnica da Universidade de São Paulo. Departamento de Engenharia de Estruturas e Fundações.

1.Concreto 2.Análise experimental de estruturas 3.Pilares I.Universidade de São Paulo. Escola Politécnica. Departamento de Engenharia de Estruturas e Fundações II.t. 
Dedico esta pesquisa ao orientador e amigo Prof. Dr. Fernando Rebouças Stucchi que muito me apoiou com conhecimento e atenção. 


\section{AGRADECIMENTOS}

A Deus pela saúde e luz em todos os momentos.

Ao orientador Prof. Dr. Fernando Rebouças Stucchi pela confiança depositada nesta pesquisa.

Ao Prof. Dr. Antonio Figueiredo pelo auxílio na parte experimental.

Ao amigo Prof. Dr. Daniel Lepikson que muito apoiou no cálculo pelo método dos elementos finitos.

À amiga Mestre em Engenharia Ana Paula Silveira dos Santos precursora desta linha de pesquisa sempre disposta a passar seus conhecimentos e incentivar com motivação e amizade.

Ao amigo Eng. Fernando Montija pelo conhecimento em concreto importante para a parte experimental.

Aos meus superiores Marcelo Coelho Ungaretti e Kalil José Skaf pela compreensão e incentivo.

Ao Engenheiro Ivan Tessarolo e aos técnicos Rui Coelho Jacomini, Reginaldo Mariano da Silva, Eduardo Machado Cavalcanti, José Ferreira Leite Neto, Alexsandro Alves de Souza, Antônio Coelho Jacomini e Renata Monte pelo auxílio e excelente desempenho no desenvolvimento experimental.

Ao Prof. Dr. Ruy Paulleti pela credibilidade e grande apoio. 
À Panambra Industrial e Técnica S.A. na pessoa do Senhor Wilian Roberto Vieira pela doação dos strain gages.

À Votorantin Cimentos pela doação de material para pesquisa.

Aos meus pais Benito, in memorian, e Nádia pelo amor incondicional e apoio constante em todas as etapas da minha vida.

Aos amigos e familiares Daniel Miranda dos Santos, Devardes Adari, Édina Marta Uzelin, Marly Coimbra, Nilce Furlan, Renata Rebesco e Renato Zaia pelo apoio, carinho, dedicação e incentivo sempre presentes em todos os momentos. 
"Creio que o esforço constante, o esforço incansável, a busca de metas claras com esforço sincero é o único caminho".

Dalai Lama 


\section{RESUMO}

O objetivo deste trabalho foi estudar o efeito do confinamento em encontros de pilares de concreto com uma determinada resistência à compressão com lajes ou vigas de concreto de menor resistência. Com isso pretendeu-se desenvolver um melhor entendimento desse assunto, ainda pouco explorado, avaliar recomendações de algumas normas e, onde necessário e possível, sugerir uma solução alternativa. Foram ensaiados à compressão axial vinte e dois modelos reduzidos que representavam pilares de canto ou internos, incorporando parte da laje, e pilares isolados, cujos resultados foram comparados com recomendações de normas, ACI-318, CSA 23.3 e pesquisadores como, Gamble e Klinar, Ospina e Alexander, Bianchini e Silveira dos Santos. Na verdade, esta pesquisa é um prosseguimento daquela realizada por Silveira dos Santos. Complementando os estudos experimentais, modelos em elementos finitos possibilitaram a melhor compreensão desse efeito e ainda viabilizaram a comparação dos resultados experimentais com o critério de confinamento sugerido pelo CM CEB-FIP e pelo Eurocode EC2. Concluiu-se que apenas para pilares internos, cercados por laje em toda a volta, há um aumento de resistência do conjunto por efeito do confinamento do concreto da laje, devendo-se ainda respeitar certos limites. Para pilares de canto é necessária a utilização de algum elemento que compense a falta do concreto, como por exemplo, uma armadura transversal. 


\begin{abstract}
The goal of this paper is to study the effect of the confinement in connections of concrete columns having certain strength with lower strength concrete slabs or beams. It was intended to develop a better understanding of this subject, still little explored, to evaluate some code recommendations and, where necessary and possible, to suggest a alternative solution. Twenty-two specimens of reduced models were tested in compression representing corner or internal columns, incorporating part of the slabs, and isolated columns. These results were compared with recommendations of codes, ACI318, CSA 23,3 and researchers as, Gamble and Klinar, Ospina and Alexander, Bianchini and Silveira dos Santos. Indeed, this research is a continuation of that one carried through by Silveira dos Santos. Complementing the experimental studies, finite elements models made possible the best understanding of this effect and still they had made possible the comparison of the experimental results with the confinement criterion suggested for CM CEB-FIP and Eurocode EC2. It had concluded that only for internal columns, surrounded by slab, there is a strength increase of the specimen caused by confinement of the slab's concrete respecting certain limits. For corner columns it's necessary the utilization of some element that compensates the missing concrete, for example, a transversal reinforcement.
\end{abstract}




\section{SUMÁRIO}

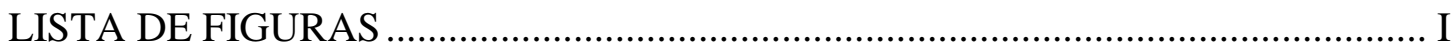

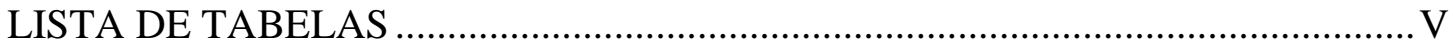

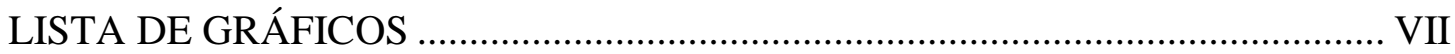

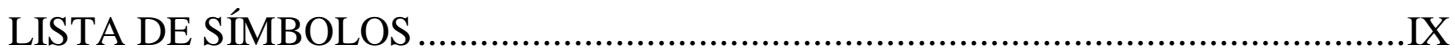

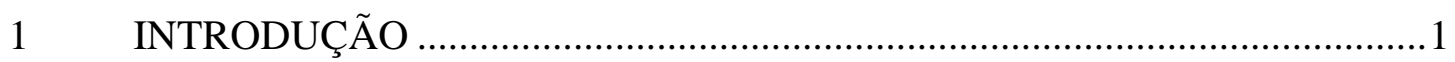

2 CONFINAMENTO DE ELEMENTOS ESTRUTURAIS DE CONCRETO

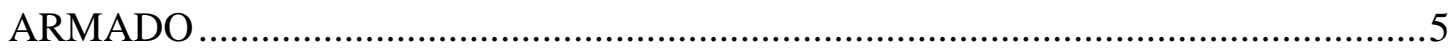

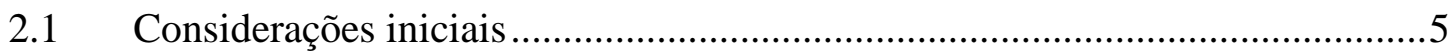

2.2 Parâmetros que influenciam o confinamento na ligação piso-pilar .....................8

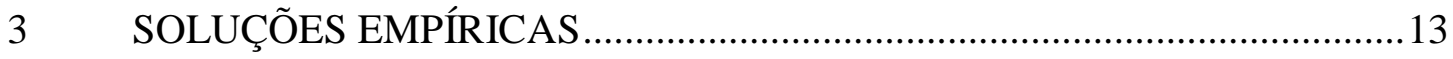

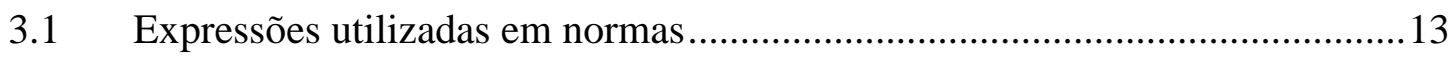

3.2 Expressões obtidas por pesquisadores ……………………………………....15

4 ANÁLISE POR MÉTODOS NUMÉRICOS ................................................17

4.1 Método dos elementos finitos ....................................................................

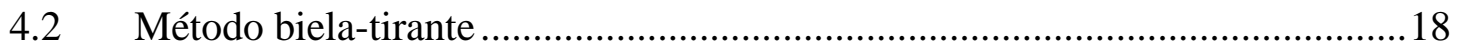

4.3 Modelos calculados pelo método dos elementos finitos ....................................22

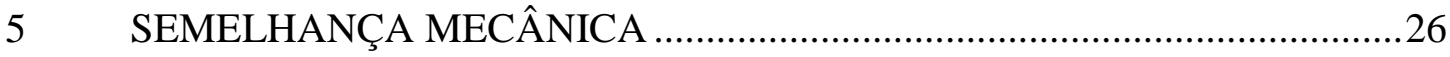

5.1 Classificação dos modelos reduzidos ...............................................................2

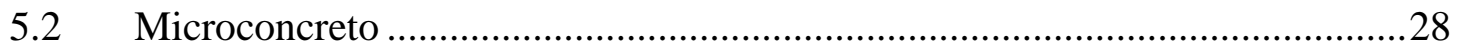

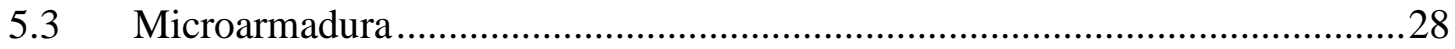

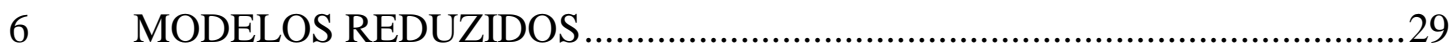

6.1 Primeira etapa - Modelos 1 e 2 2........................................................................

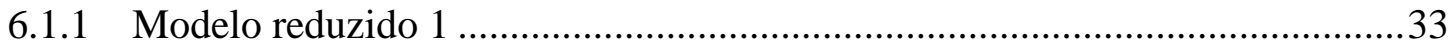




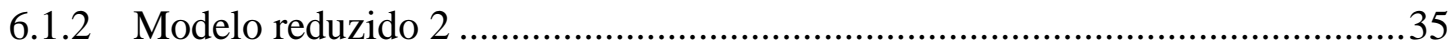

6.2 Segunda etapa - Modelos I, II, IV, V, VI e VII .........................................39

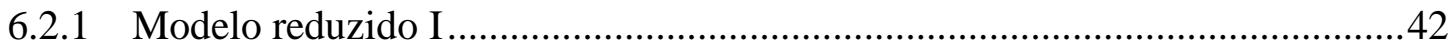

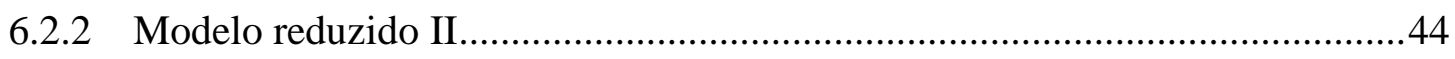

6.2.3 Modelo reduzido III .......................................................................... 44

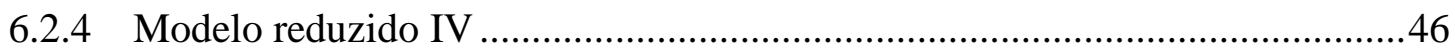

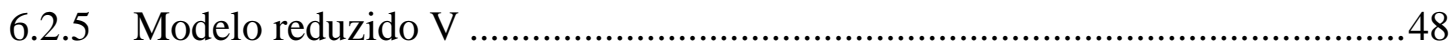

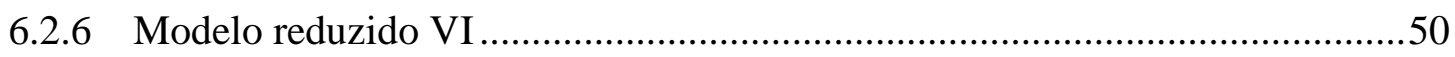

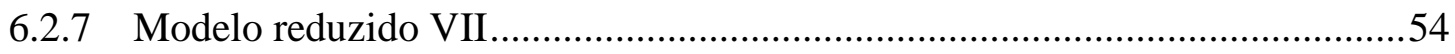

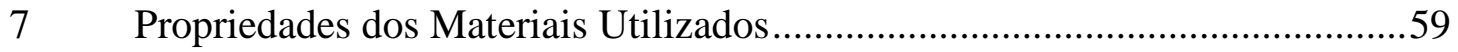

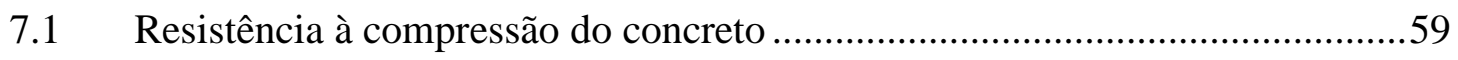

7.2 Resultados dos ensaios de resistência à compressão do concreto.....................62

7.3 Resistência do concreto à tração por compressão diametral ............................64

7.4 Resultados do ensaio de determinação da resistência à tração por compressão diametral do concreto utilizado nas regiões de laje $\left(\mathrm{f}_{\mathrm{ck}}=35 \mathrm{MPa}\right)$..........................65

7.5 Módulo de Elasticidade e coeficiente de Poisson ..........................................66

7.6 Resultados dos ensaios experimentais para obtenção do módulo de elasticidade

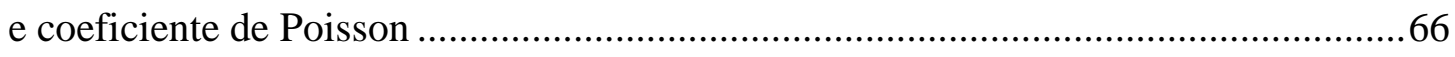

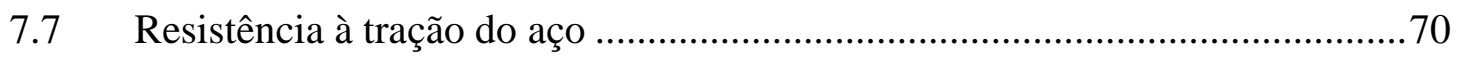

7.8 Resultados do ensaio de determinação da resistência à tração do aço..............71

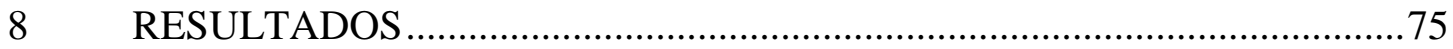

8.1 Resultados dos ensaios experimentais da primeira etapa............................75

8.1.1 Resultados dos ensaios para o modelo reduzido 1 ....................................... 75

8.1.2 Resultados dos ensaios para o modelo reduzido 2 .................................... 76

8.2 Resultados dos ensaios experimentais da segunda etapa ..............................77 
8.2.1 Resultados dos ensaios para o modelo reduzido I

8.2.2 Resultados dos ensaios para o modelo reduzido II .................................... 80

8.2.3 Resultados dos ensaios para o modelo reduzido IV .................................... 81

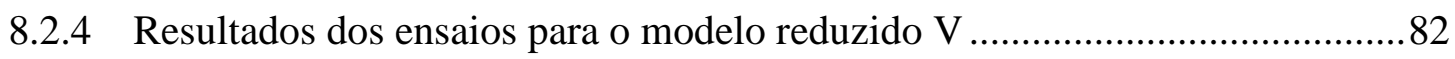

8.2.5 Resultados dos ensaios para o modelo reduzido VI..................................... 85

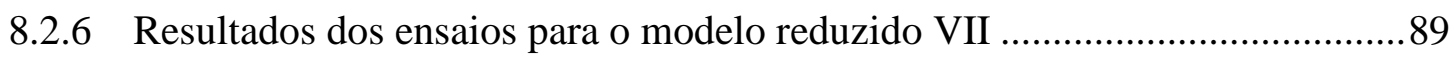

9 Resultados dos modelos calculados pelo método dos elementos finitos .........94

10 ANÁLISE DOS RESULTADOS EXPERIMENTAIS ................................103

11 ANÁlise DOS RESULTADOS OBTIDOS PELO MÉTODO DOS

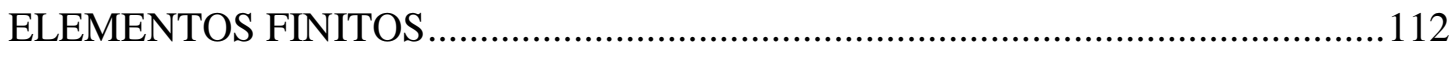

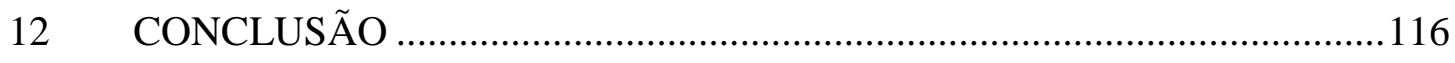

12.1 Ensaios do modelo reduzido I, que representa um pilar isolado...................116

12.2 Ensaios do modelo reduzido II, que representa um pilar isolado com faixa de

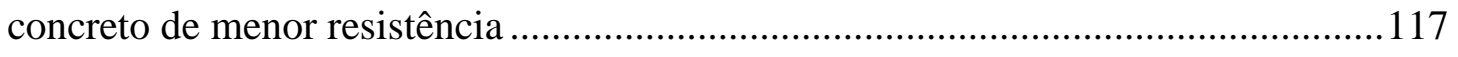

12.3 Ensaios do modelo reduzido IV, que representa um pilar central com laje de concreto de menor resistência com $4,5 \mathrm{~cm}$ de espessura

12.4 Ensaios dos modelos reduzidos V, VI e VII que representam um pilar de canto com laje de concreto de menor resistência com $7 \mathrm{~cm}$ de espessura..........................118

12.5 Modelos estudados pelo método dos elementos finitos ...............................119

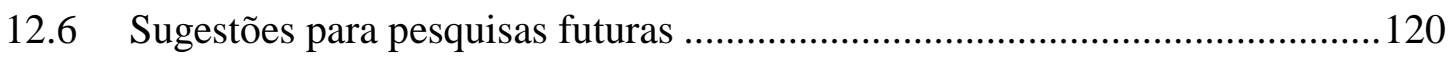

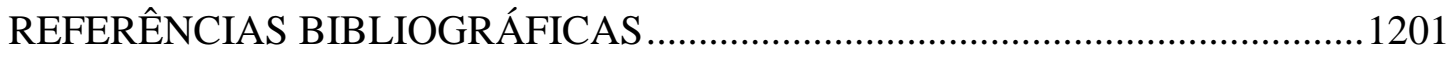

ANEXO A

ANEXO B

ANEXO C 


\section{LISTA DE FIGURAS}

Figura 1.1 Puddling___ 2

Figura 1.2 Protótipo __ 3

Figura 1.3 Posições de pilares___ 3

Figura 2.1 Efeito do confinamento sobre o concreto __ 6

Figura 2.2 Primeiros resultados experimentais de estudos sobre confinamento___ 7

Figura 2.3 Variação de $\mathrm{k}_{1}$ com a pressão lateral ___ 8

Figura 4.1 Consolo Curto de Concreto Armado __ 20

Figura 4.2 Modelagem matemática para o modelo de pilar central __ 22

Figura 4.3 Tensões $\sigma 2$ na laje do modelo de pilar central (tensões em $\mathrm{t} / \mathrm{m}^{2}$ ) ___ 23

Figura 4.4 Linhas de tensão no modelo de pilar central ___ 24

Figura 4.5 Ampliação da região onde ocorrem as forças de tração ___ 24

Figura 6.1Representação de um pilar central __ 30

Figura 6.2 Representação de um pilar de canto __ 30

Figura 6.3 Representação de um pilar isolado __ 30

Figura 6.4 Esquema do modelo reduzido $1 \ldots 33$

Figura 6.5 Exemplares dos modelos reduzidos 1 e 2 antes de serem ensaiados___ 34

Figura 6.6 Esquema do modelo reduzido $2 \ldots 37$

Figura 6.7 Armadura dos modelos 2-A e 2-B __ 37

Figura 6.8 Armadura dos modelos 2-C e 2-D__ 38

Figura 6.9 Armadura dos modelos 2-E e 2-F __ 38

Figura 6.10 Capeamento dos modelos reduzidos __ 40

Figura 6.11 Modelos reduzidos capeados __ 40

Figura 6.12 Travamento dos modelos reduzidos para pilar isolado ___ 41

Figura 6.13 Travamento dos modelos reduzidos de pilar central ___ 41 
Figura 6.14 Concretagem do modelo reduzido I 42

Figura 6.15 Modelo reduzido I capeado 43

Figura 6.16 Esquema do modelo reduzido II 44

Figura 6.17 Forma do modelo reduzido II 45

Figura 6.18 Concretagem do modelo reduzido II 45

Figura 6.19 Esquema do modelo reduzido IV 46

Figura 6.20 Modelo reduzido IV 47

Figura 6.21 Esquema do modelo reduzido V 48

Figura 6.22 Primeira fase da concretagem do modelo reduzido V 49

Figura 6.23 Segunda fase da concretagem do modelo reduzido V 49

Figura 6.24 Terceira e última fase da concretagem do modelo reduzido V 49

Figura 6.25 Cálculo da armadura de reforço na região da laje 50

Figura 6.26 Modelo reduzido VI 52

Figura 6.27 Esquema da armadura do modelo reduzido VI 52

Figura 6.28 Strain gages fixados na armadura do modelo reduzido VI 53 Figura 6.29 Primeira fase da concretagem e inserção de armadura do modelo reduzido VI 53

Figura 6.30 Esquema para o modelo reduzido VII 54

Figura 6.31 Esquema da armadura do modelo reduzido VII 55

Figura 6.32 Armadura instrumentada do modelo reduzido VII 55

Figura 6.33 Segunda fase da concretagem do modelo reduzido VII 56

Figura 6.34 Modelo reduzido VII pronto pra ser colocado na câmara úmida 56

Figura 6.35 Transporte do modelo reduzido VII 57

Figura 6.36 Desforma do modelo reduzido VII 57

Figura 7.1 Esquema de corpo-de-prova cilíndrico $10 \mathrm{~cm}$ x $20 \mathrm{~cm}$ 59

Figura 7.2 Corpo-de-prova cilíndrico $10 \mathrm{~cm}$ x $20 \mathrm{~cm}$ 59

Figura 7.3 Corpo-de-prova cilíndrico $15 \mathrm{~cm} \mathrm{x} 30 \mathrm{~cm}$ 64

Figura 7.4 Corpo-de-prova cilíndrico $15 \mathrm{~cm}$ x $30 \mathrm{~cm}$ preparado para ser ensaiado quanto a resistência à tração por compressão diametral 64

Figura 7.5 Ensaio de determinação da resistência à tração por compressão diametral de corpos-de-prova cilíndricos de dimensões $15 \mathrm{~cm}$ x $30 \mathrm{~cm}$ e $\mathrm{f}_{\mathrm{ck}}$ de $35 \mathrm{MPa}$ 66 
Figura 7.6 Ensaio para obtenção do módulo de elasticidade e coeficiente de Poisson_667

Figura 7.7 Figura Corpo-de-prova $\phi$ de 5,0 mm sendo ensaiado quanto a tração __ 71

Figura 8.1 Modelo reduzido 1-A rompido __ 76

Figura 8.2 Modelo reduzido 2-A rompido ___ 77

Figura 8.3 Modelo reduzido I-A rompido__ 78

Figura 8.4 Modelo reduzido I-C rompido _ 79

Figura 8.5 Modelo reduzido II-A rompido __ 80

Figura 8.6 Modelo reduzido IV, exemplares A, B e C rompidos ___ 82

Figura 8.7 Modelo reduzido V-B rompido __ 83

Figura 8.8 Modelo reduzido V-E rompido ___ 84

Figura 8.9 Modelo reduzido VI-A rompido ___ 85

Figura 8.10 Modelo reduzido VII-C rompido__ 89

Figura 9.1 Esquema geral dos modelos com laje estudados pelo método dos elementos finitos

Figura 9.2 Tensões $\sigma_{2}$ na laje do modelo reduzido IV (pilar central com laje de 4,5 cm de espessura) com tensão axial aplicada de 47,91 MPa (tensões em tf/ $\mathrm{m}^{2}$ ) 95

Figura 9.3 Recorte do trecho confinado do pilar contido na laje (tensões em $\mathrm{tf} / \mathrm{m}^{2}$ ) 95 Figura 9.4 Recorte na laje para visualização das tensões próximas ao trecho confinado (tensões em $\mathrm{tf} / \mathrm{m}^{2}$ ) 96

Figura 9.5 Tensões $\sigma_{1}$ na laje do modelo reduzido IV (pilar central com laje de 4,5 cm de espessura) com tensão axial aplicada de 47,91 MPa (tensões em tf $/ \mathrm{m}^{2}$ ) 96 Figura 9.6 Tensões $\sigma_{2}$ na laje do modelo reduzido representando pilar central com laje de $7 \mathrm{~cm}$ de espessura com tensão axial aplicada de 49,20 MPa (tensões em tf/m² Silveira dos Santos)

Figura 9.7 Tensões $\sigma_{1}$ na laje do modelo reduzido representando pilar central com laje de $7 \mathrm{~cm}$ de espessura com tensão axial aplicada de 49,20 MPa (tensões em tf/m² Silveira dos Santos) 97

Figura 9.8. Tensões $\sigma_{2}$ na laje da $1^{\mathrm{a}}$ série de exemplares do modelo reduzido $\mathrm{V}$ (pilar de canto com laje de $7 \mathrm{~cm}$ de espessura, exemplares V-A, V-B e V-C) com tensão axial aplicada de 47,85 MPa (tensões em $\mathrm{tf} / \mathrm{m}^{2}$ ) 98 
Figura 9.9 Tensões $\sigma_{1}$ na laje da $1^{\mathrm{a}}$ série de exemplares do modelo reduzido $\mathrm{V}$ (pilar de canto com laje de $7 \mathrm{~cm}$ de espessura, exemplares V-A, V-B e V-C) com tensão axial aplicada de 47,85 $\mathrm{MPa}$ (tensões em $\mathrm{tf} / \mathrm{m}^{2}$ ) 98

Figura 9.10 Tensões $\sigma_{2}$ na laje da $2^{\mathrm{a}}$ série de exemplares do modelo reduzido $\mathrm{V}$ (pilar de canto com laje de $7 \mathrm{~cm}$ de espessura, exemplares V-D, V-E e V-F) com tensão axial aplicada de 37,53 MPa (tensões em $\mathrm{tf} / \mathrm{m}^{2}$ )

Figura 9.11. Tensões $\sigma_{1}$ na laje da $2^{\mathrm{a}}$ série de exemplares do modelo reduzido $\mathrm{V}$ (pilar de canto com laje de $7 \mathrm{~cm}$ de espessura, exemplares V-D, V-E e V-F) ) com tensão axial aplicada de 37,53 $\mathrm{MPa}$ (tensões em $\mathrm{tf} / \mathrm{m}^{2}$ ) 99

Figura 9.12 Esquema geral dos modelos com viga estudados pelo método dos elementos finitos 100

Figura 9.13 Tensões $\sigma_{2}$ na região de concreto com resistência menor do modelo matemático de pilar central com vigas estreitas e tensão axial aplicada de $40 \mathrm{MPa}$ (tensões em $\mathrm{tf} / \mathrm{m}^{2}$ ) 101

Figura 9.14 Tensões $\sigma_{1}$ na região de concreto com resistência menor do modelo matemático de pilar central com vigas estreitas e tensão axial aplicada de $40 \mathrm{MPa}$ (tensões em $\mathrm{tf} / \mathrm{m}^{2}$ ) 101 Figura 9.15 Tensões $\sigma_{2}$ na região de concreto com resistência menor do modelo matemático de pilar central com vigas largas e tensão axial aplicada de $40 \mathrm{MPa}$ (tensões $\left.\mathrm{em} \mathrm{tf} / \mathrm{m}^{2}\right)$ 102

Figura 9.16 Tensões $\sigma_{1}$ na região de concreto com resistência menor do modelo matemático de pilar central com vigas largas e tensão axial aplicada de $40 \mathrm{MPa}$ (tensões $\left.\mathrm{em} \mathrm{tf} / \mathrm{m}^{2}\right)$ 102 


\section{LISTA DE TABELAS}

Tabela 3.1 Expressões para avaliar $\mathrm{f}_{\text {ce }}$ (resistência efetiva) em pilares 16

Tabela 6.1 Valores reais e experimentais das lajes planas (placas) 31

Tabela 6.2 Modelo reduzido 1 33

TABELA 6.3 Modelo reduzido 2 36

Tabela 6.4 Resumo dos modelos da $1^{\mathrm{a}}$ etapa 39

Tabela 6.5 Modelo reduzido I 42

Tabela 6.6 Modelo reduzido II 44

Tabela 6.7 Modelo reduzido IV 46

Tabela 6.8 Modelo reduzido V 48

Tabela 6.9 Modelo reduzido VI 51

Tabela 6.10 Modelo reduzido VII 54

Tabela 6.11 Resumo dos modelos reduzidos da $2^{\mathrm{a}}$ etapa 58

Tabela 7.1 Propriedades do concreto para cada $\mathrm{f}_{\mathrm{c} 28}$ 61

Tabela 7.2 Traço por metro cúbico para moldagem do modelos reduzidos 62

Tabela 0.3 Resistências e abatimentos dos concretos 63

Tabela 7.4 Resultados do ensaio de determinação da resistência à tração do concreto com resistência à compressão de $35 \mathrm{MPa}$ (utilizado nas regiões de laje) 65

Tabela 7.5 Dimensões iniciais dos fios de aço ensaiados 72

Tabela 7.6 Propriedades mecânicas dos fios de aço ensaiados 74

Tabela 8.1 Ensaio de compressão axial para o modelo reduzido 1 75

Tabela 8.2 Ensaio de compressão axial para o modelo reduzido 2 76

Tabela 8.3 Ensaio de compressão axial para o modelo reduzido I, exemplares A e B__77 Tabela 8.4 Ensaio de compressão axial para o modelo reduzido I, exemplares C e D_78 Tabela 8.5 Ensaio de compressão axial para o modelo reduzido II 80

Tabela 8.6 Ensaio de compressão axial para o modelo reduzido IV 81 
Tabela 8.7 Ensaio de compressão axial para a $1^{\mathrm{a}}$ série de exemplares do modelo reduzido $\mathrm{V}$ 83

Tabela 8.8 Ensaio de compressão axial para a $2^{\mathrm{a}}$ série de exemplares o modelo reduzido $\mathrm{V}$ 84

Tabela 8.9 Ensaio de compressão axial para o modelo reduzido VI 85

Tabela 8.10 Ensaio de compressão axial para o modelo reduzido VII 89

Tabela 8.11 Resultados da etapa 93

Tabela 10.1 Comparação de resultados 108 


\section{LISTA DE GRÁFICOS}

Gráfico 7.1 Carregamento do ensaio para obtenção do módulo de elasticidade e coeficiente de Poisson para o concreto com resistência à compressão de $35 \mathrm{MPa}$ 68

Gráfico 7.2 Carregamento do ensaio para obtenção do módulo de elasticidade e coeficiente de Poisson para o concreto com resistência à compressão de $50 \mathrm{MPa}$ 68

Gráfico 7.3 Ensaio de determinação da resistência à tração do aço de diâm. 5,0 mm __73

Gráfico 7.4 Ensaio de determinação da resistência à tração do aço de diâm. 4,2 mm __73 Gráfico 8.1 Força x deformação da armadura adicional $(\phi 5 \mathrm{~mm})$ do modelo reduzido VI-A 86

Gráfico 8.2 Força x deformação da armadura adicional $(\phi 5 \mathrm{~mm})$ do modelo reduzido VI-B 86

Gráfico 8.3 Força x deformação da armadura adiconal $(\phi 5 \mathrm{~mm})$ do modelo reduzido VI-C 87

Gráfico 8.4 Força x deformação da armadura da laje $(\phi 4,2 \mathrm{~mm})$ do modelo reduzido VI-A 87

Gráfico 8.5 Força x deformação da armadura da laje $(\phi 4,2 \mathrm{~mm})$ do modelo reduzido VI-B 88

Gráfico 8.6 Força x deformação da armadura da laje $(\phi 4,2 \mathrm{~mm})$ do modelo reduzido VI-C 88

Gráfico 8.7 Força x deformação da armadura de reforço $(\phi 5 \mathrm{~mm})$ do modelo reduzido VII-A 90

Gráfico 8.8 Força x deformação da armadura de reforço $(\phi 5 \mathrm{~mm})$ do modelo reduzido VII-B 90

Gráfico 8.9 Força x deformação da armadura de reforço $(\phi 5 \mathrm{~mm})$ do modelo reduzido VII-C 
Gráfico 8.10 Força $\mathrm{x}$ deformação da armadura da laje $(\phi 4,2 \mathrm{~mm})$ do modelo reduzido VII-A

Gráfico 8.11 Força x deformação da armadura da laje $(\phi 4,2 \mathrm{~mm})$ do modelo reduzido VII-B 92

Gráfico 8.12 Força x deformação da armadura da laje $(\phi 4,2 \mathrm{~mm})$ do modelo reduzido VII-C

Gráfico 10.1 Gráfico comparativo para pilares centrais quadrados em lajes cogumelos 109

Gráfico 10.2 Gráfico comparativo para pilares de canto e borda quadrados em lajes cogumelos 110 


\section{LISTA DE SÍMBOLOS}

$\mathrm{f}_{\mathrm{ck}}$ : resistência característica à compressão do concreto

$\mathrm{f}_{\mathrm{cm} 7}$ : resistência média à compressão do concreto aos 7 dias de idade

$\mathrm{f}_{\mathrm{cm} 28}$ : resistência média à compressão do concreto aos 28 dias de idade

$\mathrm{f}_{\text {cef: }}$ resistência efetiva à compressão

$\mathrm{f}_{\text {cefm: }}$ : resistência média efetiva à compressão

$\mathrm{f}_{\mathrm{cl}}$ : resistência à compressão do concreto da laje

$\mathrm{f}_{\mathrm{cp}}$ : resistência à compressão do concreto do pilar

$\mathrm{f}_{\mathrm{clm}}$ : resistência média à compressão do concreto da laje

$\mathrm{f}_{\mathrm{cpm}}$ : resistência média à compressão do concreto do pilar

$\mathrm{f}_{\mathrm{ct}}$ : resistência à tração do concreto

$\mathrm{f}_{\mathrm{ctm}}$ : resistência média à tração do concreto

$\sigma:$ tensão

h: espessura da laje

b: dimensão da face do pilar

$\mathrm{f}_{\mathrm{cc}}$ : resistência do concreto confinado;

$\mathrm{f}_{\mathrm{co}}$ : resistência do concreto não confinado;

$\mathrm{f}_{1:}$ pressão lateral;

$\mathrm{k}_{1}$ e $\mathrm{k}_{2}$ : coeficientes obtidos experimentalmente;

$\varepsilon_{\mathrm{cc}}$ : deformação última do concreto confinado;

$\varepsilon_{\mathrm{co}}$ : deformação última do concreto não confinado

$\delta_{\mathrm{u}}$ : campo de deslocamentos

бe: tensão admissível

$\mathrm{d}_{\mathrm{e}}$ : campo de deslocamentos

F: força 
$\mathrm{p}_{\mathrm{u}}$ : força de ruptura

$\mathrm{p}_{0}$ : força aplicada

$\mathrm{f}_{\mathrm{s}}$ : resistência à tração do tirante

$\mathrm{f}_{\mathrm{c}}$ : resistência à compressão do concreto da biela

1: largura do consolo

c: largura da biela

$\mathrm{A}_{\text {s: }}$ área de aço

$\mathrm{A}_{\mathrm{c}}$ : área de concreto

$\mathrm{z}$ : braço de alavanca

e: excentricidade de aplicação da força

E: módulo de elasticidade

v: coeficiente de Poisson

$\mathrm{H}_{\mathrm{p}}$ : altura do protótipo

$\mathrm{h}_{\text {mod }}$ : altura do modelo

$\mathrm{h}_{\mathrm{p}}$ : espessura da laje do protótipo

$\mathrm{h}_{\mathrm{m}}$ : espessura da laje do modelo

$\mathrm{h}_{\mathrm{v}}:$ altura da viga

$\phi$ : diâmetro

$\mathrm{R}_{\mathrm{ct}}$ : resultante resistente à tração do concreto no plano mediano diagonal

$\mathrm{R}_{\mathrm{st}}$ : resultante resistente à tração do aço

$\mathrm{A}_{\text {scalc: }}$ : área de aço calculada

$\mathrm{A}_{\text {sreal.: }}$ área de aço utilizada

a/c: relação água/cimento em massa $(\mathrm{kg} / \mathrm{kg})$

C: consumo de cimento por metro cúbico de concreto adensado $\left(\mathrm{kg} / \mathrm{m}^{3}\right)$

$\mathrm{m}$ : relação de agregados seco/cimento em massa $(\mathrm{kg} / \mathrm{kg})$

h: abatimento, em cm, do tronco de cone de Abrams 


\section{INTRODUÇÃO}

A economia na construção de edifícios altos freqüentemente leva ao uso de concreto de resistência maior em pilares do que aquele usado em lajes e vigas, pois, sendo um edifício de altura elevada, os esforços solicitantes de compressão nos pilares tornam-se cada vez maiores. O aumento da resistência do concreto do pilar está diretamente relacionado com a sua capacidade de suportar este tipo de esforço. Como o concreto com resistência maior tem um custo mais elevado que o de resistência menor, adota-se o concreto de resistência maior apenas aonde necessário, ou seja, nos pilares, e o de resistência menor em todo o restante da estrutura, porém essa solução gera algumas complicações construtivas. Uma maneira de se realizar tal feito é preencher-se a área correspondente aos pilares nas lajes ou vigas com o concreto de resistência maior, o que para o caso de lajes planas apoiadas em pilares, apresenta uma grande vantagem, pois se formam capitéis embutidos que contribuem para o aumento da resistência à punção. Essa solução é apresentada no item 10.13 do ACI 318, 2002, denominada de puddling, que ainda sugere que se estenda essa massa de concreto de resistência maior por $60 \mathrm{~cm}$ além da área do pilar. Por outro lado, sua realização efetiva é um tanto quanto dificultosa e resulta em uma solução de qualidade questionável por causa da junta e da má vibração na borda do puddling, ver figura 1.1, além de consumir um tempo considerável para sua execução. 


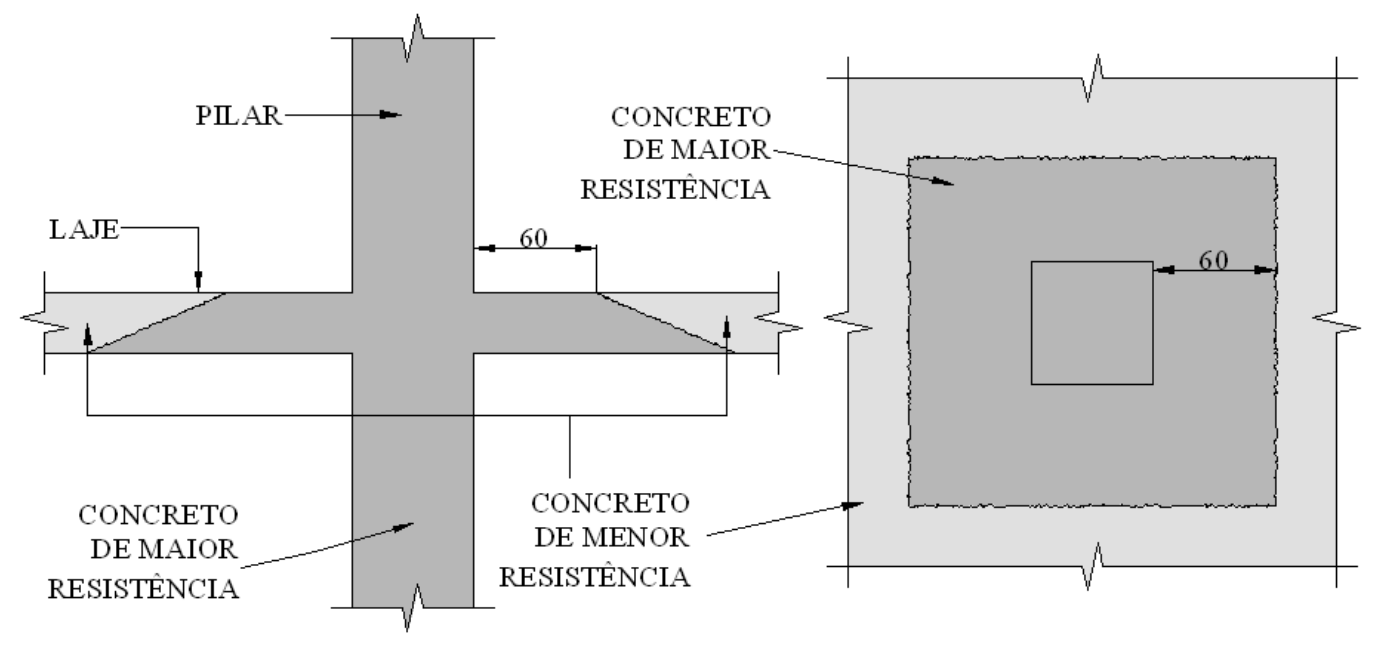

Figura 1.1 Puddling

Sabe-se que devido ao efeito do confinamento proporcionado pelas lajes que envolvem os pilares há um ganho de resistência do conjunto, mas seria esse confinamento suficiente para o aumento de resistência necessário? Na verdade, deve-se levar em conta as variáveis que influenciam esta questão, dentre as quais pode-se destacar como sendo mais relevantes: a posição do pilar com relação à laje e/ou viga, a altura dos elementos que interferem com o pilar, lajes e/ou vigas, a largura das vigas interferentes em relação à dimensão do pilar, a diferença de resistência do concreto pilar-piso, a armadura de lajes e vigas, entre outras. A interdependência entre esses parâmetros é um assunto ainda não completamente esclarecido.

Em alguns casos pode-se recorrer a um aumento de armaduras na região de interseção do pilar com o piso, como, por exemplo, em pilares de canto onde duas faces da intersecção não têm a colaboração do efeito de confinamento. O estudo desta solução é apresentado mais adiante. Este trabalho dá ênfase ao caso de pilares interceptados por lajes planas e por lajes e vigas como representam as figuras 1.2 e 1.3. 


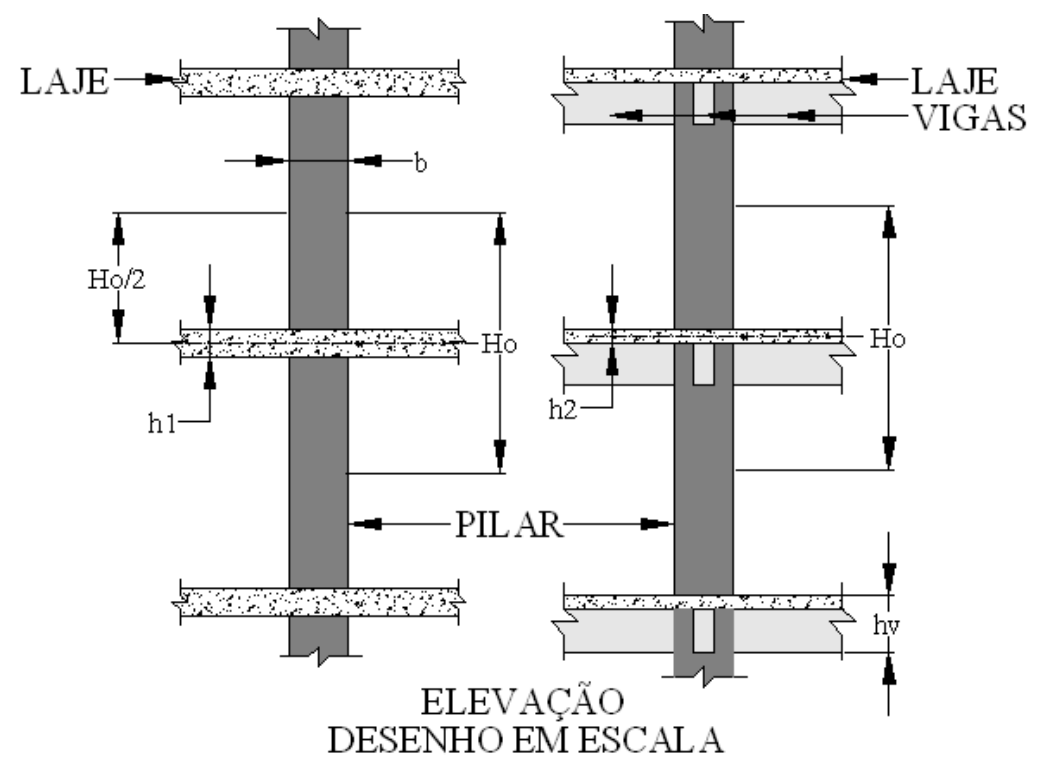

Figura 1.2 Protótipo

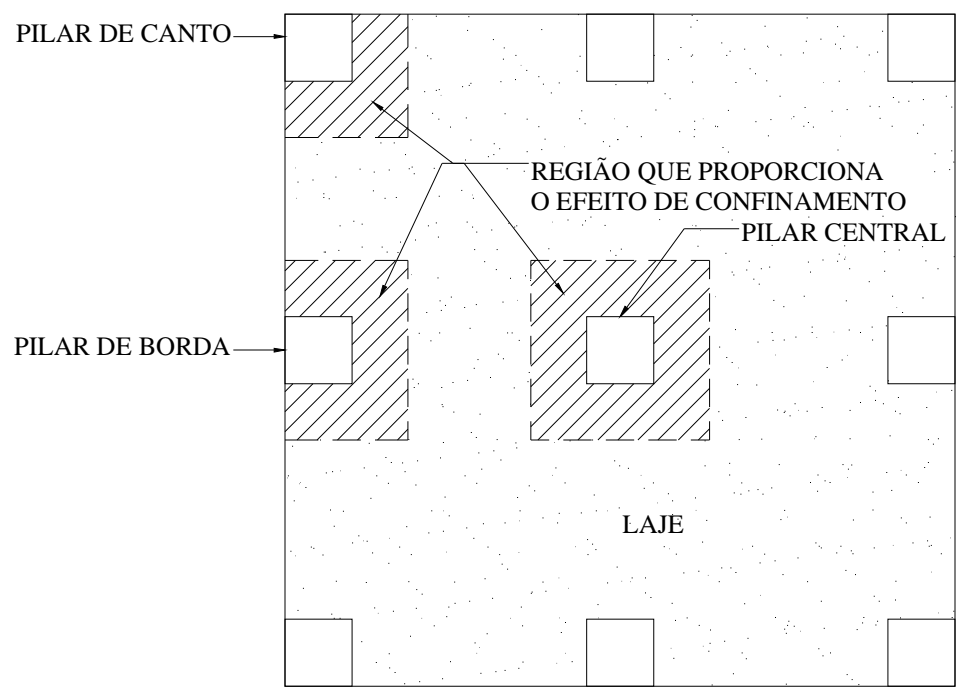

Figura 1.3 Posições de pilares

O objetivo principal é analisar até quanto o efeito do confinamento é capaz de compensar a diferença de resistência dos concretos na interface pilar-laje, considerandose os casos de um pilar central, caso mais favorável de confinamento, e pilar de canto, no qual estudaram-se algumas soluções para melhorar o confinamento.

Para essa análise, foram feitos ensaios em laboratório com modelos reduzidos representando esses pilares, utilizaram-se dois tipos de concreto ao longo da altura, tendo na região da laje, concreto de menor resistência. Esses modelos tiveram a laje 
armada ou não e foram submetidos a ensaios de compressão axial. Sendo que em alguns dos casos uma análise mais detalhada foi feita, utilizando-se um programa de elementos finitos.

Para a realização deste trabalho instituiu-se um método baseado em uma ordem lógica para estruturar a pesquisa. Inicialmente se fez um estudo teórico do fenômeno do confinamento e a partir do entendimento de tal fenômeno, foram determinados os métodos de análise que são modelos matemáticos e modelos reduzidos para ensaios em laboratório. Partiu-se, então, para estudo, pesquisa e conhecimento dos métodos escolhidos, iniciando-se pela escolha de um programa para modelagem matemática, neste caso foi o programa ADINA, que utiliza o método dos elementos finitos para o cálculo, em seguida fez-se pesquisa e estudo sobre modelos reduzidos e adaptação para o caso em análise. Definidos os métodos de análise determinaram-se os parâmetros adotados baseando-se em outras pesquisas, dados extraídos dos modelos matemáticos processados e cálculos realizados, compatibilidade com as normas vigentes e com a realidade atual: escolha de dimensões, materiais e esforços solicitantes. A partir da realização dos ensaios compararam-se os resultados obtidos com os modelos matemáticos processados, ensaios experimentais realizados por outros pesquisadores, formulações sugeridas por normas e autores e então conclusões foram obtidas.

Alguns trabalhos realizados até o presente já estudaram a resistência de pilares interceptados por pisos de concreto de menor resistência.

A norma americana baseou-se no primeiro estudo realizado por Bianchini et al., 1960. Segundo esse trabalho considera-se que se a relação entre as resistências dos concretos do pilar e do piso, $\mathrm{f}_{\mathrm{cp}} / \mathrm{f}_{\mathrm{cl}}$, for menor ou igual a 1,4 em todos os casos ou em alguns casos até 1,5, o pilar terá a maior resistência de concreto, isto é, o confinamento dado pela laje ou pelas vigas é suficiente para compensar a menor resistência do concreto da laje, isso foi investigado no atual trabalho. Poucas pesquisas foram realizadas sobre este assunto, por isso o interesse em realizar este estudo. Esta pesquisa foi inspirada e baseada em outra pesquisa de mestrado realizada pela engenheira Ana Paula Silveira dos Santos, 2004. 


\section{CONFINAMENTO DE ELEMENTOS ESTRUTURAIS DE CONCRETO ARMADO}

\subsection{Considerações iniciais}

O confinamento pode ser entendido como a restrição da diformação lateral de elementos submetidos a forças axiais por efeito de Poisson. Em decorrência do confinamento ocorrem tensões de compressão triaxial. Ele gera uma compressão transversal que pode ser obtida com a aplicação de pressão ativa, ou de forma passiva, por meio de armaduras transversais e camisas envolventes. Como um material friccional, o concreto é sensível a pressões hidrostáticas. Quando submetido a tensões confinantes, apresenta um ganho de resistência e ductilidade. Segundo Fedération Internationale du Béton-FIB, 1999, concretos de uso corrente possuem cerca de $75 \%$ em volume de agregados. Os agregados são os componentes mais rígidos do concreto e as forças de compressão caminham preferencialmente por meio deles, figura 2.1-a. Para o equilíbrio são necessárias componentes laterais, que são provenientes da coesão da pasta de cimento, figura 2.1-b. Quando se supera esta coesão, surgem as primeiras microfissuras entre agregados e a pasta de cimento, Figura 2.1-c. As microfissuras crescem com o aumento da carga e o concreto rompe com fissuração paralela à aplicação da carga. $\mathrm{O}$ confinamento atua aumentando o efeito da coesão, possibilitando um aumento de resistência, figura 2.1-d. Quando o confinamento é obtido por meio de armaduras transversais, são necessárias grandes deformações laterais para mobilizá-lo e, conseqüentemente, ocorre um grande aumento da ductilidade. 


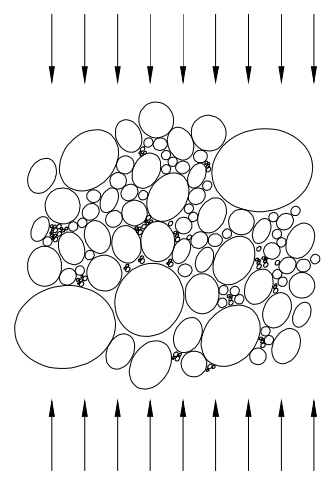

A

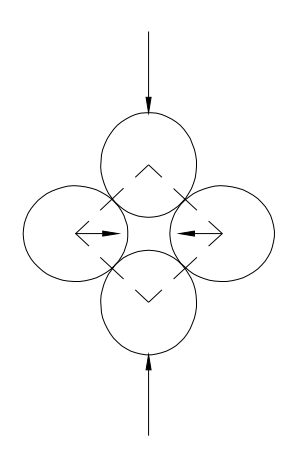

B

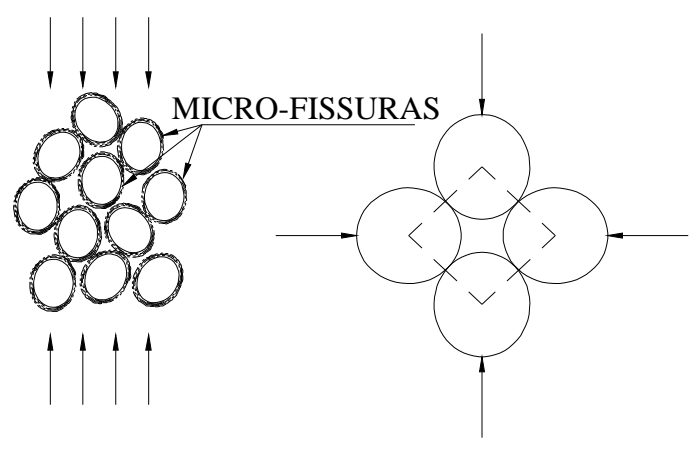

$\mathrm{C}$

$\mathrm{D}$

Figura 2.1 Efeito do confinamento sobre o concreto

Um dos primeiros trabalhos sobre confinamento do concreto consistia na realização de ensaios de compressão axial do concreto confinado por meio de pressão aplicada por fluidos e armaduras transversais em espirais. Richard et al. apud Carrazedo, 2002, verificaram que a resistência à compressão axial e a deformação última do concreto crescem na presença de pressões confinantes. Propuseram então equações para relacionar a resistência, $\mathrm{f}_{\mathrm{cc}}$, e a deformação última, $\varepsilon_{\mathrm{cc}}$, do concreto confinado com a pressão lateral, $\mathrm{f}_{1}$. Na Figura 2.2 são apresentados resultados experimentais de Richard et al. e de Balmer apud Carrazedo, 2002. Apresentam-se também as equações e a envoltória de ruptura linear por eles propostas. 


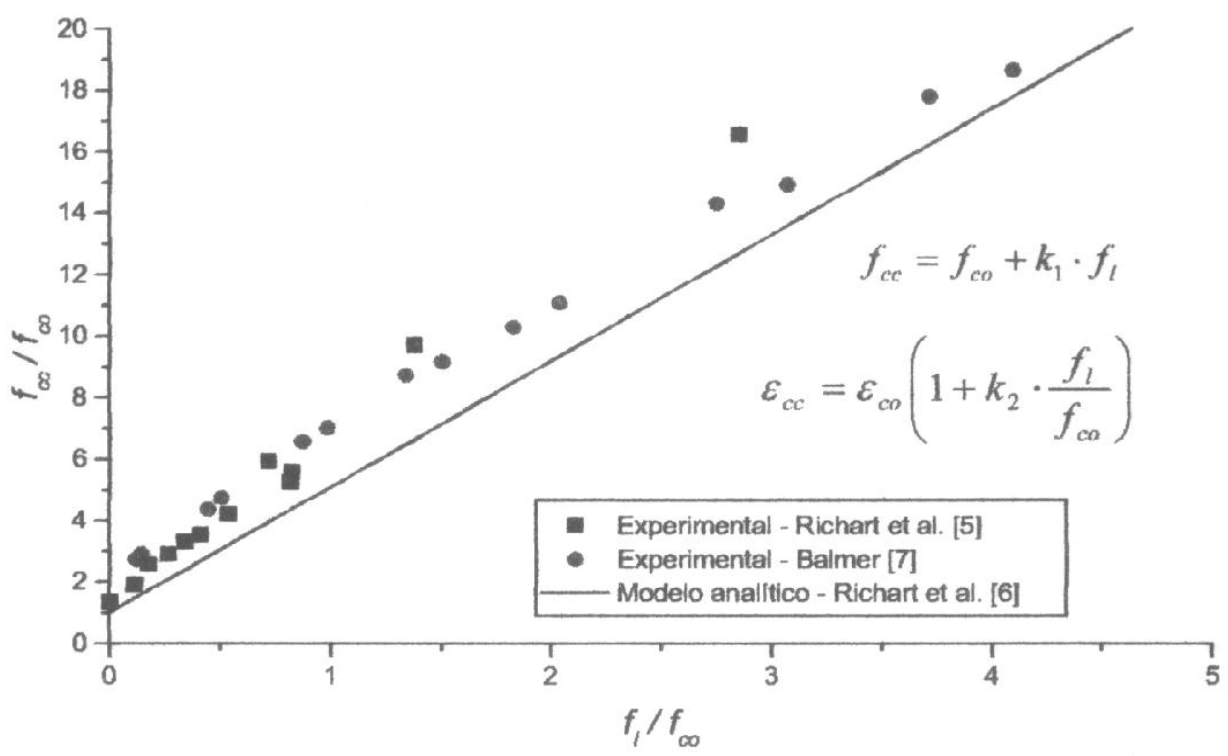

Figura 2.2 Primeiros resultados experimentais de estudos sobre confinamento

As variáveis envolvidas são:

$\mathrm{f}_{\mathrm{cc}}$ : resistência do concreto confinado;

$\mathrm{f}_{\mathrm{co}}$ : resistência do concreto não confinado;

$\mathrm{f}_{1:}$ pressão lateral;

$\mathrm{k}_{1}$ e $\mathrm{k}_{2}$ : coeficientes obtidos experimentalmente;

$\varepsilon_{\mathrm{cc}}$ : deformação última do concreto confinado;

$\varepsilon_{\mathrm{co}}$ : deformação última do concreto não confinado.

Os resultados apresentados por Richard et al. indicam que $\mathrm{k}_{1}$ varia com a pressão lateral, tendendo a 4,1 com o crescimento da mesma. No entanto os autores adotaram para $\mathrm{k}_{1} \mathrm{o}$ valor constante de 4,1 e $\mathrm{k}_{2}=5^{*} \mathrm{k}_{1}$. A figura 2.3 mostra a variação de $\mathrm{k}_{1}$ com a pressão lateral. 


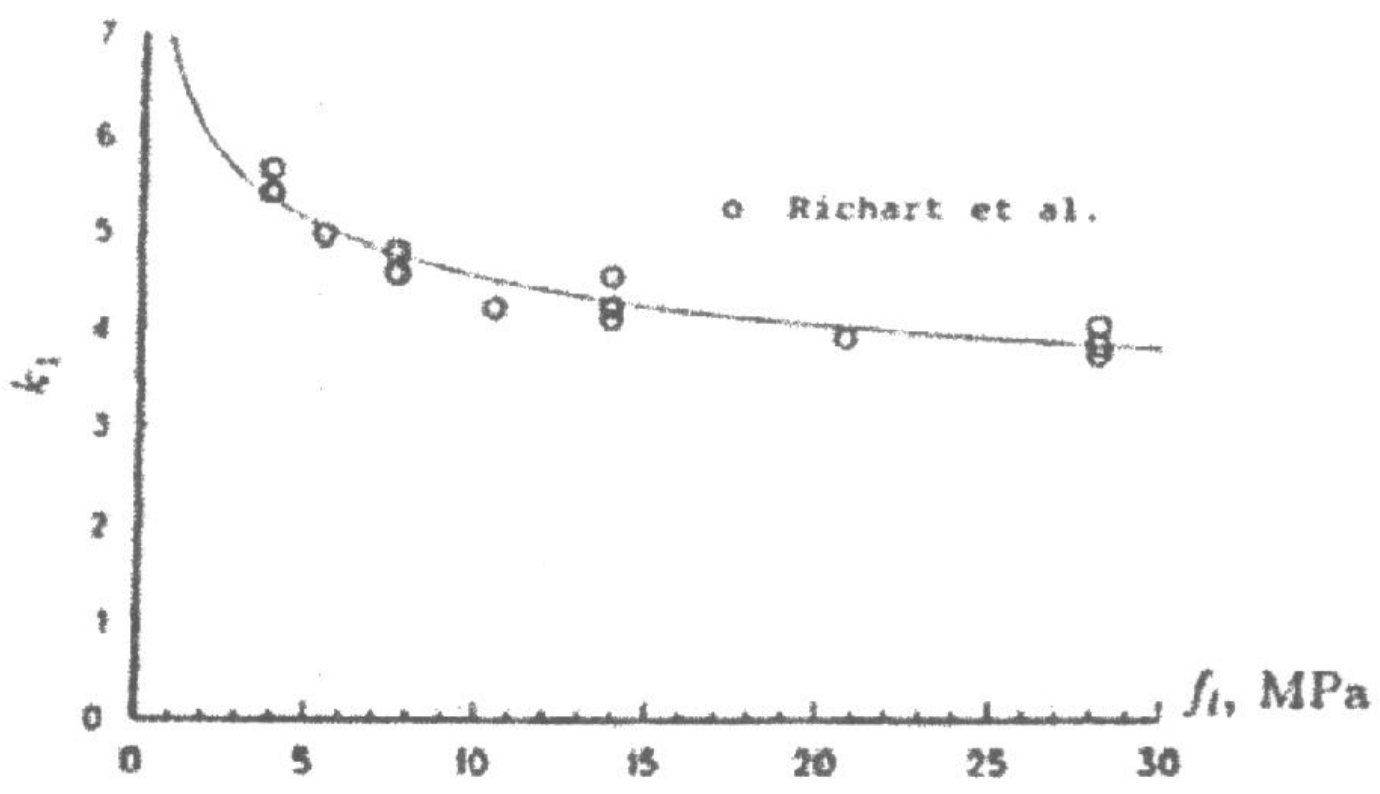

Figura 2.3 Variação de $\mathbf{k}_{1}$ com a pressão lateral

Sendo,

$\mathrm{k}_{1}$ : coeficiente obtido experimentalmente;

$\mathrm{f}_{1}$ : pressão lateral.

\subsection{Parâmetros que influenciam o confinamento na ligação piso-pilar}

Pilares com diferentes resistências de concreto ao longo da altura ocorrem, entre outros casos, na interface pilar-laje, por exemplo. Nesse trabalho estudaram-se lajes e vigas com concreto de resistência característica à compressão de $35 \mathrm{MPa}$ e pilares com $50 \mathrm{MPa}$ de resistência de concreto. Estes valores foram escolhidos por serem bastante utilizados atualmente, mantendo a relação aproximada de $1,4, \mathrm{f}_{\mathrm{cp}} / \mathrm{f}_{\mathrm{cl}}$, entre as citadas resistências.

O confinamento na região de concreto menos resistente é proporcionado pela laje que o rodeia, pela armadura da mesma e pelo concreto do próprio pilar localizado acima e abaixo da camada da laje, Bianchini, 1960.

Destacam-se como principais parâmetros que influenciam o comportamento do pilar como sendo: resistência do concreto à compressão, posição relativa do pilar, 
relação entre a espessura da laje ou viga e a dimensão da seção do pilar, forma da seção do pilar, carga na laje, armadura da laje e finalmente armadura do pilar.

Um pilar pode ser considerado central, de borda ou de canto conforme sua posição com relação à laje de piso, como ilustrado na figura 1.3. Este trabalho ateve-se a encontros de pilares com lajes planas nos experimentos práticos, e também, os casos de encontro com vigas, por programas de análise pelo método dos elementos finitos.

O confinamento oferecido pela laje é diferente para cada um dos três tipos de pilares: de canto, de borda e central. O efeito do confinamento é mais representativo no caso de pilares centrais onde a região de intersecção do pilar com a laje encontra-se cercada pela laje continuamente ao longo das quatro faces. Pode-se afirmar que este é o caso mais favorável de confinamento. Quando se analisam vigas que cruzam o pilar, não mais existe essa continuidade de material ao redor do pilar. Entende-se que, na realidade, a existência de vigas conduz a espessuras menores de lajes, algo em torno de 12 a $15 \mathrm{~cm}$ e, assim sendo, essas proporcionarão um confinamento bem menor daquele proveniente de lajes planas com espessuras em torno de 20 a $30 \mathrm{~cm}$ em proporções reais, ver a figura 2.4 a seguir.

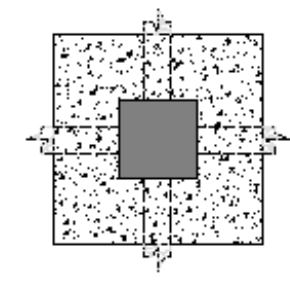

PLANTA

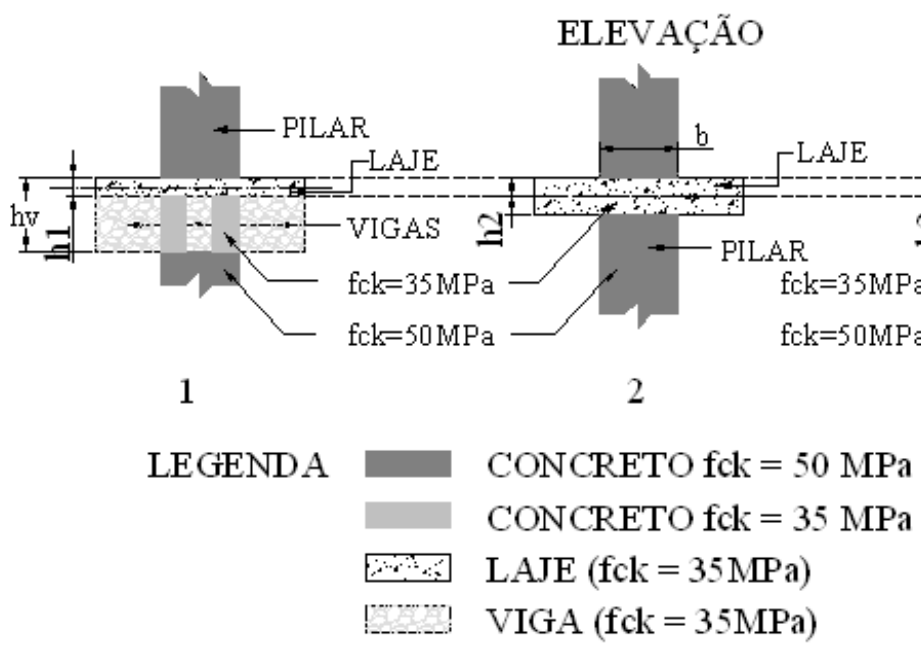

Figura 2.4 Representação de pilares interceptados por lajes e vigas 
De forma a elucidar o assunto, foi estudado esse tipo de interseção pelo método dos elementos finitos, comparando o confinamento dado por laje, com aquele dado por vigas. Contrariamente, Bianchini, 1960, observou que os pilares internos interceptados por lajes e vigas apresentam resultados de resistência efetiva maiores que os interceptados somente por laje. Este resultado foi obtido em decorrência do fato de a espessura da laje ter sido mantida ao se acrescentarem vigas, o que na realidade não é usual. Assim sendo, por menor que seja a contribuição por parte das vigas, observou-se um pequeno acréscimo na resistência do conjunto.

Teria ainda que ser levada em consideração a influência de cargas aplicadas nas lajes e vigas. Desde que alguma intensidade, mesmo que pequena, de carga na laje é inevitável na prática, é importante pesquisar também encontros de lajes planas com pilares nos quais as lajes são carregadas. Estudos desenvolvidos por Ospina e Alexander, 1998, mostram que o comportamento dos modelos com laje carregada é diferente daquele observado em modelos com laje descarregada, porém pouco influenciando na resistência final do pilar. Esse estudo, porém, não foi realizado nessa pesquisa por causa da complexidade de montagem experimental de tal modelo, mas pode ser estudado considerando o método dos elementos finitos, comparando o confinamento dado por laje descarregada com laje carregada.

Pretende-se completar os resultados, de casos mais simples para que posteriormente, em outros trabalhos, sejam estudados casos mais complexos cada vez mais próximos da realidade. Tem-se a consciência de evoluir gradativamente nos ensaios para evitar a obtenção de resultados mascarados. Tem-se, até os dias atuais, pouco conhecimento sobre o assunto. A pesquisa deve ser orientada inicialmente para se conhecer a essência do comportamento dos modelos, considerando apenas os parâmetros fundamentais, eliminando os parâmetros secundários. Os modelos reduzidos, nesses casos, são úteis porque viabilizam a realização de mais ensaios com o mesmo orçamento e têm por trás uma teoria sólida, a semelhança mecânica. Depois de obtidos bons resultados experimentais e do bom entendimento do fenômeno pode-se partir, de forma mais segura, para uma análise considerando fenômenos secundários e ensaios com protótipos nas grandezas reais. Sem tal embasamento corre-se o risco de resultados mascarados levando a conclusões equivocadas e até incoerentes. Somado a isso, vem o 
fato de que quando se trata de ensaios experimentais, sabe-se que a possibilidade de ocorrerem distorções de resultados é grande e para evitá-la deve-se tomar precauções e cuidados especiais. Quanto maior a complexidade do ensaio, maior o risco dessa ocorrência, como, por exemplo, a aplicação de uma carga na laje poderia causar alguma influência no efeito do confinamento, mas, ainda não se tem resultados de pesquisas suficientes para que seja feita uma análise fiel de tal fenômeno. Contudo ao se considerar tal parâmetro a dificuldade de montagem do ensaio seria muito aumentada e conseqüentemente a possibilidade de ocorrerem resultados distorcidos.

Quanto à relação entre a espessura do piso e a dimensão da seção do pilar sabe-se que, quanto maior a relação entre a espessura do piso e a dimensão da seção do pilar, maior é o ganho de resistência devido ao efeito do confinamento proporcionado pelo piso.

Neste estudo, utilizou-se uma resistência de concreto de pilar em torno de 1,4 do valor da resistência do concreto da laje, limite estabelecido na norma americana ACI 318, 2002 e na norma canadense CSA A23.3, 1994, com base em Gamble, 1991 e Ospina, 1998.

Poucos estudos foram feitos a respeito da influência da forma do pilar no seu confinamento por laje. A forma da seção do pilar também influencia em seu confinamento. Nesta pesquisa utilizaram-se pilares de seção quadrada a mesma seção utilizada por Silveira dos Santos, 2004, para que se possam ter os mesmos parâmetros de comparação de resultados. Entre os objetivos desse trabalho está em grande destaque a continuidade dessa pesquisa visando estudar outro caso de pilar central, que foi tema principal, além de pesquisar casos de pilares de canto, encontro de pilares com vigas e ainda um estudo de armadura mínima para pilares para que o valor da resistência efetiva seja o valor medido nos corpos-de-prova cilíndricos.

Silveira dos Santos, 2004, realizou ensaios com e sem armadura na laje e observou um acréscimo na resistência efetiva do conjunto contendo armadura. Estudo desenvolvido por McHarg, Cook, Mitchell e Yoon, 2000, analisou a influência da distribuição da armadura da laje por meio de ensaios de quatro modelos reduzidos com pilares internos. Variações de distribuição de armadura foram estudadas e comparadas. Constatou-se que houve um aumento na capacidade resistente do pilar interno dos 
modelos cuja armadura da laje se concentrava próxima ao pilar em relação aos modelos com distribuição uniforme da armadura da laje. Nessa pesquisa, porém distribuiu-se a armadura uniformemente na laje apenas para melhoria do confinamento, uma vez que a variação de distribuição de armadura da laje não estava no escopo deste trabalho.

A influência da armadura do pilar na resistência efetiva do conjunto pilar-laje foi estudada por Shu e Hawkins, 1992. Pilares isolados de concreto simples atingiram uma resistência efetiva um pouco superior à obtida em pilares de concreto armado com as mesmas dimensões, porém, apresentaram ruptura brusca. Segundo os autores, a armadura do pilar não causou uma mudança significativa na interação entre os concretos de menor e maior resistência.

Realizou-se um estudo de armadura transversal mínima para pilares. Sabe-se que por causa da geometria dos corpos-de-prova rompidos para o controle do concreto, estes atingem a resistência de projeto. Já quando se estuda a resistência à compressão de pilares, cuja geometria é mais esbelta, os mesmos atingem resistências menores.

Pretendeu-se estudar por meio de ensaios, qual é a área de uma armadura transversal no pilar, que fosse a mínima para que o mesmo, ao ser ensaiado à compressão, atinja a mesma resistência do corpo-de-prova. Esses ensaios estão detalhados e sua formulação apresentada mais adiante. 


\section{SOLUÇÕES EMPÍRICAS}

\subsection{Expressões utilizadas em normas}

O confinamento proporcionado por lajes e vigas a pilares com diferentes resistências do concreto ao longo da altura ainda é pouco esclarecido nas normas mundiais. A norma brasileira, por exemplo, não faz nenhuma referência a este assunto. O ACI 318, 2002, admite que não existe nenhuma redução de resistência no caso de pilares com concreto de resistência maior que as lajes que o interceptam, desde que a resistência do concreto do pilar não ultrapasse em mais de $40 \%$ da resistência do concreto da laje. Quando isso ocorre dois são os casos recomendados pelo citado código: pilares centrais, ou seja, rodeados por laje nos quatro lados ou por vigas que tenham aproximadamente a mesma altura e pilares de borda e de canto. No primeiro caso a resistência efetiva no nó pilar-laje é igual a $75 \%$ da resistência do pilar ( $\mathrm{fc}_{\text {pilar }}$ ) acrescida de $35 \%$ da resistência das lajes ( $\mathrm{f}_{\text {claje }}$ ) ou vigas. A equação 3.1 apresenta essa relação:

$$
f_{\text {cef }}^{\text {conjunto }}=0,75 \times f_{\text {c pilar }}+0,35 \times f_{\text {claje }}
$$

Sendo:

$\mathrm{f}_{\text {cef conjunto: }}$ resistência efetiva do conjunto pilar-laje;

$\mathrm{f}_{\mathrm{c} \text { pilar }}$ : resistência do concreto do pilar;

$\mathrm{f}_{\mathrm{c} \text { laje }}$ : resistência do concreto da laje.

No segundo caso deve-se recorrer ao processo de puddling esclarecido anteriormente, ou considerar-se a resistência menor, ou seja, a resistência da laje.

Esta recomendação baseia-se nos resultados experimentais obtidos por Bianchini, 1960, que propôs o seguinte: 
1. Quando a relação entre a resistência do pilar, $f_{c p}$, e a da laje, $f_{c l}$ for menor ou igual a 1,4, para todos os pilares (borda, canto e central):

$$
f_{\text {cef }}^{\text {conjunto }}=f_{c p}
$$

Sendo:

$\mathrm{f}_{\text {cef conjunto: }}$ resistência efetiva do conjunto;

$\mathrm{f}_{\mathrm{cp}}$ : resistência do concreto do pilar.

2. Quando $\mathrm{f}_{\mathrm{cp}} / \mathrm{f}_{\mathrm{cl}}$ é maior que 1,4 , para pilares de borda ou de canto.

$$
f_{\text {cef } \text { conjunto }}=f_{c l}
$$

Equação 3.3

Sendo:

$\mathrm{f}_{\text {cef conjunto }}$ é a resistência efetiva do conjunto;

$\mathrm{f}_{\mathrm{cl}}$ é a resistência do concreto da laje.

Enquanto que para pilares centrais, temos o valor calculado pela equação 3.1. Comparando-se as equações 3.2 e 3.3 nota-se uma contradição óbvia. Por exemplo, supondo-se $\mathrm{f}_{\mathrm{cp}}=40 \mathrm{MPa}$ e $\mathrm{f}_{\mathrm{cl}}=30 \mathrm{MPa}$, então $\mathrm{f}_{\mathrm{cp}} / \mathrm{f}_{\mathrm{cl}}=1,33<1,4$. Assim sendo, de acordo com a equação 3.2 , tem-se:

$$
f_{\text {cef } \text { conjunto }}=f_{c p}=40 \mathrm{MPa}
$$

Contudo, supondo $\mathrm{f}_{\mathrm{cp}}=45 \mathrm{MPa}$ e $\mathrm{f}_{\mathrm{cl}}$ sendo ainda $30 \mathrm{MPa}$, então $\mathrm{f}_{\mathrm{cp}} / \mathrm{f}_{\mathrm{cl}}=1,5>1,4$. e de acordo com a equação 3.3, temos:

$$
f_{\text {cef } \text { conjunto }}=f_{c l}=30 \mathrm{MPa} \quad \text { para pilares de borda ou de canto. }
$$

Este resultado é incoerente, pois, logicamente, poder-se-ia aplicar ao menos os mesmos $40 \mathrm{MPa}$ do primeiro caso, Shu e Hawkins, 1992.

A norma canadense CSA A23.3, 1994, apresenta uma outra expressão para se chegar no valor da resistência efetiva, segundo a equação 3.4.

$$
f_{\text {cef }}^{\text {conjunto }}=0,25 f_{\text {c pilar }}+1,05 f_{\text {claje }}
$$


Sendo:

$\mathrm{f}_{\text {cef conjunto: }}$ resistência efetiva do conjunto pilar-laje;

$\mathrm{f}_{\mathrm{c} \text { pilar }}$ : resistência do concreto do pilar;

$\mathrm{f}_{\mathrm{c} \text { laje }}$ : resistência do concreto da laje.

Outros pesquisadores chegaram a diferentes expressões. Alguns destes, relacionados a pilares centrais, de canto e de borda estão ilustrados na tabela 3.1.

\subsection{Expressões obtidas por pesquisadores}

Gamble, 1991, por meio de experimentos com pilares de resistência 40\% maior em relação às lajes, também conseguiu obter uma expressão cujo valor da resistência na interface laje-pilar correspondia a $67 \%$ da resistência do pilar, $\mathrm{f}_{\text {cpilar, }}$, mais $47 \%$ da resistência da laje, $\mathrm{f}_{\text {claje }}$, em casos onde se tinha pilar interno. A equação 3.5 apresenta tal relação.

$$
f_{\text {cef }}^{\text {conjunto }}=0,67 \times f_{\text {c pilar }}+0,47 \times f_{\text {claje }}
$$

Equação 3.5

Sendo que as variáveis seguem a legenda da equação 3.4.

Já Ospina et al., 1998, definiu uma outra relação para obter o valor da resistência efetiva como sendo:

$$
f_{\text {cef conjunto }}=\left(1,4-\frac{0,35}{\frac{e}{b}}\right) \times f_{\text {claje }}+\left(\frac{0,25}{\frac{e}{b}}\right) \times f_{\text {c pilar }}
$$

com e/b $\geq 0,33$.

Sendo:

$\mathrm{f}_{\text {cef conjunto: }}$ resistência efetiva do conjunto pilar-laje;

$\mathrm{f}_{\mathrm{c} \text { pilar: }}$ resistência do concreto do pilar;

$\mathrm{f}_{\mathrm{c} \text { laje: }}$ resistência do concreto da laje;

e: espessura da laje;

b: dimensão lateral da seção quadrada do pilar. 
Tabela 3.1 Expressões para avaliar $\mathbf{f}_{\text {ce }}$ (resistência efetiva) em pilares

\begin{tabular}{|c|c|c|c|}
\hline \multicolumn{2}{|c|}{ Autor ou norma } & Pilares internos & Pilares de canto ou borda \\
\hline \multicolumn{4}{|c|}{ Pilares interceptados por laje ou por laje e vigas de altura aproximadamente igual } \\
\hline \multirow{3}{*}{ BIANCHINI, 1960} & & $\mathrm{f}_{\mathrm{cp}}$ se $\mathrm{f}_{\mathrm{cp}} \leq 1,5 \mathrm{f}_{\mathrm{cl}}$ & \multirow{2}{*}{$\mathrm{f}_{\mathrm{cp}}$ se $\mathrm{f}_{\mathrm{cp}} \leq 1,4 \mathrm{f}_{\mathrm{cl}}$} \\
\hline & & $0,75 \mathrm{xf}_{\mathrm{cp}}+0,375 \mathrm{xf}_{\mathrm{cl}} \leq \mathrm{f}_{\mathrm{cp}}$ & \\
\hline & & $\begin{array}{l}\text { para } f_{c p} / f_{c l} \text { entre } 1,5 \text { e } 3,0 \text { (pilar laje) } \\
\text { ou entre } 1,5 \text { e } 2,0 \text { (pilar-laje e viga) }\end{array}$ & $\mathrm{f}_{\mathrm{cl}}$ se $\mathrm{f}_{\mathrm{cp}}>1,4 \mathrm{f}_{\mathrm{cl}}$ \\
\hline \multirow{2}{*}{ ACI 318, 1999} & se $f_{\mathrm{cp}} \leq 1,4 \mathrm{f}_{\mathrm{c}} \mathrm{l}$ & $\mathrm{f}_{\mathrm{cp}}$ & $\mathrm{f}_{\mathrm{cp}}$ \\
\hline & se $f_{c p}>1,4 f_{c l}$ & $0,35 \mathrm{xf}_{\mathrm{cl}}+0,75 \mathrm{xf}_{\mathrm{cp}} \leq \mathrm{f}_{\mathrm{cp}}$ & $\mathrm{f}_{\mathrm{cl}}$ \\
\hline \multirow[b]{2}{*}{ ACI 318, 2005} & se $f_{c p} \leq 1,4 f_{c l}$ & $\mathrm{f}_{\mathrm{cp}}$ & $\mathrm{f}_{\mathrm{cp}}$ \\
\hline & se $f_{c p}>1,4 f_{c} l$ & $\begin{array}{c}0,35 \mathrm{xf}_{\mathrm{cl}}+0,75 \mathrm{xf} \mathrm{f}_{\mathrm{cp}} \leq \mathrm{f}_{\mathrm{cp}} \\
\operatorname{para~}_{\mathrm{cp}} / \mathrm{f}_{\mathrm{cl}} \leq 2,5\end{array}$ & $\mathrm{f}_{\mathrm{cl}}$ \\
\hline \multirow{2}{*}{ CSA 23.3, 1984} & se $f_{\mathrm{cp}} \leq 1,4 \mathrm{f}_{\mathrm{cl}}$ & $\mathrm{f}_{\mathrm{cp}}$ & $f_{\mathrm{cp}}$ \\
\hline & se $f_{c p}>1,4 f_{c l}$ & $0,35 \mathrm{xf}_{\mathrm{cl}}+0,75 \mathrm{xf}_{\mathrm{cp}}$ & $\mathrm{f}_{\mathrm{cl}}$ \\
\hline \multirow{2}{*}{ CSA $23.3,1994$} & se $\mathrm{f}_{\mathrm{cp}} \leq 1,4 \mathrm{f}_{\mathrm{cl}}$ & $\mathrm{f}_{\mathrm{cp}}$ & \multirow{2}{*}{$\mathrm{f}_{\mathrm{cl}}$} \\
\hline & se $f_{c p}>1,4 f_{c l}$ & $1,05 \mathrm{xf}_{\mathrm{cl}}+0,25 \mathrm{xf}_{\mathrm{cp}} \leq \mathrm{f}_{\mathrm{cp}}$ & \\
\hline \multicolumn{4}{|c|}{ Para pilares interceptados por laje } \\
\hline \multirow{3}{*}{$\begin{array}{c}\text { GAMBLE e } \\
\text { KLINAR, } 1991\end{array}$} & se $\mathrm{f}_{\mathrm{cp}} \leq 1,4 \mathrm{f}_{\mathrm{cl}}$ & fcp & fcp \\
\hline & \multirow[t]{2}{*}{ se $\mathrm{f}_{\mathrm{cp}}>1,4 \mathrm{f}_{\mathrm{cl}}$} & \multirow[t]{2}{*}{$0,47 \mathrm{xf}_{\mathrm{cl}}+0,67 \mathrm{xf}_{\mathrm{cp}} \geq 1,4 \mathrm{xf}_{\mathrm{cl}}$} & $0,85 \mathrm{xf}_{\mathrm{cl}}+0,32 \mathrm{xf}_{\mathrm{cp}} \geq 1,4 \mathrm{xf}_{\mathrm{cl}}$ \\
\hline & & & somente pilares de borda \\
\hline \multirow{2}{*}{$\begin{array}{c}\text { OSPINA e } \\
\text { ALEXANDER, } \\
1998\end{array}$} & se $f_{c p} \leq 1,4 f_{c l}$ & $\mathrm{f}_{\mathrm{cp}}$ & \multirow[b]{2}{*}{ somente pilares internos } \\
\hline & se $\mathrm{f}_{\mathrm{cp}}>1,4 \mathrm{f}_{\mathrm{cl}}$ & $\begin{array}{c}{[1,4-0,35 /(\mathrm{e} / \mathrm{b})] \mathrm{xf}_{\mathrm{cl}}+[0,25 /(\mathrm{e} / \mathrm{b})] \mathrm{xf}_{\mathrm{cp}}} \\
\text { com e/b } \geq 0,33\end{array}$ & \\
\hline
\end{tabular}

Sendo:

$\mathrm{f}_{\mathrm{cp}}$ : resistência do concreto do pilar à compressão;

$\mathrm{f}_{\mathrm{cl}}$ : resistência do concreto da laje à compressão;

e: espessura da laje;

b: dimensão da face do pilar. 


\section{ANÁLISE POR MÉTODOS NUMÉRICOS}

\subsection{Método dos elementos finitos}

Pesquisadores e estudiosos, com o objetivo de estudar a teoria da elasticidade, ou mecânica dos meios contínuos, vêm desenvolvendo modelos matemáticos que possam representar adequadamente a situação física real de componentes sujeitos a esforços mecânicos.

Em análise estrutural, o objetivo pode ser a determinação do campo de deslocamentos, as deformações internas ou as tensões atuantes no sistema devido à aplicação de cargas, além de outros. Navier, Cauchy, Poisson, Green, dentre outros, muito contribuíram para a teoria matemática da elasticidade, que, por sua vez, tem auxiliado na determinação das variáveis envolvidas nas deformações de elementos estruturais. Porém, a aplicação de tais teorias a casos práticos apresenta dificuldades, como por exemplo, na análise estrutural, na perfeita representação matemática de carregamentos, na geometria, nas condições de contorno, principalmente no comportamento dos materiais compostos e não lineares como o concreto armado. Por apresentar-se de forma complexa demais, ainda não se inventaram hipóteses simplificadoras capazes de representar e permitir alguma forma de modelagem matemática que conduza a resultados satisfatórios.

Com a evolução das estruturas, porém, existe um interesse crescente por estudos mais precisos para a análise das mesmas. Este interesse vem unido a uma necessidade cada vez maior de se estudar o comportamento de elementos estruturais complexos, o que conduz a tratamentos analíticos mais elaborados, baseados em teorias gerais, e que são, via de regra, de soluções extremamente difíceis. 
Desta forma, tem-se procurado desenvolver e aplicar métodos numéricos que permitam respeitar os princípios teóricos de forma acessível e precisa. Dentre estes métodos, os que têm sido mais utilizados são aqueles baseados na divisão do meio contínuo em partes mais simples: a estrutura, o fluido, o gás etc.

O Método dos Elementos Finitos (MEF) é seguramente o processo que mais tem sido usado para a discretização de meios contínuos. A sua larga utilização se deve também ao fato de poder ser aplicado, além dos problemas clássicos da mecânica estrutural elástico-linear, para os quais o método foi inicialmente desenvolvido, também para problemas tais como: problemas não lineares estáticos ou dinâmicos, mecânica dos sólidos, mecânica dos fluidos, eletromagnetismo, transmissão de calor, filtração de meios porosos, campo elétrico, acústica etc.

O ideal no caso desta pesquisa seria dispor de elementos capazes de representar o comportamento não linear do concreto simples à compressão. Como isso ainda é muito difícil e se constituiria em uma dissertação em si, decidiu-se usar o modelo linear que fornece um resultado razoável para a avaliação do confinamento tanto para a laje descarregada, como para carregada, ou para pisos em lajes e vigas.

\subsection{Método biela-tirante}

O método biela-tirante nasceu da mente criativa de Mörsch, se desenvolveu com Blevot e depois com Schlaich-Shafer. O método tem apoio teórico no Teorema Estático.

O Teorema Estático, também conhecido como Teorema do Limite Inferior, diz que:

Seja $\sigma_{\mathrm{e}}$ um campo de tensões em equilíbrio com o carregamento externo $\boldsymbol{p}_{0}$, isto é, seja um campo de tensões tal que: 


$$
\left(p_{0}, \delta_{\mathrm{u}}\right)=\left(\boldsymbol{\sigma}_{\mathrm{e}}, \delta_{\mathrm{e}}\right), \forall \delta_{\mathrm{u}}
$$

Sendo:

$\delta_{\mathrm{e}}, \delta_{\mathrm{u}}:$ um campo de deslocamentos virtuais, compatível com os vínculos;

$p_{0}:$ carregamento;

Diz-se que o campo $\sigma_{\mathrm{e}}$ é estaticamente admissível. Suponha-se, além disso, que este campo seja plasticamente admissível, isto é:

$$
\mathrm{F}\left(\sigma_{\mathrm{e}}\right) \leq 0
$$

Nessa condição o teorema diz que $\boldsymbol{p}_{0}$ é menor que a carga última $\boldsymbol{p}_{u}$, carga de ruína.

O teorema estático tem vários corolários, dentre os quais pode-se citar:

- Se uma estrutura for dimensionada supondo-se material elástico linear para um carregamento $\boldsymbol{p}_{0}$, então $\boldsymbol{p}_{u} \geq \boldsymbol{p}_{0}$, ou seja, ela foi dimensionada a favor da segurança.

- De todos os campos de tensão estática e plasticamente admissíveis o que provoca o colapso é o que maximiza $\mathrm{p}_{0}$, isto é $\boldsymbol{p}_{u}=\operatorname{máx} \boldsymbol{p}_{0}$.

Qualquer campo de tensão estática e plasticamente admissível serve para dimensionar uma estrutura a favor da segurança. Este fato justifica diversas técnicas de detalhamento de estruturas, como dividir forças igualmente entre parafusos em ligações de estruturas metálicas ou utilizar o cálculo elástico para dimensionar estruturas de concreto no estado limite último de colapso plástico, desde que a estrutura tenha capacidade de acomodação plástica para tal. Estruturas metálicas têm, estruturas de concreto muitas vezes têm, mas nem sempre.

O método biela-tirante é um método simplificado de dimensionamento de estruturas de concreto. Para explicá-lo, utilizaremos um exemplo: consolo curto de concreto armado de altura $h$, comprimento $a$ e profundidade $l$, sujeito ao carregamento vertical $P_{0}$ com excentricidade $e$ de aplicação, figura 4.1. 


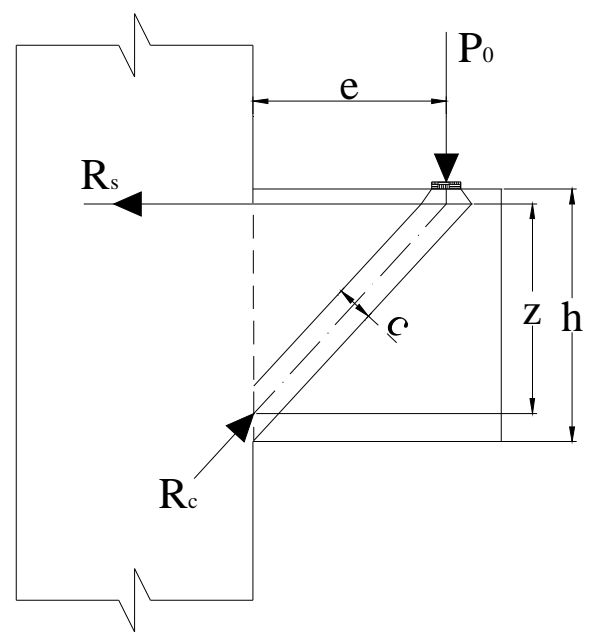

\section{Figura 4.1 Consolo Curto de Concreto Armado}

O campo de tensões estaticamente admissível é formado por um tirante horizontal de aço na parte superior do consolo e por uma biela (escora inclinada) comprimida de concreto. Para o campo de tensões estar em equilíbrio, basta que a treliça simples indicada na mesma figura seja resolvida. As forças no aço e no concreto são dadas respectivamente por

$$
R_{s}=\frac{P_{0} e}{z} \quad \text { e } \quad R_{c}=\frac{P_{0} \sqrt{e^{2}+z^{2}}}{z}
$$

Sendo:

$\mathrm{R}_{\mathrm{s}}$ : força no aço;

$\mathrm{R}_{\mathrm{c}}$ : força no concreto;

$\mathrm{P}_{0}$ : carregamento;

e: excentricidade de aplicação do carregamento;

$\mathrm{z}<\mathrm{h}$ : o braço de alavanca como indicado na figura da página anterior.

Para que o campo de tensões seja plasticamente admissível é necessário que a área da seção transversal do tirante de aço e da biela de concreto obedeçam a: 


$$
A_{s} \geq \frac{R_{s}}{f_{s}} \quad \text { e } \quad A_{c} \geq \frac{R_{c}}{f_{c}}
$$

respectivamente, sendo $\mathrm{f}_{\mathrm{s}}$ a resistência à tração do tirante e $\mathrm{f}_{\mathrm{c}}$ a resistência à compressão do concreto da biela. Se c for a largura da biela, tem-se que respeitar:

$$
c \geq \frac{A_{c}}{l}
$$

Sendo:

1: largura do consolo.

Por outro lado, se já se conhecem todas as dimensões e as resistências dos materiais do consolo, então, respeitando-se a equação apresentada por Pimenta, 2003:

$$
p_{u}=\operatorname{máxp}_{0}=\min \left\{\frac{f_{s} A_{s} z}{e}, \frac{f_{c} b c z}{\sqrt{e^{2}+z^{2}}}\right\}
$$

Sendo:

$\mathrm{p}_{\mathrm{u}}$ : carga de ruptura;

$\mathrm{p}_{0}$ : carregamento;

$\mathrm{f}_{\mathrm{s}}$ : resistência à tração do tirante;

$\mathrm{f}_{\mathrm{c}}$ : resistência à compressão do concreto da biela;

1: largura do consolo;

c: largura da biela;

$\mathrm{A}_{\mathrm{s}}$ : área de aço;

$\mathrm{A}_{\mathrm{c}}$ : área de concreto;

z: braço de alavanca;

e: excentricidade de aplicação do carregamento. 


\subsection{Modelos calculados pelo método dos elementos finitos}

Fez-se uma análise de alguns modelos por um programa que utiliza o método dos elementos finitos. A figura 4.2 mostra um dos casos estudado, que é o caso de pilar central com laje.

Para simular o atrito das faces de topo com a prensa restringiu-se o deslocamento lateral dos nós nestas faces de contato. Os modelos foram elaborados com as resistências dos pilares $f_{c p}$ e lajes $f_{c l}$ e com os respectivos valores para módulos de elasticidade, $E$, e coeficientes de Poisson, v, e ainda como modelos elásticos lineares. Nas figuras 4.2 e 4.3, observa-se a modelagem matemática.
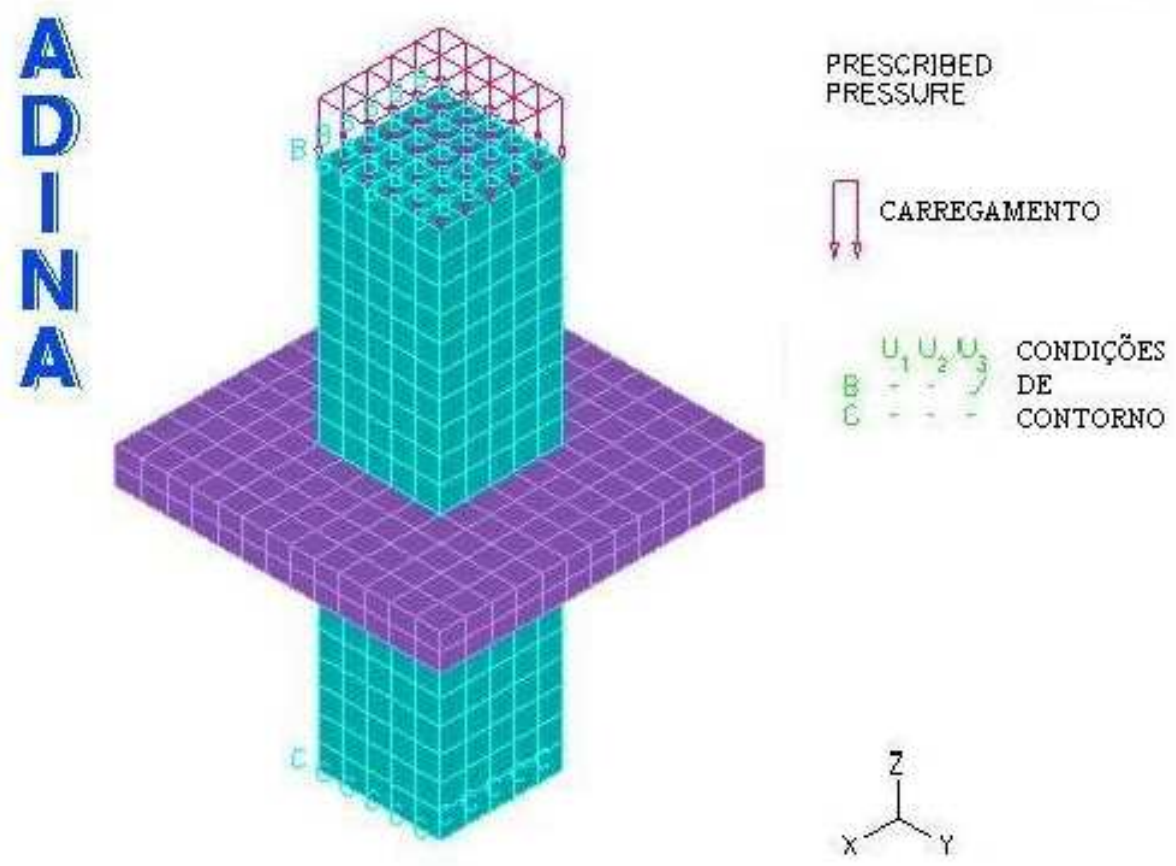

Figura 4.2 Modelagem matemática para o modelo de pilar central 


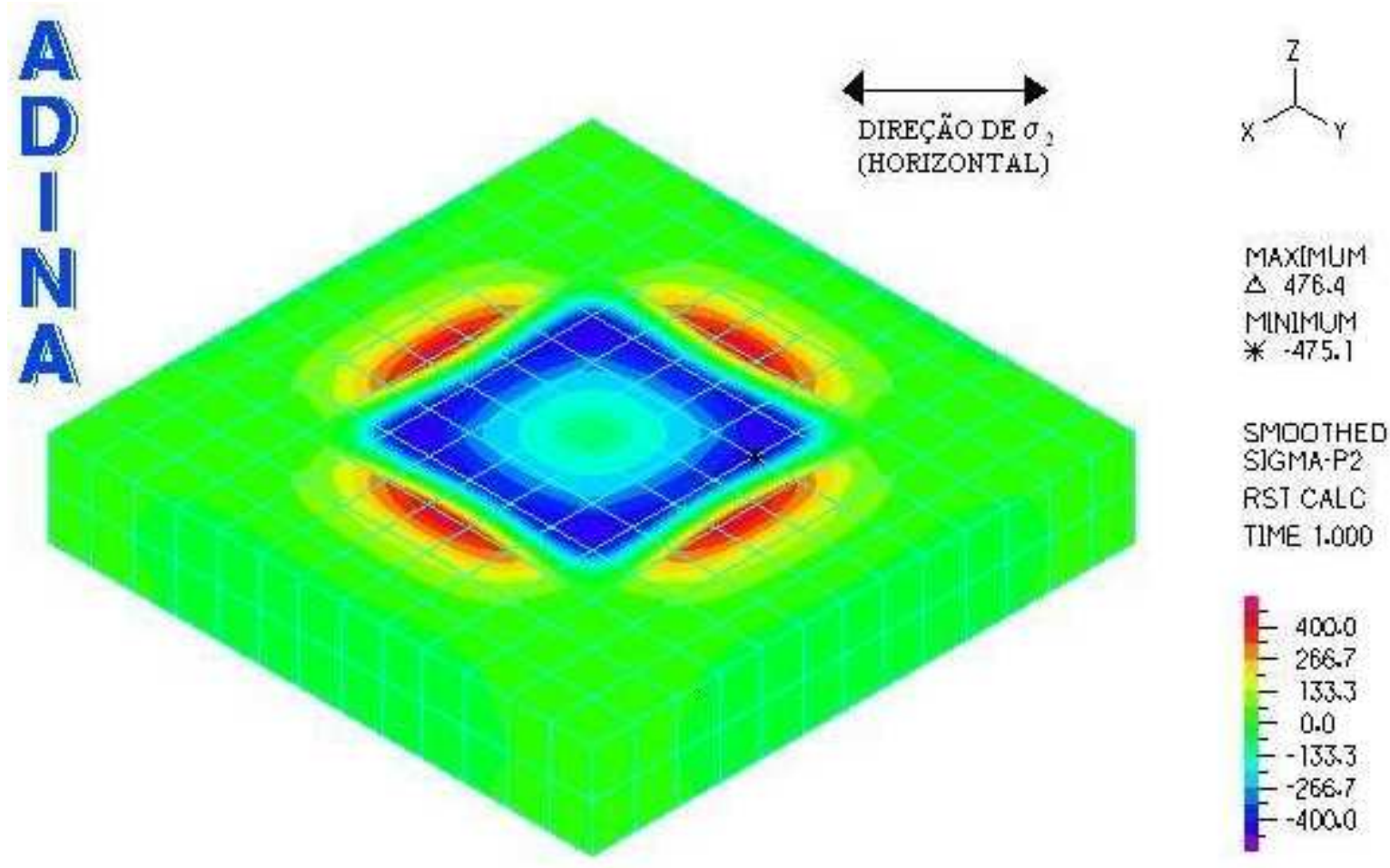

Figura 4.3 Tensões $\sigma_{2}$ na laje do modelo de pilar central (tensões em t/m $\mathbf{m}^{2}$ )

Na figura 4.3 nota-se que máxima tensão de tração na laje aparece ao redor do elemento confinado, trecho do pilar em contato com a laje, quando o mesmo é submetido à compressão axial. Com este resultado, pode-se supor que uma armadura na laje com maior concentração próxima ao pilar será mais eficiente para o efeito de confinamento do que uma armadura distribuída uniformemente em toda a laje.

De fato, como já citado anteriormente, McHarg, Cook, Mitchell e Yoon, 2000, chegaram a essa conclusão com os resultados obtidos em seus ensaios realizados no ano de 2000.

Seguindo para uma segunda análise desse modelo, utiliza-se o método biela-tirante. Analisando o elemento laje-pilar, observa-se que é possível montar um modelo biela-tirante para resolver o problema. As bielas e os tirantes podem ter direções orientadas pelo fluxo de tensões, usando o processo do caminho de carga, como pode ser observado na figura 4.4 . 


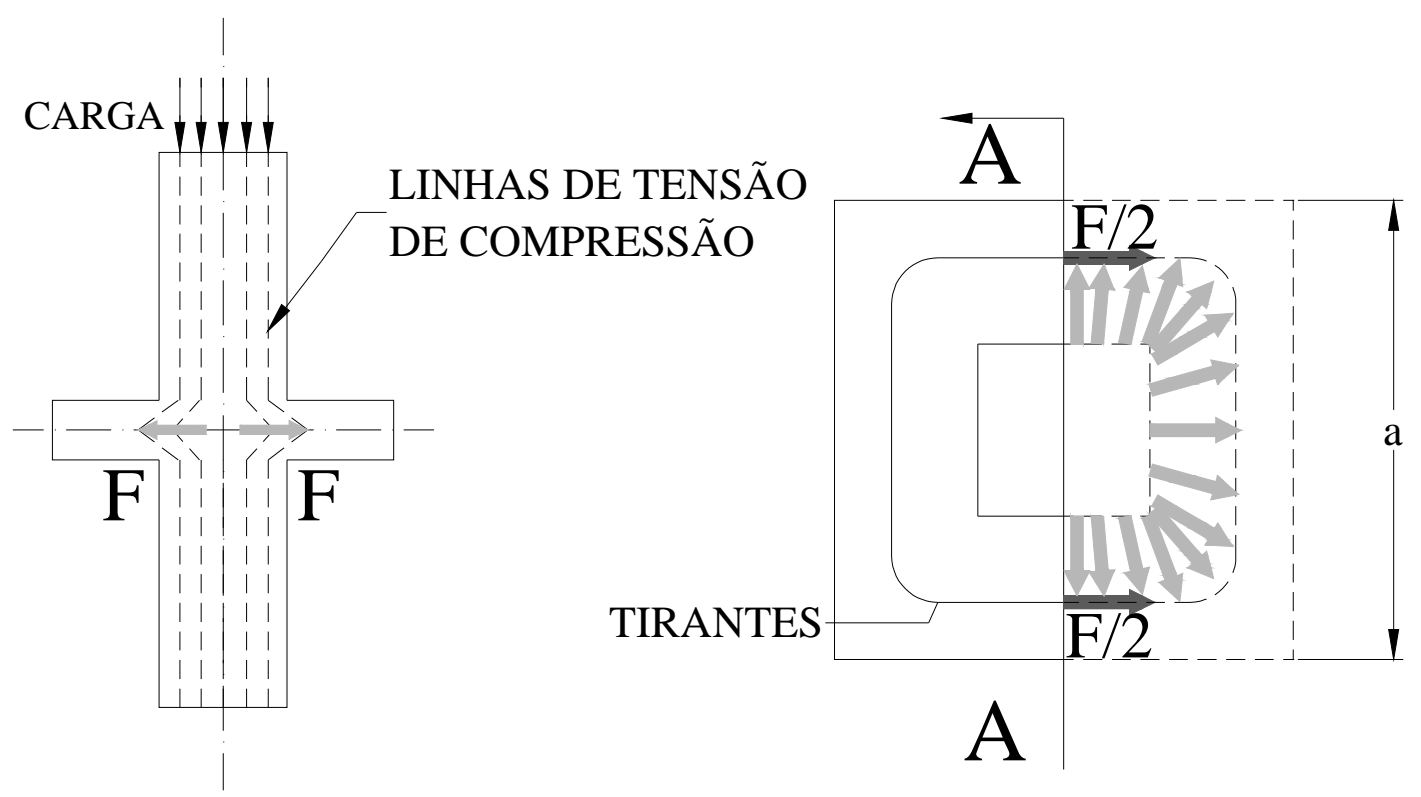

Figura 4.4 Linhas de tensão no modelo de pilar central

A figura 4.5 mostra a região onde aparecem forças de tração ampliada:

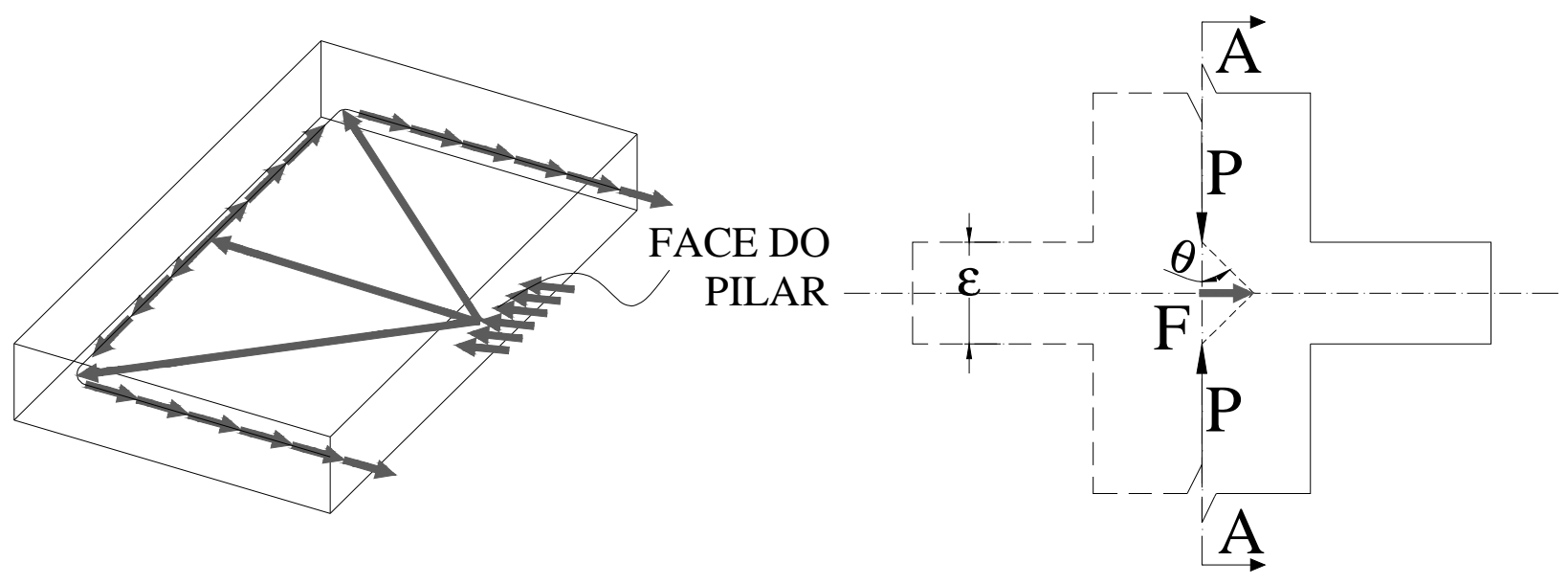

Figura 4.5 Ampliação da região onde ocorrem as forças de tração

Pode-se então calcular a intensidade da força $\mathrm{F}$ confinante em função do carregamento P aplicado:

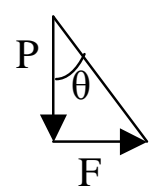

$$
\theta=\operatorname{arctg} \frac{\mathrm{F}}{\mathrm{P}}
$$


E, conseqüentemente, calcular-se a máxima força de confinamento proporcionada pela laje na região do pilar de concreto de menor resistência:

$$
F=\sigma_{c t m} e b
$$

Sendo:

$\sigma_{c t m}:$ tensão de tração no concreto;

F: efeito do confinamento;

e: espessura da laje;

b: largura considerada da laje.

Nesse caso, considerou-se a laje não armada. Pode-se aumentar o efeito do confinamento considerando-se a armação da laje. Desta forma a resistência à tração do concreto é somada à resistência à tração correspondente à armadura.

Como citado no início deste trabalho, existem os casos de pilares de borda e os de pilares de canto, nos quais o efeito do confinamento proporcionado pela laje não existirá em uma ou duas das faces do pilar, dependendo do caso. Assim sendo, deve-se absorver toda a força de tração por meio de uma armadura transversal colocada na região da laje nestas faces. Esse é um dos objetivos de estudo desta pesquisa de mestrado, somados com outros casos de pilares centrais, além dos já estudados por Silveira dos Santos, 2004. Tem-se em vista ainda o estudo do confinamento proporcionado, em pilares com uma região de concreto de menor resistência, por vigas cuja largura da seção possa variar entre toda a seção do pilar e apenas parte da mesma.

Analisando-se as representações da distribuição de tensões de ambos os métodos, pode-se concluir que métodos numéricos são instrumentos importantíssimos para se estudar o comportamento de estruturas, principalmente quando estas são complexas. Nota-se ainda que estes métodos representam de maneira bastante satisfatória o desenvolvimento da distribuição de cargas dentro de uma determinada estrutura e, afinados para cada caso específico, podem ser adaptados para muitos outros tipos de análise. Cabe ao profissional que realiza tal análise ser crítico para saber discernir o método mais apropriado para cada situação. Mais adiante foram comparados os resultados obtidos pelos métodos numéricos com os resultados experimentais. 


\section{SEMELHANÇA MECÂNICA}

"A análise experimental de estruturas por meio de modelos é uma atividade tão antiga quanto o desejo do homem em compreender os fenômenos da natureza".[MARTINS, 1990]

Por meio da semelhança mecânica pode-se analisar uma estrutura de dimensões reduzidas para compreender fenômenos que ocorrem em escala natural, tendo a grande vantagem de custo reduzido de ensaio. Para tal análise ser fiel, no entanto, se faz necessária uma perfeita representação da estrutura em questão. A complexidade de se representar uma estrutura por meio de um modelo reduzido é tamanha que impulsionou um tema de doutorado desenvolvido pelo professor Martins, 1990. Ele estudou modelos reduzidos utilizando microconcreto e microarmadura. Os modelos estudados nesta pesquisa seguirão os parâmetros desenvolvidos pelo professor Martins, 1990.

A princípio deve-se entender o que é um modelo. Martins, 1990, cita as seguintes definições: "é a representação física, geralmente em escala reduzida, de uma estrutura ou de parte dela"; modelo é "um elemento ou um conjunto de elementos estruturais, constituídos em escala reduzida, para serem ensaiados e para os quais as leis de semelhança podem ser empregadas para interpretar os resultados obtidos".

De um modo geral, deve-se estabelecer uma escala para a redução do tamanho do protótipo em estudo. Para tal não existe uma regra rígida. Em alguns casos, pesquisadores trabalham com peças, cujas dimensões não guardam relação de escala com o protótipo correspondente e ainda assim denominam de modelo. Nestes casos, podem ser concebidos métodos de projeto observando-se o comportamento ou os modos de ruptura de tais peças, mesmo que as mesmas não obedeçam às condições de semelhança. 
Silveira dos Santos, 2004, em sua dissertação abordou resumidamente a formulação na qual embasa-se toda a teoria de micromodelo desenvolvida pelo professor Martins, 1990. Não será repetida tal abordagem, apenas elucidados os conceitos básicos para o entendimento desta representação reduzida dos modelos a serem estudados.

\subsection{Classificação dos modelos reduzidos}

Martins, 1990 classifica os modelos em três classes de acordo com seu comportamento quando solicitados: modelos elásticos, indiretos e diretos. A primeira classe engloba modelos que apesar de terem semelhança geométrica com o protótipo, são compostos por materiais elástico e homogêneo diferentemente do material do protótipo. A classe correspondente aos modelos indiretos representa um tipo especial de modelo elástico que permite a obtenção das linhas de influência de reações de apoio e de esforços internos solicitantes, esta classe de modelos também não apresenta, necessariamente, semelhança física com o protótipo, hoje em dia é pouco utilizada, pois para cálculo de modelos no regime elástico os computadores são uma ferramenta bastante ágil. Os modelos diretos constituem uma classe com completa semelhança geométrica com o protótipo, com correspondência nas cargas aplicadas, assim sendo, as tensões, as deformações e os deslocamentos medidos neste tipo de modelo, para um determinado carregamento, podem ser considerados representativos do estado do protótipo, na mesma condição de carga, segundo Martins, 1990. Utilizaram-se, nesta pesquisa, modelos diretos. 


\subsection{Microconcreto}

Para se construir tais modelos diretos, foi utilizado o microconcreto, que é um material, desenvolvido em laboratório, com a finalidade de representar o concreto estrutural usual. Com a utilização de tal material para a construção dos modelos reduzidos, tem-se uma representação das fases sucessivas de fissuração, plastificação e ruína dos protótipos. O microconcreto é um material obtido pela mistura mecânica de um aglomerante, cimento Portland comum, com um material inerte, areia e água.

Nesta pesquisa utilizou-se a escala 1:4,3, baseando-se no fato de que as escalas mais adequadas para os modelos de microconcreto, segundo conclusões da tese de Martins, são as compreendidas no intervalo de 1:4 a 1:6 e mantendo a escala utilizada por Silveira dos Santos, 2004, para que se possam ter parâmetros comparativos de resultados. O microconcreto usado foi o microconcreto 4,8, a fração granulométrica mais grossa da areia possui diâmetro máximo igual a 4,8 mm, segundo Martins, 1990, o mais recomendado para a fabricação dos modelos. Porém utilizou-se, como Silveira dos Santos, 2004, a brita 0 com diâmetro próximo a 4,8 $\mathrm{mm}$ e areia média com dimensão característica de $2,4 \mathrm{~mm}$.

\subsection{Microarmadura}

Martins, 1990, para sua pesquisa desenvolveu em laboratório microarmaduras que mantivessem as propriedades de interesse, as quais citou como sendo: o diagrama tensão $\mathrm{x}$ deformação, a resistência ao escoamento, a deformação na ruptura e as propriedades de aderência na interface aço-concreto. Segundo ele, os diâmetros de microarmaduras devem estar entre $2 \mathrm{~mm}$ e $4 \mathrm{~mm}$. Nos modelos desta pesquisa utilizaram-se os diâmetros de 4,2 $\mathrm{mm}$ para armadura construtiva e $5 \mathrm{~mm}$ para armadura adicional. Com isso tem-se a facilidade de não ter que fabricar a armadura e ainda a garantia que a mesma mantenha as propriedades citadas acima. 


\section{MODELOS REDUZIDOS}

A estrutura a ser pesquisada compõe-se de pilares e lajes planas conforme esquematizada na figura 1.1.

Adotou-se $\mathrm{h}_{\mathrm{o}}$ do protótipo sendo $2,80 \mathrm{~m}$, esse valor representa uma medida usual de piso a piso em edifícios reais na atualidade. Não se pode, porém, considerar $h_{o}$ como sendo pé-direito, pois, para esta pesquisa, toma-se meia altura do pilar abaixo e a acima do nível do andar de referência. A largura do pilar é chamada de "b" e a espessura da laje plana, "e". A resistência do concreto dos pilares considerada foi superior à resistência do concreto das lajes (cerca de $40 \%$ maior) como já citado anteriormente. Foi utilizado concreto de resistência característica de $50 \mathrm{MPa}$ para os pilares e de $35 \mathrm{MPa}$ para as lajes, estes valores de resistência foram escolhidos porque estão em uso em edifícios nos dias de hoje e mantém a proporção desejada para os ensaios.

Para analisar tal estrutura utilizou-se um modelo reduzido, representando pilar de canto conforme a figura 6.2 e um pilar central, de acordo com a figura 6.1. Na figura 6.3 observa-se um pilar isolado que foi moldado com concreto de resistência de $50 \mathrm{MPa}$. 


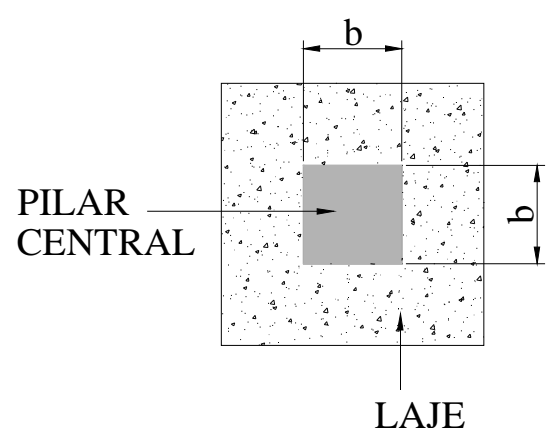

PLANTA

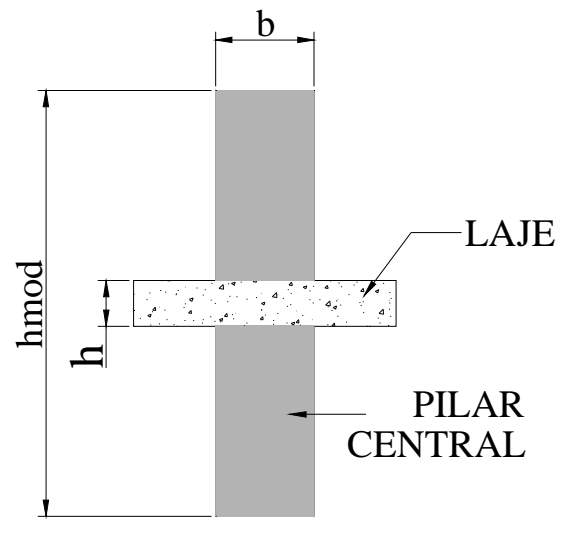

ELEVAÇÃO

Figura 6.1Representação de um pilar central

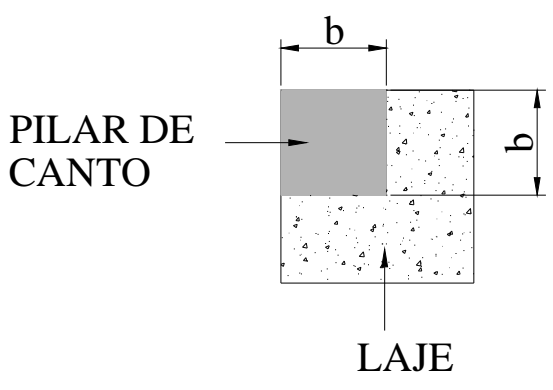

PLANTA

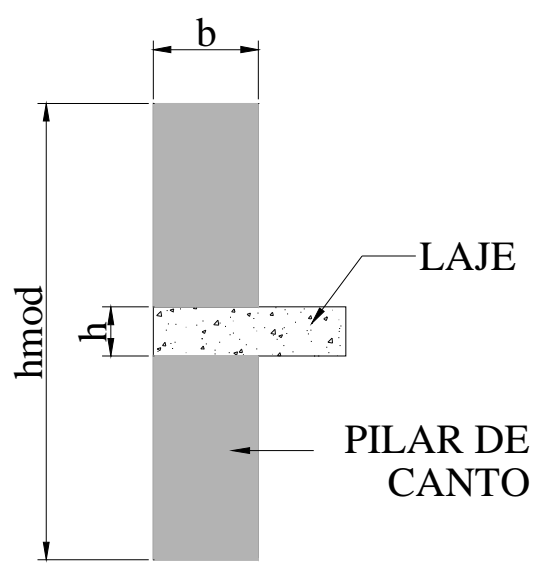

ELEVAÇÃO

Figura 6.2 Representação de um pilar de canto
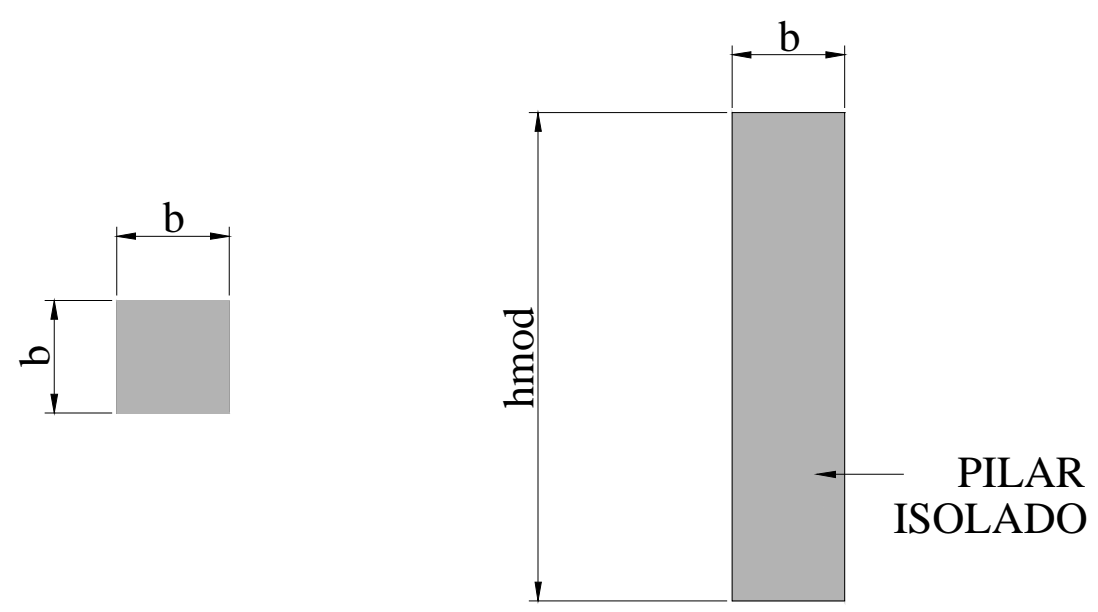

PLANTA

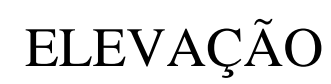

Figura 6.3 Representação de um pilar isolado 
Esses modelos têm resistências cuja relação entre elas é:

$$
\frac{f_{c p}}{f_{c l}} \geq 1,4
$$

Sendo:

$f_{c p}$ : resistência do pilar, $50 \mathrm{MPa}$;

$f_{c l}$ : resistência das lajes, $35 \mathrm{MPa}$.

Portanto tem-se:

$$
\frac{50}{35}=1,428
$$

Note que " $e$ ", espessura da placa de concreto, varia conforme os valores das espessuras das lajes planas. Os valores experimentais dessas espessuras foram obtidos pela equação a seguir:

$$
e_{\mathrm{mod}}=\frac{h_{\mathrm{mod}}}{h_{0}} \times e_{0}
$$

Sendo

$\mathrm{e}_{\text {mod }}$ : valor correspondente à espessura do modelo;

$\mathrm{e}_{0}$ : valor correspondente à espessura do protótipo;

$\mathrm{h}_{\mathrm{o}}$ : altura do protótipo;

$\mathrm{h}_{\text {mod: }}$ altura do modelo.

Segundo o fator de escala adotado de 1:4,3 tem-se, para o cálculo das medidas experimentais das espessuras das lajes planas, $\mathrm{e}_{\mathrm{exp}}$, a altura do modelo, $\mathrm{h}_{\text {mod }}$, igual a $65 \mathrm{~cm}$, pois $\mathrm{h}_{0}$, do protótipo, vale, aproximadamente, $280 \mathrm{~cm}$ como visto acima. A tabela 6.1 apresenta os valores das espessuras adotados.

Tabela 6.1 Valores reais e experimentais das lajes planas (placas)

\begin{tabular}{|c|c|c|}
\hline e, real $(\mathrm{cm})$ & $\begin{array}{c}\text { e, experimental }(\mathrm{cm}) \\
\text { calculado }\end{array}$ & $\begin{array}{c}\text { e, experimental }(\mathrm{cm}) \\
\text { adotado }\end{array}$ \\
\hline 20 & 4,64 & 4,5 \\
\hline 30 & 6,96 & 7,0 \\
\hline
\end{tabular}


Graças ao trabalho de Martins, 1990, pode-se então, investigar o comportamento das estruturas de concreto, segundo análise de modelos reduzidos utilizando microconcreto e microarmadura. O microconcreto usado será o de 4,8, como citado anteriormente que, segundo o autor, é o mais recomendado para a fabricação dos modelos.

Todos os modelos e corpos-de-prova de concreto, depois de moldados, foram levados e mantidos na câmara úmida por 26 dias, retirados para secagem e ensaiados aos 28 dias de idade. Essa pesquisa foi dividida em duas etapas.

\subsection{Primeira etapa - Modelos 1 e 2}

A resistência à compressão do concreto varia conforme a geometria do corpo-deprova ensaiado. Por norma a resistência é obtida pela divisão da força de ruptura à compressão axial de um corpo-de-prova cilíndrico de diâmetro $15 \mathrm{~cm}$ e altura de $30 \mathrm{~cm}$ pela área do mesmo, obtendo-se assim um valor em MPa. Porém, ao se romper um outro corpo-de-prova com geometria variada do primeiro a resistência à compressão é diferente da obtida anteriormente. O objetivo da primeira etapa desta pesquisa é encontrar uma área mínima de armadura transversal no pilar que compense a perda de resistência do conjunto devido à geometria.

Pode-se determinar uma área mínima de estribos em pilares, cuja geometria é mais esbelta que a do corpo-de-prova cilíndrico, que compense essa diferença de resistência através de um efeito de confinamento proporcionado por esses estribos. Para tal realizou-se ensaios com pilares isolados, ou seja, sem laje nem vigas, nos quais variou-se a área de estribos com a intenção de analisar esse efeito. A seguir tem-se detalhado cada um dos modelos reduzidos utilizados para este fim. 


\subsubsection{Modelo reduzido 1}

Este representa o protótipo do pilar isolado com concreto de resistência $50 \mathrm{MPa}$, sendo suas dimensões de $15 \mathrm{~cm} \times 15 \mathrm{~cm}$ e altura total de $65 \mathrm{~cm}$, que corresponde às dimensões reais de $64,5 \times 64,5 \mathrm{~cm}$ e altura de $279,5 \mathrm{~cm}$. Foram ensaiados dois exemplares desse modelo diferenciados pela nomenclatura A e B. A tabela 6.2 e a figura 6.4 mostram este modelo. Eles foram moldados na horizontal, em duas etapas e vibrados na mesa vibratória.

Tabela 6.2 Modelo reduzido 1

\begin{tabular}{|c|c|c|c|}
\hline Modelo & Forma & Armação & $\mathrm{f}_{\mathrm{ck}}(\mathrm{MPa})$ \\
\hline $1-\mathrm{A} / 1-\mathrm{B}$ & $\begin{array}{c}\mathrm{h}=65 \mathrm{~cm} \\
15 \times 15 \mathrm{~cm}\end{array}$ & 0 & 50 \\
\hline
\end{tabular}
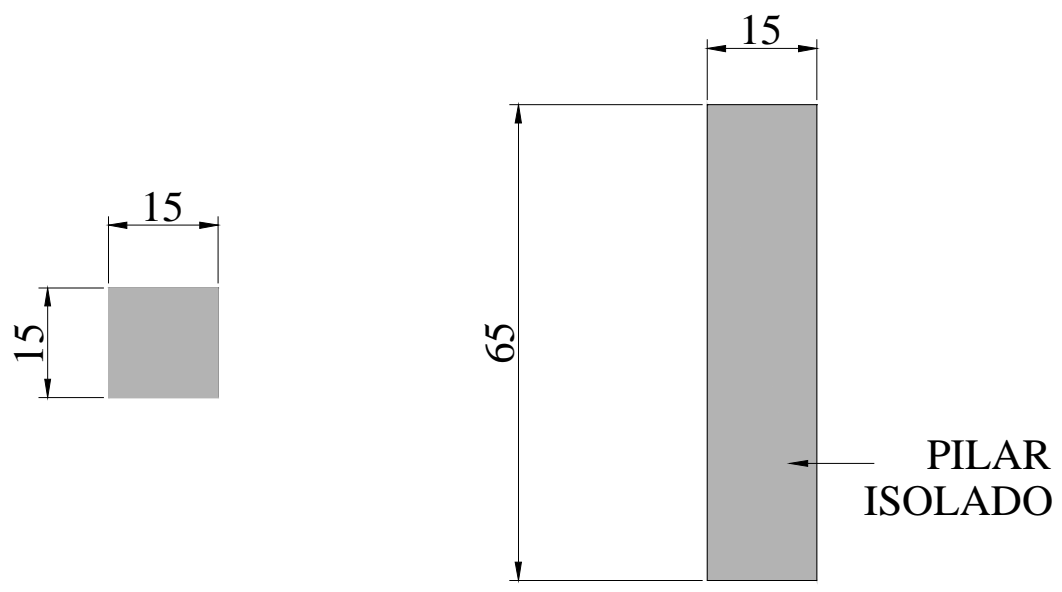

PLANTA

\section{ELEVAÇÃO}

Figura 6.4 Esquema do modelo reduzido 1

Sabe-se que a resistência à compressão axial de um modelo diminui conforme se aumenta sua esbeltez, entre outros fatores. Isso implica que o modelo ensaiado, sem armadura alguma, teria uma resistência efetiva menor que aquela medida no corpo-deprova cilíndrico. Silveira dos Santos, 2004, em seus ensaios, obteve um resultado de resistência efetiva $22 \%$ inferior. Esperava-se algo em torno disso nos ensaios realizados 
nessa pesquisa, porém, observou-se uma variabilidade muito grande, estes valores estão apresentados no capítulo referente aos resultados e análises da primeira etapa. Acreditase que tal variabilidade se deve a problemas práticos ocorridos nos ensaios. Os ensaios realizados nessa primeira etapa da pesquisa serviram de aprendizado para a próxima etapa, na qual, para evitar-se as distorções observadas na primeira etapa, forma tomadas medidas que serão detalhadas no item 6.2 mais adiante. Decidiu-se não utilizar os resultados dessa primeira etapa, pois a variação, citada anteriormente, decorrente das falhas nos ensaios foi maior do que a variação das grandezas se pretendia medir. Para colocar em outras palavras, seria como medir variações milimétricas com uma escala em metro.

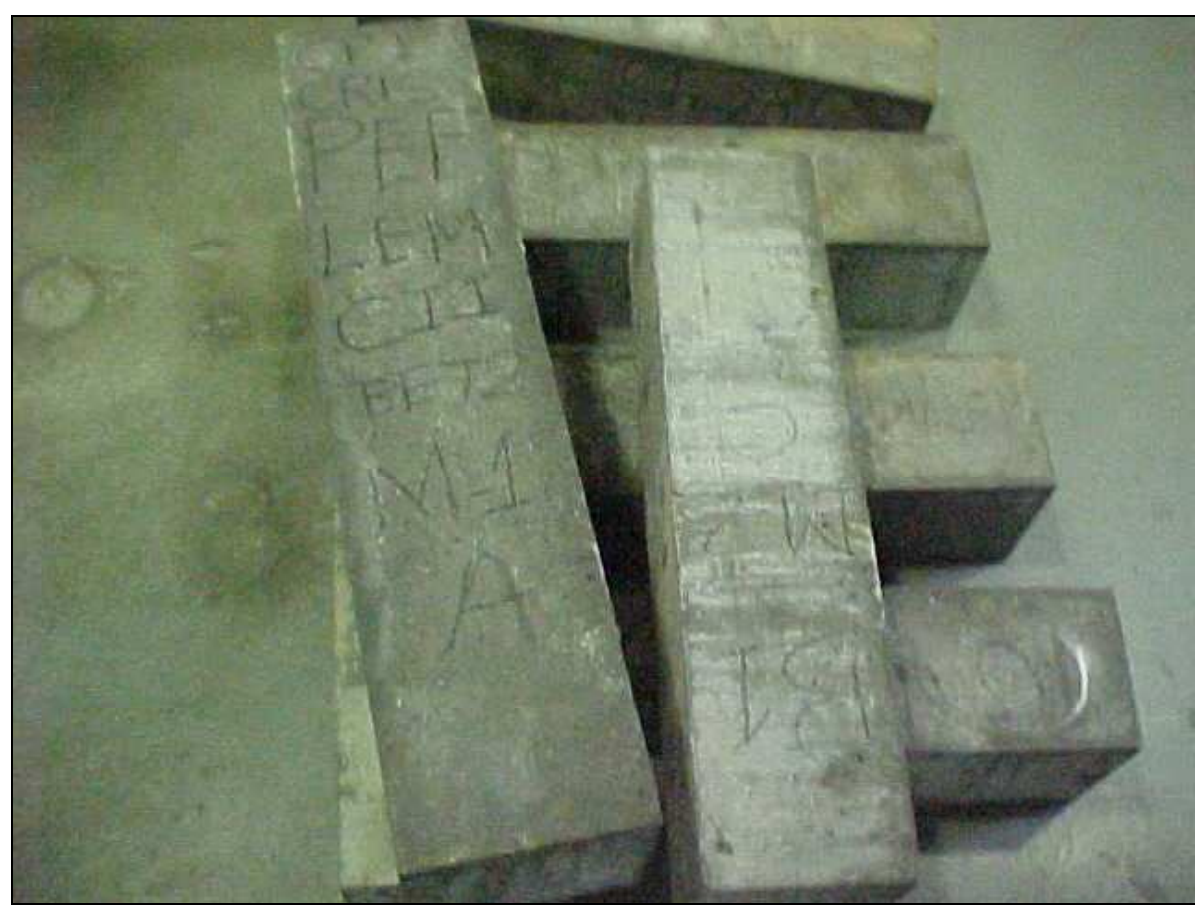

Figura 6.5 Exemplares dos modelos reduzidos 1 e 2 antes de serem ensaiados 


\subsubsection{Modelo reduzido 2}

Esse caso estuda a armadura mínima para um pilar para que haja um efeito de confinamento que compense a diferença geométrica. $\mathrm{O}$ efeito da geometria do corpo-deprova ensaiado influencia na resistência efetiva do mesmo. Desta forma pode-se prever uma armadura, chamada de mínima, capaz de proporcionar um confinamento ao concreto constituinte de um corpo-de-prova mais esbelto que compense a perda da resistência à compressão que este sofre por conta de sua geometria.

Para o cálculo dessa armadura mínima adotou-se a resistência média à tração do concreto. Considerando-se um pilar de seção quadrada com $65 \mathrm{~cm}$ de altura e lado de 15 cm constituído de concreto com resistência à compressão de $50 \mathrm{MPa}$, calcula-se a resultante resistente no plano longitudinal médio:

$$
\begin{gathered}
f_{c k}=50 M P a \\
f_{c t m}=0,3 \times \sqrt[3]{\left(f_{c k}\right)^{2}} M P a \\
f_{c t m}=4,1 M P a \\
F=0,15 \times 0,65 \times 410=40 t f
\end{gathered}
$$

Sendo:

$\mathrm{f}_{\mathrm{ck}}$ : resistência à compressão do concreto;

$\mathrm{f}_{\mathrm{ctm}}$ : resistência média à tração do concreto;

F: resultante resistente à tração do concreto no plano longitudinal médio.

Supondo uma perda de resistência à compressão do conjunto de $17 \%$ em relação à resistência do concreto medida em corpos-de-prova padrão, este valor foi baseado nos critérios de Avran et al., 1981, e nos resultados dos ensaios de Silveira dos Santos, 2004, calcula-se uma área de aço que resista a $20 \%$ da resultante estimada para o concreto, ou seja:

$$
F_{s t}=0,20 \times 40=8 t f
$$

Sendo:

$\mathrm{F}_{\mathrm{st}}$ : resultante resistente à tração nas barras de aço. 
Considerando-se um aço com resistência característica à tração de $600 \mathrm{MPa}$, pode-se calcular a área de aço necessária para a face do pilar e conseqüentemente a área necessária por metro linear de um pilar com a seção descrita acima:

$$
\begin{gathered}
A_{s}=8 / 6=1,33 \mathrm{~cm}^{2} / 0,65 \mathrm{~m} \text { em duas faces } \\
A_{s}=1,02 \mathrm{~cm}^{2} / \mathrm{m} \text { por face }
\end{gathered}
$$

Sendo:

$$
\mathrm{A}_{\mathrm{s}} \text { : área de aço. }
$$

Foi elaborado o modelo 2 com concreto de resistência de $50 \mathrm{MPa}$ e variou-se a armadura transversal com a intenção de investigar qual a área mínima de estribos que resultaria para esta resistência. Para viabilizar a montagem do modelo, acrescentou-se uma armadura longitudinal com 1,55 mm de diâmetro. A contribuição desta armadura corresponde a um valor em torno de $3 \%$ do valor da resistência total estimada. Pode-se, portanto, desprezar esta armação no conjunto. A tabela 6.3 mostra a nomenclatura adotada para estes exemplares e respectivas armaduras, as figuras 6.6 a 6.9 representam este modelo e mostram as respectivas armaduras utilizadas em cada um deles, que foram moldados e vibrados da mesma forma que o modelo reduzido 1.

TABELA 6.3 Modelo reduzido 2

\begin{tabular}{|l|c|c|c|}
\hline Modelo & Forma $(\mathrm{cm})$ & Armação & $\mathrm{f}_{\mathrm{ck}}(\mathrm{MPa})$ \\
\hline 2-A/2-B & $\begin{array}{c}\mathrm{h}=65 \\
15 \times 15\end{array}$ & $\begin{array}{c}\text { long. }=4 \phi 1,55 \mathrm{~mm} \\
\text { estr. }=\phi 4,2 \mathrm{c} / 18,5 \mathrm{~cm}\end{array}$ & 50 \\
\hline 2-C/2-D & $\begin{array}{c}\mathrm{h}=65 \\
15 \times 15\end{array}$ & $\begin{array}{c}\text { long. }=4 \phi 1,55 \mathrm{~mm} \\
\text { estr. }=\phi 4,2 \mathrm{c} / 8,5 \mathrm{~cm}\end{array}$ & 50 \\
\hline 2-E/2-F & $\begin{array}{c}\mathrm{h}=65 \\
15 \times 15\end{array}$ & $\begin{array}{c}\text { long. }=4 \phi 1,55 \mathrm{~mm} \\
\text { estr. }=\phi 4,2 \mathrm{c} / 6 \mathrm{~cm}\end{array}$ & 50 \\
\hline
\end{tabular}



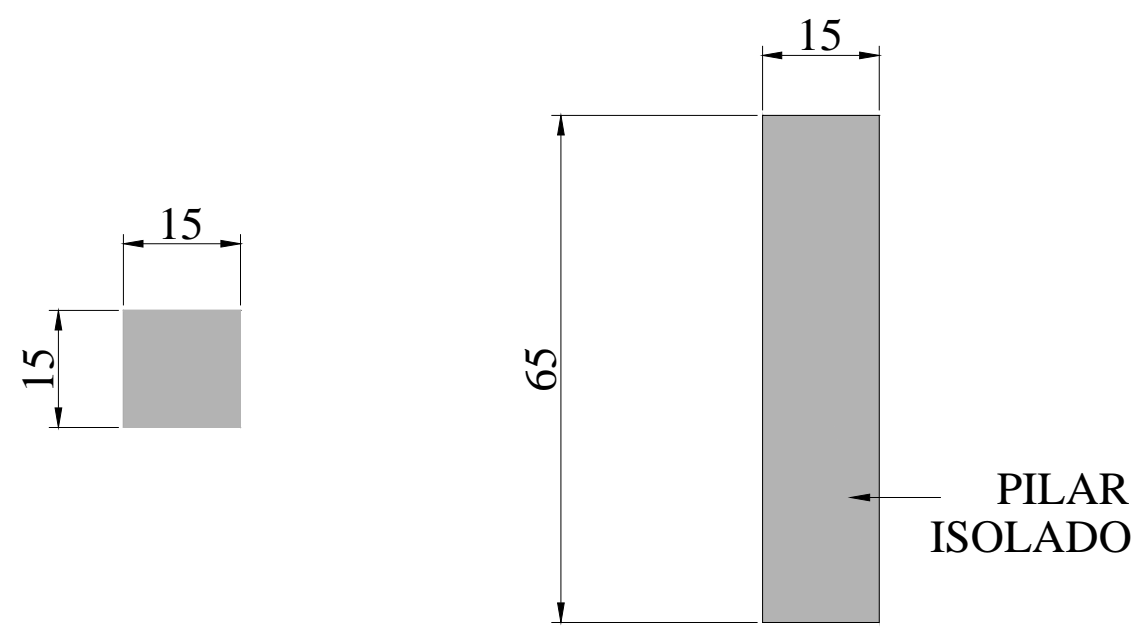

\section{PLANTA}

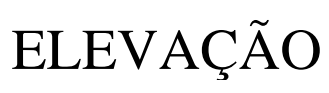

Figura 6.6 Esquema do modelo reduzido 2

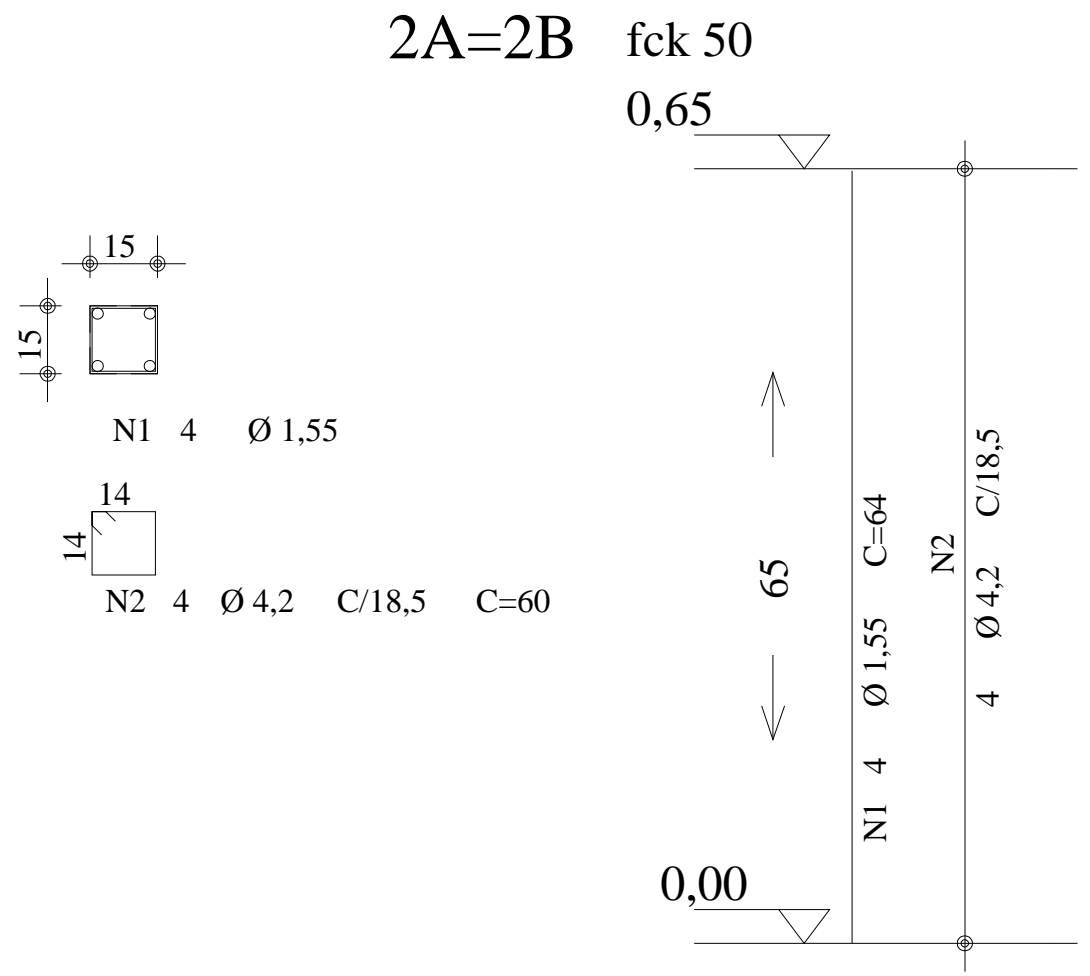

Figura 6.7 Armadura dos modelos 2-A e 2-B 


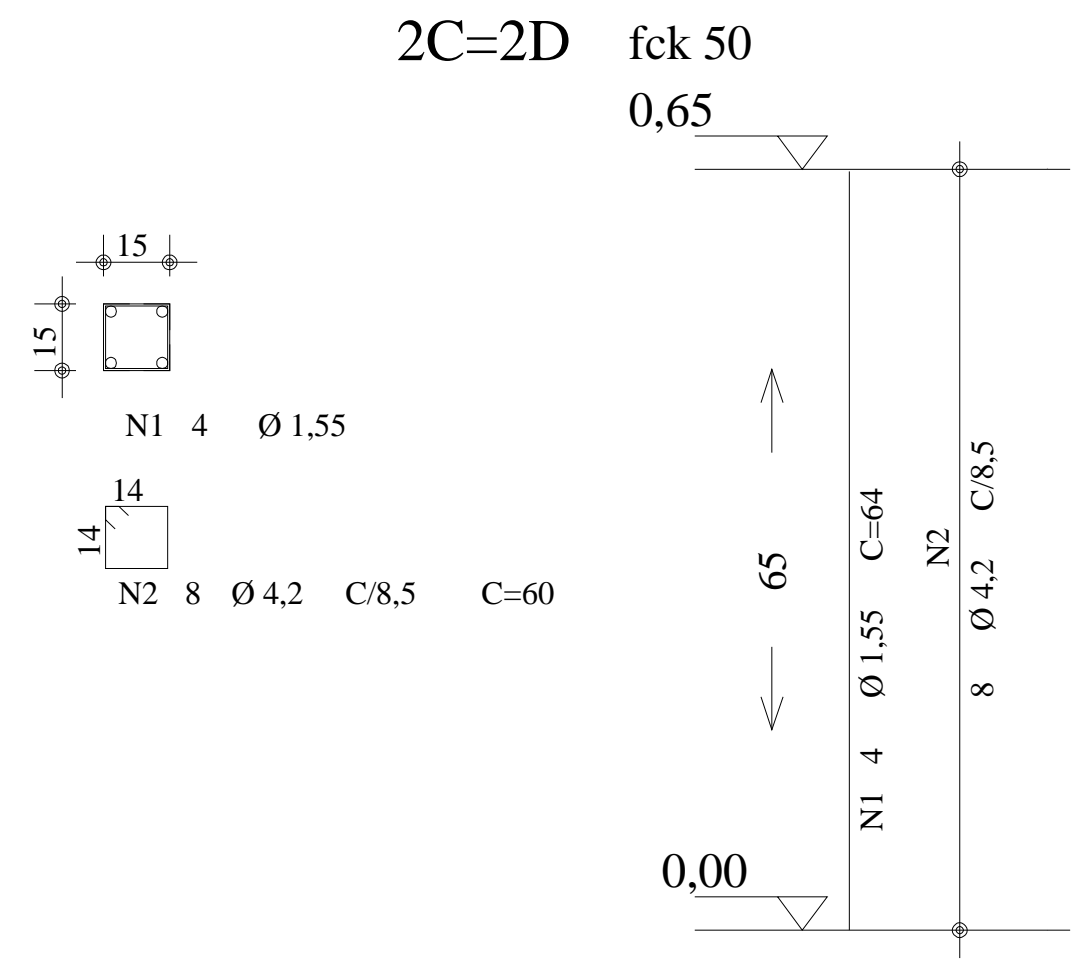

Figura 6.8 Armadura dos modelos 2-C e 2-D

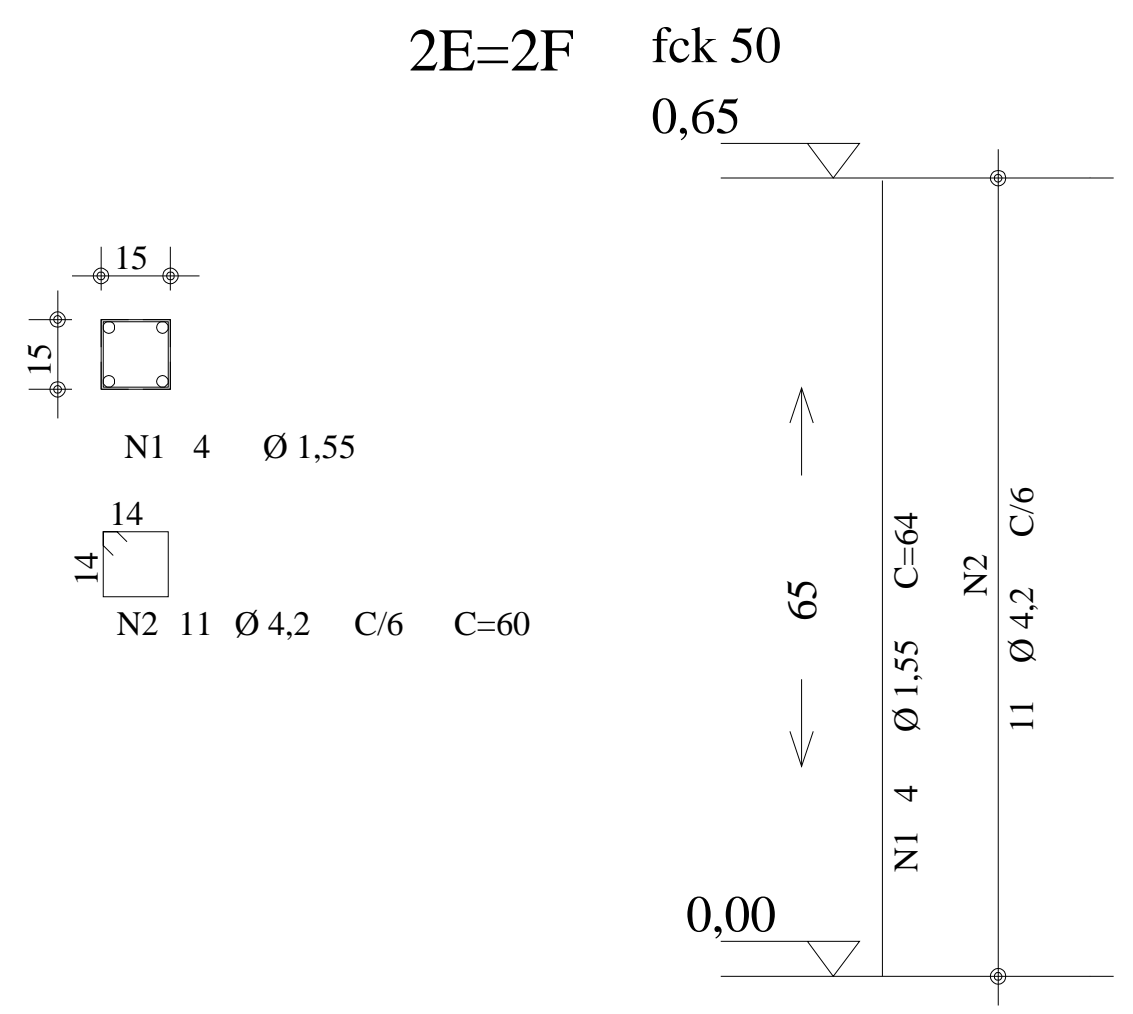

Figura 6.9 Armadura dos modelos 2-E e 2-F 
A tabela 6.4 resume os modelos da primeira etapa.

Tabela 6.4 Resumo dos modelos da $1^{\text {a }}$ etapa

\begin{tabular}{|c|cc|c|c|}
\hline Modelo & \multicolumn{2}{|c|}{ Forma (cm) } & Armação & fck (MPa) \\
\hline 1-A/1-B & $\mathrm{h}=65$ & $15 \times 15$ & 0 & 50 \\
\hline 2-A/2-B & $\mathrm{h}=65$ & $15 \times 15$ & $\begin{array}{c}\text { long. } \phi 4 \times 1,55 \mathrm{~mm} \\
\text { estr. } \phi 4.2 \mathrm{c} / 18,5 \mathrm{~cm}\end{array}$ & 50 \\
\hline 2-C/2-D & $\mathrm{h}=65$ & $15 \times 15$ & $\begin{array}{r}\text { long. } \phi 4 \times 1,55 \mathrm{~mm} \\
\text { estr. } \phi 4,2 \mathrm{c} / 8,5 \mathrm{~cm}\end{array}$ & 50 \\
\hline 2-E/2-F & $\mathrm{h}=65$ & $15 \times 15$ & $\begin{array}{r}\text { Iong. } \phi 4 \times 1,55 \mathrm{~mm} \\
\text { estr. } \phi 4,2 \mathrm{c} / 6 \mathrm{~cm}\end{array}$ & 50 \\
\hline
\end{tabular}

\subsection{Segunda etapa - Modelos I, II, III, IV, V, VI e VI}

Pilares de canto, centrais e isolados são estudados nessa etapa com a intenção de investigar o efeito do confinamento proporcionado pela laje, as consequiências da ausência deste confinamento e maneiras de compensá-lo. Assim foram formulados, modelados e ensaiados os modelos reduzidos I, II, III, IV, V, VI e VII que estão detalhados mais adiante.

A realização da primeira fase de ensaios proporcionou um aprendizado que despertou a necessidade de se tomarem outros cuidados. Acredita-se que os resultados podem ter sido distorcidos pelas seguintes razões que se procurou evitar nos ensaios subseqüentes, são estas: má vibração do concreto causando um excesso de bolhas que podem diminuir a resistência do conjunto; excesso de vibração ocasionando a decantação das britas e conseqüente alteração da homogeneidade do concreto e de sua resistência; as formas poderiam estar fora de esquadro e para evitar tal situação, fez-se uma verificação mais apurada das mesmas para que ficassem com faces paralelas ou perpendiculares entre si, conforme o caso, pois a força de compressão deve ser aplicada de forma igualmente distribuída nos topos dos pilares, e, o fato de as faces de topo não estarem paralelas, pode gerar um efeito de flexão ou uma ruptura por esmagamento do concreto em alguma elevação da face de topo também alterando o resultado; o capeamento dos topos dos pilares, que consiste em se aplicar uma camada de enxofre, com a qual se tem a certeza de planicidade e do perpendicularismo desta com as faces do 
modelo. Esta certeza é proveniente de um equipamento que funciona como uma forma para esta camada de enxofre e ainda dispõe de duas lâminas colocadas perpendiculares à face inferior desta forma. As fotos da figura 6.10 mostram este equipamento e elucidam como o mesmo é utilizado. Nota-se que uma adaptação foi feita para a base de $15 \mathrm{~cm}$ x $15 \mathrm{~cm}$ do modelo reduzido, uma vez que este equipamento foi elaborado para capeamento de blocos de maior dimensão. As fotos da figura 6.11 mostram os modelos reduzidos capeados. O travamento do conjunto é importante para evitar efeitos de segunda ordem, indesejados para os ensaios executados, portanto, foi dedicada maior atenção a esse fim e as figuras 6.12 e 6.13 mostram esse travamento para cada um dos tipos de modelos. Além destes cuidados, houve um aumento da amostragem de modelos reduzidos de dois para três exemplares de cada.

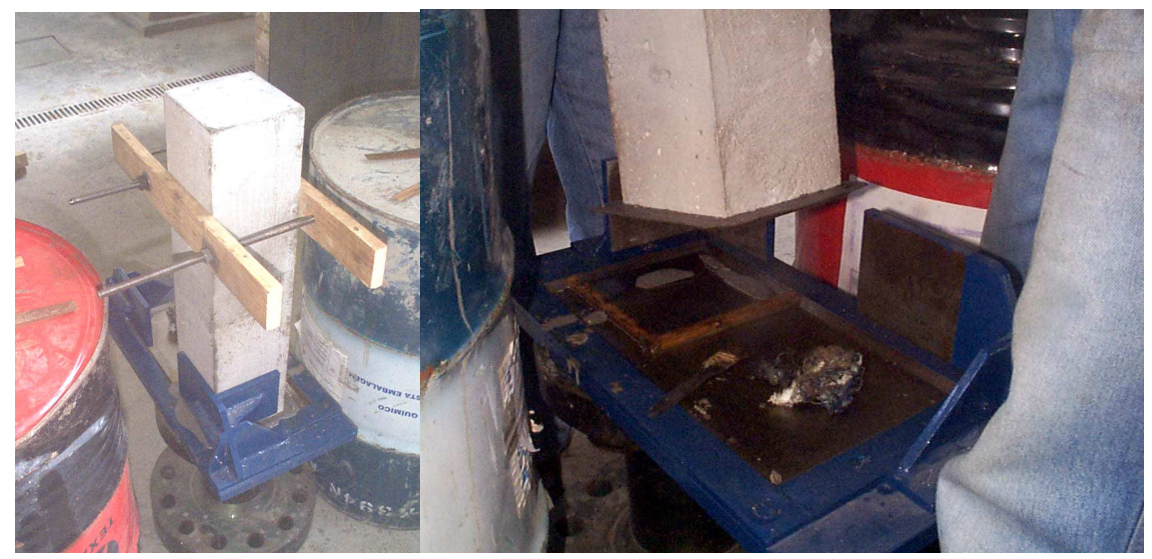

Figura 6.10 Capeamento dos modelos reduzidos

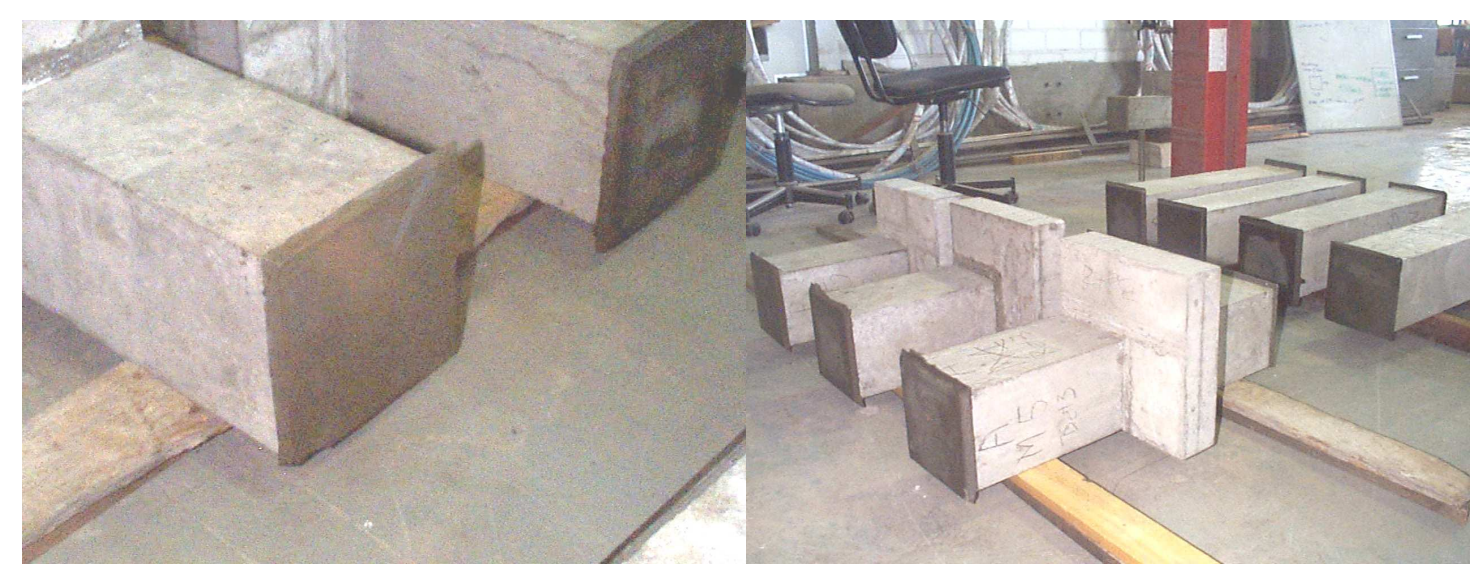

Figura 6.11 Modelos reduzidos capeados 


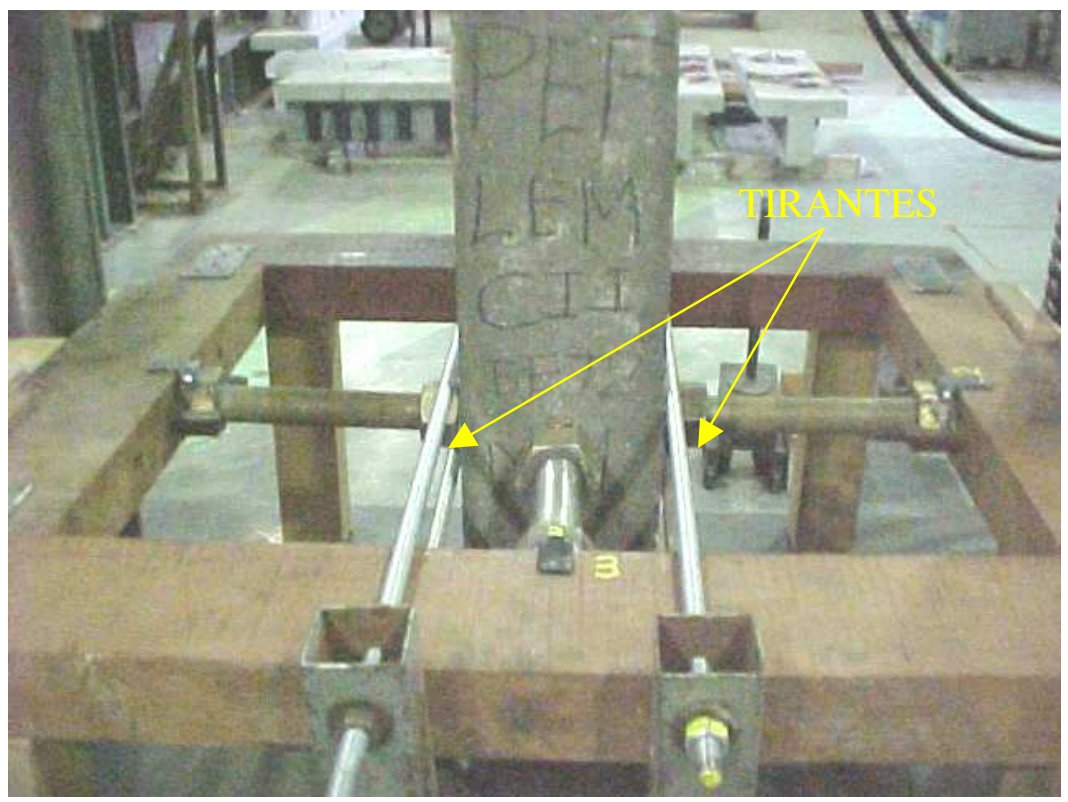

Figura 6.12 Travamento dos modelos reduzidos para pilar isolado

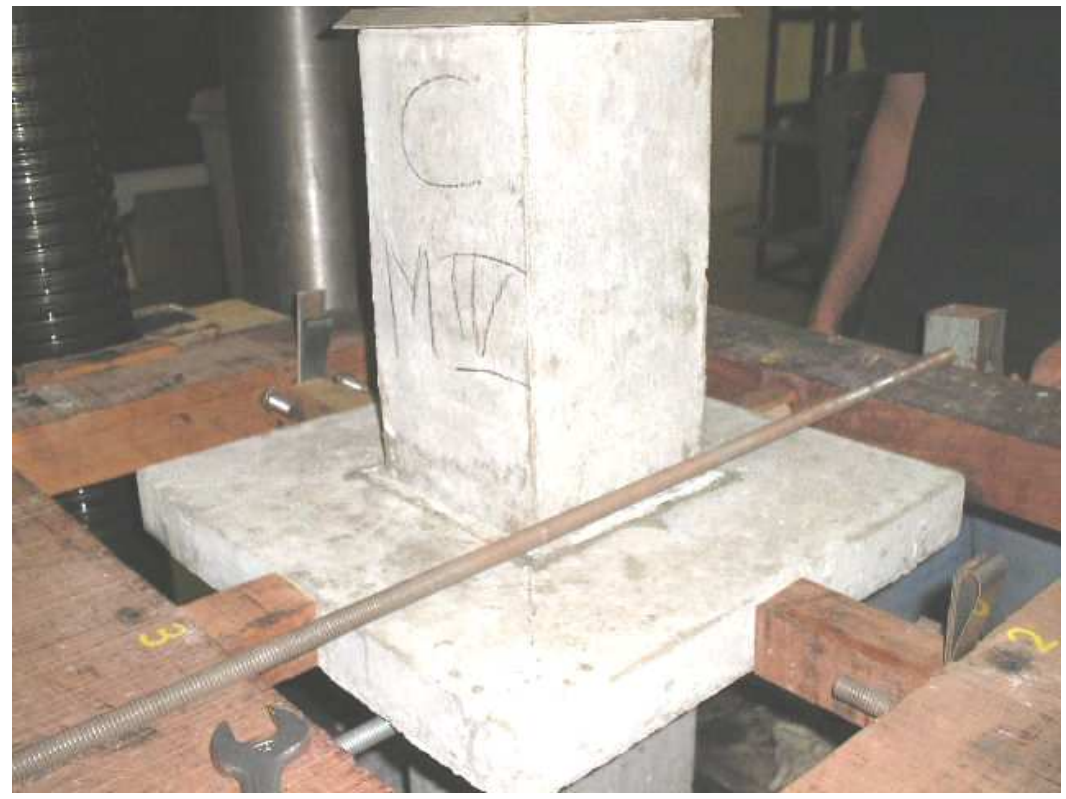

Figura 6.13 Travamento dos modelos reduzidos de pilar central 


\subsubsection{Modelo reduzido I}

O modelo reduzido I desta segunda etapa representa um pilar isolado com concreto de resistência de $50 \mathrm{MPa}$. Suas dimensões são de $15 \mathrm{~cm}$ x $15 \mathrm{~cm}$ de base e 65 $\mathrm{cm}$ de altura, como mostrado nas figuras 6.14 e 6.15 e detalhado na tabela 6.5. Este modelo foi moldado na horizontal e vibrado com vibrador de haste.

Tabela 6.5 Modelo reduzido I

\begin{tabular}{|c|c|c|c|c|c|}
\hline Modelo & \multicolumn{2}{|c|}{ Forma (cm) } & \multicolumn{1}{|c|}{ Armação } & $\mathrm{f}_{\text {ck }}(\mathrm{MPa})$ \\
\hline $\begin{array}{c}\mathrm{I}-\mathrm{A} / \mathrm{I}-\mathrm{B} \\
\text { I-C/I-D }\end{array}$ & $\mathrm{P}$ & $\begin{array}{c}\mathrm{h}=65 \\
15 \times 15\end{array}$ & $\mathrm{P}$ & 0 & 50 \\
\hline
\end{tabular}

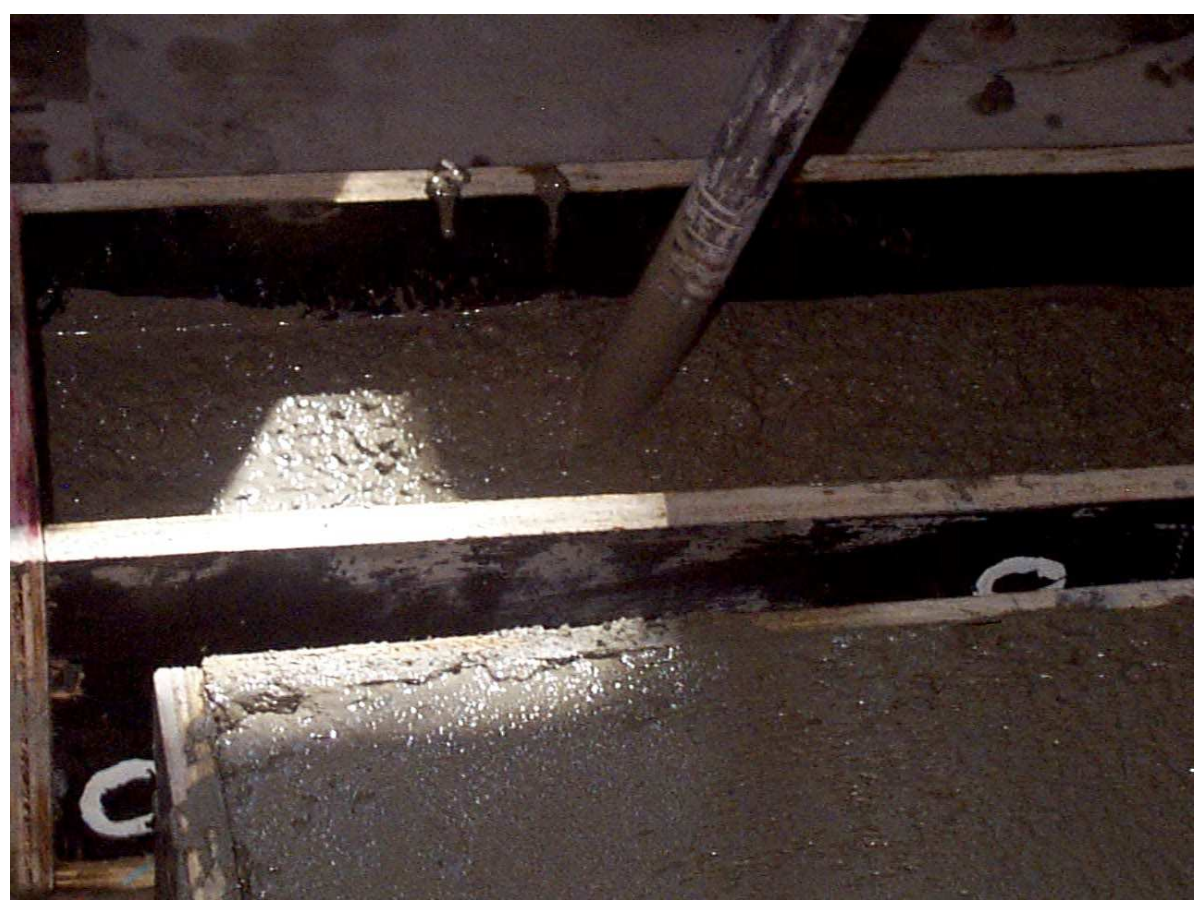

Figura 6.14 Concretagem do modelo reduzido I 


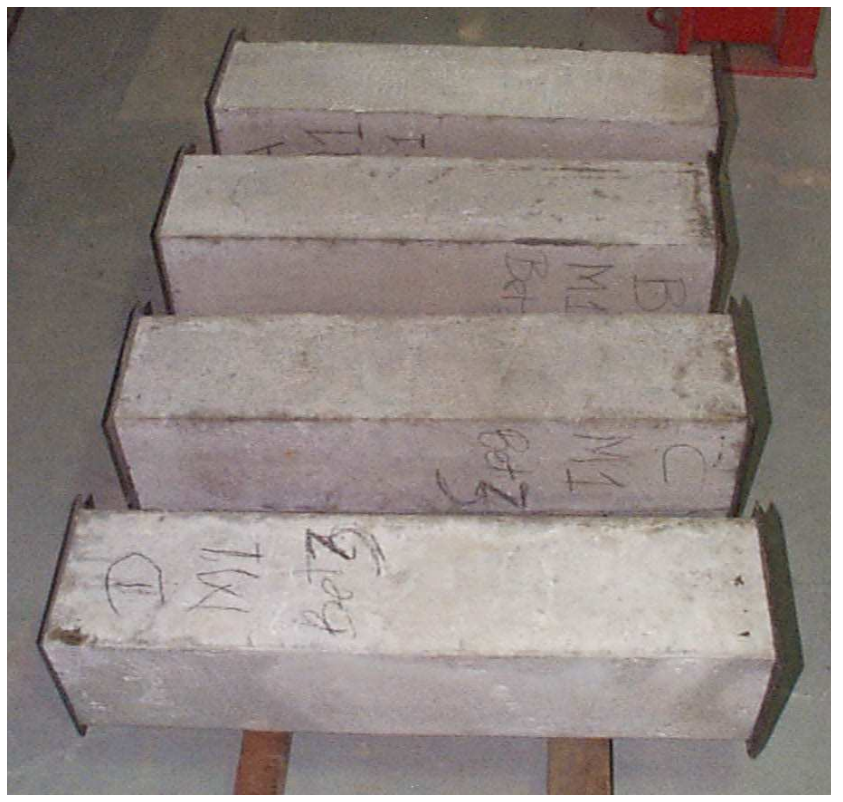

Figura 6.15 Modelo reduzido I capeado 


\subsubsection{Modelo reduzido II}

Este modelo representa um pilar isolado constituído de concreto com resistência de $50 \mathrm{MPa}$, dividido ao meio por uma faixa horizontal de $4,5 \mathrm{~cm}$ de altura de concreto de menor resistência, $35 \mathrm{MPa}$, que corresponde a uma laje de 19,35 cm de altura real. Suas dimensões de base são $15 \mathrm{~cm}$ x $15 \mathrm{~cm}$ e $65 \mathrm{~cm}$ de altura total. A tabela 6.6 e as figuras 6.16 a 6.18 o representam. Esse modelo foi moldado na horizontal e vibrado na mesa vibratória.

Tabela 6.6 Modelo reduzido II

\begin{tabular}{|c|c|c|c|c|c|}
\hline Modelo & \multicolumn{2}{|c|}{ Forma (cm) } & \multicolumn{2}{|c|}{ Armação } & $\mathrm{f}_{\text {ck }}(\mathrm{MPa})$ \\
\hline \multirow{2}{*}{$\begin{array}{c}\text { II-A/II-B } \\
\text { II-C }\end{array}$} & $\mathrm{P}$ & $\begin{array}{c}\mathrm{h}=65 \\
15 \times 15\end{array}$ & $\mathrm{P}$ & 0 & 50 \\
\cline { 2 - 6 } & $\mathrm{L}$ & $\begin{array}{c}\mathrm{h}=4,5 \\
15 \times 15\end{array}$ & $\mathrm{~L}$ & 0 & 35 \\
\hline
\end{tabular}

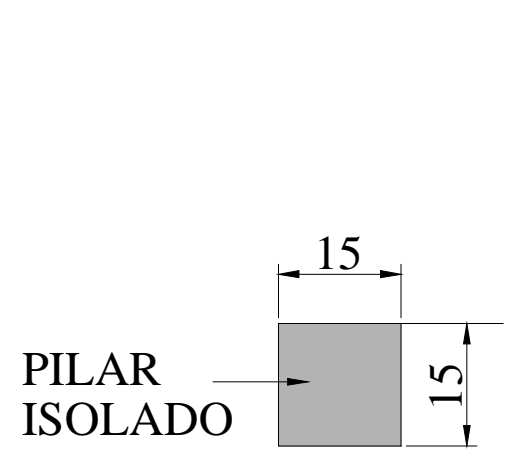

PLANTA

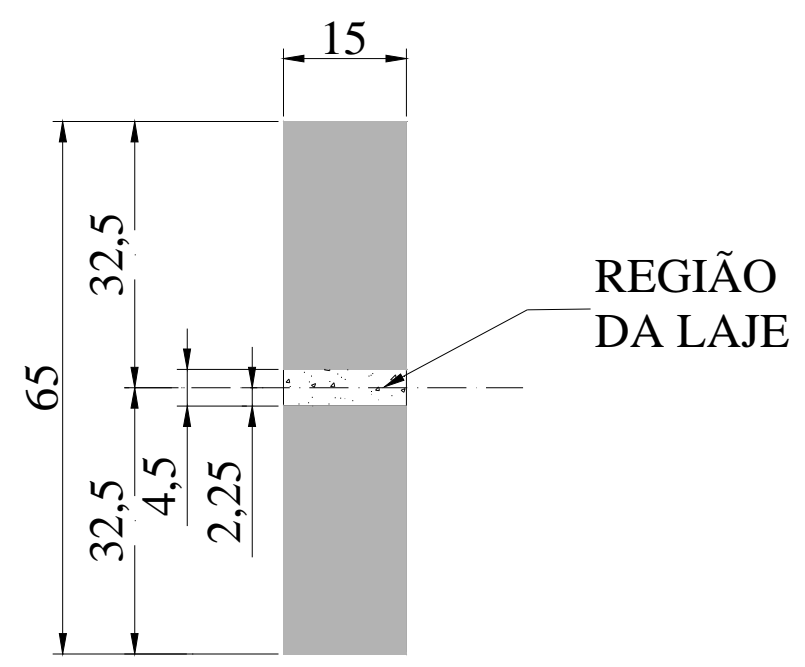

ELEVAÇÃO

Figura 6.16 Esquema do modelo reduzido II 


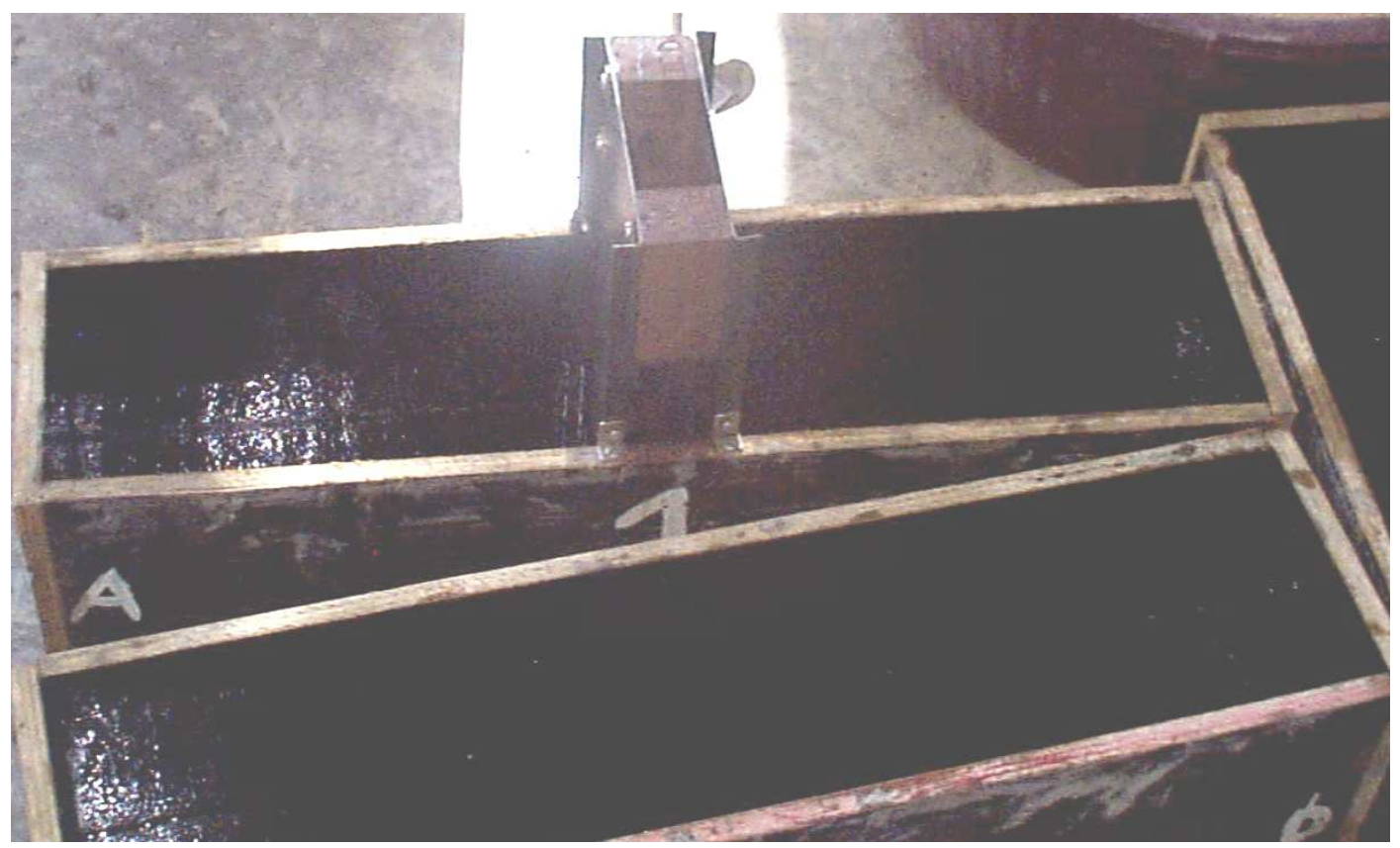

Figura 6.17 Forma do modelo reduzido II

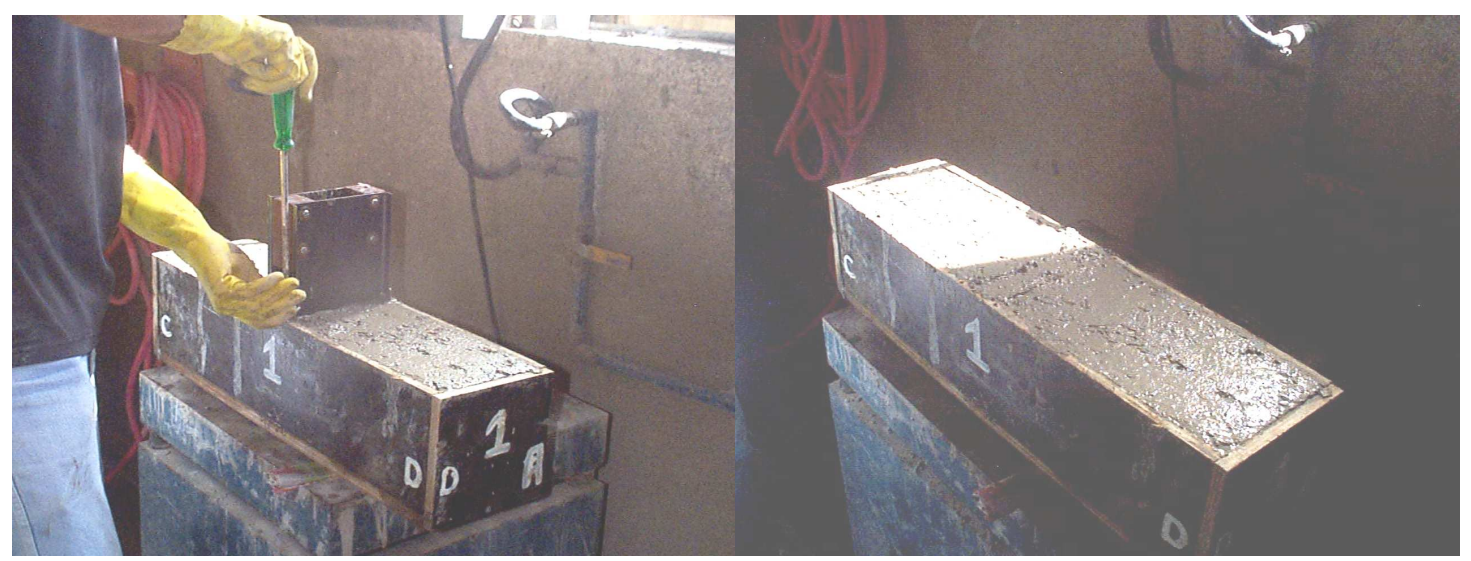

Figura 6.18 Concretagem do modelo reduzido II

\subsubsection{Modelo reduzido III}

Este modelo é similar ao modelo reduzido II, porém, com laje de $7 \mathrm{~cm}$ de altura. Os resultados destes ensaios foram descartados pois as resistências médias à compressão do concreto obtidas aos 28 dias ficaram fora do valor esperado, ou seja, a resistência à compressão do concreto da laje ficou com o mesmo valor da resistência à compressão do concreto dos pilares. 


\subsubsection{Modelo reduzido IV}

Este é o primeiro modelo de conjunto pilar com laje e estuda o pilar central, com uma espessura de laje de 4,5 cm correspondente a uma laje de piso de dimensão real de aproximadamente $19 \mathrm{~cm}$, espessura essa não analisada por Silveira dos Santos em seus ensaios. As figuras 6.19 e 6.20 e a tabela 6.7 detalham tal modelo cujas dimensões serão de $40 \mathrm{~cm}$ x $40 \mathrm{~cm}$ para os lados da laje e o pilar tendo sua seção mantida em $15 \mathrm{~cm}$ x 15 $\mathrm{cm}$ e altura total do conjunto de $65 \mathrm{~cm}$. A partir desse modelo, inclusive ele, todos os modelos forma moldados na vertical em três etapas:

- pilar de baixo, concretado até meia altura e vibrado com vibrador de haste, depois completado até o topo e vibrado novamente;

- laje, vibrada também com vibrador de haste;

- pilar de cima, com procedimento semelhante ao pilar de baixo

Tabela 6.7 Modelo reduzido IV

\begin{tabular}{|c|c|c|c|c|c|}
\hline Modelo & \multicolumn{2}{|c|}{ Forma (cm) } & \multicolumn{2}{|c|}{ Armação } & $\mathrm{f}_{\mathrm{ck}}(\mathrm{MPa})$ \\
\hline IV-A a C & $\mathrm{P}$ & $\begin{array}{c}\mathrm{h}=6 \quad 15 \\
\mathrm{x} 15\end{array}$ & $\mathrm{P}$ & 0 & 50 \\
\cline { 2 - 5 } & $\mathrm{L}$ & $\begin{array}{c}40 \times 40 \\
\mathrm{~h}=4,5\end{array}$ & $\mathrm{~L}$ & 0 & 35 \\
\hline
\end{tabular}

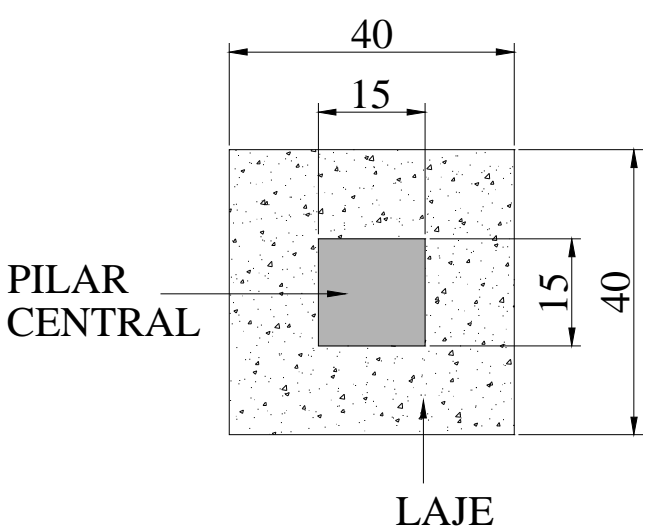

PLANTA

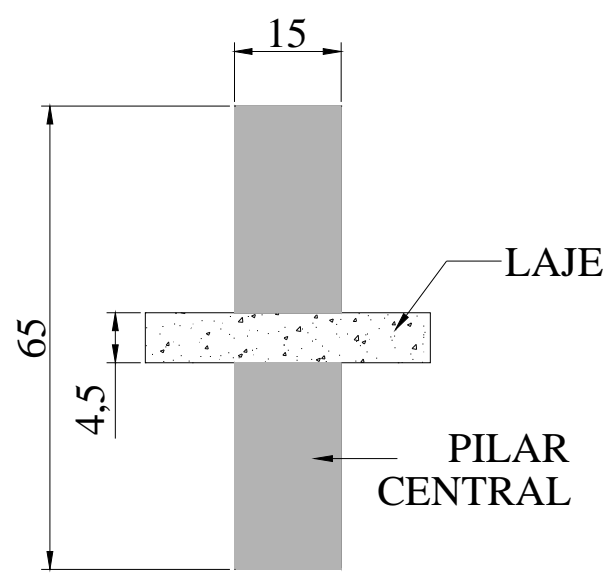

ELEVAÇÃO

Figura 6.19 Esquema do modelo reduzido IV 


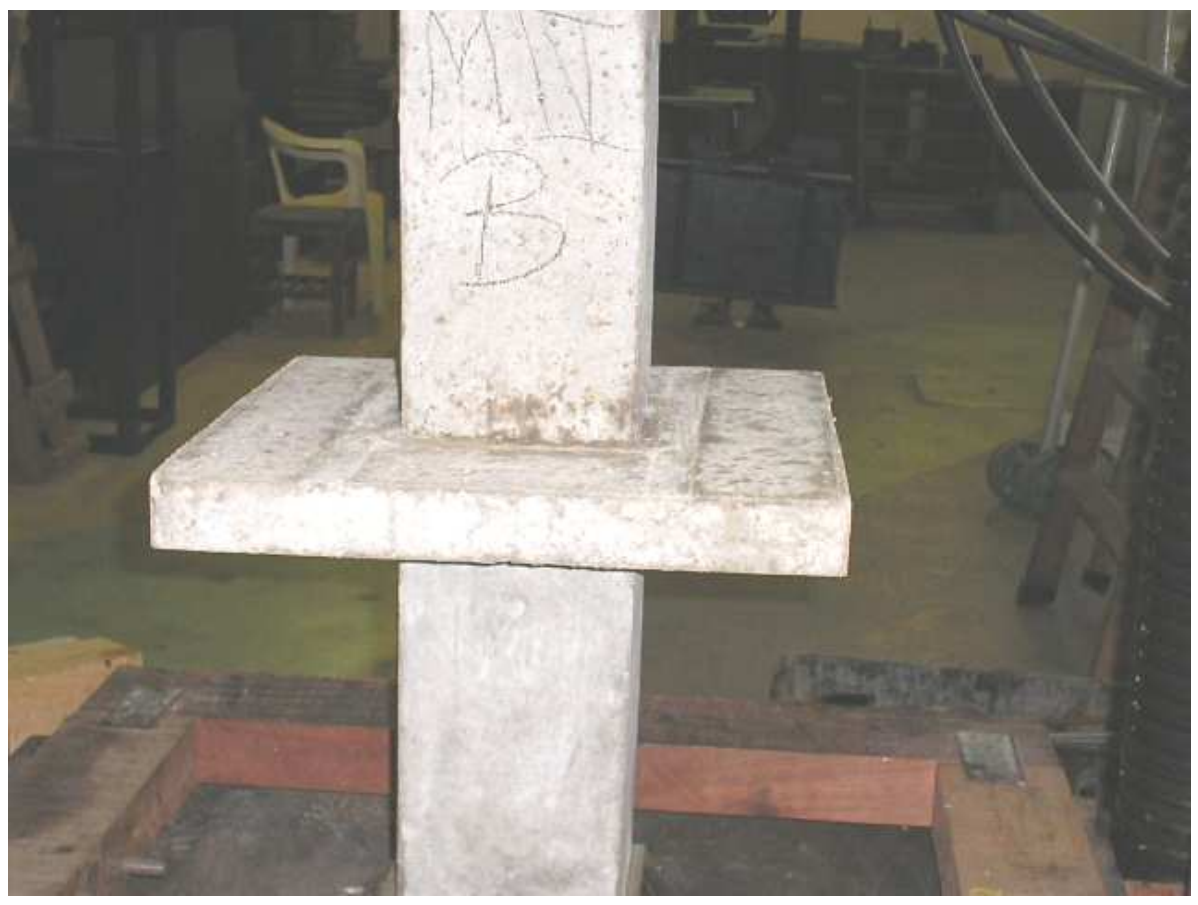

Figura 6.20 Modelo reduzido IV 


\subsubsection{Modelo reduzido $\mathrm{V}$}

Um pilar de canto, tendo espessura de laje de 7,0 cm, correspondente à laje de piso de dimensão real de aproximadamente $30 \mathrm{~cm}$, é representado por este modelo. Foi moldado sem armadura alguma para investigar se a falta da laje reduz a capacidade resistente do conjunto. As figuras 6.21 a 6.24 e a tabela 6.8 o detalham. Suas dimensões são de $27,5 \mathrm{~cm}$ x $27,5 \mathrm{~cm}$ para os lados da laje e o pilar tendo sua seção mantida em $15 \mathrm{~cm}$ x $15 \mathrm{~cm}$ e altura total do conjunto de $65 \mathrm{~cm}$. Foram moldados 6 exemplares desse modelo cuja nomenclatura variou de V-A a V-F. Dividiram-se esses exemplares em duas séries: primeira e segunda, sendo os exemplares $\mathrm{V}-\mathrm{A}$ a $\mathrm{V}-\mathrm{C}$ da primeira série e V-E a V-F da segunda. A diferença entre as séries foi o valor da resistência média do concreto aos 28 dias de idade. No capítulo referente a resultados esta diferença está detalhada.

Tabela 6.8 Modelo reduzido V

\begin{tabular}{|c|c|c|c|c|c|}
\hline Modelo & \multicolumn{2}{|c|}{ Forma (cm) } & \multicolumn{2}{c|}{ Armação } & $\mathrm{f}_{\mathrm{ck}}(\mathrm{MPa})$ \\
\hline \multirow{2}{*}{ V-A a F } & $\mathrm{P}$ & $\begin{array}{c}\mathrm{h}=65 \\
15 \times 15\end{array}$ & $\mathrm{P}$ & 0 & 50 \\
\cline { 2 - 5 } & $\mathrm{L}$ & $\begin{array}{c}27,5 \times 27,5 \\
\mathrm{~h}=7\end{array}$ & $\mathrm{~L}$ & 0 & 35 \\
\hline
\end{tabular}

PILAR DE CANTO

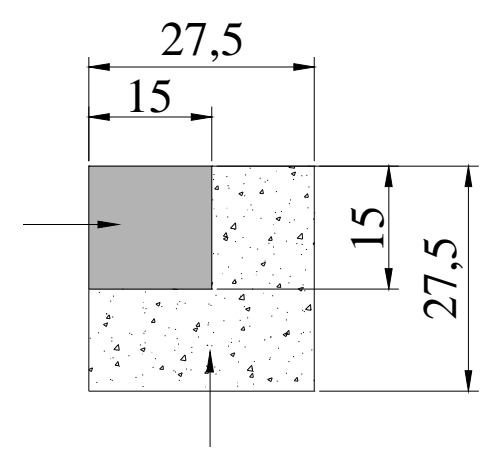

LAJE

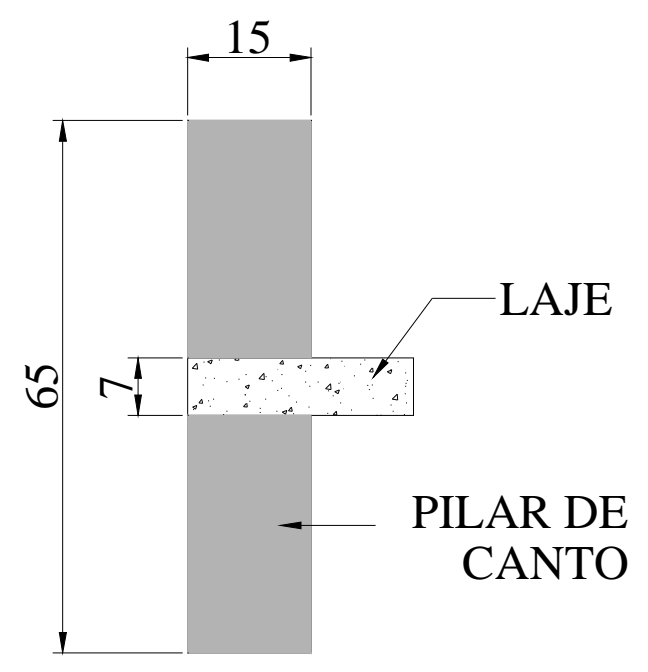

ELEVAÇÃO

PLANTA

Figura 6.21 Esquema do modelo reduzido V 


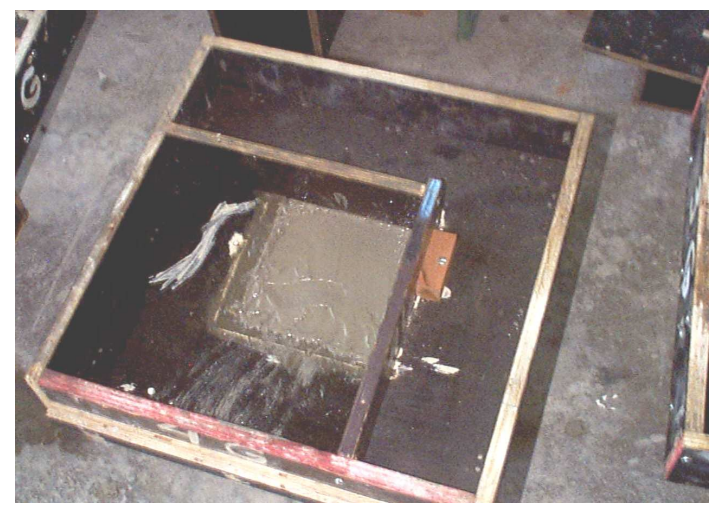

Figura 6.22 Primeira fase da concretagem do modelo reduzido V

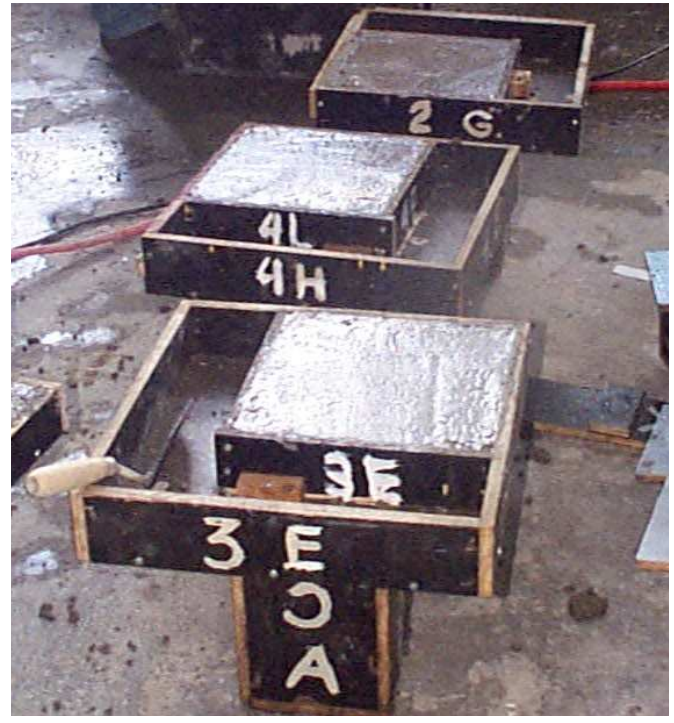

Figura 6.23 Segunda fase da concretagem do modelo reduzido $\mathrm{V}$

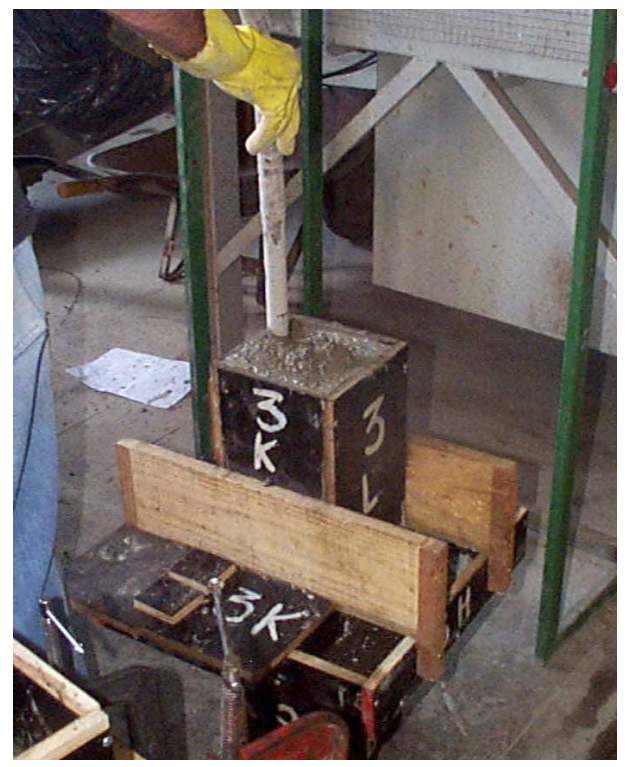

Figura 6.24 Terceira e última fase da concretagem do modelo reduzido $\mathrm{V}$ 


\subsubsection{Modelo reduzido VI}

Esse modelo tem a finalidade de estudar o pilar de canto, com espessura de laje de 7,0 cm correspondente à laje de piso de dimensão real de aproximadamente $30 \mathrm{~cm}$. Foi inserida uma armadura complementar na laje para compensar a falta da mesma em duas de suas faces. A área de armadura necessária, $\mathrm{A}_{\mathrm{s}}$, foi calculada a partir da resultante à tração do concreto de um plano diagonal mediano de um conjunto de pilar central como mostra a figura 6.25 .
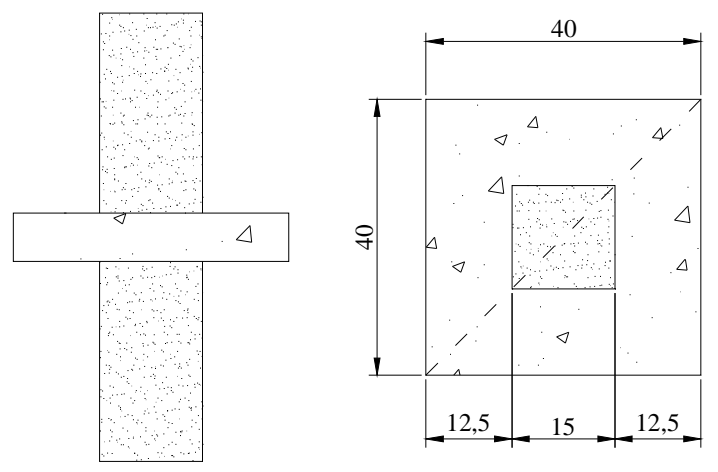

PILAR CENTRAL
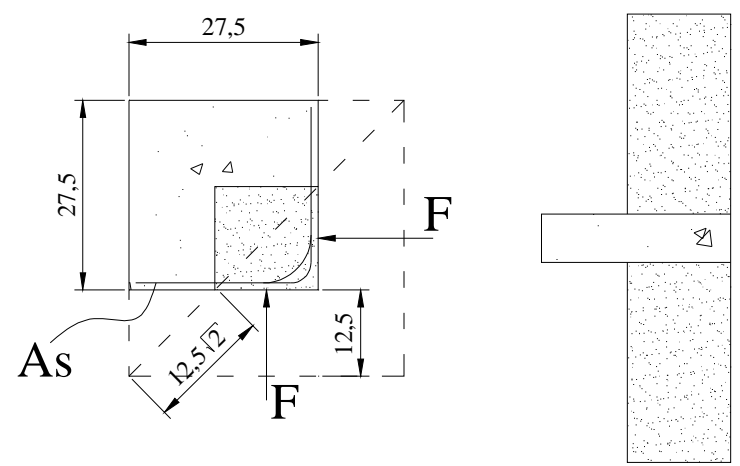

Figura 6.25 Cálculo da armadura de reforço na região da laje

Supondo que a armadura complementar tenha que resistir a essa resultante, proveniente da ausência da laje calculou-se a área de aço das barras:

$$
\begin{gathered}
f_{c k}=35 \mathrm{MPa} \\
f_{c t m}=0,3 \times \sqrt[3]{\left(f_{c k}\right)^{2}} \mathrm{MPa} \\
f_{c t m}=3,21 \mathrm{MPa} \\
R_{c t}=3,21 \times 0,125 \times 2 \times \sqrt{2} \times 0,07 \times 1000=79,44 \mathrm{kN} \\
R_{s t}=R_{c t}=79,44 \mathrm{kN} \\
\text { aço CA- } 60 \rightarrow A_{\text {scalc. }}=\frac{79,44}{60} \\
\text { aço CA-60 } \rightarrow A_{\text {scalc. }}=1,3 \mathrm{~cm}^{2}
\end{gathered}
$$

Adotou-se utilizar 9 barras de diâmetro $5 \mathrm{~mm}$ : 


$$
A_{\text {seal }}=9 \times 0,196=1,77 \mathrm{~cm}^{2}
$$

Sabe-se que o aço não escoa nesse ensaio, portanto fazendo-se a conta ao contrário pode-se prever qual será a tensão real no aço:

$$
\begin{gathered}
\text { aço CA- } 60 \rightarrow \sigma_{s}=\frac{79,44}{1,77} \\
\text { aço CA- } 60 \rightarrow \sigma_{s} \approx 45 \mathrm{kN} / \mathrm{cm}^{2}
\end{gathered}
$$

Sendo:

$\mathrm{f}_{\mathrm{ck}}$ : resistência característica à compressão do concreto

$\mathrm{f}_{\mathrm{ctm}}$ : resistência média à tração do concreto

$\mathrm{R}_{\mathrm{ct}}$ : resultante à tração do concreto no plano mediano diagonal

$\mathrm{R}_{\mathrm{st}}$ : resultante à tração do aço

$\mathrm{A}_{\text {s calc. }}$ área de aço calculada

$\mathrm{A}_{\mathrm{s} \text { real. }}$ área de aço utilizada

As figuras 6.26 a 6.29 e a tabela 6.9 detalham esse modelo cujas dimensões são de $27,5 \mathrm{~cm}$ x $27,5 \mathrm{~cm}$ para os lados da laje e o pilar tendo sua seção mantida em $15 \mathrm{~cm} \times 15 \mathrm{~cm}$ e altura total do conjunto de $65 \mathrm{~cm}$. O raio médio da dobra das barras complementares foi de $7,5 \mathrm{~cm}$ e foi calculado considerando-se 15 diâmetros. Essa armadura foi disposta em três feixes com três barras cada um totalizando 9 barras de diâmetro $5 \mathrm{~mm}$ o que resulta em uma área de aço de $1,77 \mathrm{~cm}^{2}$. Nesse caso, a barra mais externa de cada feixe foi dobrada com um raio um pouco menor que as outras para diminuir a região de concreto sem armadura. Foram adicionados a esse modelo e ao modelo reduzido VII strain gages que mediram a deformação do aço para o cálculo da força efetiva absorvida pela barra. Dois gages foram fixados em cada um dos exemplares: um deles em uma das barras da armadura complementar da laje e outro em uma das barras da armadura construtiva, esse último fixado à barra mais próxima à região confinada.

Tabela 6.9 Modelo reduzido VI

\begin{tabular}{|c|c|c|c|c|c|}
\hline Modelo & \multicolumn{2}{|c|}{ Forma (cm) } & \multicolumn{2}{c|}{ Armação } & $\mathrm{f}_{\mathrm{ck}}(\mathrm{MPa})$ \\
\hline \multirow{3}{*}{ VI-A a C } & $\mathrm{P}$ & $\begin{array}{c}\mathrm{h}=65 \\
15 \times 15\end{array}$ & $\mathrm{P}$ & 0 & 50 \\
\cline { 2 - 5 } & $\mathrm{L}$ & $\begin{array}{c}27,5 \times 27,5 \\
\mathrm{~h}=7\end{array}$ & $\mathrm{~L}$ & $\begin{array}{c}2 \times 3 \phi 4,2 \mathrm{~mm} \\
3 \times 3 \phi 5 \mathrm{~mm}\end{array}$ & 35 \\
\hline
\end{tabular}




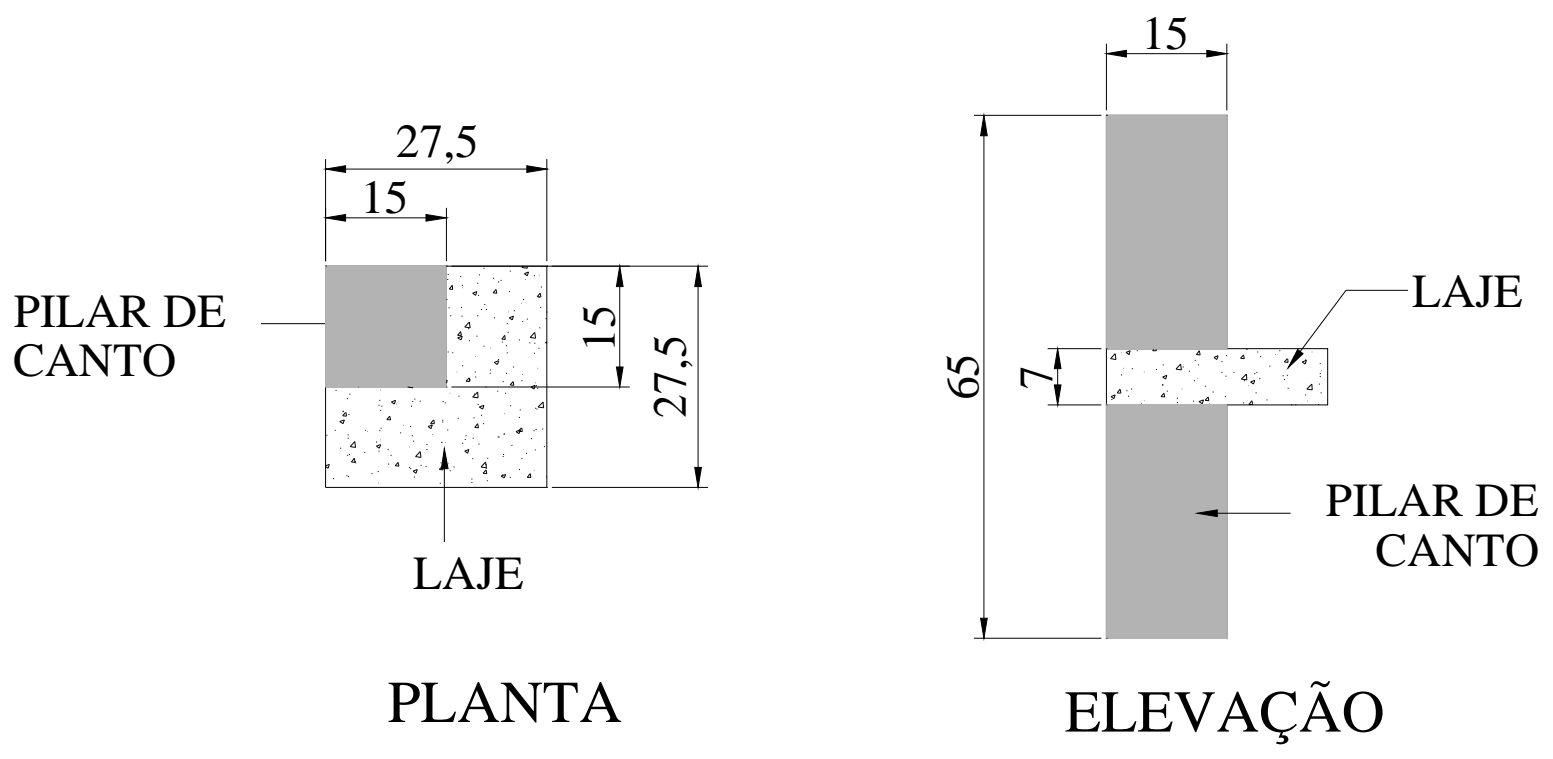

Figura 6.26 Modelo reduzido VI

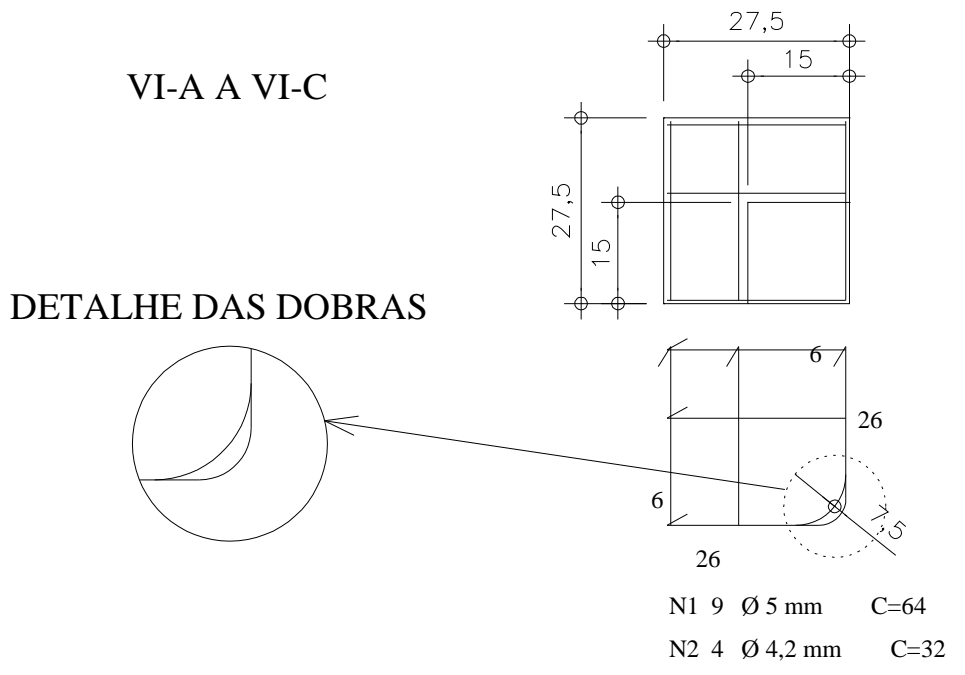

DETALHE DA ARMADURA NA REGIÃO DA LAJE $\underline{2 \times 2 N 2}$
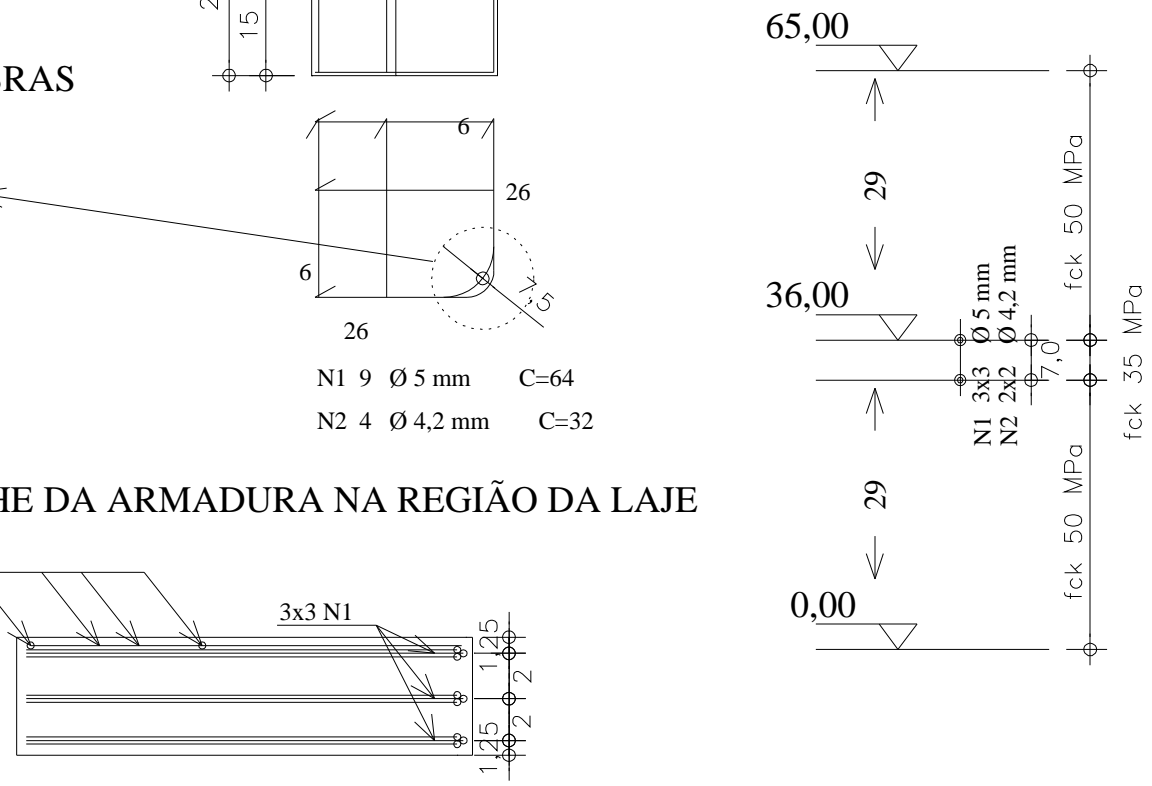

Obs.: Medidas em centímetros, exceto onde indicado

Figura 6.27 Esquema da armadura do modelo reduzido VI 


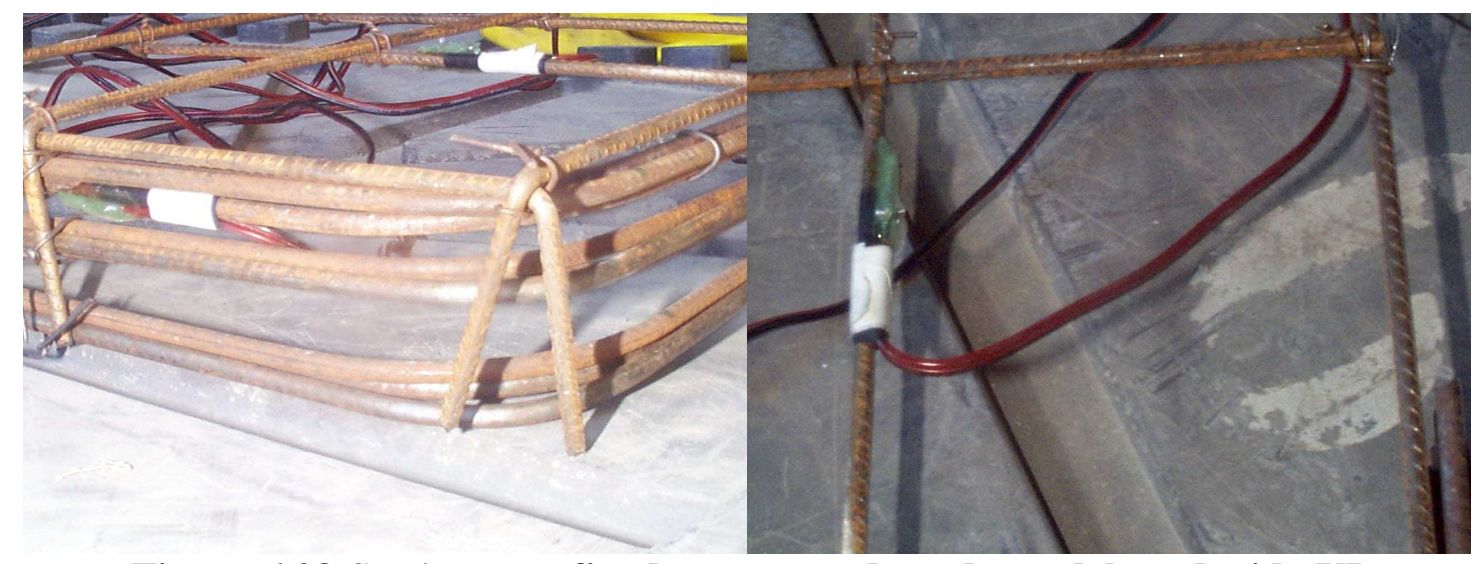

Figura 6.28 Strain gages fixados na armadura do modelo reduzido VI

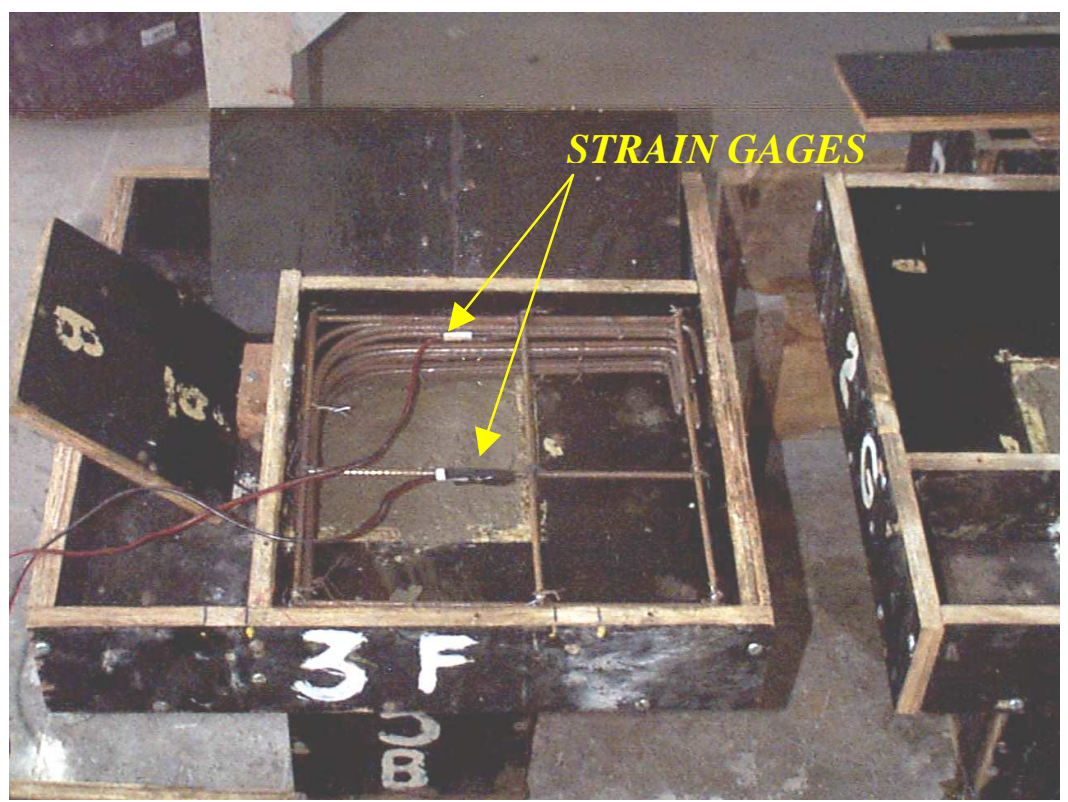

Figura 6.29 Primeira fase da concretagem e inserção de armadura do modelo reduzido VI 


\subsubsection{Modelo reduzido VII}

Esse modelo tem a finalidade de estudar o pilar de canto, com espessura de laje de 7,0 cm correspondente à laje de piso de dimensão real de aproximadamente $30 \mathrm{~cm}$. Nesse caso uma armadura complementar na laje corresponde a 1/3 da armadura do modelo VI. A figuras 6.30 a 6.36 e a tabela 6.10 detalham esse modelo cujas dimensões serão de $27,5 \mathrm{~cm}$ x $27,5 \mathrm{~cm}$ para os lados da laje e o pilar tendo sua seção mantida em $15 \mathrm{~cm} \times 15 \mathrm{~cm}$ e altura total do conjunto de $65 \mathrm{~cm}$. Aqui também foram usados strain gages.

Tabela 6.10 Modelo reduzido VII

\begin{tabular}{|c|c|c|c|c|c|}
\hline Modelo & \multicolumn{2}{|c|}{ Forma $(\mathrm{cm})$} & \multicolumn{2}{c|}{ Armação } & $\mathrm{f}_{\mathrm{ck}}(\mathrm{MPa})$ \\
\hline \multirow{3}{*}{ VII-A a C } & $\mathrm{P}$ & $\begin{array}{c}\mathrm{h}=65 \\
15 \times 15\end{array}$ & $\mathrm{P}$ & 0 & 50 \\
\cline { 2 - 5 } & $\mathrm{L}$ & $\begin{array}{c}27,5 \times 27,5 \\
\mathrm{~h}=7\end{array}$ & $\mathrm{~L}$ & $\begin{array}{c}2 \times 3 \phi 4,2 \mathrm{~mm} \\
3 \phi 5 \mathrm{~mm}\end{array}$ & 35 \\
\hline
\end{tabular}

PILAR DE CANTO

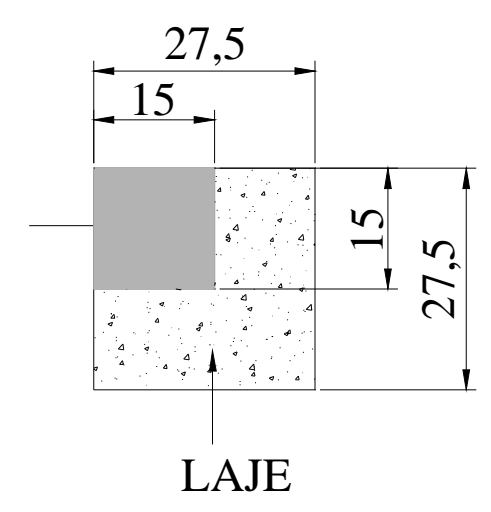

PLANTA

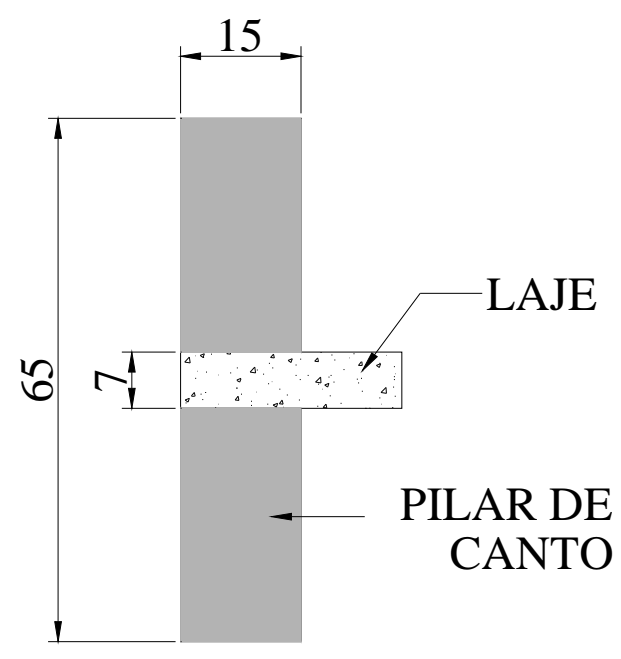

ELEVAÇÃO

Figura 6.30 Esquema para o modelo reduzido VII 
VII-A A VII-C
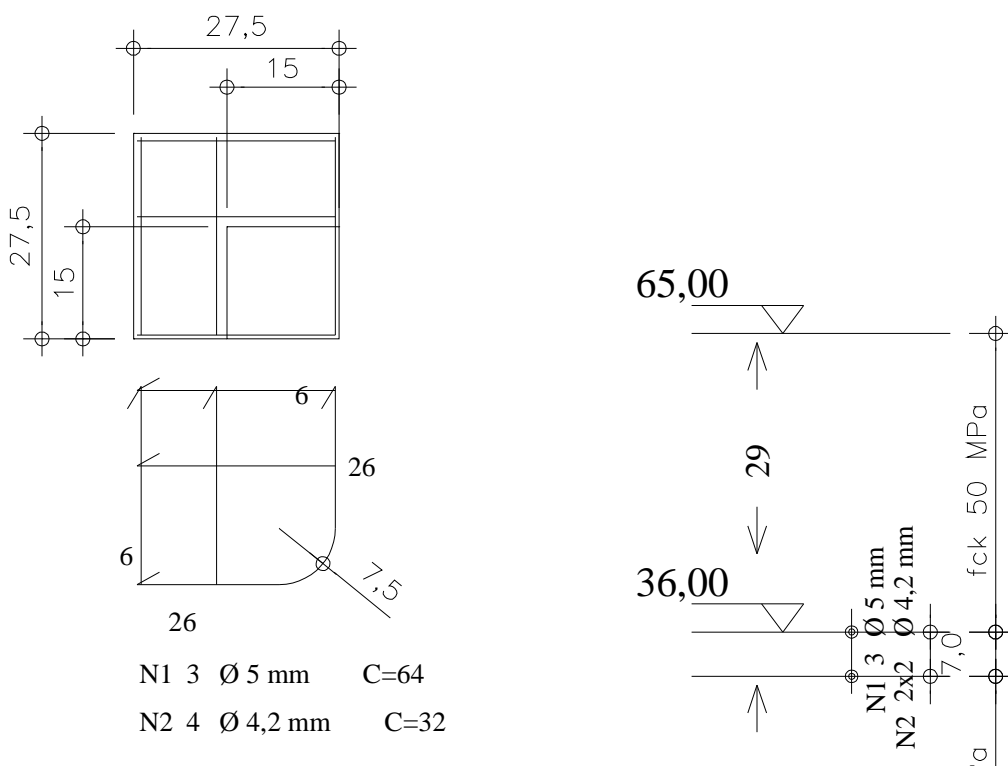

DETALHE DA ARMADURA NA REGIÃO DA LAJE $2 \times 2 \mathrm{~N} 2$
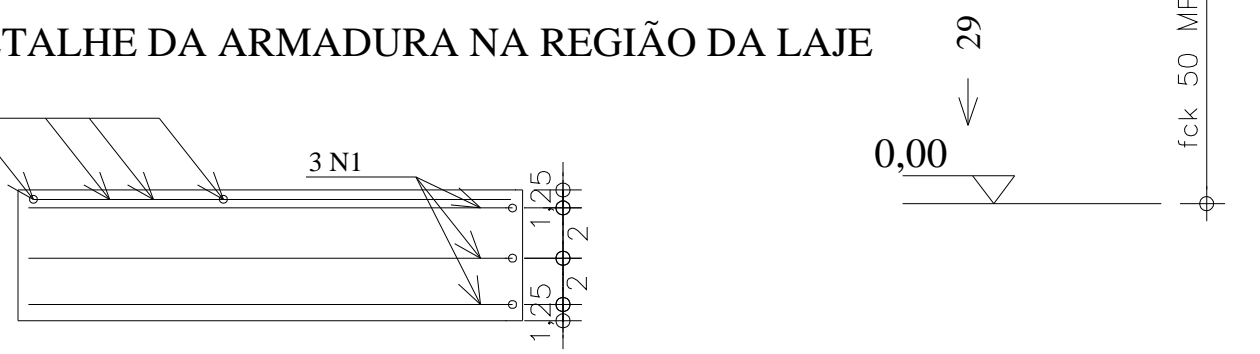

Obs.: Medidas em centímetros, exceto onde indicado

Figura 6.31 Esquema da armadura do modelo reduzido VII

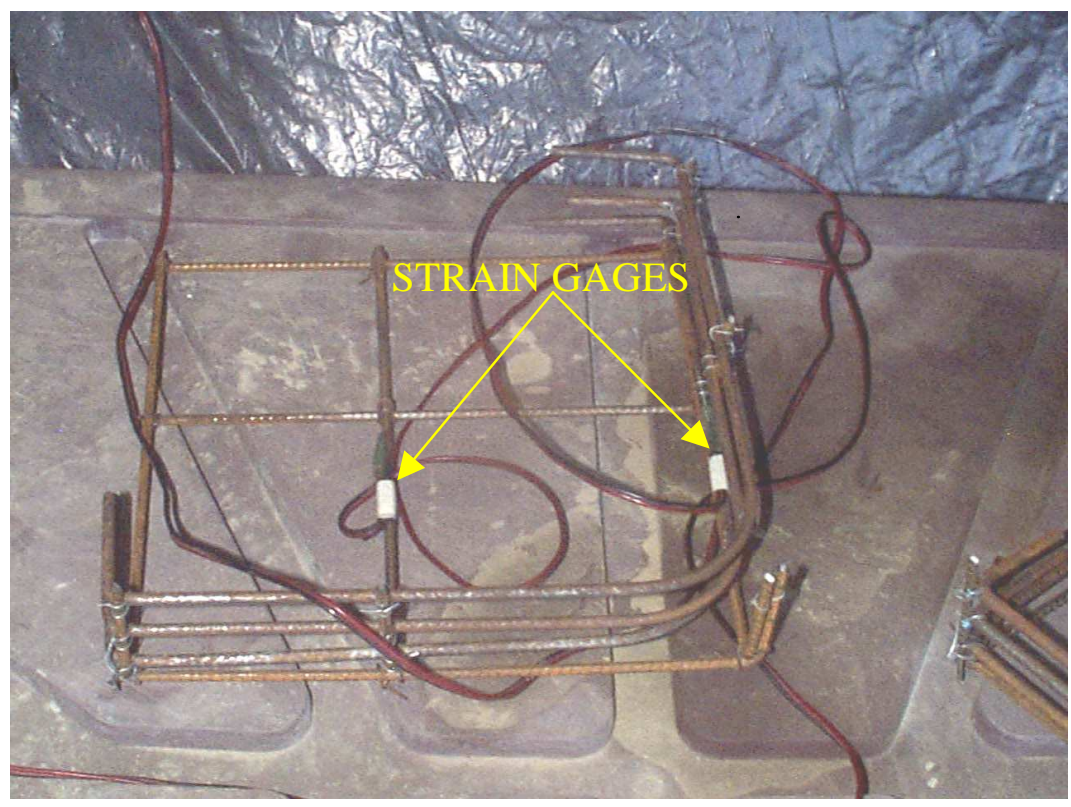

Figura 6.32 Armadura instrumentada do modelo reduzido VII 


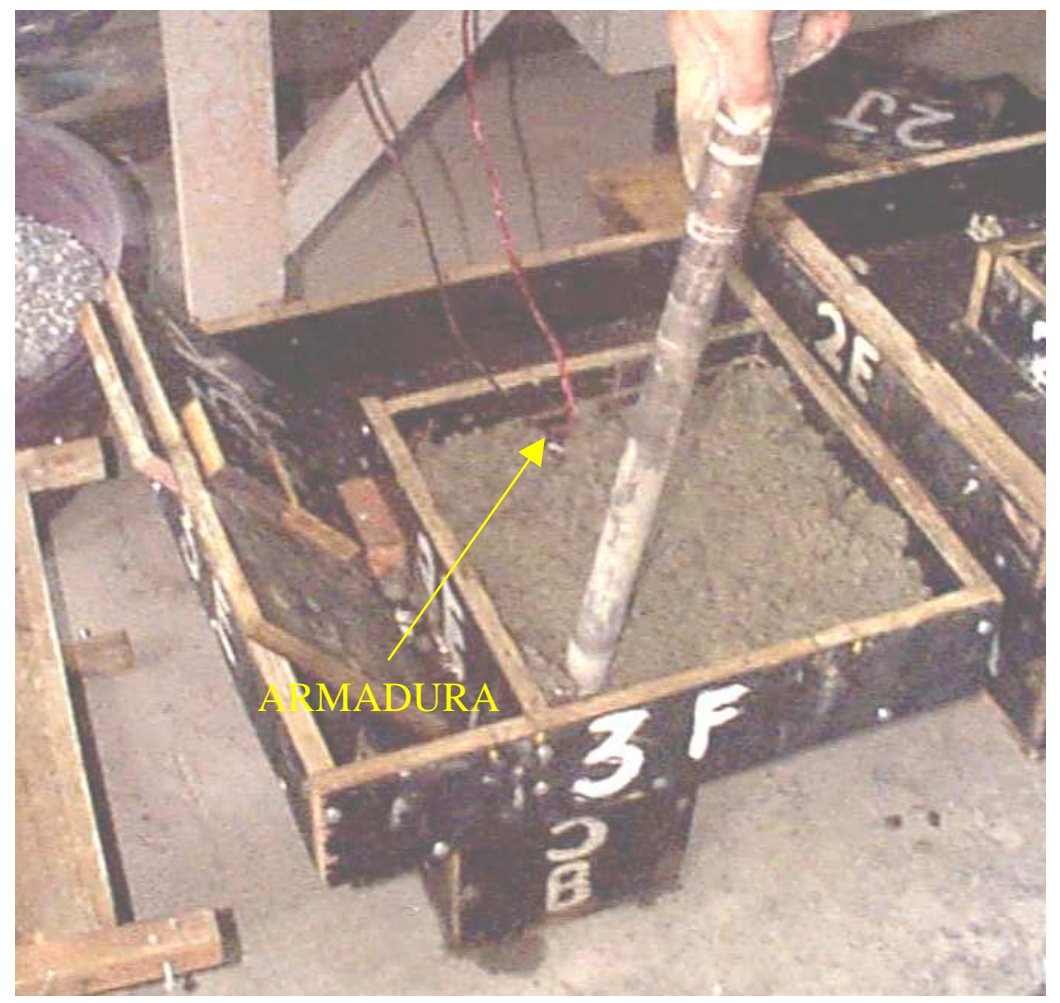

Figura 6.33 Segunda fase da concretagem do modelo reduzido VII

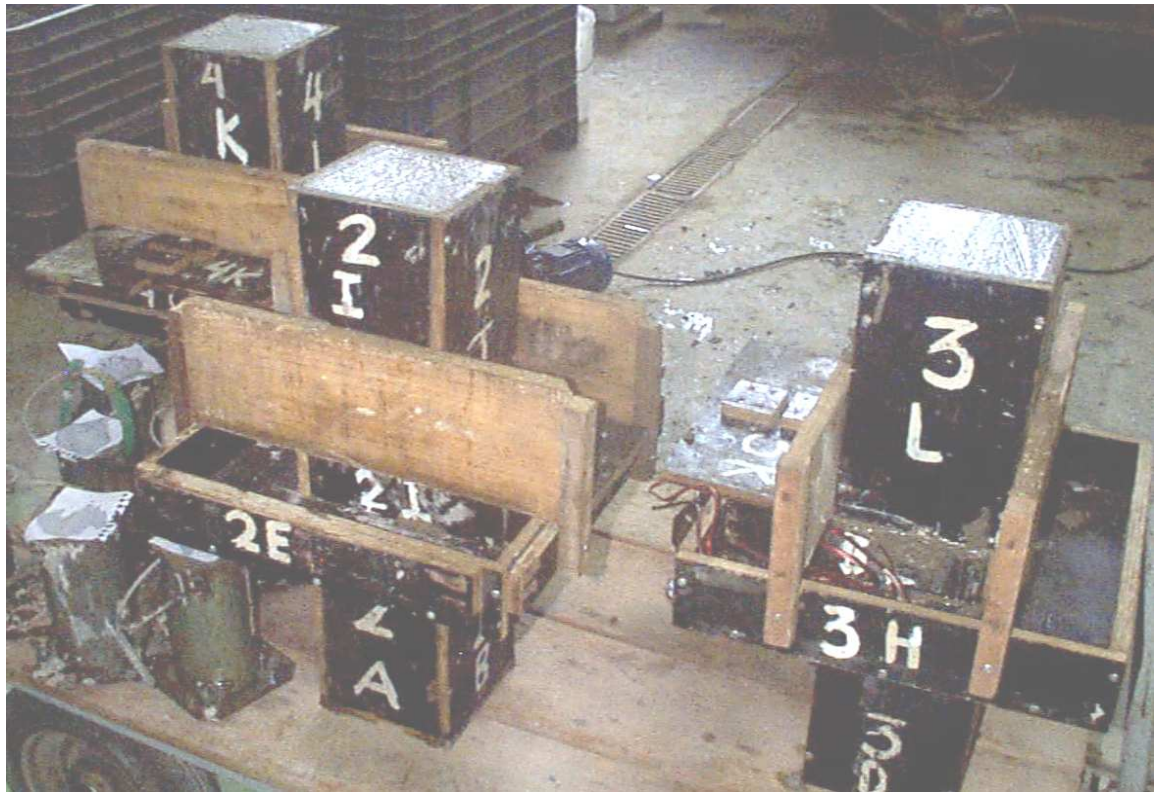

Figura 6.34 Modelo reduzido VII pronto pra ser colocado na câmara úmida 


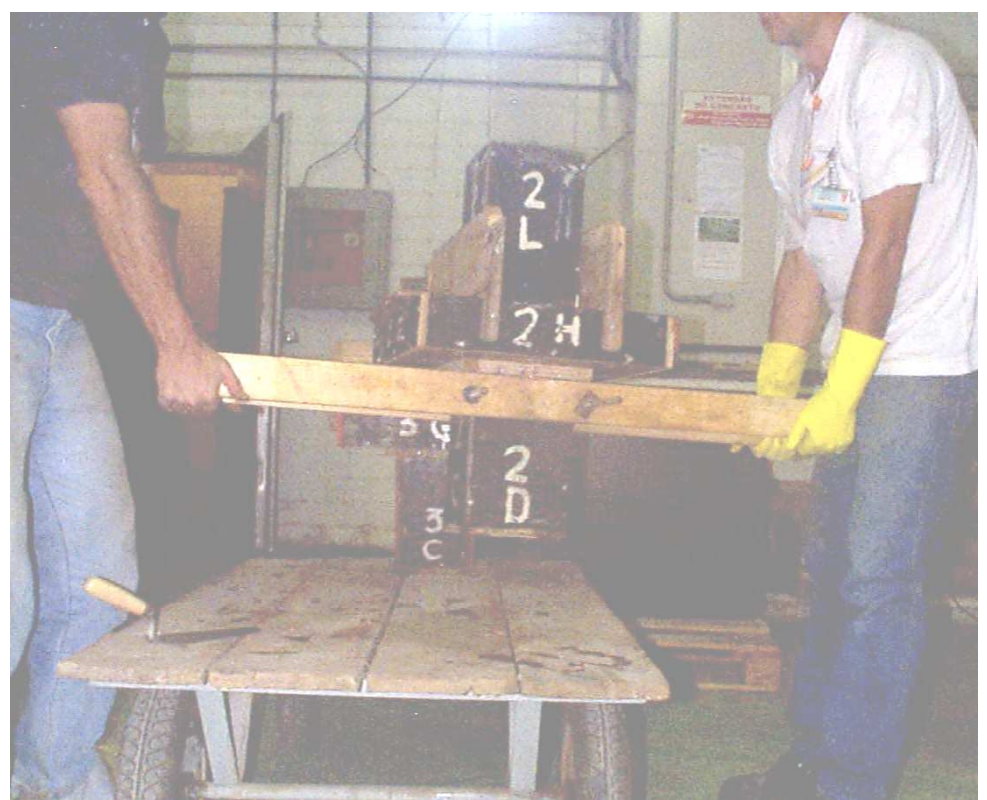

Figura 6.35 Transporte do modelo reduzido VII

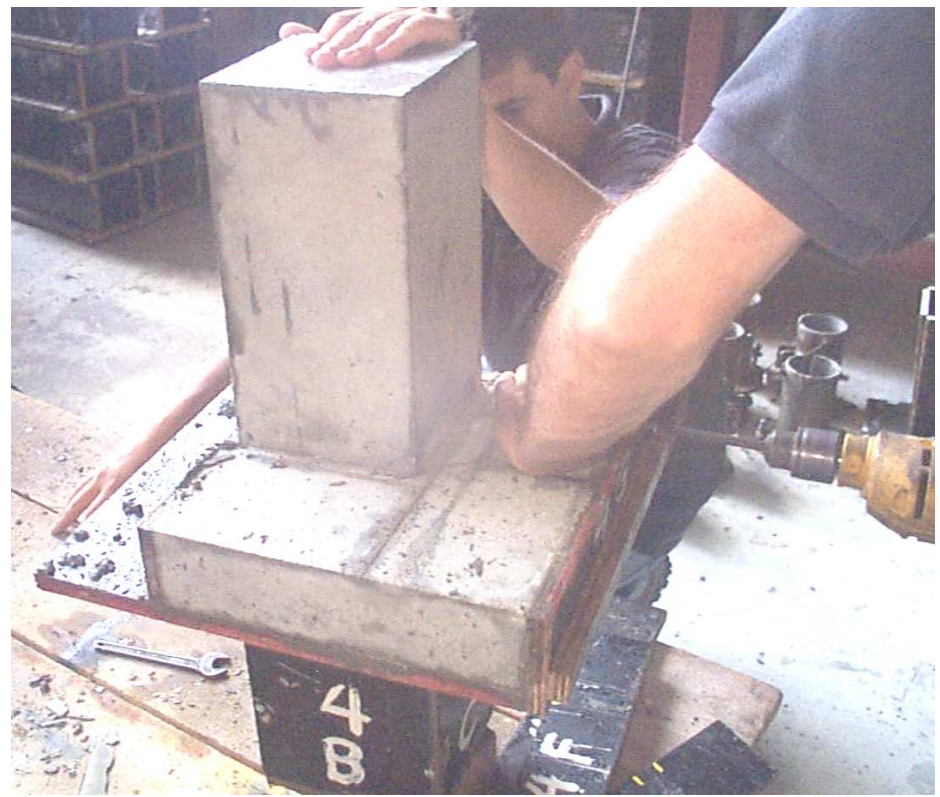

Figura 6.36 Desforma do modelo reduzido VII

A tabela 6.11 mostra um resumo de todos os modelos reduzidos da segunda etapa que foram descritos. 
Tabela6.11 Resumo dos modelos reduzidos da $2^{\mathrm{a}}$ etapa

\begin{tabular}{|c|c|c|c|c|c|}
\hline Modelo & \multicolumn{2}{|r|}{ Forma $(\mathrm{cm})$} & \multicolumn{2}{|r|}{ Armação } & $\mathrm{f}_{\mathrm{ck}}(\mathrm{MPa})$ \\
\hline $\mathrm{I}-\mathrm{A}$ a D & $\mathrm{P}$ & \begin{tabular}{cc|}
$\mathrm{h}=65$ & 15 \\
$\mathrm{x} 15$ & \\
\end{tabular} & $\mathrm{P}$ & 0 & 50 \\
\hline \multirow{2}{*}{ II-A a C } & $\mathrm{P}$ & $\begin{array}{c}\mathrm{h}=65 \\
15 \times 15\end{array}$ & $\mathrm{P}$ & 0 & 50 \\
\hline & $\mathrm{L}$ & $\begin{array}{l}\mathrm{h}=4,5 \\
15 \times 15\end{array}$ & $\mathrm{~L}$ & 0 & 35 \\
\hline \multirow{2}{*}{ IV-A a C } & $\mathrm{P}$ & $\begin{array}{r}\mathrm{h}=65 \\
\mathrm{x} 15\end{array}$ & $\mathrm{P}$ & 0 & 50 \\
\hline & $\mathrm{L}$ & $\begin{array}{cc}\mathrm{h}=4,5 & 40 \\
\mathrm{x} 40 & \\
\end{array}$ & $\mathrm{~L}$ & 0 & 35 \\
\hline \multirow{2}{*}{$\mathrm{V}-\mathrm{A}$ a $\mathrm{F}$} & $\mathrm{P}$ & $\begin{array}{c}\mathrm{h}=65 \\
15 \times 15\end{array}$ & $\mathrm{P}$ & 0 & 50 \\
\hline & $\mathrm{L}$ & $\begin{array}{c}h=7 \\
27,5 \times 27,5\end{array}$ & $\mathrm{~L}$ & 0 & 35 \\
\hline \multirow{2}{*}{ VI-A a C } & $\mathrm{P}$ & $\begin{array}{c}h=65 \\
15 \times 15\end{array}$ & $\mathrm{P}$ & 0 & 50 \\
\hline & $\mathrm{L}$ & $\begin{array}{c}\mathrm{h}=7 \\
27,5 \times 27,5\end{array}$ & $\mathrm{~L}$ & $\begin{array}{c}2 \times 3 \phi 4,2 \mathrm{~mm} \\
3 \times 3 \phi 5 \mathrm{~mm}\end{array}$ & 35 \\
\hline \multirow{2}{*}{ VII-A a C } & $\mathrm{P}$ & $\begin{array}{c}h=65 \\
15 \times 15\end{array}$ & $\mathrm{P}$ & 0 & 50 \\
\hline & $\mathrm{L}$ & $\begin{array}{c}\mathrm{h}=7 \\
27,5 \times 27,5\end{array}$ & $\mathrm{~L}$ & $\begin{array}{c}2 \times 3 \phi 4,2 \mathrm{~mm} \\
3 \phi 5 \mathrm{~mm}\end{array}$ & 35 \\
\hline
\end{tabular}




\section{PROPRIEDADES DOS MATERIAIS UTILIZADOS}

$\mathrm{O}$ anexo B contém fotos adicionais dos ensaios descritos a seguir.

\subsection{Resistência à compressão do concreto}

Foram usados corpos-de-prova cilíndricos de $10 \mathrm{~cm}$ x $20 \mathrm{~cm}$ como mostram as figuras 7.1 e 7.2, cuja função é determinar as diferentes resistências à compressão dos concretos empregados nos modelos reduzidos.

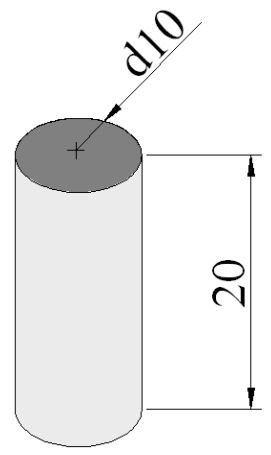

Figura 7.1 Esquema de corpo-de-prova cilíndrico $10 \mathrm{~cm}$ x $20 \mathrm{~cm}$

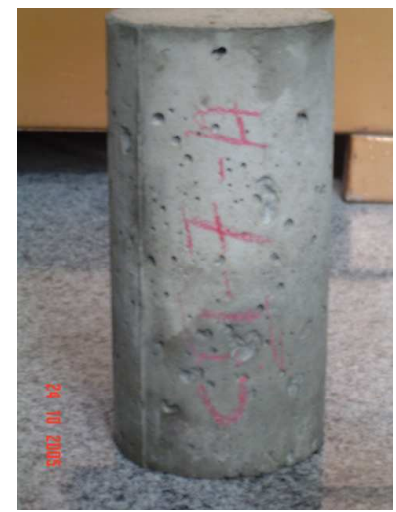

Figura 7.2 Corpo-de-prova cilíndrico $10 \mathrm{~cm}$ x $20 \mathrm{~cm}$ 
Esses corpos-de-prova foram rompidos aos 7 dias e aos 28 dias e as resistências denominadas respectivamente de $\mathrm{f}_{\mathrm{c} 7}$ e $\mathrm{f}_{\mathrm{c} 28}$. Foi feita uma correção devido à geometria dos corpos-de-prova ensaiados. Segundo Avran, 1981, deve-se considerar $97 \%$ do valor da resistência obtida no ensaio de compressão para corpos-de-prova com dimensões $10 \mathrm{~cm}$ x $20 \mathrm{~cm}$ quando comparada com a resistência obtida ao se ensaiarem os de $15 \mathrm{~cm}$ x $30 \mathrm{~cm}$. Esta correção foi feita para todos os concretos ensaiados e os valores de $\mathrm{f}_{\mathrm{cm}}$ apresentados nos resultados já estão corrigidos em $97 \%$.

Segundo a norma NBR 5738: 2003 foram moldados 6 corpos-de-prova cilíndricos para cada betonada, 3 para serem rompidos aos 7 dias e 3 aos 28 dias. Para a determinação da consistência do concreto, seguiu-se o descrito na NBR-NM 67: 1998.

Foi verificado se o valor da resistência obtida aos 7 dias esteve de acordo com o valor da resistência esperada para essa idade. Assim sendo, quando o concreto atingisse a idade de 28 dias, provavelmente a resistência do mesmo estaria próxima da especificada. Caso aos 7 dias a resistência não alcançasse o valor estimado, não seria necessário aguardar 28 dias para moldar outros corpos-de-prova e outros modelos.

Utilizou-se para essa pesquisa o estudo de dosagem de concreto realizado por Silveira dos Santos, que se baseou no método de dosagem IPT. Segundo Tango, 2001, este método é bastante simples e suas principais características são: ênfase na experimentação expedita, com os materiais disponíveis na obra; possibilidade de adaptação a outros métodos de dosagem podendo-se optar ou não por adotar distribuições granulométricas impostas para os agregados; emprego do Diagrama IPT de Dosagem ou de suas equações.

Foi utilizado o Cimento Portland CP V-ARI RS proveniente da empresa Cimento Votoran cuja propriedade marcante, como o próprio nome já diz, é a alta resistência inicial. É resistente a sulfatos, sendo um cimento de coloração clara, uniforme e com menores quantidades de adições pozolânicas ou inertes, o mesmo usado por Silveira dos Santos, 2004.

O agregado miúdo empregado foi uma areia natural média, dimensão característica $2,4 \mathrm{~mm}$. O agregado graúdo, a brita 0 , cuja dimensão varia de 2,36 $\mathrm{mm}$ a 12,5 mm, adotando-se para este trabalho, o diâmetro médio de 4,8 $\mathrm{mm}$. 
As tabelas a seguir apresentam para cada corpo-de-prova, as especificações correspondentes aos concretos que foram utilizados e, conseqüentemente, caracterizam cada concreto empregado.

Tabela 7.1 Propriedades do concreto para cada $\mathbf{f}_{\mathbf{c} 28}$

\begin{tabular}{|c|c|c|}
\hline & PILAR & LAJE \\
\cline { 2 - 3 } & $\begin{array}{c}\mathbf{f}_{\mathbf{c k}}=\mathbf{5 0} \\
\mathbf{M P a}\end{array}$ & $\begin{array}{c}\mathbf{f}_{\mathbf{c k}}=\mathbf{3 5} \\
\mathbf{M P a}\end{array}$ \\
\hline $\mathbf{a} / \mathbf{c} \mathbf{( k g / k g )}$ & 0,50 & 0,70 \\
\hline $\mathbf{m} \mathbf{( k g / k g )}$ & 3,03 & 5,65 \\
\hline $\mathbf{C ~ ( k g / \mathbf { m } ^ { 3 } )}$ & 503,00 & 358,00 \\
\hline $\mathbf{f}_{\mathbf{c 7}} \mathbf{( \mathbf { M P a } )}$ & 36,20 & 24,10 \\
\hline $\mathbf{f}_{\mathbf{c 2 8}}(\mathbf{M P a})$ & 50,00 & 35,00 \\
\hline $\mathbf{h}(\mathbf{c m})$ & $4 \pm 1$ & $6 \pm 1$ \\
\hline
\end{tabular}

Sendo:

$\mathrm{f}_{\mathrm{ck}}$ : resistência característica do concreto à compressão;

$\mathrm{f}_{\mathrm{c} 7}$ e $\mathrm{f}_{\mathrm{c} 28}$ : resistências do concreto à compressão aos 7 e aos 28 dias de idade, respectivamente;

a/c: relação água/cimento em massa $(\mathrm{kg} / \mathrm{kg}) ;$

C: consumo de cimento por metro cúbico de concreto adensado $\left(\mathrm{kg} / \mathrm{m}^{3}\right)$;

m: relação de agregados seco/cimento em massa $(\mathrm{kg} / \mathrm{kg})$;

h: abatimento, em cm, do tronco de cone de Abrams. 
Tabela 7.2 Traço por metro cúbico para moldagens dos modelos reduzidos

\begin{tabular}{|c|c|c|}
\hline \multirow{2}{*}{ Para 1 $\mathbf{~ m}^{\mathbf{3}}$} & PILAR & LAJE \\
\cline { 2 - 3 } & $\begin{array}{c}\mathbf{f}_{\mathbf{c k}}=\mathbf{5 0} \\
\mathbf{M P a}\end{array}$ & $\begin{array}{c}\mathbf{f}_{\text {ck }}=\mathbf{3 5} \\
\mathbf{M P a}\end{array}$ \\
\hline $\begin{array}{c}\text { Cimento } \\
\left(\mathbf{k g} / \mathbf{m}^{\mathbf{3}}\right)\end{array}$ & 503,00 & 358,00 \\
\hline $\begin{array}{c}\text { Areia } \\
\left(\mathbf{k g} / \mathbf{m}^{\mathbf{3}}\right)\end{array}$ & 613,66 & 948,70 \\
\hline $\begin{array}{c}\text { Pedra } \\
\left(\mathbf{k g} / \mathbf{m}^{\mathbf{3}}\right)\end{array}$ & 910,43 & 1074,00 \\
\hline $\begin{array}{c}\text { Água } \\
\left(\mathbf{k g} / \mathbf{m}^{\mathbf{3}}\right)\end{array}$ & 251,50 & 250,60 \\
\hline
\end{tabular}

Sendo:

$\mathrm{f}_{\mathrm{ck}}$ : resistência característica do concreto à compressão.

\subsection{Resultados dos ensaios de resistência à compressão do concreto}

A tabela 7.3 mostra os resultados gerais dos ensaios de resistência à compressão axial de todos os concretos utilizados nesta pesquisa. Os corpos-de-prova para esse fim tinham dimensões de $10 \mathrm{~cm}$ x $20 \mathrm{~cm}$, a correção de resistência, conforme explicada acima, está apresentada em cada um dos resultados dos concretos. Mais adiante, ao se mostrar os resultados dos modelos reduzidos, as resistências que aparecem em cada tabela já é a corrigida. 
Tabela 7.3 Resistências e abatimentos dos concretos

\begin{tabular}{|c|c|c|c|c|c|c|c|c|c|}
\hline \multicolumn{10}{|c|}{ RESISTÊNCIAS E ABATIMENTOS DOS CONCRETOS (CORPOS-DE-PROVA DE $10 \mathrm{~cm}$ x $20 \mathrm{~cm})$} \\
\hline & \multirow[t]{2}{*}{ BETONADA } & \multicolumn{2}{|c|}{$\begin{array}{c}\mathrm{F}_{\text {RUPTURA }}(\mathrm{tf}) \\
\text { IDADE (DIAS) }\end{array}$} & \multirow{2}{*}{$\begin{array}{l}\text { RESISTÊNCIA À } \\
\text { COMPRESSÃO } \mathrm{f}_{\mathrm{c}, 7} \\
\text { (MPa) }\end{array}$} & \multirow{2}{*}{$\begin{array}{l}\text { RESISTÊNCIA } \\
\text { MÉDIA Ȧ } \\
\text { COMPRESSÃO } \\
\text { f }_{\mathrm{cm}, 7} \text { (MPa) }\end{array}$} & \multirow{2}{*}{$\begin{array}{l}\text { ABATIMENTO } \\
(\mathrm{cm})\end{array}$} & \multirow{2}{*}{$\begin{array}{c}\text { RESISTÊNCIA À } \\
\text { COMPRESSÃA } \mathrm{f}_{c 28} \\
\text { (MPa) }\end{array}$} & \multirow{2}{*}{$\begin{array}{c}\text { REEISTÊNCIA } \\
\text { MÉDIA Ȧ } \\
\text { COMPRESSÃO } \\
\text { f }_{\text {con28 }} \text { MPa) }\end{array}$} & \multirow{2}{*}{$\begin{array}{l}\text { RESISTÊNCIA À } \\
\text { COMPRESSÃO } \\
\text { CORRIGIDA } f_{\mathrm{cm}, 2} \\
\text { (MPa) }\end{array}$} \\
\hline & & 7 & 28 & & & & & & \\
\hline CP-A & \multirow{3}{*}{1} & 35,65 & 42,00 & 45,39 & \multirow{3}{*}{45,84} & \multirow{3}{*}{6,5} & 53,47 & \multirow{3}{*}{53,30} & \multirow{3}{*}{51,70} \\
\hline CP-B & & 35,30 & 40,00 & 44,95 & & & 51,18 & & \\
\hline CP-C & & 47,17 & 43,40 & 47,17 & & & 55,25 & & \\
\hline CP-A & \multirow{3}{*}{2} & 27,35 & 36,00 & 34,82 & \multirow{3}{*}{32,85} & \multirow{3}{*}{2} & 45,83 & \multirow{3}{*}{44,68} & \multirow{3}{*}{43,34} \\
\hline CP-B & & 22,75 & 35,45 & 28,97 & & & 45,13 & & \\
\hline CP-C & & 27,30 & 33,85 & 34,76 & & & 43,09 & & \\
\hline CP-A & \multirow{3}{*}{3} & 39,35 & 37,30 & 50,10 & & & 47,49 & & \\
\hline CP-B & & 39,75 & 50,25 & 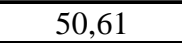 & 50,74 & 6 & 63,98 & 57,66 & 55,93 \\
\hline CP-C & & 40,45 & 48,30 & 51,50 & & & 61,50 & & \\
\hline CP-A & & 38,65 & 44,69 & 49,21 & & & 56,90 & & \\
\hline CP-B & 4 & 39,10 & 45,40 & 49,78 & 49,57 & 7 & 57,80 & 56,85 & 55,14 \\
\hline CP-C & & 39,05 & 43,87 & 49,72 & & & 55,85 & & \\
\hline CP-A & & 20,40 & 23,96 & 25,97 & & & 30,50 & & \\
\hline CP-B & 5 & 20,50 & 25,21 & 26,10 & 25,04 & 2 & 32,10 & 31,31 & 30,37 \\
\hline CP-C & & 18,10 & 24,61 & 23,05 & & & 31,33 & & \\
\hline CP-A & & 22,90 & 27,90 & 29,16 & & & 35,52 & & \\
\hline CP-B & 6 & 23,85 & 29,14 & 30,37 & 29,99 & 3 & 37,10 & 36,42 & 35,32 \\
\hline \begin{tabular}{ll|}
$\mathrm{CP}-\mathrm{C}$ \\
\end{tabular} & & 23,90 & 28,77 & 30,43 & & & 36,63 & & \\
\hline CP-A & & 38,65 & 42,37 & 49,21 & & & 53,95 & & \\
\hline CP-B & 7 & 37,30 & 42,81 & 47,49 & 48,91 & 6 & 54,50 & 54,02 & 52,40 \\
\hline CP-C & & 39,30 & 42,10 & 50,04 & & & 53,60 & & \\
\hline CP-A & & 34,45 & 45,15 & 43,86 & & & 57,49 & & \\
\hline CP-B & 8 & 28,65 & 45,45 & 36,48 & 42,04 & 7 & 57,87 & 58,42 & 56,67 \\
\hline CP-C & & 35,95 & 47,05 & 45,77 & & & 59,91 & & \\
\hline CP-A & & 24,35 & 32,20 & 31,00 & & & 41,00 & & \\
\hline CP-B & 9 & 22,80 & 29,05 & 29,03 & 30,28 & 2 & 36,99 & 39,79 & 38,60 \\
\hline CP-C & & 24,20 & 32,50 & 30,81 & & & 41,38 & & \\
\hline CP-A & & 29,50 & 43,55 & 37,56 & & & 55,45 & & \\
\hline CP-B & 10 & 29,40 & 41,00 & 37,43 & 38,64 & 6 & 52,20 & 53,13 & 51,54 \\
\hline \begin{tabular}{ll|}
$\mathrm{CP}-\mathrm{C}$ \\
\end{tabular} & & 32,15 & 40,65 & 40,93 & & & 51,75 & & \\
\hline CP-A & & 38,80 & 42,05 & 49,40 & & & 53,54 & & \\
\hline CP-B & 11 & 36,75 & 43,80 & 46,79 & 48,17 & 6,5 & 55,77 & 55,34 & 53,68 \\
\hline CP-C & & 37,95 & 44,55 & 48,32 & & & 56,72 & & \\
\hline CP-A & & 24,40 & 30,00 & 31,07 & & & 38,20 & & \\
\hline CP-B & 12 & 24,70 & 30,35 & 31,44 & 31,38 & 3 & 38,64 & 38,13 & 36,99 \\
\hline CP-C & & 24,85 & 29,50 & 31,64 & & & 37,56 & & \\
\hline CP-A & & 33,20 & 41,50 & 42,27 & & & 52,84 & & \\
\hline CP-B & 13 & 32,80 & 39,75 & 41,76 & 43,12 & 6 & 50,61 & 52,71 & 51,13 \\
\hline$\overline{\mathrm{CP}-\mathrm{C}}$ & & 35,60 & 42,95 & 45,33 & & & 54,69 & & \\
\hline CP-A & & 36,90 & 49,50 & 46,99 & & & 63,02 & & \\
\hline CP-B & 14 & 38,15 & 48,10 & 48,58 & 48,69 & 6,5 & 61,24 & 62,45 & 60,58 \\
\hline CP-C & & 39,65 & 49,55 & 50,49 & & & 63,09 & & \\
\hline CP-A & & 20,25 & 26,35 & 25,78 & & & 33,55 & & \\
\hline CP-B & 15 & 20,45 & 26,20 & 26,04 & 25,85 & 6 & 33,36 & 33,68 & 32,67 \\
\hline CP-C & & 20,20 & 26,80 & 25,72 & & & 34,12 & & \\
\hline
\end{tabular}




\subsection{Resistência do concreto à tração por compressão diametral}

Para esse ensaio utilizaram-se corpos-de-prova cilíndricos com dimensões de $15 \mathrm{~cm}$ x $30 \mathrm{~cm}$, como mostra a figura 7.3. Apenas o concreto utilizado nas regiões de laje foi submetido a esse ensaio, pois, para a pesquisa atual, é nessa região que a resistência à tração do concreto tem maior importância. Como já esclarecido anteriormente, é essa resistência que proporciona o efeito do confinamento.

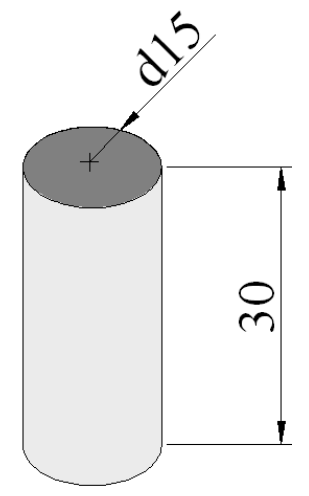

Figura 7.3 Corpo-de-prova cilíndrico $15 \mathrm{~cm} \times 30 \mathrm{~cm}$

A NBR 7222: 1982 apresenta as diretrizes que foram seguidas para a realização desse ensaio. A foto da figura 7.4 mostra o corpo-de-prova já preparado para o ensaio.

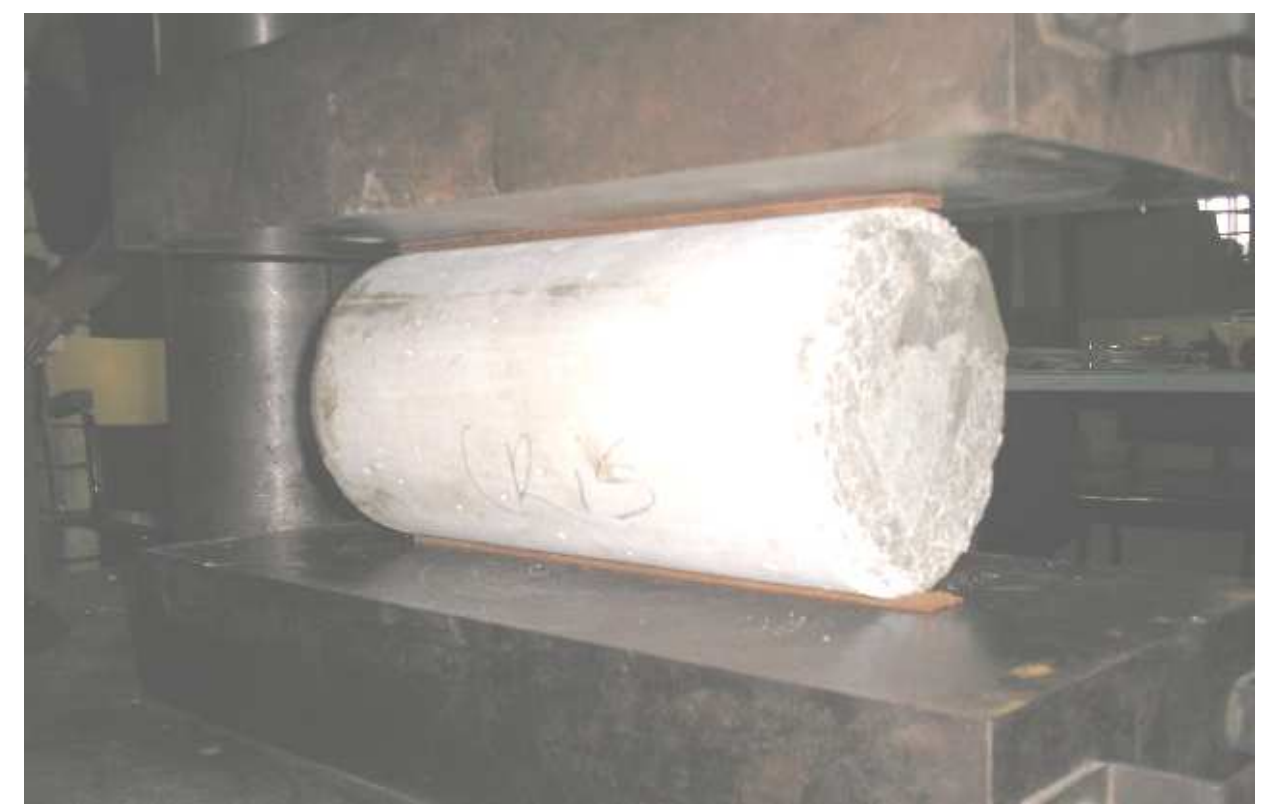

Figura 7.4 Corpo-de-prova cilíndrico $15 \mathrm{~cm}$ x $30 \mathrm{~cm}$ preparado para ser ensaiado quanto a resistência à tração por compressão diametral 


\subsection{Resultados do ensaio de determinação da resistência à tração por compressão} diametral do concreto utilizado nas regiões de laje $\left(\mathbf{f}_{\mathrm{ck}}=35 \mathrm{MPa}\right)$

Foram ensaiados três corpos-de-prova cilíndricos com dimensões de $15 \mathrm{~cm}$ x $30 \mathrm{~cm}$ e os resultados estão apresentados na tabela 7.3 e na figura 7.5. A resistência do concreto à tração aos 28 dias de idade foi calculada pela equação 7.1:

$$
f t, d=\frac{2 \times F}{\pi \times d \times h}
$$

Equação 7.1

Sendo:

F: força de ruptura do corpo-de-prova, medida no ensaio;

d: diâmetro efetivo do mesmo;

h: altura efetiva do corpo-de-prova.

Tabela 7.4 Resultados do ensaio de determinação da resistência à tração do concreto com resistência à compressão de $35 \mathrm{MPa}$ (utilizado nas regiões de laje)

\begin{tabular}{|c|c|c|c|c|c|c|}
\hline \multicolumn{7}{|c|}{ RESISTÊNCIA A TRAÇÃO DO CONCRETO } \\
\hline \multicolumn{7}{|c|}{$\mathrm{f}_{\mathrm{cm} 28}=35,32$} \\
\hline & $\begin{array}{l}\text { DIÂMETRO } \\
(\mathrm{cm})\end{array}$ & $\begin{array}{l}\text { DIÂMETRO } \\
\text { MÉDIO (cm) }\end{array}$ & $\begin{array}{l}\text { ALTURA } \\
\quad(\mathrm{cm})\end{array}$ & $\begin{array}{l}\text { ALTURA } \\
\text { MÉDIA } \\
(\mathrm{cm})\end{array}$ & $\mathrm{F}_{\text {RUPTURA }}(\mathrm{kN})$ & $\begin{array}{c}\text { RESISTÊNCIA } \\
\text { À TRAÇÃO } \\
(\mathrm{MPa})\end{array}$ \\
\hline \multirow{3}{*}{$\mathrm{CP}-\mathrm{A}$} & 15,000 & \multirow{3}{*}{15,01} & 29,999 & \multirow{3}{*}{30,01} & \multirow{3}{*}{236,40} & \multirow{3}{*}{3,34} \\
\hline & 15,010 & & 30,010 & & & \\
\hline & 15,025 & & 30,011 & & & \\
\hline \multirow{3}{*}{ CP-B } & 15,017 & \multirow{3}{*}{15,01} & 30,120 & \multirow{3}{*}{30,08} & \multirow{3}{*}{256,60} & \multirow{3}{*}{3,62} \\
\hline & 15,001 & & 30,080 & & & \\
\hline & 15,002 & & 30,050 & & & \\
\hline \multirow{3}{*}{$\mathrm{CP}-\mathrm{C}$} & 15,045 & \multirow{3}{*}{15,12} & 30,200 & \multirow{3}{*}{30,17} & \multirow{3}{*}{243,60} & \multirow{3}{*}{3,40} \\
\hline & 15,098 & & 30,150 & & & \\
\hline & 15,205 & & 30,150 & & & \\
\hline \multicolumn{6}{|c|}{$\mathrm{f}_{\mathrm{cm} 28} / \mathrm{f}_{\mathrm{tm} 28}=10,24$} & $\mathrm{f}_{\mathrm{tm} 28}=3,45$ \\
\hline
\end{tabular}




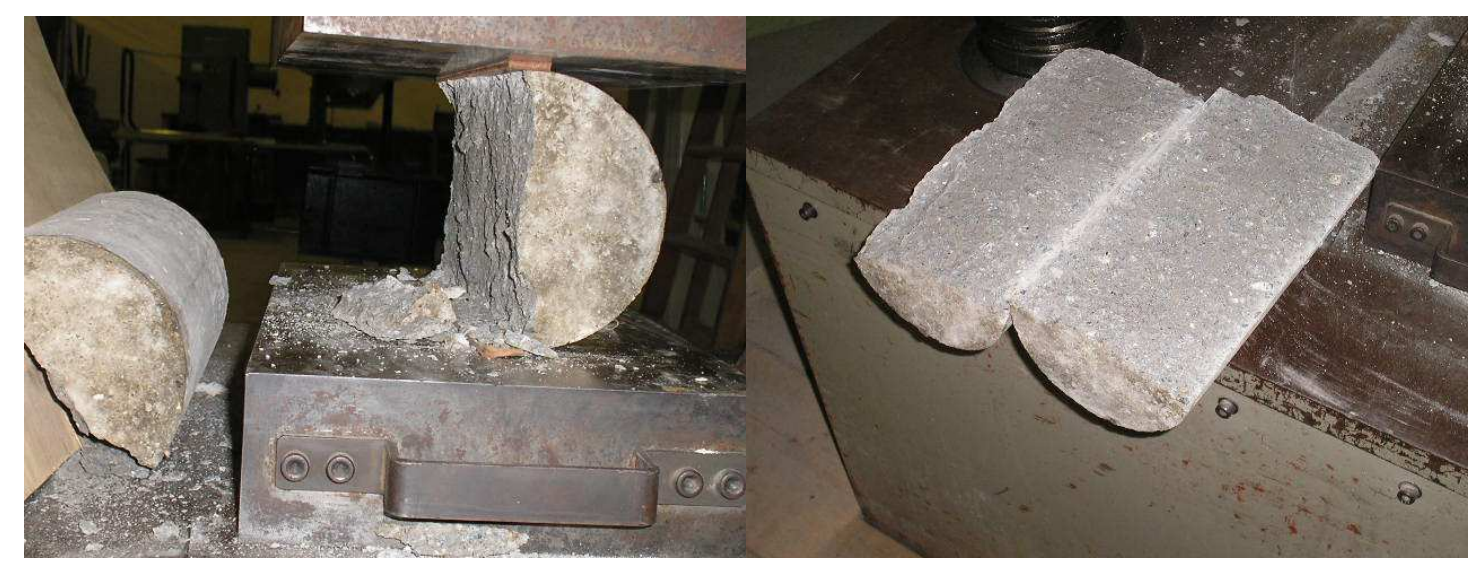

Figura 7.5 Ensaio de determinação da resistência à tração por compressão diametral de corpos-de-prova cilíndricos de dimensões $15 \mathrm{~cm}$ x $30 \mathrm{~cm}$ e $f_{\mathrm{ck}}$ de $35 \mathrm{MPa}$

\subsection{Módulo de Elasticidade e coeficiente de Poisson}

Para se obter módulo de elasticidade ou módulo de deformação tangente inicial, $\mathrm{E}_{\mathrm{ci}}$ e o coeficiente de Poisson, $v$, foram utilizados corpos-de-prova de dimensões $15 \mathrm{~cm}$ x $30 \mathrm{~cm}$, como mostra a figura 7.4 .

Para a realização desses ensaios as diretrizes da NBR 8522: 2003 foram seguidas. Tanto o concreto de resistência característica à compressão de $50 \mathrm{MPa}$ como o de $35 \mathrm{MPa}$ foram ensaiados.

\subsection{Resultados dos ensaios experimentais para obtenção do módulo de elasticidade e coeficiente de Poisson}

Foram realizados ensaios em 3 corpos-de-prova para cada um dos concretos, $35 \mathrm{MPa}$ e $50 \mathrm{MPa}$. As deformações foram medidas por relógios analógicos com precisão de milésimo de milímetro, uma casa a mais do que a exigida pela NBR 8522: 2003. As fotos da figura 7.6 mostram o aparelho de medição e a seqüência do ensaio. Nota-se que ao mesmo tempo foram feitas leituras de deformação horizontal para posterior obtenção do coeficiente de Poisson. As medidas de cada um dos corpos-de-prova estão apresentadas no anexo $\mathrm{C}$. 


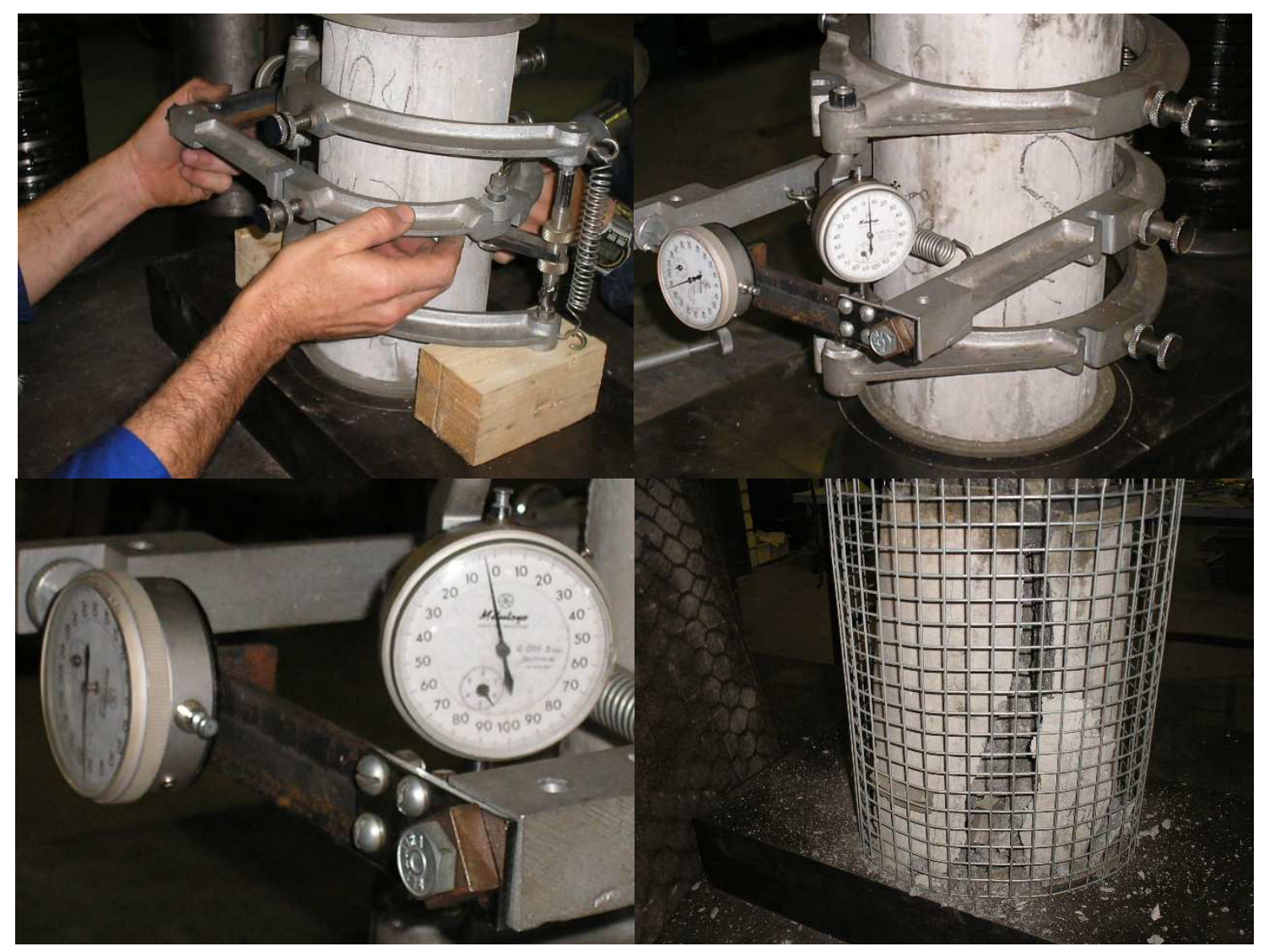

Figura 7.6 Ensaio para obtenção do módulo de elasticidade e coeficiente de Poisson

Os gráficos 7.1 e 7.2 mostram o carregamento para realização deste ensaio para cada um dos tipos de concreto utilizados. O valor da resistência à compressão dos concretos ensaiados foi obtido através do ensaio de compressão axial de corpos-de-prova cilíndricos de dimensões $10 \mathrm{~cm}$ x $20 \mathrm{~cm}$ realizado para cada uma das betonadas que originaram os corpos-de-prova de $15 \mathrm{~cm}$ x $30 \mathrm{~cm}$. A partir desse valor, se obtém a intensidade da força observada nos gráficos 7.1 e 7.2 que segundo a NBR 8522: 2003 deve ser de 30\% do valor de $\mathrm{f}_{\mathrm{cm}, 28}$. Após o terceiro carregamento o aparelho de aferição de deformações é retirado, sem descarregar o corpo-de-prova e então o mesmo é levado à ruptura. Deve-se ainda tomar o cuidado de observar se o valor da resistência efetiva para cada um dos corpos-de-prova ensaiados não seja diferente em mais de $20 \%$ de $\mathrm{f}_{\mathrm{c}}$, caso isso ocorra deve-se descartar este resultado. No caso desta pesquisa os valores efetivos não atingiram esta diferença. 


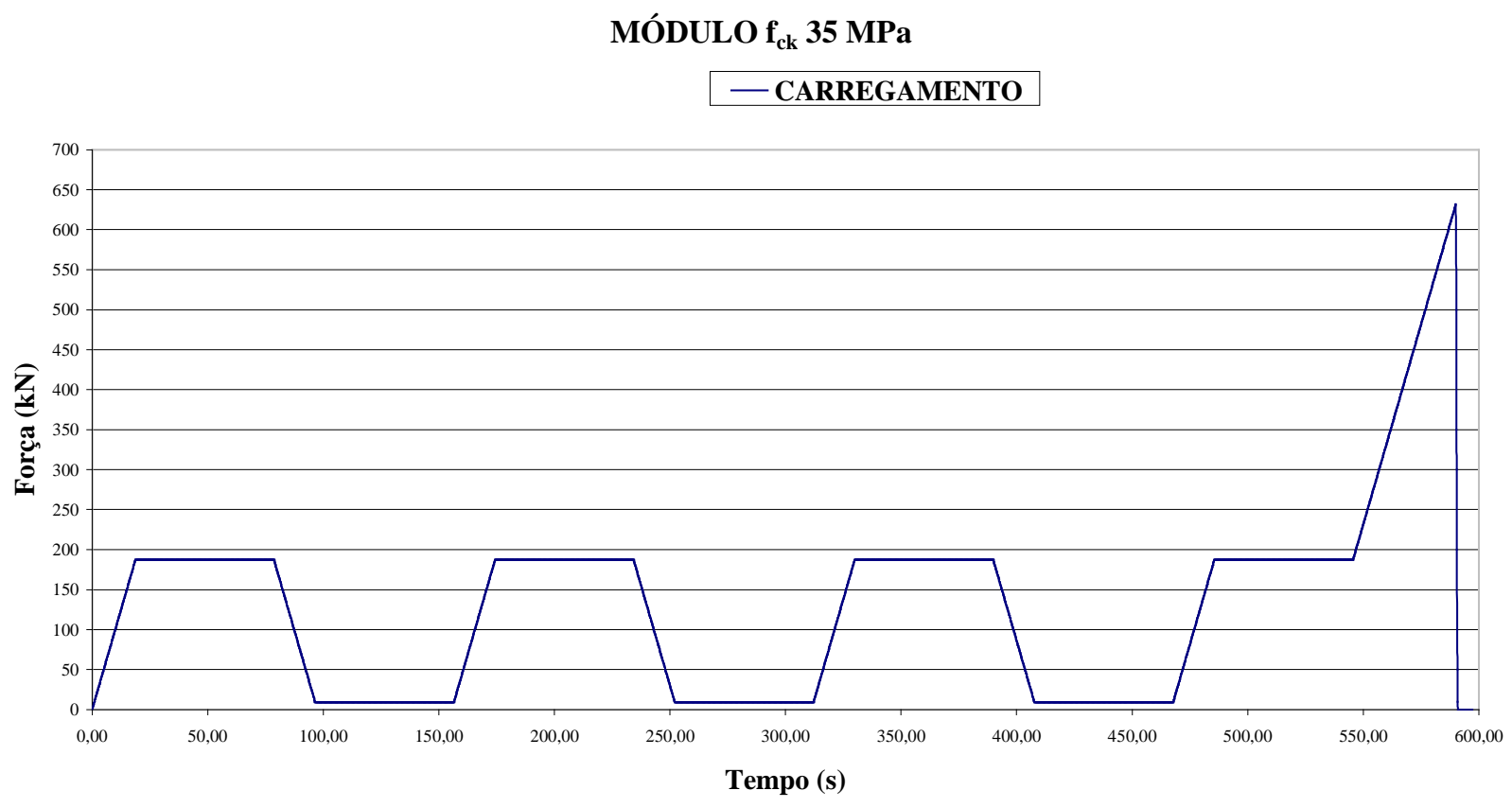

Gráfico 7.1 Carregamento do ensaio para obtenção do módulo de elasticidade e coeficiente de Poisson para o concreto com resistência à compressão de 35 MPa

MÓDULO f ck 50 MPa

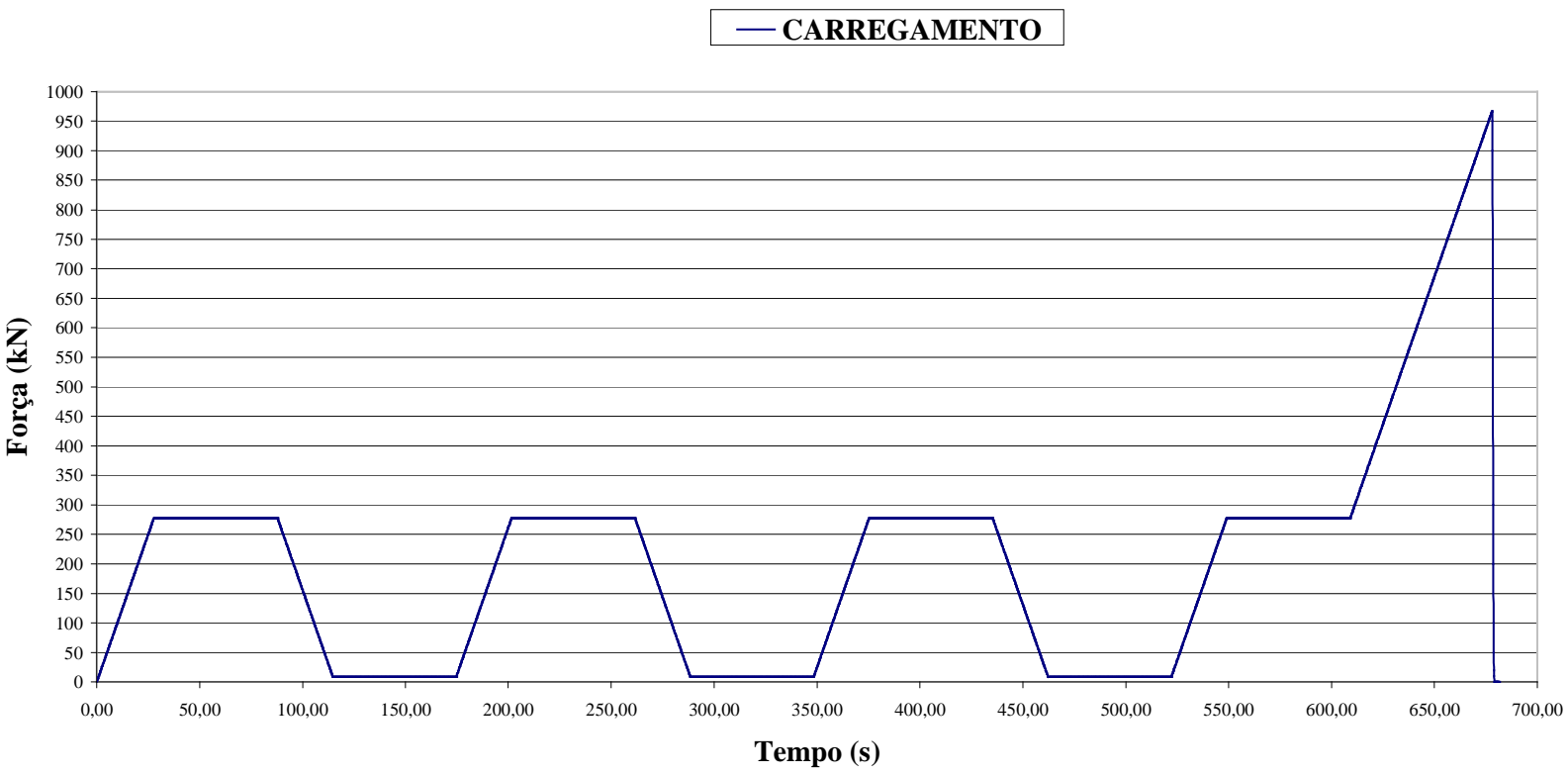

Gráfico 7.2 Carregamento do ensaio para obtenção do módulo de elasticidade e coeficiente de Poisson para o concreto com resistência à compressão de 50 MPa 
Com base nos dados colhidos neste ensaio calculou-se o módulo de elasticidade, $\mathrm{E}_{\mathrm{ci}}$, em gigapascais, seguindo-se as recomendações da NBR 8522: 2003, através da seguinte equação:

$$
E_{c i}=\frac{\sigma_{b}-\sigma_{a}}{\varepsilon_{b}-\varepsilon_{a}} \times 10^{-3}
$$

Sendo:

$\sigma_{\mathrm{b}}$ : tensão maior, em megapascais $\left(\sigma_{\mathrm{b}}=0,3 \mathrm{f}_{\mathrm{c}}\right)$;

$\sigma_{\mathrm{a}}$ : tensão básica, em megapascais $\left(\sigma_{\mathrm{a}}=0,5 \mathrm{MPa}\right)$;

$\varepsilon_{\mathrm{b}}$ : deformação média dos corpos-de-prova ensaiados sob a tensão maior;

$\varepsilon_{\mathrm{a}}$ : deformação média dos corpos-de-prova ensaiados sob a tensão básica.

Portanto:

- para o concreto com resistência média à compressão aos 28 dias de idade, $\mathrm{f}_{\mathrm{cm} 28}$, de 52,40 MPa tem-se:

$$
\begin{gathered}
E_{c i}=\frac{15,72-0,5}{8,55 \times 10^{-4}-2,50 \times 10^{-4}} \times 10^{-3} \\
E c i=25,2 G P a
\end{gathered}
$$

- para o concreto com resistência média à compressão aos 28 dias de idade, $\mathrm{f}_{\mathrm{cm} 28}$, de 35,32 MPa tem-se:

$$
\begin{gathered}
E_{c i}=\frac{10,60-0,5}{6,50 \times 10^{-4}-1,45 \times 10^{-4}} \times 10^{-3} \\
E c i=21,0 G P a
\end{gathered}
$$

Os resultados foram arredondados para a primeira casa decimal e expressos em gigapascais, conforme recomendação da NBR8522: 2003.

O coeficiente de Poisson obtém-se por meio do quociente da deformação horizontal pela vertical. Portanto para o concreto de $\mathrm{f}_{\mathrm{cm} 28}=52,40 \mathrm{MPa}$ tem-se

$$
\begin{gathered}
v=\frac{\varepsilon_{H}}{\varepsilon_{V}} \\
v_{52,40}=\frac{2,05}{8,55}
\end{gathered}
$$

Equação 7.3 


$$
v_{52,40}=0,24
$$

Para o concreto de $\mathrm{f}_{\mathrm{cm} 28}=35,32 \mathrm{MPa}$, utilizando-se a equação 7.3 tem-se

$$
\begin{aligned}
& v_{35,32}=\frac{1,17}{6,50} \\
& v_{35,32}=0,18
\end{aligned}
$$

Cabe ressaltar neste ponto que a máquina Shimadzu, na qual foram realizados os ensaios de compressão desta pesquisa, foi aferida quanto a erros. O resultado desta aferição foi um erro tendendo a $4 \%$ para menos, ou seja, com o acréscimo de carga se aproxima de $4 \%$, porém nunca tendo ultrapassado 6\%. Adotou-se desprezar este erro uma vez que todos os ensaios de compressão, sem exceção, foram realizados na mesma máquina. Os gráficos e fotos desta aferição encontram-se no anexo A deste trabalho.

\subsection{Resistência à tração do aço}

A resistência à tração do aço foi determinada para monitor o aço utilizado em cada um dos modelos reduzidos. Dois diâmetros de aço foram empregados de 5,0 mm e de 4,2 mm, ambos CA-60. O primeiro deles para servir de armadura complementar na região do pilar com concreto de resistência menor, sem laje confinando e o segundo foi empregado como armadura construtiva das lajes. Esse ensaio baseia-se em submeter corpos-de-prova, no caso barras de aço, a forças de tração, monitorando-se as deformações, depois, seguindo o ensaio até a ruptura para se determinar uma ou mais das propriedades mecânicas, tais como a força máxima suportada, o alongamento, o limite de resistência à tração, o alongamento específico e o módulo de elasticidade. Nesta pesquisa obteve-se a força máxima, o limite de resistência à tração, o alongamento, a resistência à tração média e a resistência média ao escoamento. Foram ensaiados 9 corpos-de-prova constituídos cada um de barras de, aproximadamente, 50 cm de comprimento total, das quais 5 de aço de diâmetro $5 \mathrm{~mm}$ e 4 de diâmetro 4,2 mm.

Para se proceder este ensaio, inicialmente mediu-se o comprimento entre duas marcas, feitas próximas às extremidades de cada uma das barras ensaiadas, chamando-se esta medida de comprimento inicial. Após o rompimento de cada uma das barras, 
mediu-se novamente a distância entre as marcas sendo este o comprimento final. Fazendo-se a diferença entre as duas medidas, obtém-se o alongamento "a". Para se obter o alongamento específico, faz-se o quociente do alongamento pelo comprimento inicial. A carga máxima " $\mathbf{F}_{\mathbf{m}}$ " foi lida na máquina EMIC DL10000, na qual se realizou o ensaio, no instante da ruptura de cada corpo-de-prova. O limite de resistência à tração “和” foi calculado dividindo-se o valor da carga máxima pela área da seção inicial do corpo-de-prova, obteve-se ainda a resistência média " $\mathbf{f}_{\mathbf{t m}}$ " e a resistência ao escoamento média "f $\mathbf{y}_{\mathbf{y m}}$ ". Utilizou-se um clip gage para medir a deformação de cada corpo-de-prova de forma mais precisa. A figura 7.7 mostra um dos corpos-de-prova sendo ensaiado.

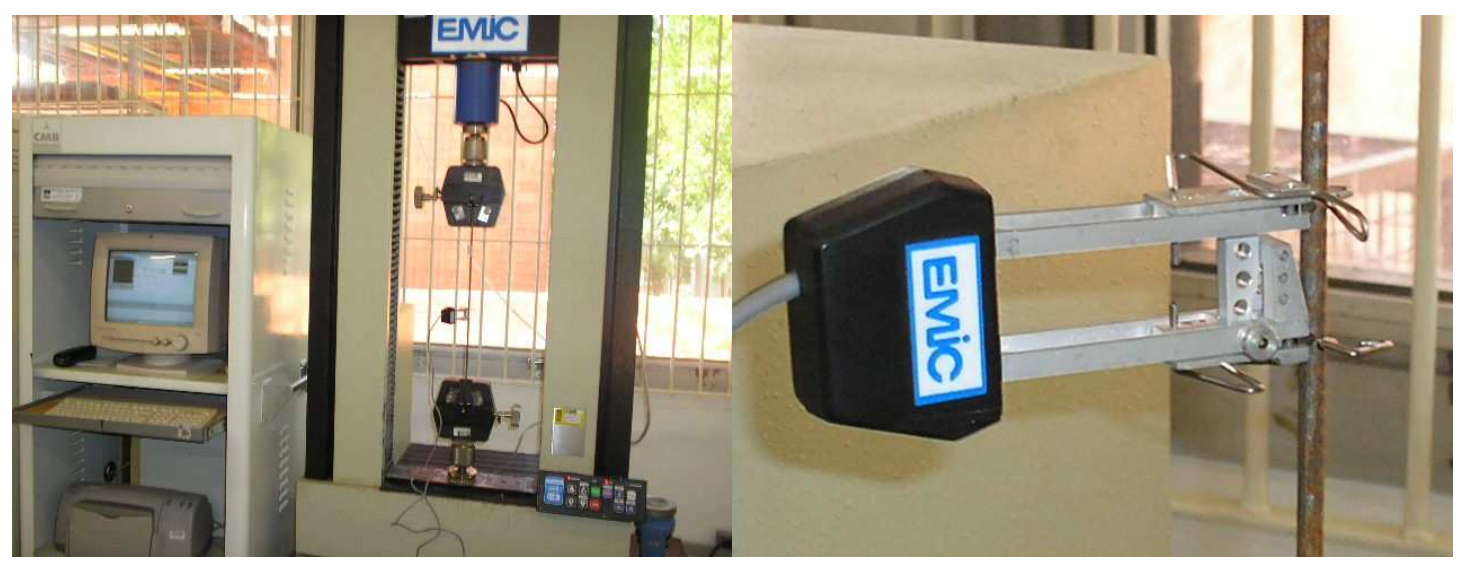

Figura 7.7 Figura Corpo-de-prova $\phi$ de $5,0 \mathrm{~mm}$ sendo ensaiado quanto a tração

\subsection{Resultados do ensaio de determinação da resistência à tração do aço}

Os corpos-de-prova são constituídos de aço tipo CA-60 e foram ensaiados a uma velocidade de $19 \mathrm{kgf} / \mathrm{s}$, seguindo-se as recomendações da NBR 6152: 1980. Os valores das medidas iniciais estão apresentados na tabela 7.4. A partir dos dados colhidos no ensaio elaborou-se a tabela $7.5 \mathrm{com}$ as propriedades mecânicas de ambos os diâmetros de aço utilizados. Foi apresentado apenas um gráfico para cada diâmetro ensaiado, o gráfico 7.3 correspondente a um fio de diâmetro $5 \mathrm{~mm}$ e o 7.4 que corresponde a um dos fios de diâmetro 4,2 mm. Porém para obtenção dos valores tabelados e cálculo das 
propriedades utilizaram-se todos os gráficos dos 9 corpos-de-prova ensaiados. Os demais gráficos encontram-se no anexo A.

Tabela 7.5 Dimensões iniciais dos fios de aço ensaiadas

\begin{tabular}{|c|c|c|c|}
\hline $\begin{array}{c}\text { CORPO } \\
\text { DE } \\
\text { PROVA }\end{array}$ & $\begin{array}{l}\text { Diâmetro } \\
\text { (ф) mm }\end{array}$ & $\begin{array}{c}\text { Diâmetro } \\
\text { Médio( } \phi) \mathrm{mm}\end{array}$ & $\begin{array}{c}\text { Comprimento } \\
\text { Total }(\mathrm{cm})\end{array}$ \\
\hline B1 & $\begin{array}{l}5,250 \\
5,100 \\
5,110 \\
\end{array}$ & 5,153 & 51,70 \\
\hline B2 & $\begin{array}{l}5,100 \\
5,050 \\
5,200 \\
\end{array}$ & 5,117 & 51,40 \\
\hline B3 & $\begin{array}{l}5,150 \\
5,250 \\
5,055 \\
\end{array}$ & 5,152 & 50,60 \\
\hline B4 & $\begin{array}{l}5,250 \\
5,155 \\
5,200 \\
\end{array}$ & 5,202 & 42,00 \\
\hline B5 & $\begin{array}{l}5,055 \\
5,000 \\
5,100 \\
\end{array}$ & 5,052 & 42,00 \\
\hline B6 & $\begin{array}{l}5,210 \\
5,230 \\
5,220 \\
\end{array}$ & 5,220 & 50,00 \\
\hline B7 & $\begin{array}{l}4,230 \\
4,200 \\
4,210 \\
\end{array}$ & 4,213 & 50,40 \\
\hline B8 & $\begin{array}{l}4,250 \\
4,230 \\
4,210 \\
\end{array}$ & 4,230 & 50,20 \\
\hline B9 & $\begin{array}{l}4,205 \\
4,250 \\
4,210 \\
\end{array}$ & 4,222 & 50,70 \\
\hline
\end{tabular}


FIO $4 \phi 5$ mm

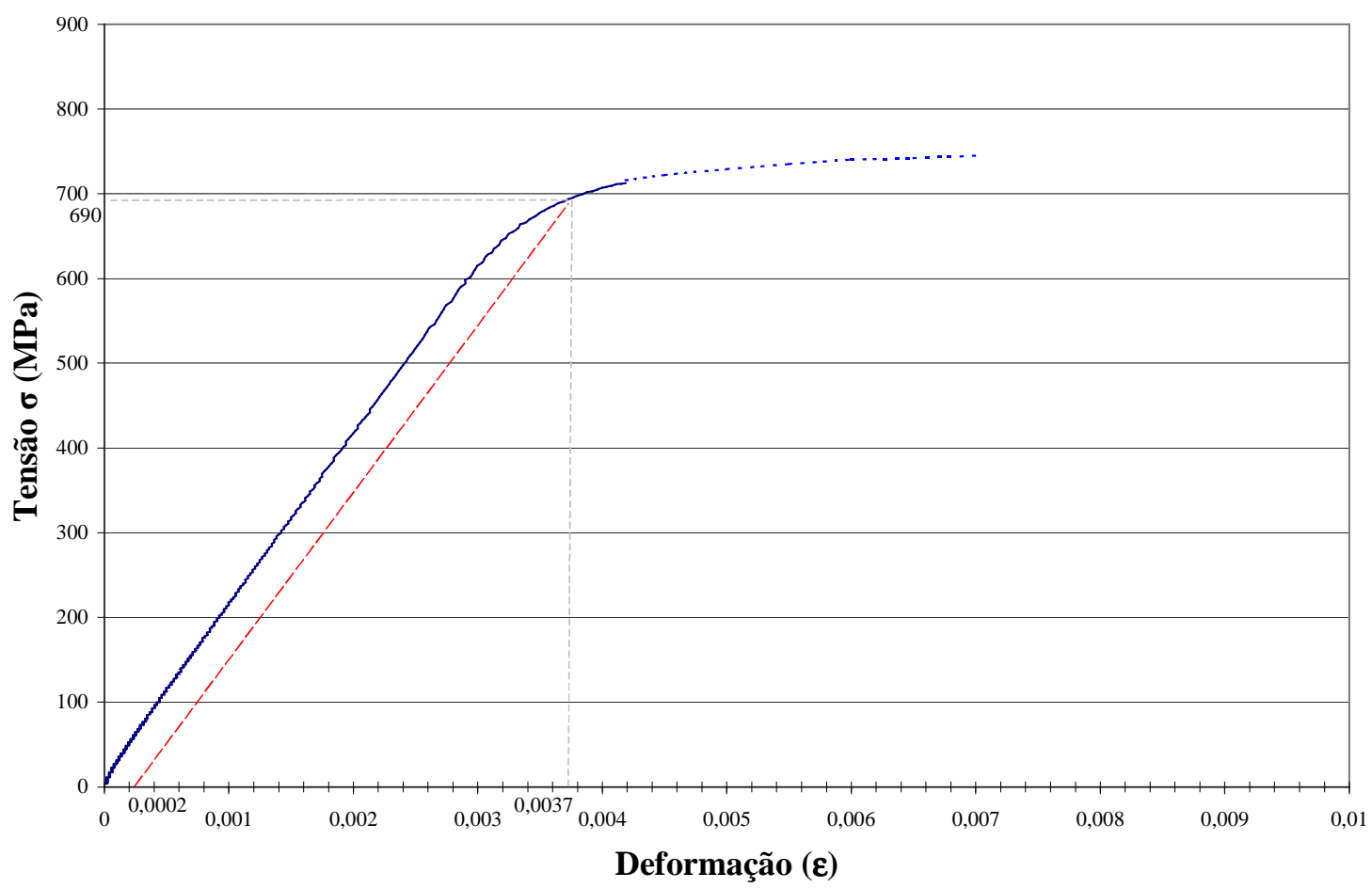

Gráfico 7.3 Ensaio de determinação da resistência à tração do aço de diâm. 5,0 mm

FIO $7 \phi 4,2 \mathrm{~mm}$

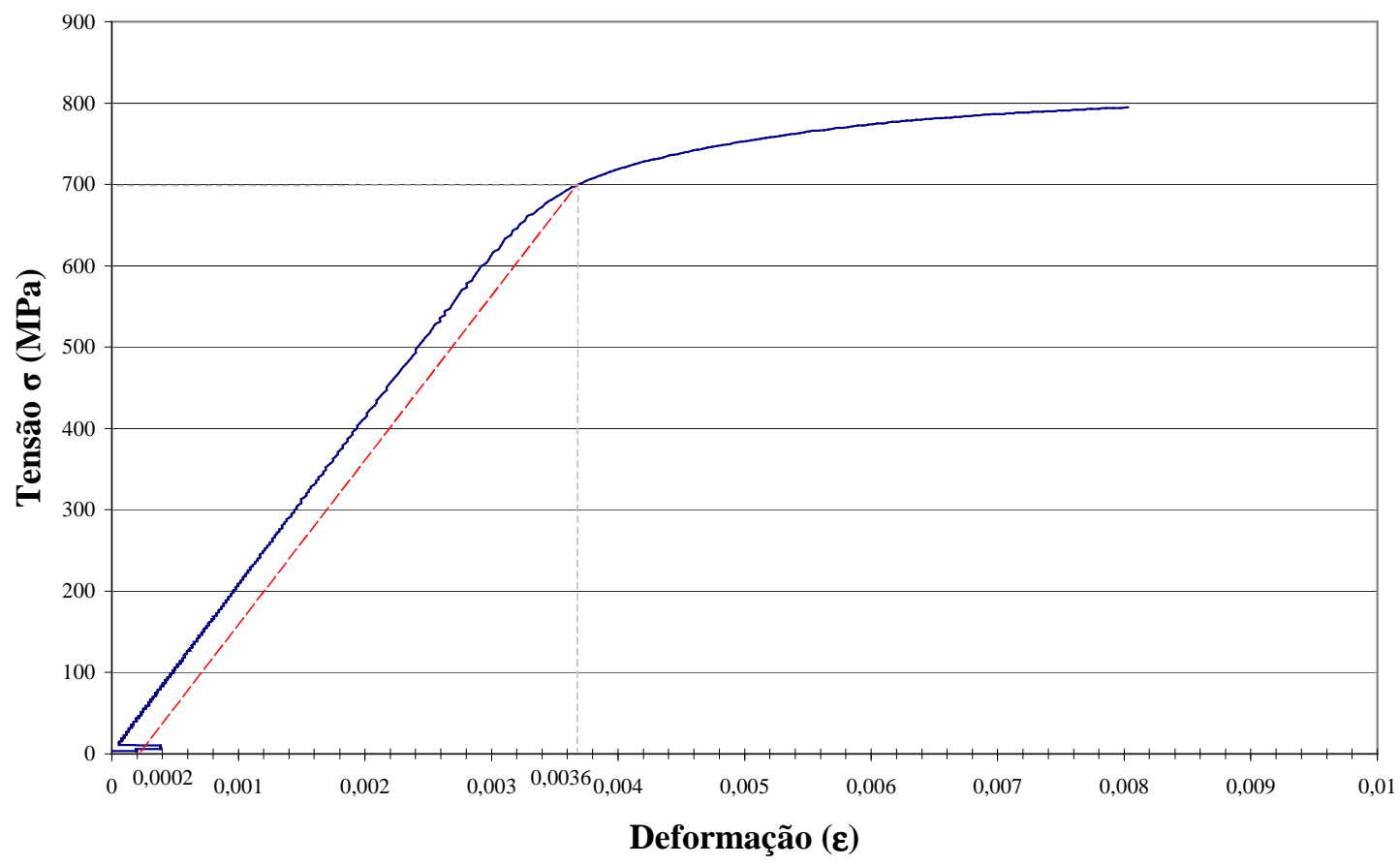

Gráfico 7.4 Ensaio de determinação da resistência à tração do aço de diâm. 4,2 mm 
Tabela 7.6 Propriedades mecânicas dos fios de aço ensaiados

\begin{tabular}{|c|c|c|c|c|c|c|c|}
\hline FIO & $\begin{array}{c}\mathrm{F}_{\mathrm{m}} \\
(\mathrm{N})\end{array}$ & $\begin{array}{c}\text { Diâmetro } \\
\text { Médio( } \phi) \mathrm{mm}\end{array}$ & $\begin{array}{c}\mathrm{S}_{\mathrm{o}} \\
(\mathrm{cm} 2)\end{array}$ & $\begin{array}{c}\mathrm{f}_{\mathrm{t}} \\
(\mathrm{MPa})\end{array}$ & $\begin{array}{c}\mathrm{l}_{\mathrm{o}} \\
(\mathrm{cm})\end{array}$ & $\begin{array}{c}\mathrm{l}_{\mathrm{f}} \\
(\mathrm{cm})\end{array}$ & $\mathrm{a}_{\mathrm{e}}$ \\
\hline 1 & 15075 & 5,15 & 0,209 & 721,29 & 43,20 & 44,50 & 0,0301 \\
\hline 2 & 15063 & 5,12 & 0,206 & 731,21 & 43,60 & 45,10 & 0,0344 \\
\hline 3 & 15000 & 5,15 & 0,208 & 721,15 & 42,70 & 44,20 & 0,0351 \\
\hline 4 & 15175 & 5,20 & 0,210 & 722,62 & 35,30 & 36,70 & 0,0397 \\
\hline 5 & 15038 & 5,05 & 0,200 & 751,90 & 36,30 & 37,80 & 0,0413 \\
\hline 6 & 15151 & 5,22 & 0,206 & 735,49 & 42,90 & 44,20 & 0,0303 \\
\hline 7 & 10889 & 4,21 & 0,139 & 783,38 & 42,40 & 42,80 & 0,0094 \\
\hline 8 & 11026 & 4,23 & 0,141 & 781,99 & 42,50 & 43,30 & 0,0188 \\
\hline 9 & 11088 & 4,22 & 0,140 & 792,00 & 43,40 & 44,00 & 0,0138 \\
\hline
\end{tabular}

Sendo:

$\mathrm{F}_{\mathrm{m}}$ : força máxima;

$\mathrm{S}_{0}$ : área da seção inicial do fio;

$\mathrm{f}_{\mathrm{t}:}$ resistência à tração;

$1_{0}$ : comprimento inicial entre marcas;

$1_{\mathrm{f}}$ : comprimento final entre as marcas;

$\mathrm{a}_{\mathrm{e}}$ : alongamento específico.

Utilizando-se os gráficos anteriores calcula-se a resistência média à tração $\left(\mathrm{f}_{\text {tm }}\right)$ de cada um dos aços utilizados, diâmetro de $5,0 \mathrm{~mm}$ e de 4,2 $\mathrm{mm}$, sendo estas respectivamente 730,61 $\mathrm{MPa}$ e 785,79 $\mathrm{MPa}$. A resistência média ao escoamento ficou em torno de $690 \mathrm{MPa}$ para o diâmetro de 5,00 mm e de $700 \mathrm{MPa}$ para o de 4,2 mm. 


\section{RESULTADOS}

O anexo B contém fotos adicionais dos ensaios descritos a seguir.

\subsection{Resultados dos ensaios experimentais da primeira etapa}

Os modelos 1 e 2 da primeira etapa foram ensaiados e os resultados estão apresentados nas tabelas a seguir. Os modelos tiveram resultados com variações acima da desejada para a análise em questão.

\subsubsection{Resultados dos ensaios para o modelo reduzido 1}

Pode-se observar na tabela 8.1 e na figura 8.1 os resultados do ensaio de compressão axial para o modelo 1, sem armação

Tabela 8.1 Ensaio de compressão axial para o modelo reduzido 1

\begin{tabular}{|c|c|c|}
\hline \multicolumn{3}{|c|}{ MODELO REDUZIDO 1 } \\
\hline EXEMPLAR & $\mathrm{f}_{\mathrm{cm} 28}=48,90 \mathrm{MPa}$ \\
\hline M1-A & 985 & $\begin{array}{c}\text { RESISTÊNCIA } \mathrm{A} \\
\text { COMPRESSÃO }(\mathrm{MPa})\end{array}$ \\
\hline M1-B & 856 & 43,80 \\
\hline \multicolumn{3}{|c|}{$\mathrm{f}_{\mathrm{cefm}}=$} \\
\hline
\end{tabular}




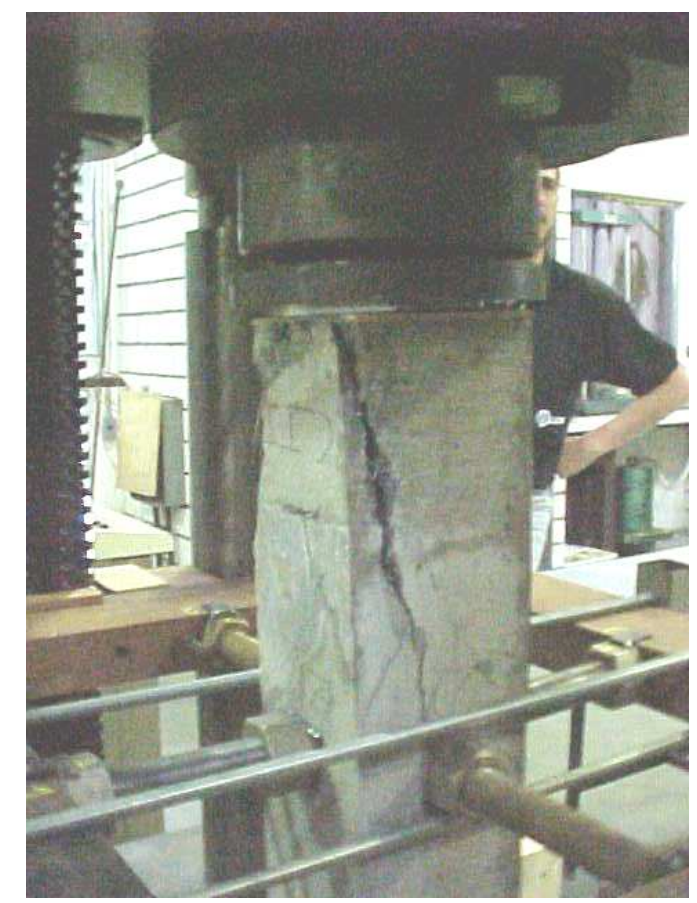

Figura 8.1 Modelo reduzido 1-A rompido

\subsubsection{Resultados dos ensaios para o modelo reduzido 2}

O modelo 2, que possui armadura mínima transversal de confinamento, apresentou os resultados mostrados na tabela 8.2 e na figura 8.2.

Tabela 8.2 Ensaio de compressão axial para o modelo reduzido 2

\begin{tabular}{|c|c|c|}
\hline \multicolumn{3}{|c|}{ MODELO REDUZIDO 2 } \\
\hline \multicolumn{3}{|c|}{$\mathrm{f}_{\mathrm{cm} 28}=48,20 \mathrm{MPa}$} \\
\hline EXEMPLAR & $\begin{array}{c}\mathrm{F}_{\text {RUPTURA }} \\
(\mathrm{kN})\end{array}$ & $\begin{array}{c}\text { RESISTÊNCIA À } \\
\text { COMPRESS ÃO (MPa) }\end{array}$ \\
\hline M2-A & 860 & 38,22 \\
\hline M2-B & 899 & 39,96 \\
\hline M2-C & 862 & 38,31 \\
\hline M2-D & 880 & 39,11 \\
\hline M2-E & 983 & 43,69 \\
\hline M2-F & 897 & 39,87 \\
\hline & \multicolumn{2}{c}{$\mathrm{f}_{\text {cefm }}=$} \\
\hline
\end{tabular}




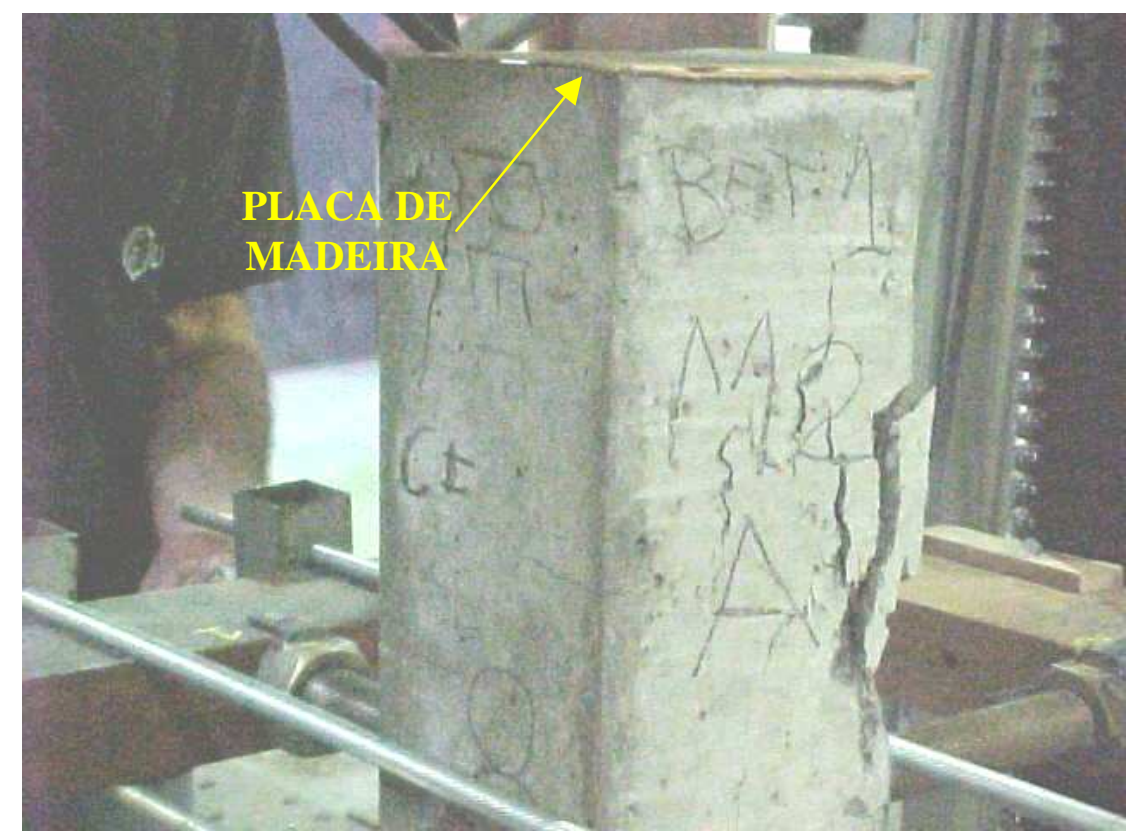

Figura 8.2 Modelo reduzido 2-A rompido

\subsection{Resultados dos ensaios experimentais da segunda etapa}

\subsubsection{Resultados dos ensaios para o modelo reduzido I}

O modelo reduzido I representa um pilar isolado com resistência do concreto à compressão de 51,70 MPa para os exemplares A e B e 55,93 MPa para C e D. Os resultados deste ensaio estão apresentados nas tabelas 8.3 e 8.4 nas figuras 8.3 e 8.4. As medidas de todos os modelos reduzidos estão apresentadas no anexo $\mathrm{C}$, sendo os cálculos realizados a partir de suas médias.

Tabela 8.3 Ensaio de compressão axial para o modelo reduzido I, exemplares A e B

\begin{tabular}{|c|c|c|}
\hline \multicolumn{3}{|c|}{ MODELO REDUZIDO I } \\
\hline \multicolumn{3}{|c|}{$\mathrm{f}_{\mathrm{cm} 28}=51,70 \mathrm{MPa}$} \\
\hline EXEMPLAR & $\begin{array}{c}\mathrm{F}_{\text {RUPTURA }} \\
(\mathrm{kN})\end{array}$ & $\begin{array}{c}\text { RESISTENNCIA À } \\
\text { COMPRESSÃO (MPa) }\end{array}$ \\
\hline MI-A & 1041 & 46,27 \\
\hline MI-B & 1106 & 49,16 \\
\hline \multicolumn{3}{|c|}{$\mathrm{f}_{\mathrm{cefm}}=$} \\
\hline
\end{tabular}




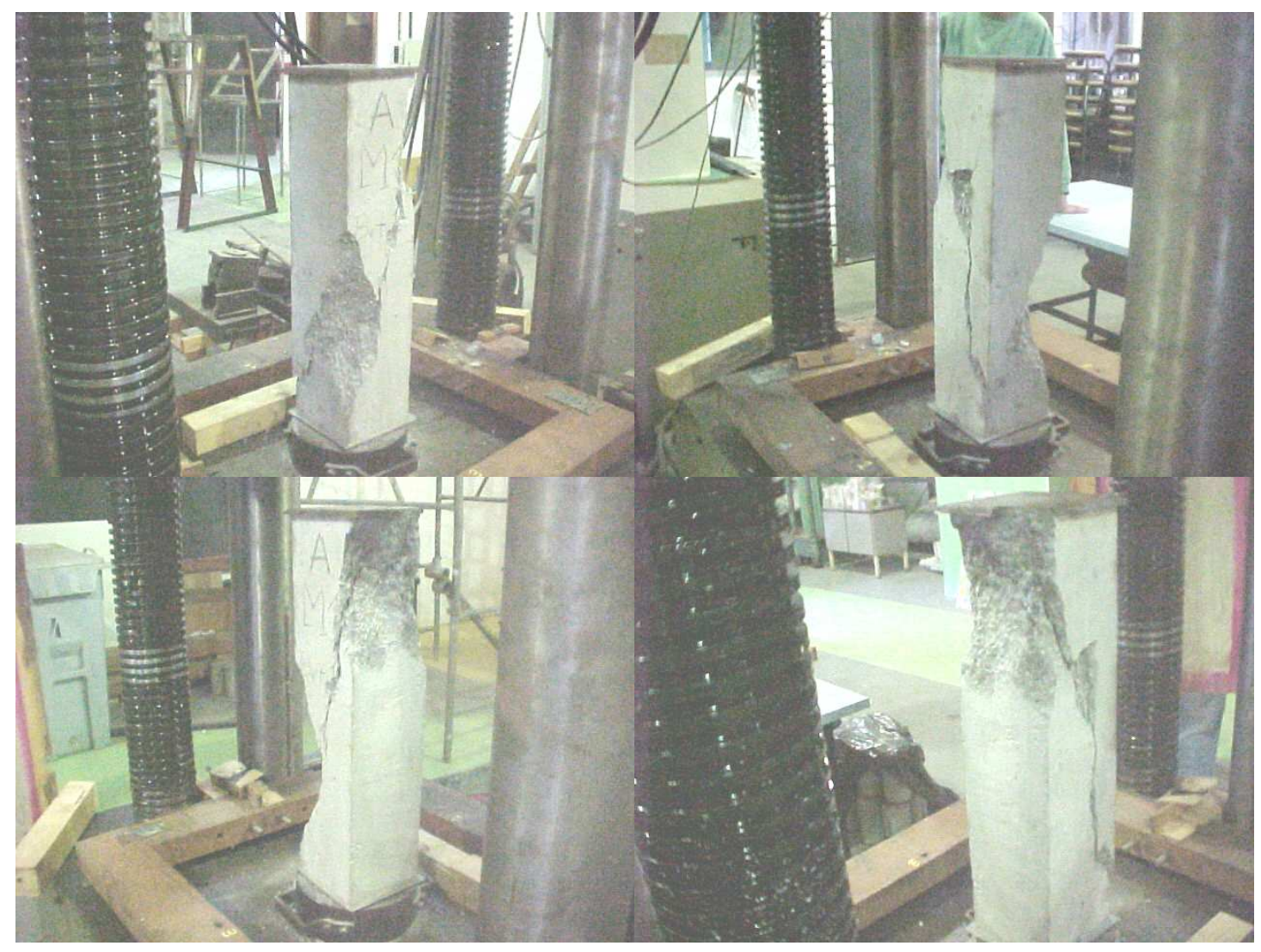

Figura 8.3 Modelo reduzido I-A rompido

Tabela 8.4 Ensaio de compressão axial para o modelo reduzido I, exemplares C e D

\begin{tabular}{|c|c|c|}
\hline \multicolumn{3}{|c|}{ MODELO REDUZIDO I } \\
\hline \multicolumn{3}{|c|}{$\mathrm{f}_{\mathrm{cm} 28}=55,93 \mathrm{MPa}$} \\
\hline EXEMPLAR & $\begin{array}{c}\mathrm{F}_{\text {RUPTURA }} \\
(\mathrm{kN})\end{array}$ & $\begin{array}{c}\text { RESISTENCIA À } \\
\text { COMPRESSÃO (MPa) }\end{array}$ \\
\hline MI-C & 1171 & 52,04 \\
\hline MI-D & 1199 & 53,29 \\
\hline \multicolumn{3}{|c|}{$\mathrm{f}_{\mathrm{cefm}}=$} \\
\hline
\end{tabular}




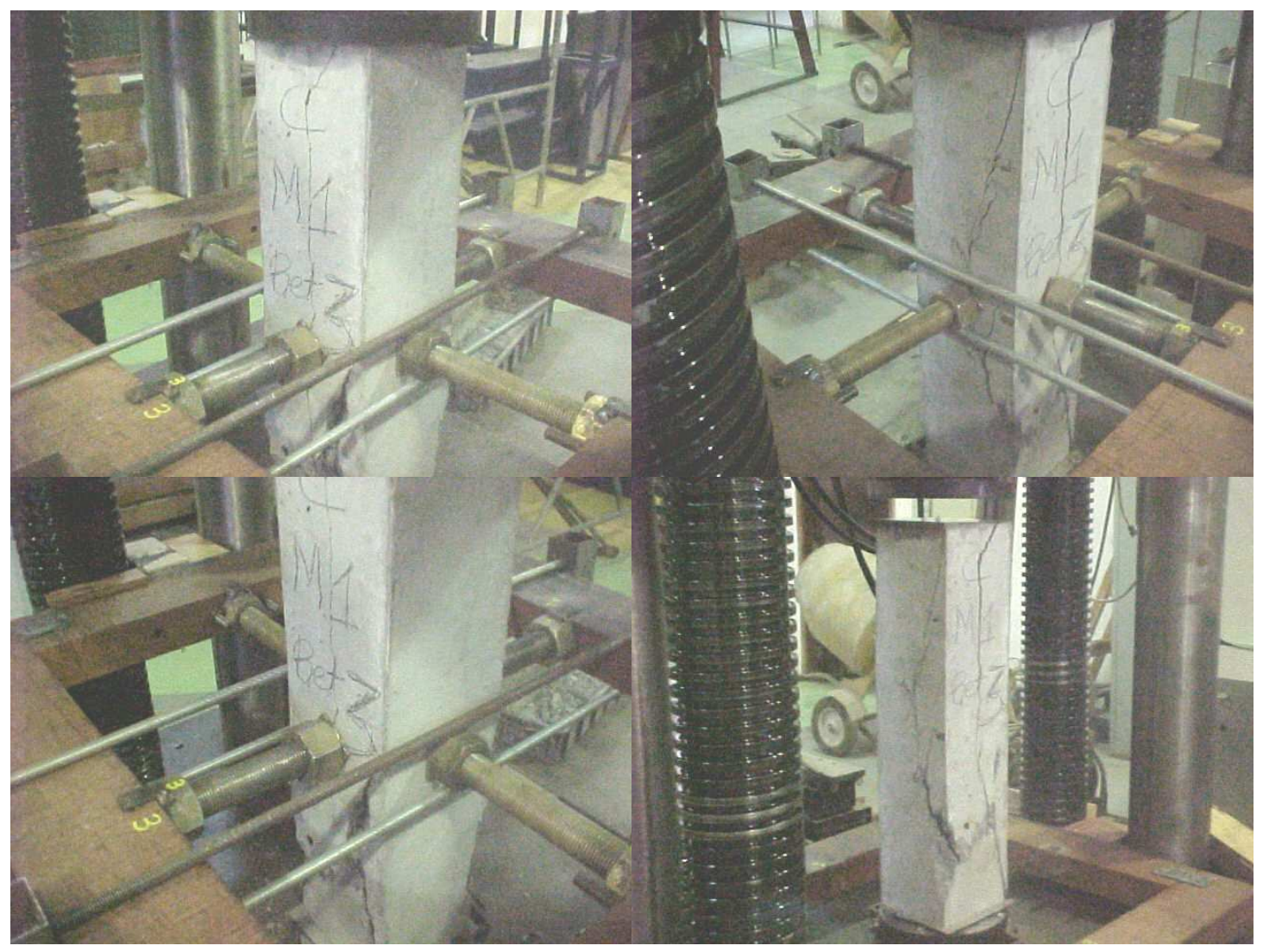

Figura 8.4 Modelo reduzido I-C rompido 


\subsubsection{Resultados dos ensaios para o modelo reduzido II}

Um pilar isolado com uma faixa de $4,5 \mathrm{~cm}$ de espessura de concreto de resistência à compressão menor é representado pelo modelo reduzido II. Esta faixa, cujo concreto tem resistência à compressão de 30,37 $\mathrm{MPa}$, está no lugar de uma laje. O concreto do pilar tem resistência à compressão de 52,04 $\mathrm{MPa}$, sendo a relação entre os valores destas resistências de 1,71, ou seja, acima do limite de 1,4 estipulado pela maioria das normas e pesquisadores. Os resultados deste ensaio estão apresentados na tabela 8.5 e na figura 8.5 .

Tabela 8.5 Ensaio de compressão axial para o modelo reduzido II

\begin{tabular}{|c|c|c|}
\hline \multicolumn{3}{|c|}{ MODELO REDUZIDO II } \\
\hline \multicolumn{2}{|c|}{$\mathrm{f}_{\mathrm{clm} 28}=30,37 \mathrm{MPa}$} & $\mathrm{f}_{\mathrm{cp} 28}=52,04 \mathrm{MPa}$ \\
\hline EXEMPLAR & $\begin{array}{c}\mathrm{F}_{\text {RUPTURA }} \\
(\mathrm{kN})\end{array}$ & $\begin{array}{c}\text { RESISTÊNCIA À } \\
\text { COMPRESSÃO (MPa) }\end{array}$ \\
\hline MII-A & 824 & 36,62 \\
\hline MII-B & 842 & 37,42 \\
\hline MII-C & 886 & 39,38 \\
\hline \multicolumn{3}{|c|}{$\mathrm{f}_{\text {cefm }}=$} \\
\hline
\end{tabular}

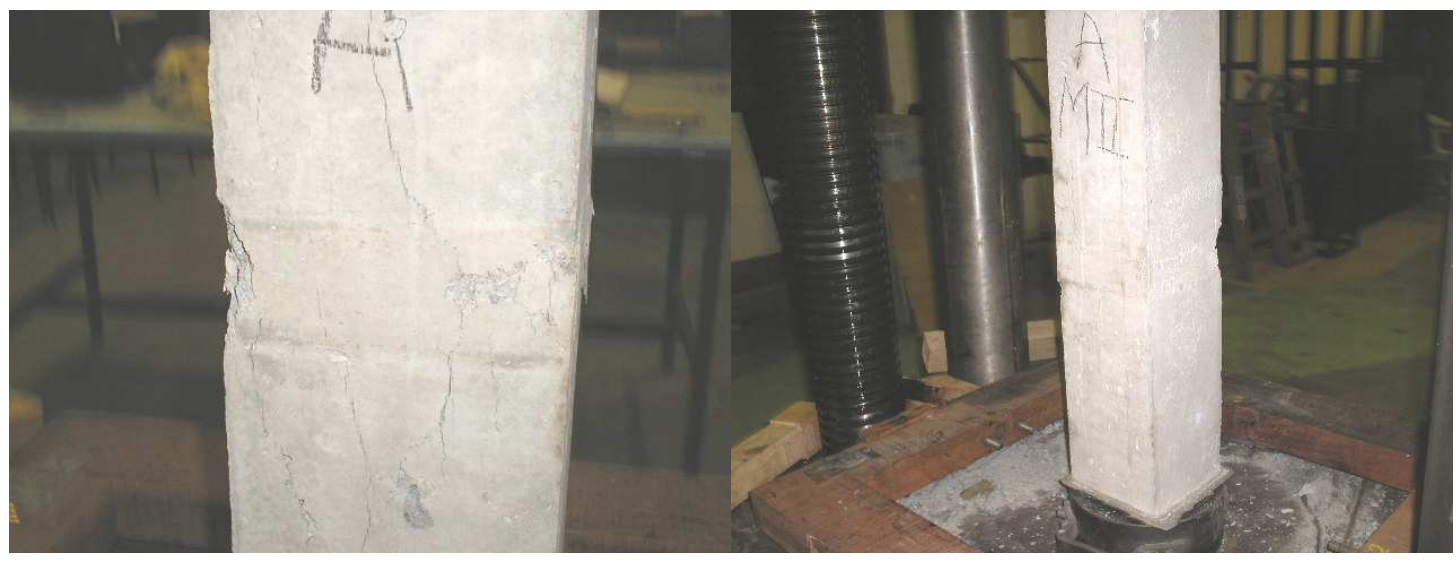

Figura 8.5 Modelo reduzido II-A rompido 


\subsubsection{Resultados dos ensaios para o modelo reduzido IV}

O modelo reduzido IV representa um pilar central com resistência média do concreto à compressão de 53,77 MPa, com laje de 4,5 cm de espessura e resistência do concreto de 35,32 MPa. A relação entre as resistências dos concretos foi de 1,52, acima de 1,4. Os resultados deste ensaio podem ser observados na tabela 8.6 e na figura 7.6.

Tabela 8.6 Ensaio de compressão axial para o modelo reduzido IV

\begin{tabular}{|c|c|c|}
\hline \multicolumn{3}{|c|}{ MODELO REDUZIDO IV } \\
\hline $\mathrm{f}_{\mathrm{clm} 28}=35,32 \mathrm{MPa}$ & $\mathrm{f}_{\mathrm{cpm} 28}=53,77 \mathrm{MPa}$ \\
\hline EXEMPLAR & $\begin{array}{c}\mathrm{F}_{\text {RUPTURA }} \\
(\mathrm{kN})\end{array}$ & $\begin{array}{c}\text { RESISTÊNCIA À } \\
\text { COMPRESS ÃO }(\mathrm{MPa})\end{array}$ \\
\hline MIV-A & 1096 & 48,71 \\
\hline MIV-B & 1028 & 45,69 \\
\hline MIV-C & 1110 & 49,33 \\
\hline \multicolumn{3}{|c|}{$\mathrm{f}_{\mathrm{cefm}}=$} \\
\hline
\end{tabular}




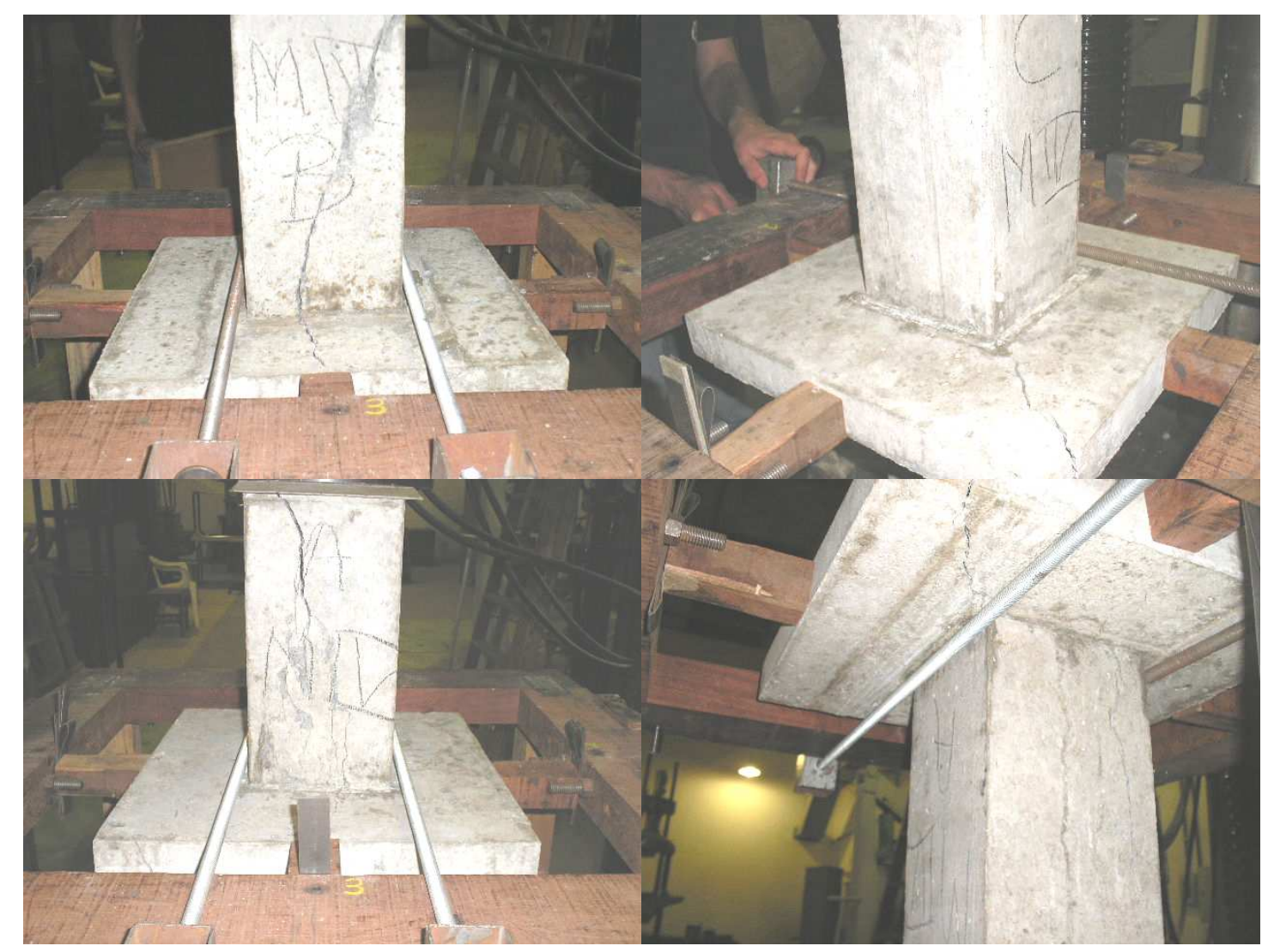

Figura 8.6 Modelo reduzido IV, exemplares A, B e C rompidos

\subsubsection{Resultados dos ensaios para o modelo reduzido $\mathrm{V}$}

Um pilar de canto é representado pelo modelo reduzido $\mathrm{V}$, sem nenhuma armadura. Este modelo foi ensaiado em duas séries de exemplares, a primeira composta pelos exemplares cada uma A, B, C e a segunda pelos exemplares D, E, F.

Uma segunda série foi realizada devido ao fato de o valor da resistência do concreto da laje da primeira série ter resultado em 43,34 MPa e ficado muito próximo ao valor da resistência do concreto do pilar, que foi de 53,82 $\mathrm{MPa}$, sendo que a relação entre eles foi de 1,24, menor que o limite de 1,4. A segunda série apresentou uma relação de 1,85 entre os valores das resistências dos concretos do pilar, que foi de 60,58 MPa e da laje, que ficou em 32,67 MPa. Estando esta relação acima e a primeira abaixo do valor limite de 1,4 pode-se analisar melhor este caso. As tabelas 8.7 e 8.8 e as figuras 8.7 e 8.8 apresentam os resultados de cada uma das séries de exemplares ensaiados. 
Tabela 8.7 Ensaio de compressão axial para a $1^{\text {a }}$ série de exemplares do modelo reduzido $V$

\begin{tabular}{|c|c|c|}
\hline \multicolumn{3}{|c|}{ MODELO REDUZIDO V - $1^{\mathrm{a}}$ SÉRIE } \\
\hline \multicolumn{2}{|c|}{$\mathrm{f}_{\mathrm{clm} 28}=43,34 \mathrm{MPa}$} & $\mathrm{f}_{\mathrm{cpm} 28}=53,82 \mathrm{MPa}$ \\
\hline EXEMPLAR & $\begin{array}{c}\mathrm{F}_{\text {RUPTURA }} \\
(\mathrm{kN})\end{array}$ & $\begin{array}{c}\text { RESISTÊNCIA À } \\
\text { COMPRESSÃO (MPa) }\end{array}$ \\
\hline MV-A & 1088 & 48,36 \\
\hline MV-B & 1056 & 46,93 \\
\hline MV-C & 1086 & 48,27 \\
\hline \multicolumn{3}{|c|}{$\mathrm{f}_{\text {cefm }}=$} \\
\hline
\end{tabular}

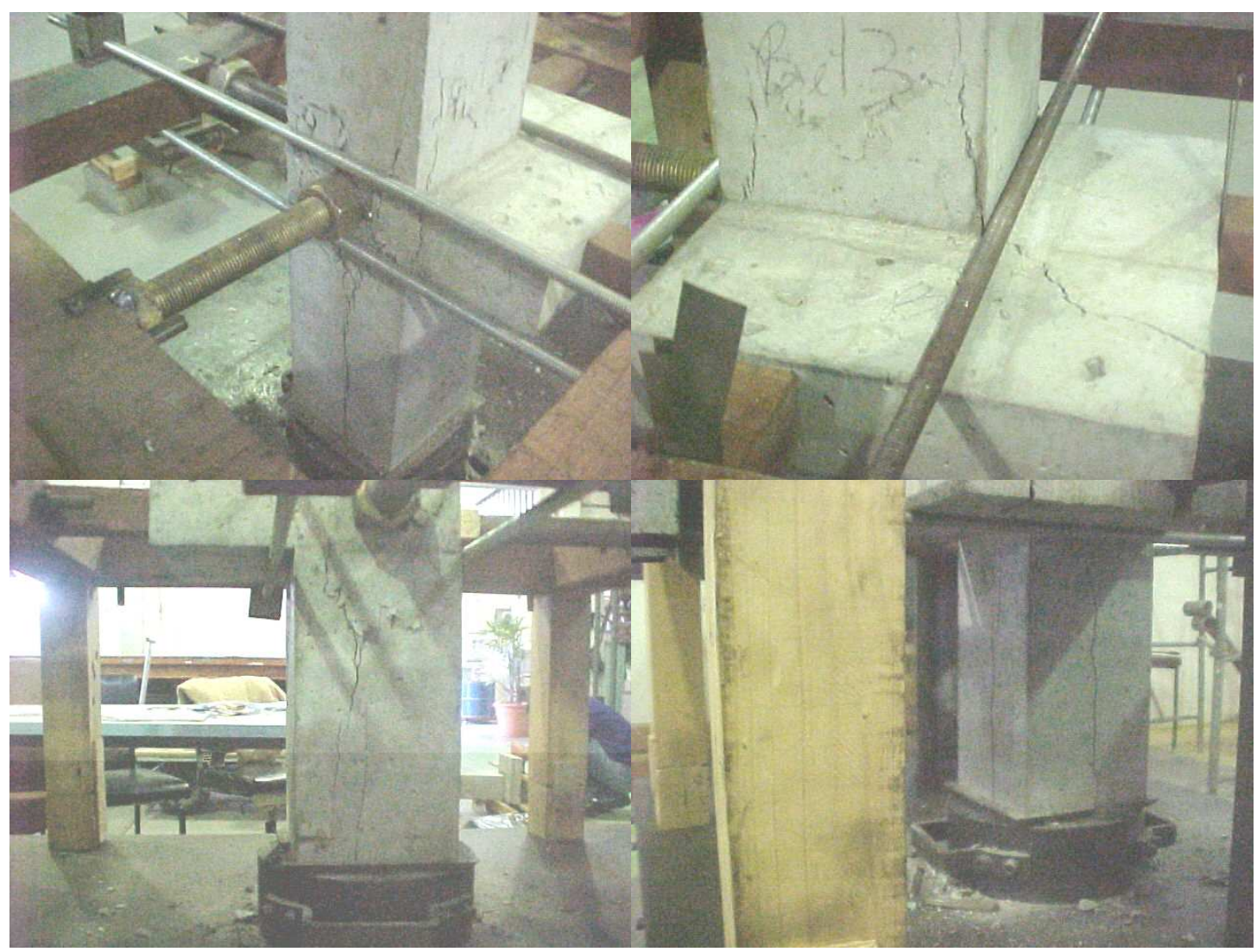

Figura 8.7 Modelo reduzido V-B rompido 
Tabela 8.8 Ensaio de compressão axial para a $2^{\text {a }}$ série de exemplares o modelo reduzido $\mathrm{V}$

\begin{tabular}{|c|c|c|}
\hline \multicolumn{3}{|c|}{ MODELO REDUZIDO V - $2^{\mathrm{a}}$ SÉRIE } \\
\hline $\mathrm{f}_{\mathrm{clm} 28}=32,67 \mathrm{MPa}$ & $\mathrm{f}_{\mathrm{cpm} 28}=60,58 \mathrm{MPa}$ \\
\hline EXEMPLAR & $\begin{array}{c}\mathrm{F}_{\text {RUPTURA }} \\
(\mathrm{kN})\end{array}$ & $\begin{array}{c}\text { RESISTÊNCIA À } \\
\text { COMPRESSÃO }(\mathrm{MPa})\end{array}$ \\
\hline MV-D & 843 & 37,47 \\
\hline MV-E & 857 & 38,09 \\
\hline MV-F & 833 & 37,02 \\
\hline \multicolumn{3}{|c|}{$\mathrm{f}_{\mathrm{cefm}}=$} \\
\hline
\end{tabular}

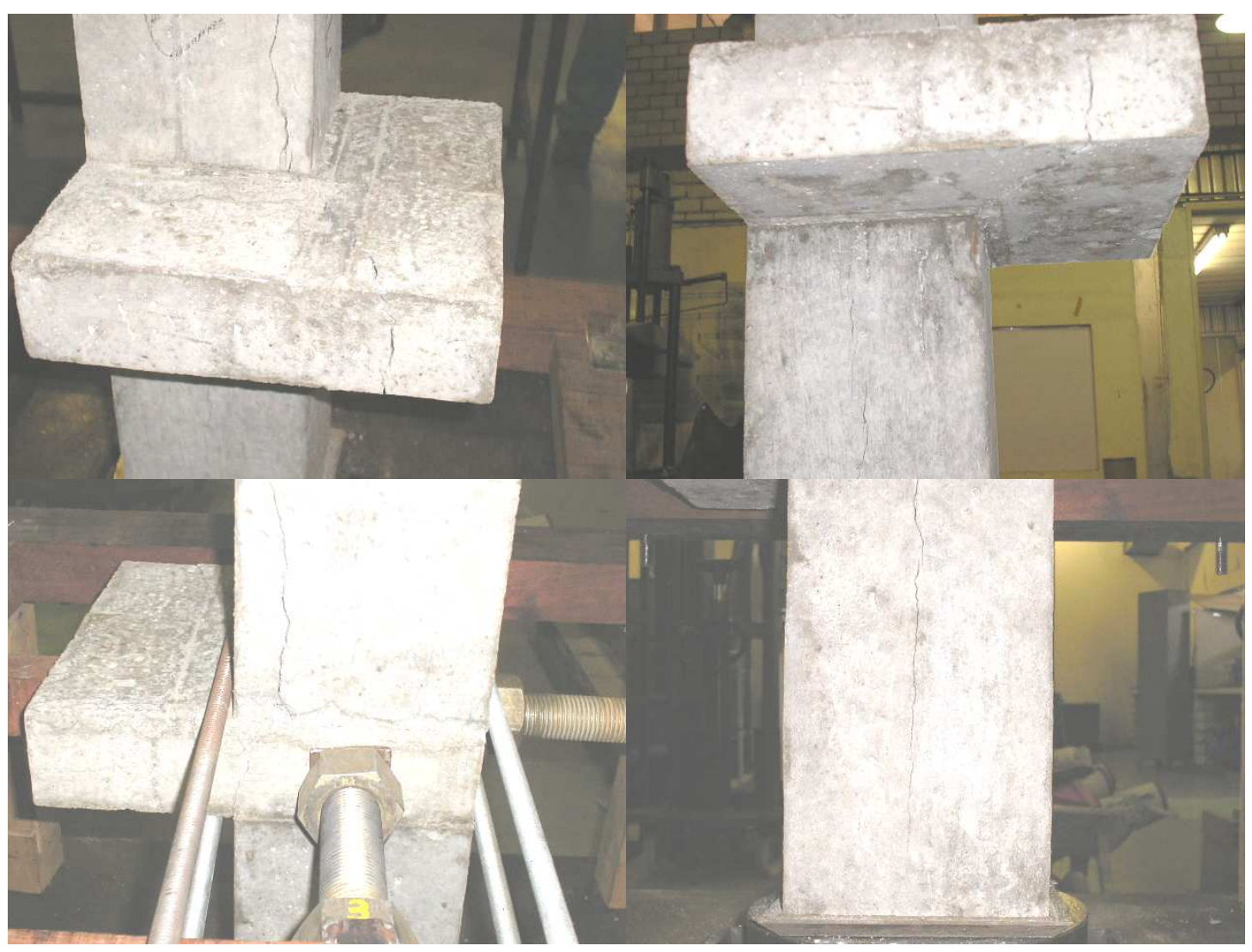

Figura 8.8 Modelo reduzido V-E rompido 


\subsubsection{Resultados dos ensaios para o modelo reduzido VI}

O modelo reduzido VI compõe-se de pilar com laje em duas faces, ou seja, também representa um pilar de canto, assim como o modelo $\mathrm{V}$, porém, neste modelo tem-se armadura complementar na região da laje nas faces do pilar onde a mesma não existe. Essa armadura foi calculada segundo esclarecido no capítulo 6 concluindo-se assim a necessidade de uma armadura constituída por 9 barras de aço com diâmetro de 5 $\mathrm{mm}$, sendo um deles, o superior, monitorado por um strain gage, assim como uma das armaduras de distribuição da laje, como mostrado no capítulo 6. Os resultados estão apresentados na tabela 8.9, na figura 8.9 e nos gráficos 8.1 a 8.6.

Tabela 8.9 Ensaio de compressão axial para o modelo reduzido VI

\begin{tabular}{|c|c|c|}
\hline \multicolumn{3}{|c|}{ MODELO REDUZIDO VI } \\
\hline \multicolumn{2}{|c|}{$\mathrm{f}_{\mathrm{clm} 28}=36,99 \mathrm{MPa}$} & $\mathrm{f}_{\mathrm{cpm} 28}=52,41 \mathrm{MPa}$ \\
\hline EXEMPLAR & $\begin{array}{c}\mathrm{F}_{\text {RUPTURA }} \\
(\mathrm{kN})\end{array}$ & $\begin{array}{c}\text { RESISTÊNCIA } \AA \\
\text { COMPRESSÃO } \\
(\mathrm{MPa})\end{array}$ \\
\hline MVI-A & 1025 & 45,56 \\
\hline MVI-B & 1003 & 44,58 \\
\hline MVI-C & 1052 & 46,75 \\
\hline \multicolumn{3}{|c|}{$\mathrm{f}_{\text {cefm }}=$} \\
\hline
\end{tabular}

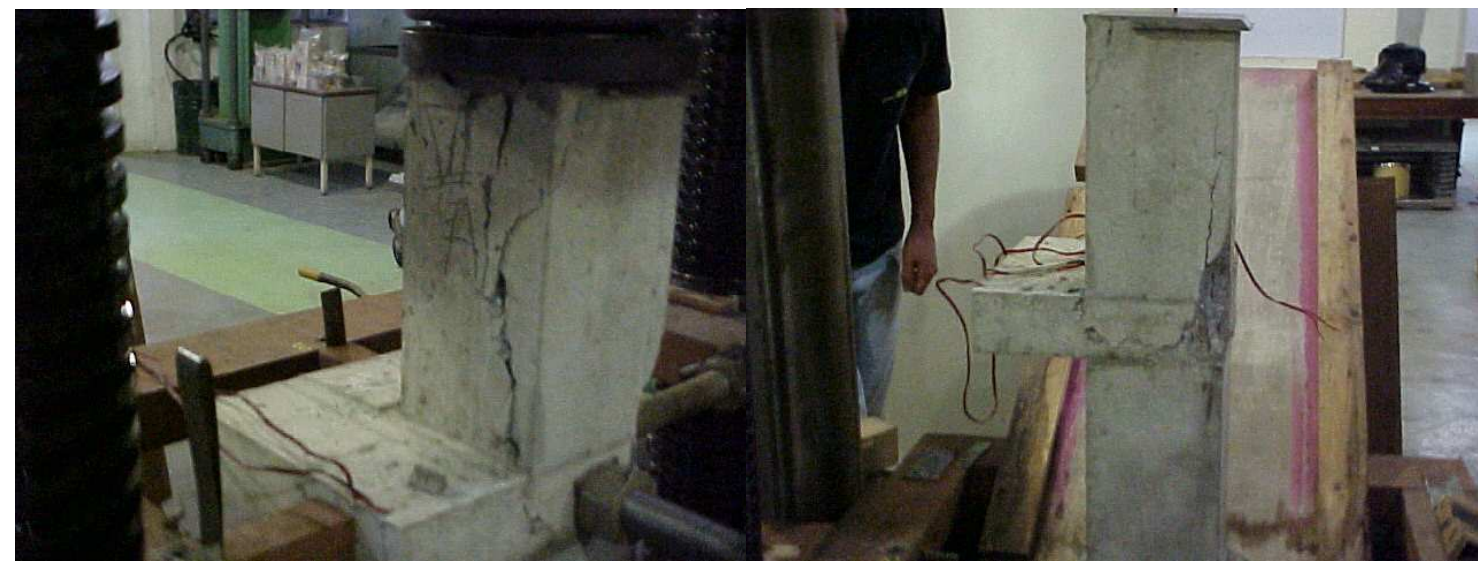

Figura 8.9 Modelo reduzido VI-A rompido 


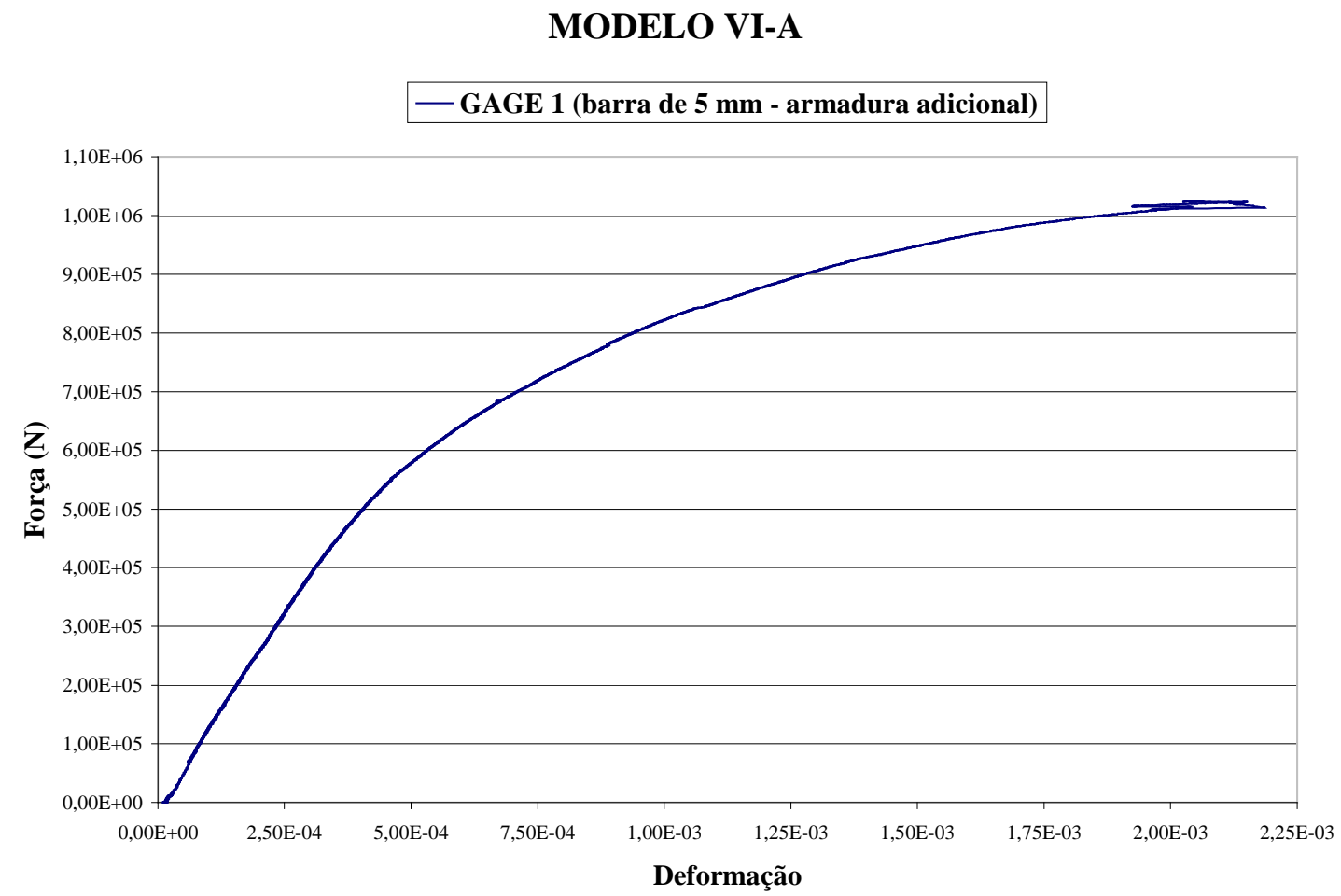

Gráfico 8.1 Força x deformação da armadura adicional ( $\phi 5 \mathrm{~mm})$ do modelo reduzido VI-A MODELO VI-B

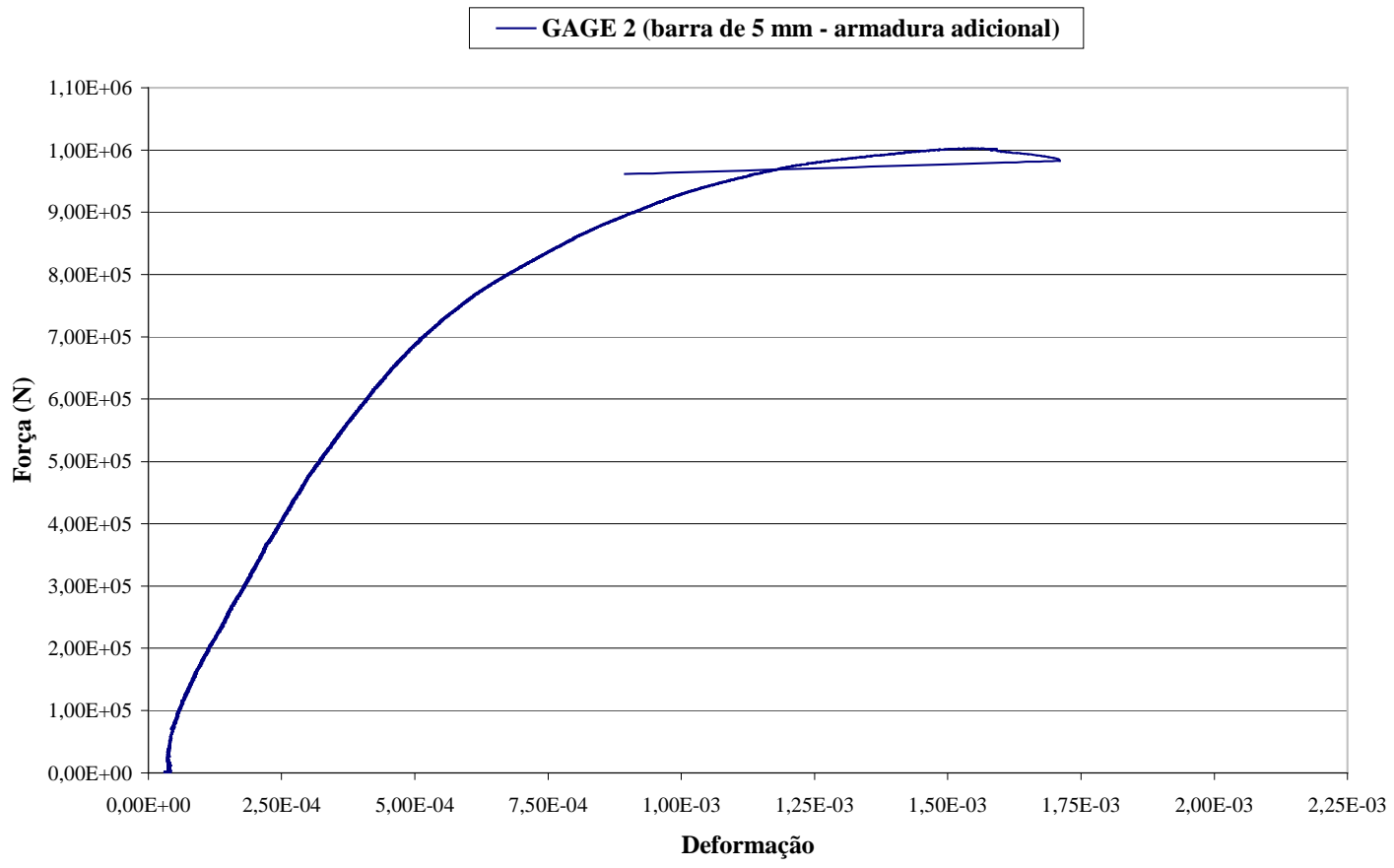

Gráfico 8.2 Força x deformação da armadura adicional $(\phi 5 \mathrm{~mm})$ do modelo reduzido VI-B 


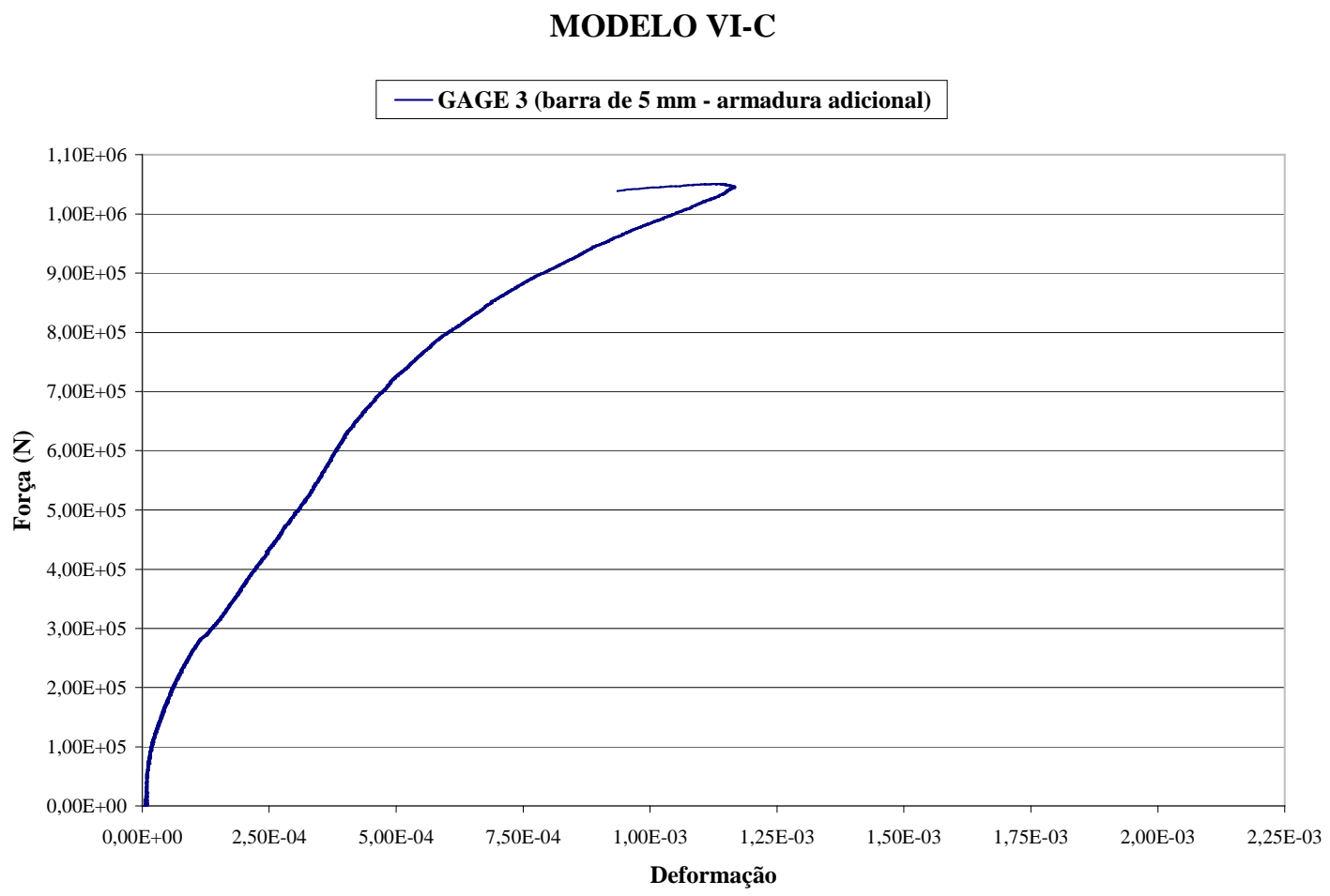

Gráfico 8.3 Força x deformação da armadura adicional $(\phi 5 \mathrm{~mm})$ do modelo reduzido VI-C

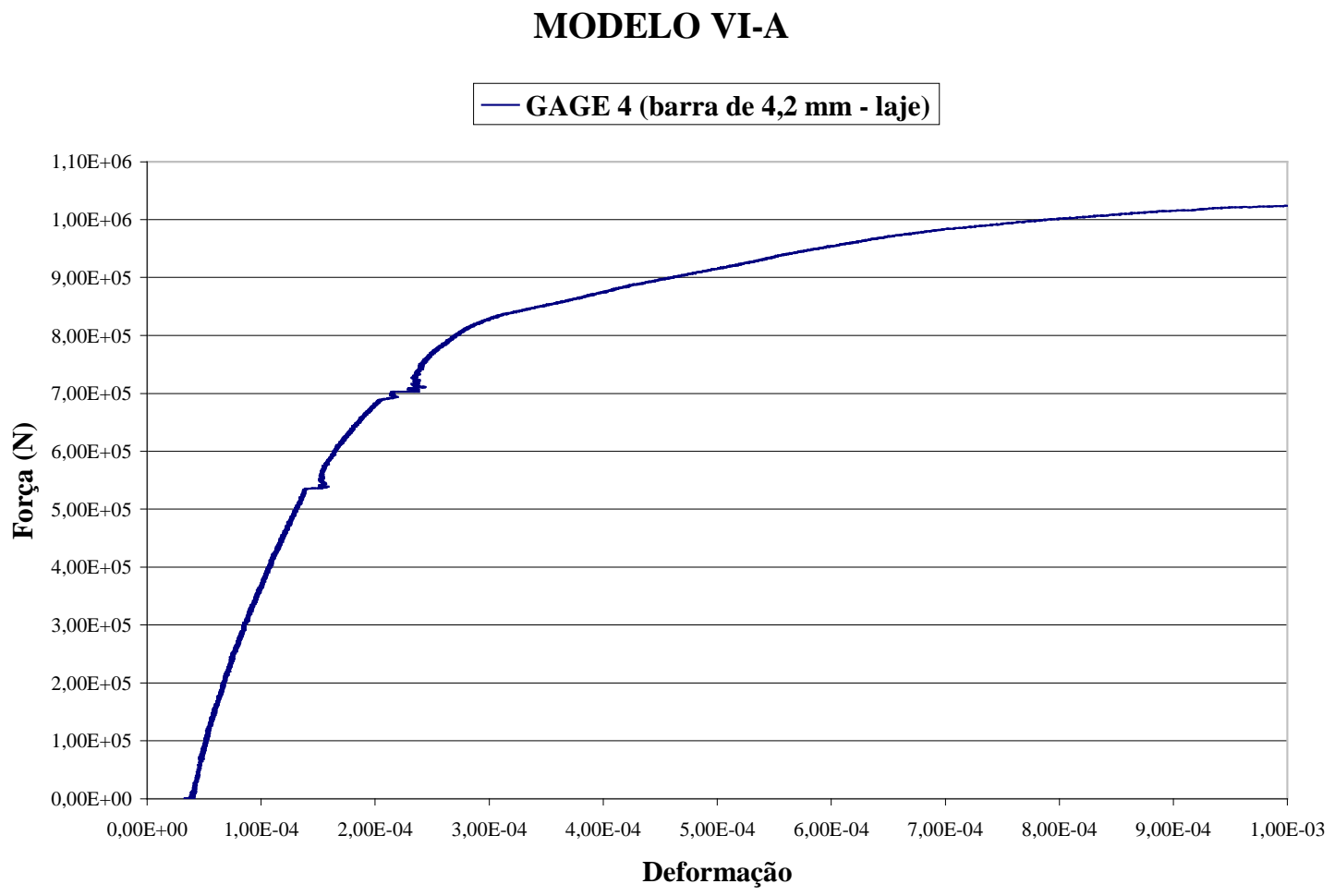

Gráfico 8.4 Força x deformação da armadura da laje $(\phi 4,2 \mathrm{~mm})$ do modelo reduzido VI-A 


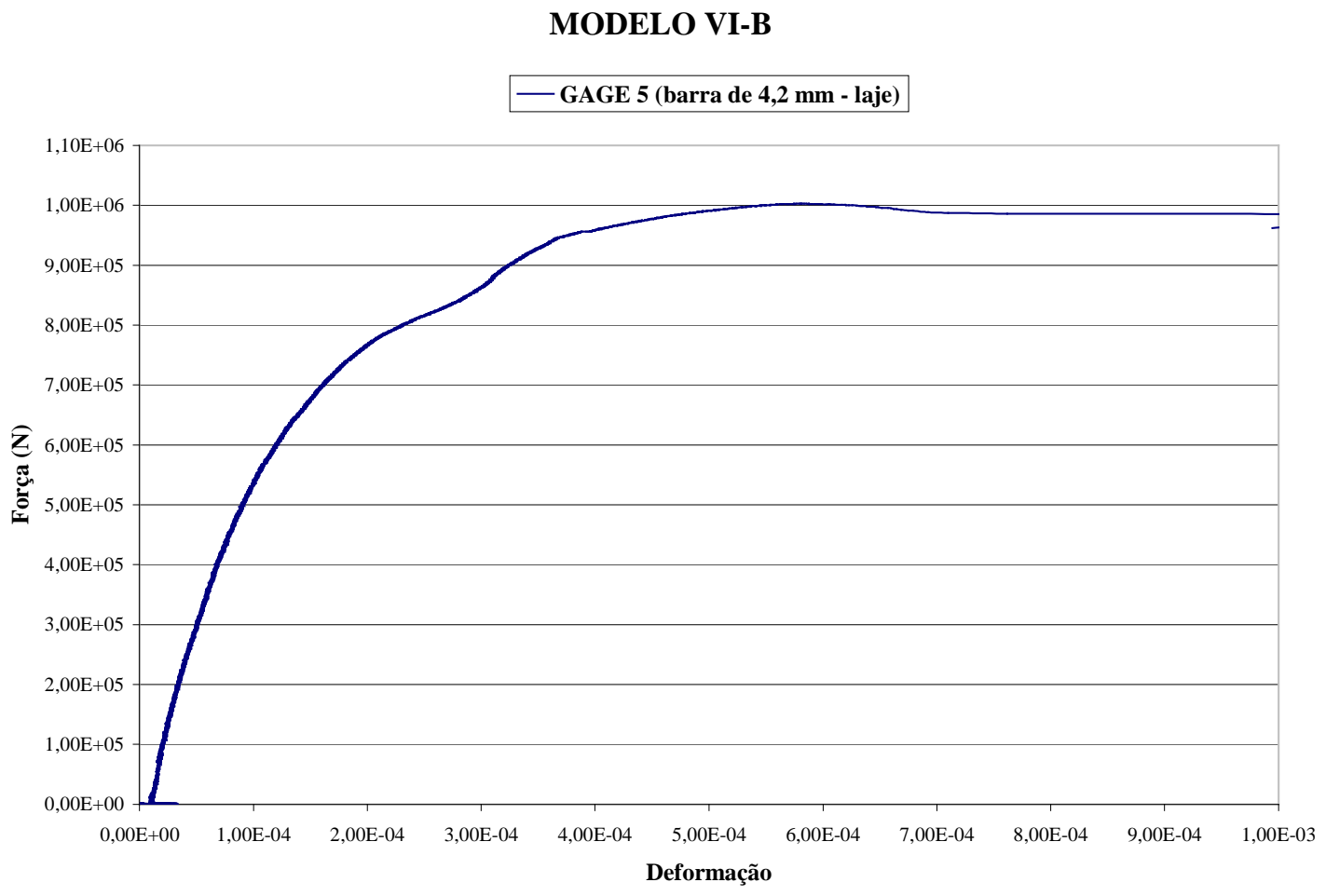

Gráfico 8.5 Força x deformação da armadura da laje $(\phi 4,2 \mathrm{~mm})$ do modelo reduzido VI-B

\section{MODELO VI-C}

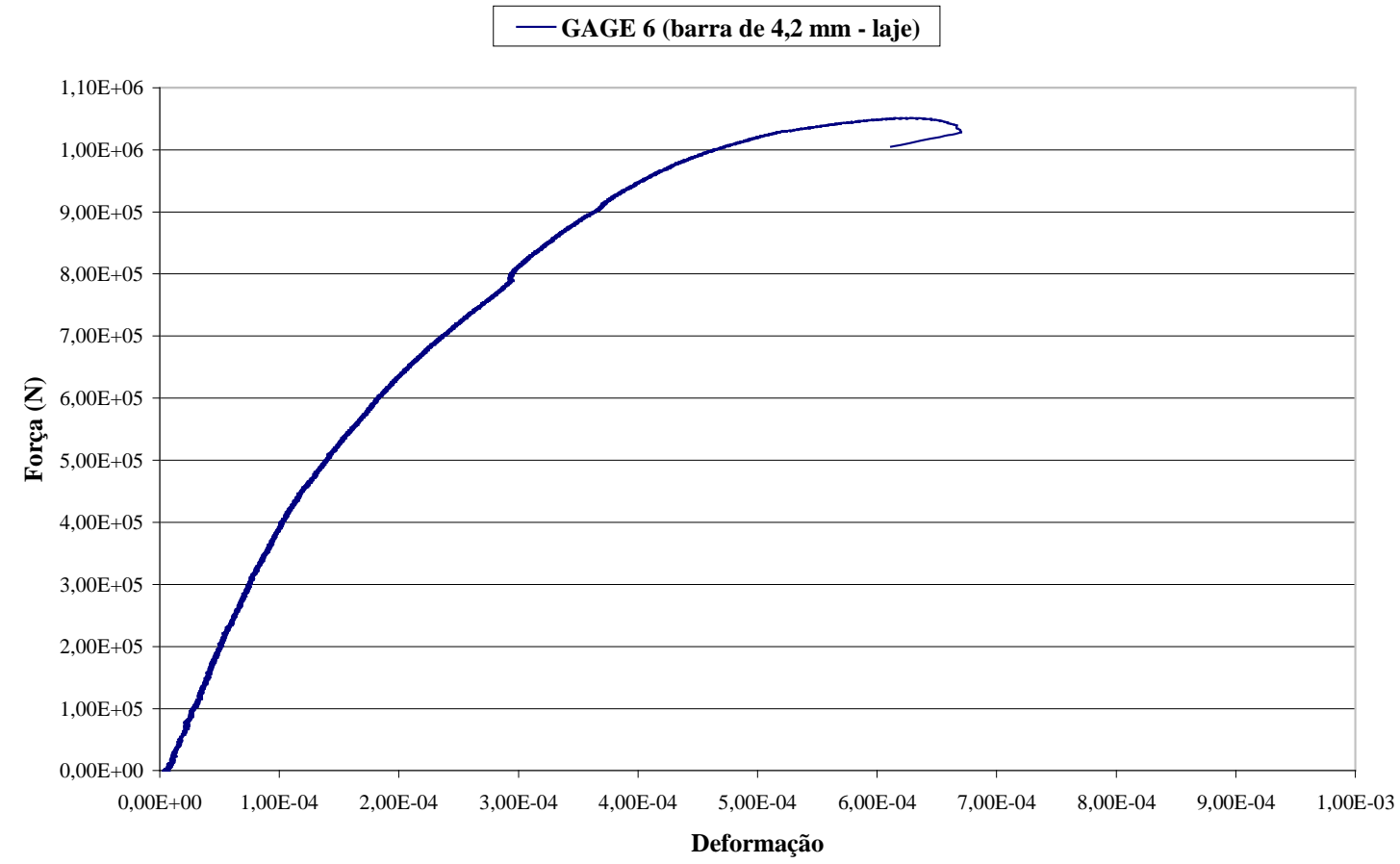

Gráfico 8.6 Força x deformação da armadura da laje $(\phi 4,2 \mathrm{~mm})$ do modelo reduzido VI-C 


\subsubsection{Resultados dos ensaios para o modelo reduzido VII}

Para o modelo reduzido VII utilizou-se uma armadura complementar correspondente a 1/3 da armadura do modelo reduzido VI. Os resultados dos ensaios deste modelo estão na tabela 8.10 , figura 8.10 e gráficos 8.7 a 8.12 . A tabela 8.11 apresenta um resumo dos resultados de todos os ensaios da segunda etapa desta pesquisa.

Tabela 8.10 Ensaio de compressão axial para o modelo reduzido VII

\begin{tabular}{|c|c|c|}
\hline \multicolumn{3}{|c|}{ MODELO REDUZIDO VII } \\
\hline \multicolumn{2}{|c|}{$\mathrm{f}_{\text {clm28 }}=38,60 \mathrm{MPa}$} & $\mathrm{f}_{\text {cpm28 }}=54,11 \mathrm{MPa}$ \\
\hline EXEMPLAR & $\begin{array}{c}\mathrm{F}_{\text {RUPTURA }} \\
(\mathrm{kN})\end{array}$ & $\begin{array}{c}\text { RESISTÊNCIA À } \\
\text { COMPRESSÃO } \\
(\mathrm{MPa})\end{array}$ \\
\hline MVII-A & 1029 & 45,73 \\
\hline MVII-B & 995 & 44,22 \\
\hline MVII-C & 1046 & 46,49 \\
\hline \multicolumn{3}{|c|}{$\mathrm{f}_{\text {cefm }}=$} \\
\hline
\end{tabular}

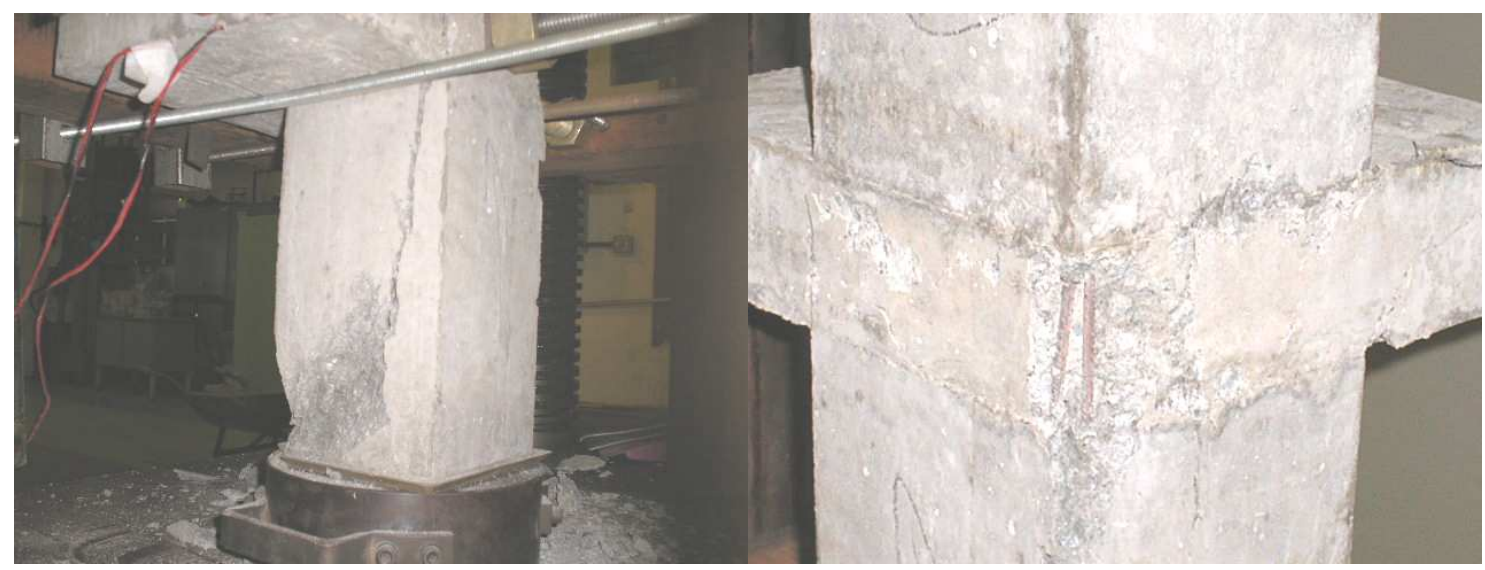

Figura 8.10 Modelo reduzido VII-C rompido 


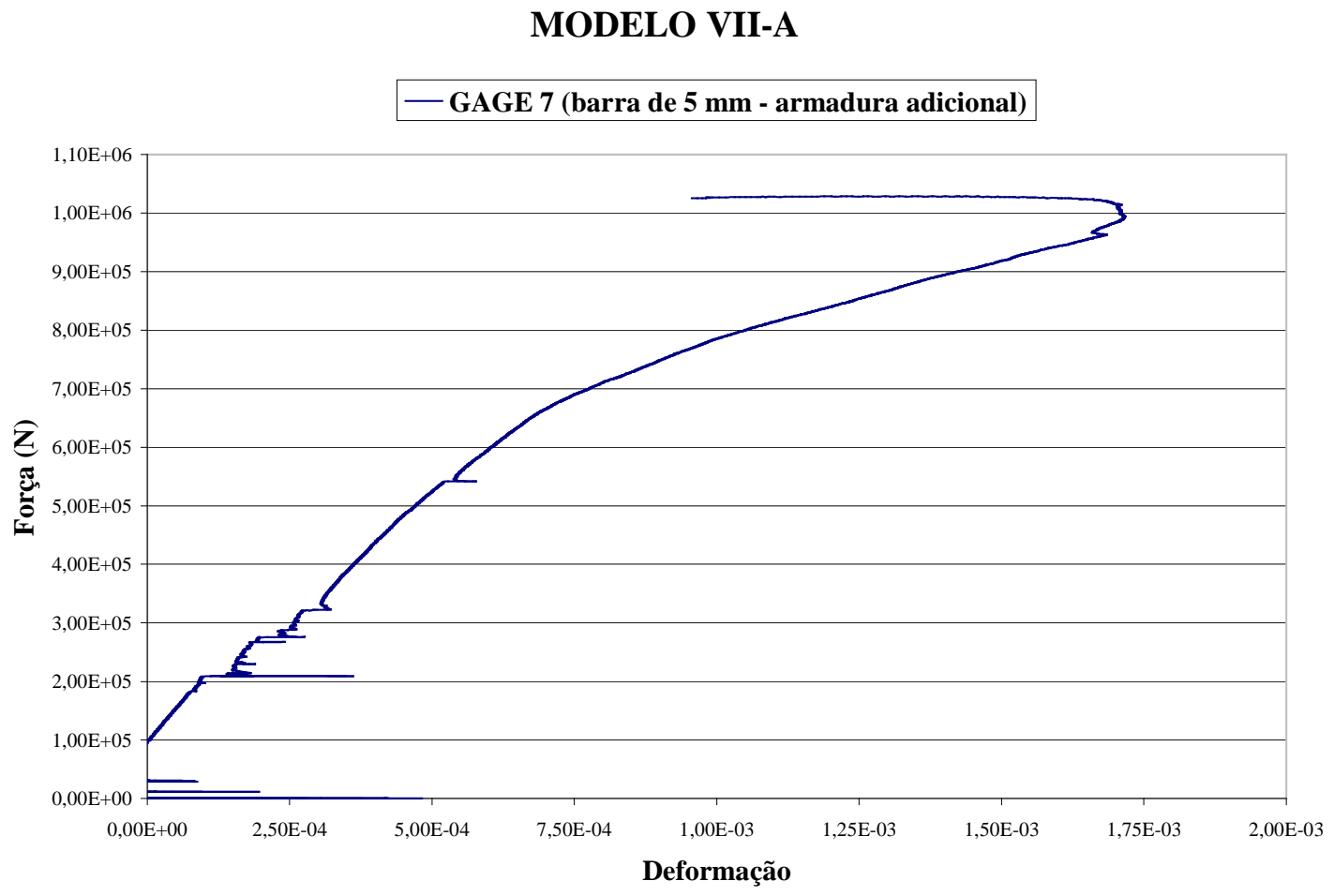

Gráfico 8.7 Força x deformação da armadura de reforço ( $\phi 5 \mathrm{~mm})$ do modelo reduzido VII-A

MODELO VII-B

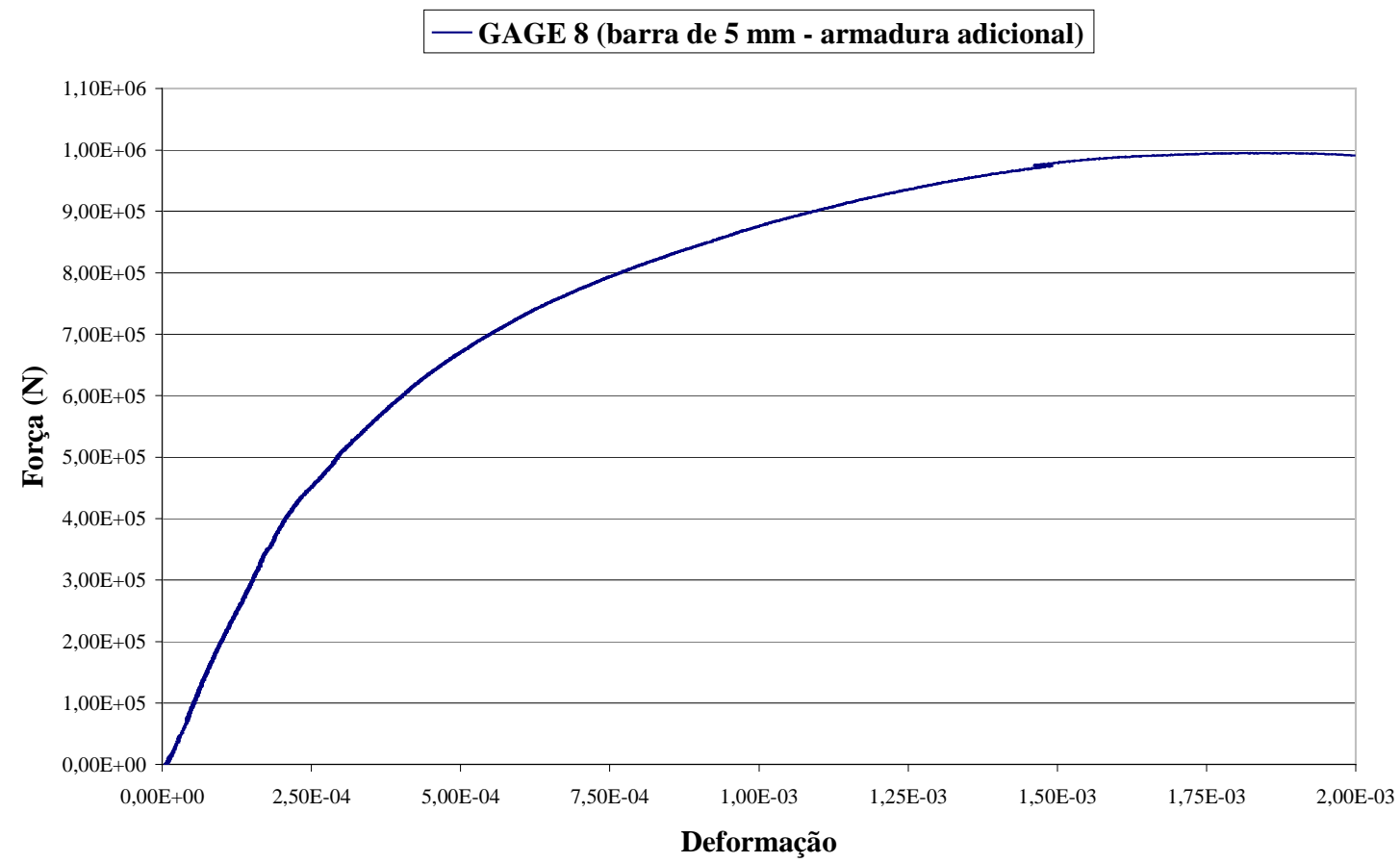

Gráfico 8.8 Força x deformação da armadura de reforço $(\phi 5 \mathrm{~mm})$ do modelo reduzido VII-B 


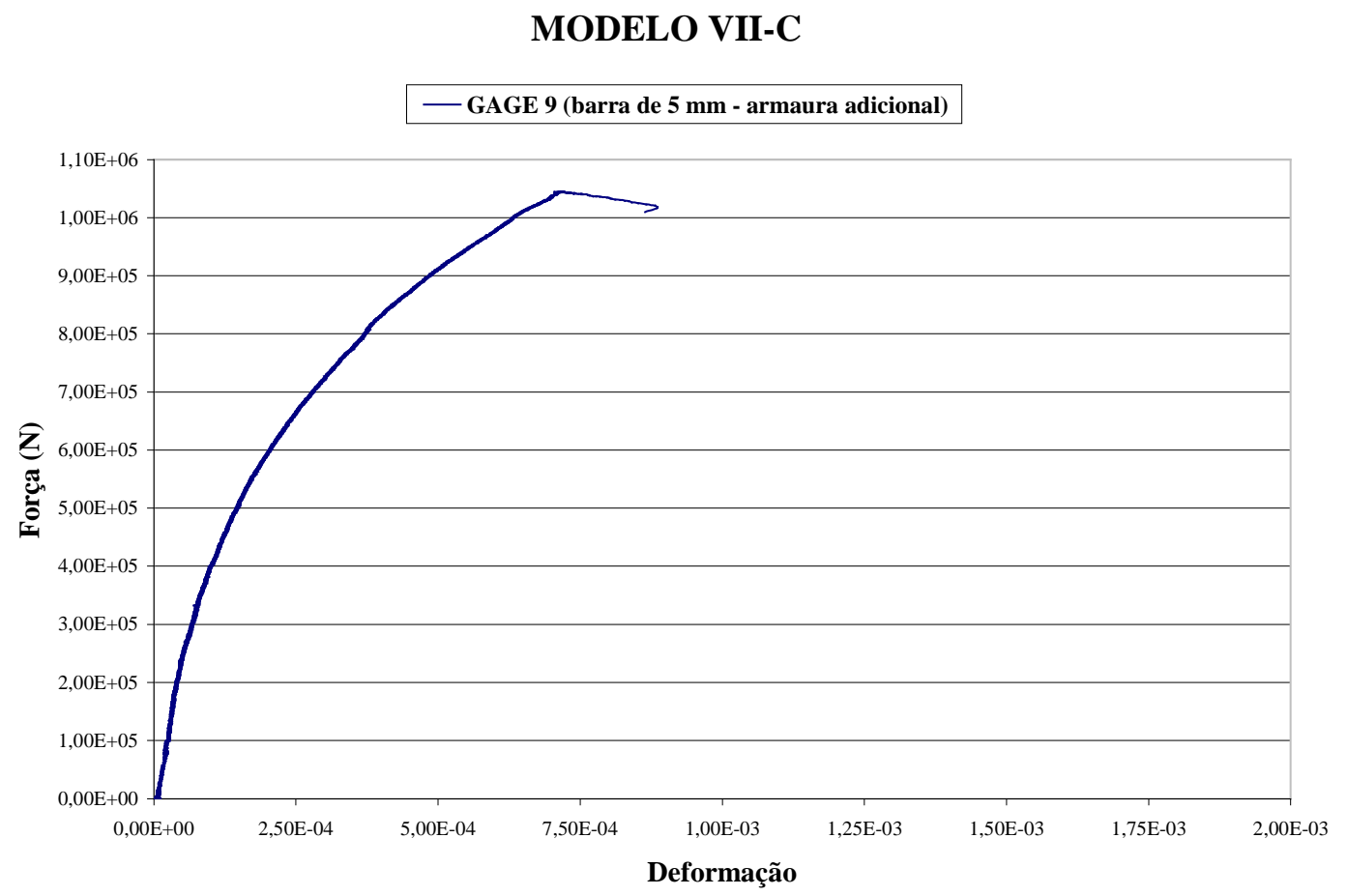

Gráfico 8.9 Força x deformação da armadura de reforço $(\phi 5 \mathrm{~mm})$ do modelo reduzido VII-C

MODELO VII-A

- GAGE 10 (barra de 4,2 mm - laje)

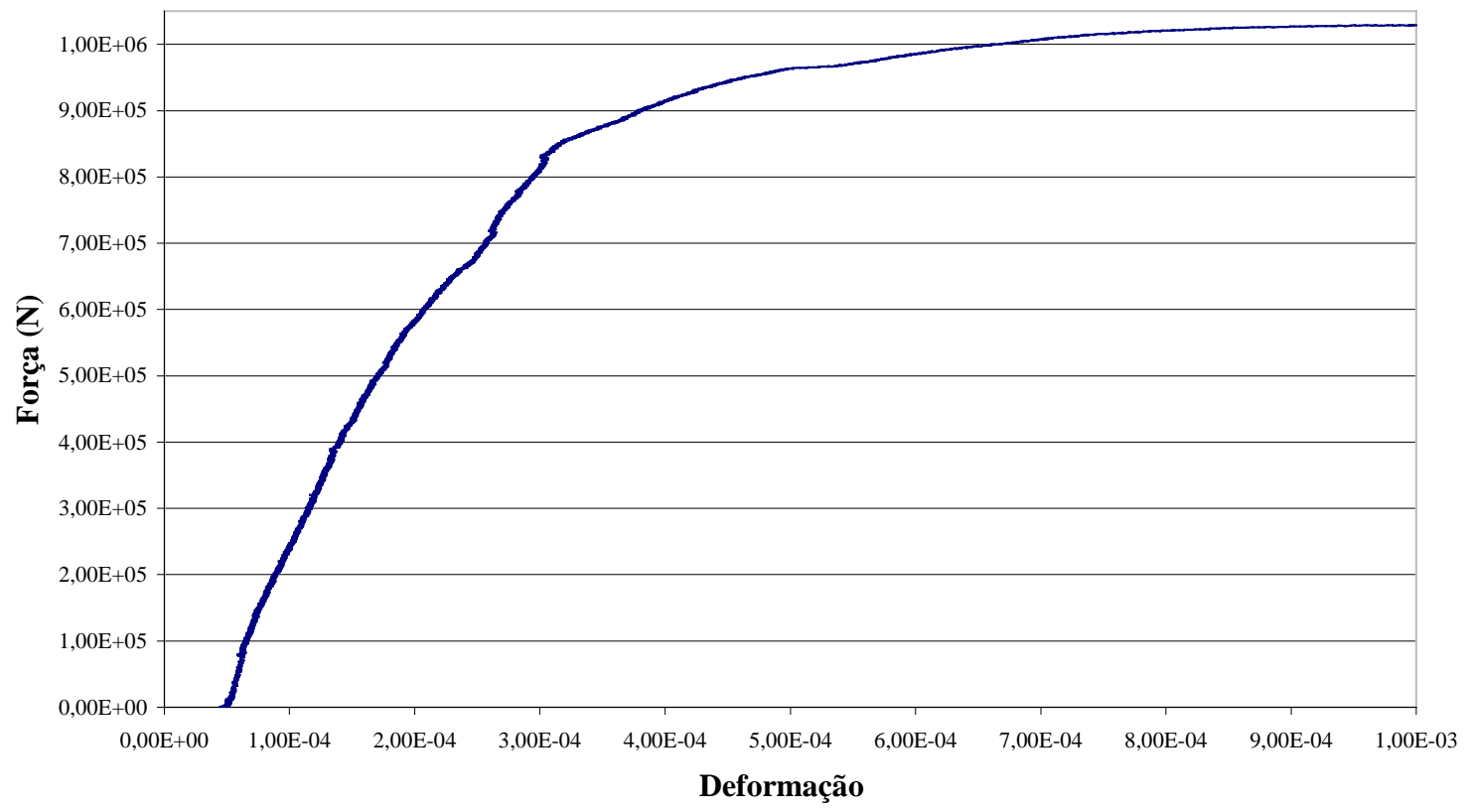

Gráfico 8.10 Força $x$ deformação da armadura da laje $(\phi 4,2 \mathrm{~mm})$ do modelo reduzido VII-A 


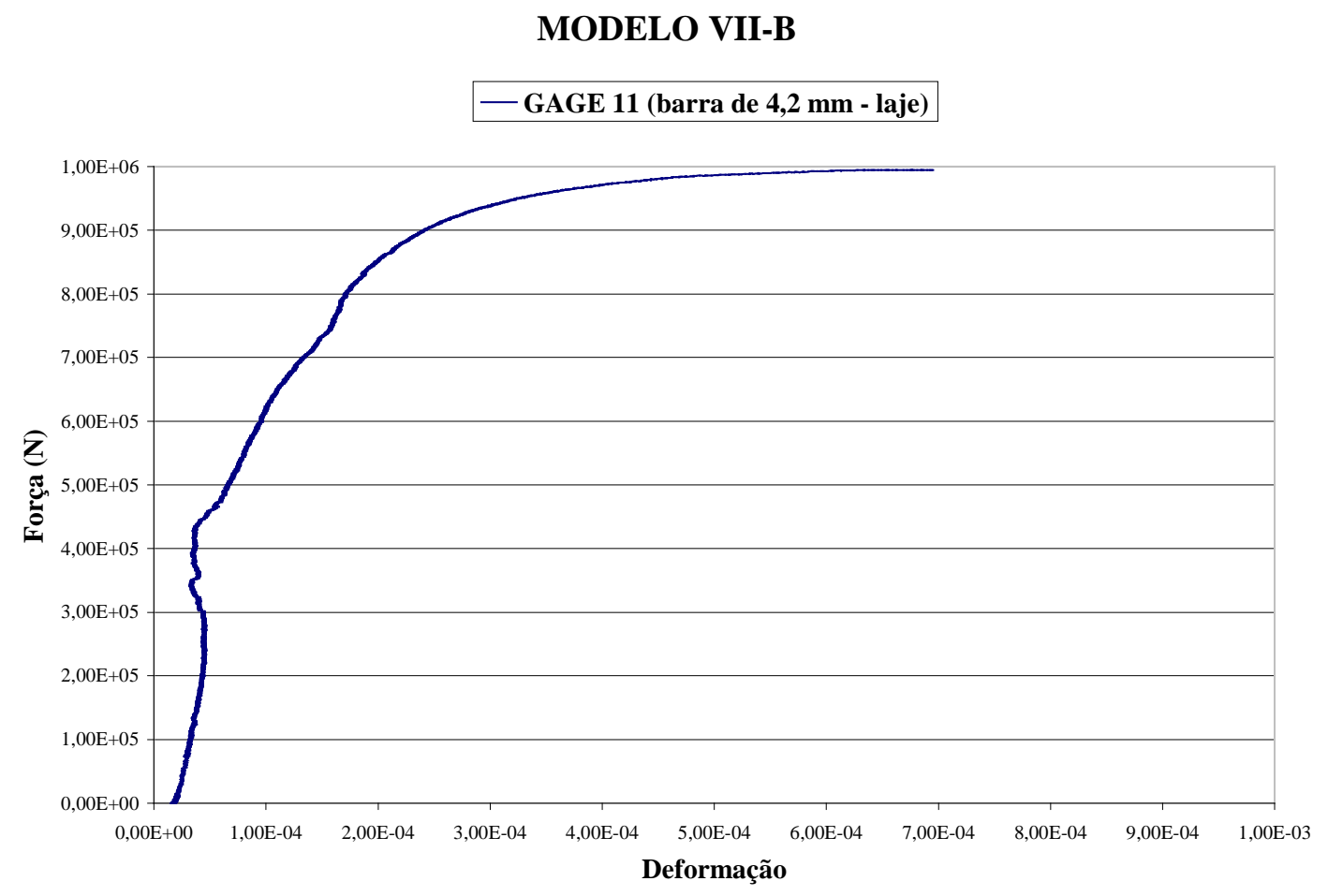

Gráfico 8.11 Força x deformação da armadura da laje ( $\phi$ 4,2 mm) do modelo reduzido VII-B

MODELO VII-C

GAGE 12 (barra de 4,2 mm - laje)

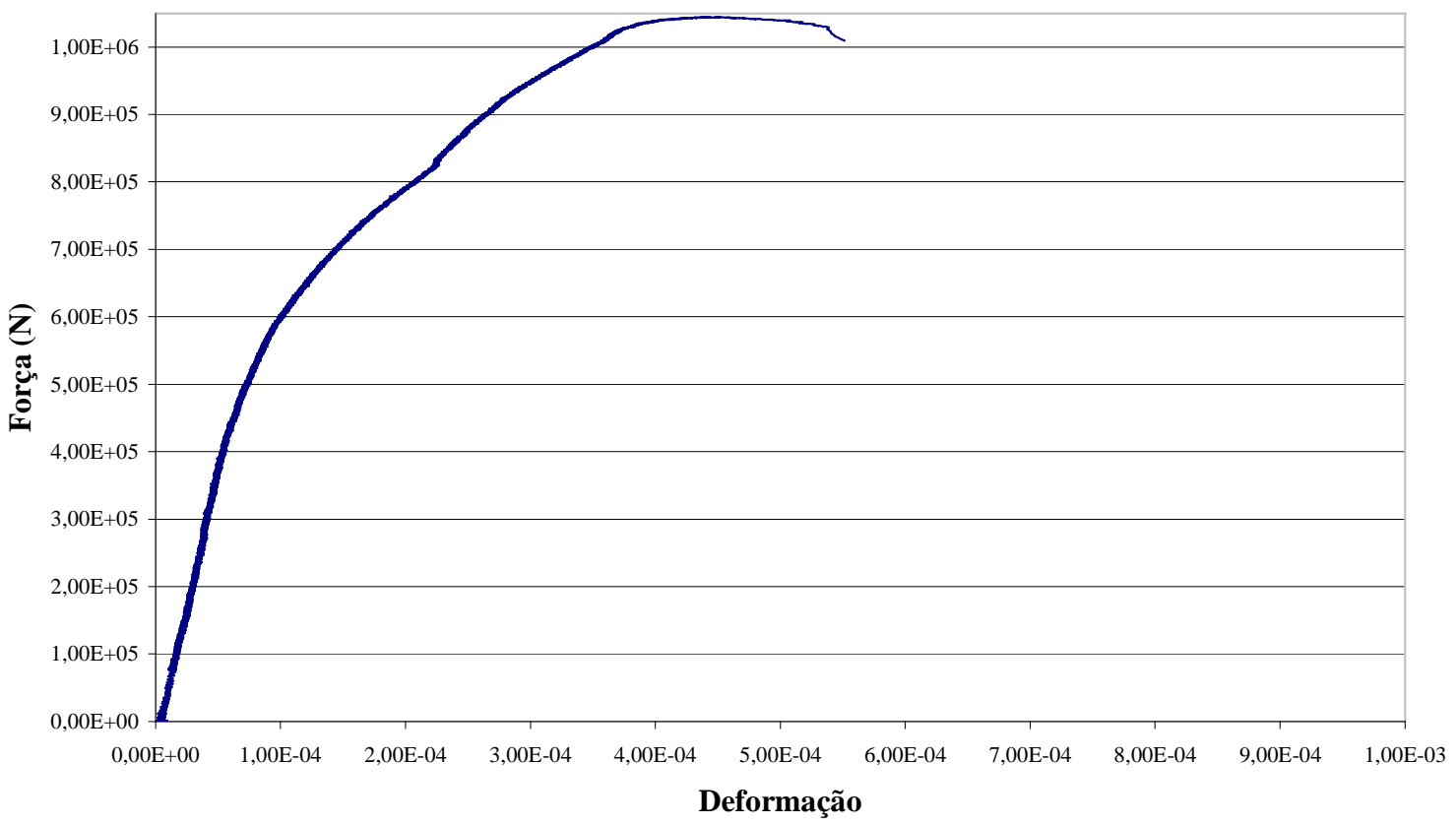

Gráfico 8.12 Força x deformação da armadura da laje ( $\phi$ 4,2 mm) do modelo reduzido VII-C 
Tabela 8.11 Resultados da etapa

\begin{tabular}{|c|c|c|c|c|c|c|c|c|c|c|c|c|c|}
\hline \multirow{3}{*}{ MODELO } & \multirow{3}{*}{ DESCRIÇÃO } & \multicolumn{3}{|c|}{ GEOMETRIA } & \multicolumn{4}{|c|}{ CONCRETO } & \multirow{2}{*}{\multicolumn{2}{|c|}{$\begin{array}{c}\text { RESISTÊNCIA DO } \\
\text { CONJUNTO À } \\
\text { COMPRESSÃO }\end{array}$}} & \multirow{2}{*}{$\begin{array}{l}\text { RESISTÊNCIA } \\
\text { MÉDIA DO } \\
\text { CONJUNTO À } \\
\text { COMPRESSÃO }\end{array}$} & \multirow{2}{*}{$\begin{array}{c}\text { PERDADE } \\
\text { RESISTÊNCIA } \\
\text { EM REL. À } \\
\text { MÉDIA DE } \\
\text { RESIS. DO } \\
\text { CONC. DO } \\
\text { PILAR } \\
\end{array}$} & \multirow{2}{*}{$\begin{array}{c}\text { GANHO DE } \\
\text { RESISTÊNCIA } \\
\text { EM REL. À } \\
\text { RESIS. DO } \\
\text { CONC. DA LAJE }\end{array}$} \\
\hline & & \multicolumn{2}{|c|}{ FORMA } & \multirow[t]{2}{*}{ ARMAÇÃO } & \multicolumn{2}{|c|}{$\mathrm{f}_{\mathrm{cm}, 28}$} & $\mathrm{f}_{\mathrm{cpm}}$ & \multirow{2}{*}{$\mathrm{f}_{\mathrm{cpm}} / \mathrm{f}_{\mathrm{cl}}$} & & & & & \\
\hline & & & $\mathrm{cm}$ & & & $\mathrm{MPa}$ & MPa & & EXEMPLAR & $\mathrm{MPa}$ & $\mathrm{MPa}$ & $\%$ & $\%$ \\
\hline \multirow{4}{*}{ M I } & \multirow{4}{*}{ PILAR ISOLADO } & \multirow{2}{*}{\multicolumn{2}{|c|}{$\mathrm{h}=65$}} & \multirow{4}{*}{0} & \multirow{2}{*}{\multicolumn{2}{|c|}{51,70}} & & \multirow[t]{2}{*}{ _ } & $\mathrm{A}$ & 46,27 & 47.72 & 7.71 & - \\
\hline & & & & & & & & & $\mathrm{B}$ & 49,16 & & & \\
\hline & & \multirow{2}{*}{\multicolumn{2}{|c|}{$15 \times 15$}} & & \multirow{2}{*}{\multicolumn{2}{|c|}{55,93}} & & \multirow{2}{*}{ - } & $\mathrm{C}$ & 52,04 & \multirow{2}{*}{52,67} & \multirow{2}{*}{5,84} & \multirow{2}{*}{-} \\
\hline & & & & & & & & & $\mathrm{D}$ & 53,29 & & & \\
\hline \multirow{3}{*}{ M II } & \multirow{3}{*}{$\begin{array}{l}\text { PILAR ISOLADO } \\
\text { COM FAIXA } \\
\text { REPRES. LAJE }\end{array}$} & $\mathrm{P}$ & $\mathrm{h}=65$ & \multirow{3}{*}{0} & $\mathrm{P}$ & 52,40 & \multirow{3}{*}{52,40} & \multirow{3}{*}{1,71} & $\mathrm{~A}$ & 36,62 & & & \\
\hline & & & $15 \times 15$ & & $\mathrm{~L}$ & 30,37 & & & $\mathrm{~B}$ & 37,42 & 37,81 & 27,84 & 24,50 \\
\hline & & $\mathrm{L}$ & $\mathrm{h}=4,5$ & & $\mathrm{P}$ & 52,40 & & & $\mathrm{C}$ & 39,38 & & & \\
\hline & PILAR CENTRAL & $P$ & $\mathrm{~h}=65$ & & $\mathrm{P}$ & 52,40 & & & $\mathrm{~A}$ & 48,71 & & & \\
\hline M IV & COM LAJE DE & & $15 \times 15$ & 0 & $\mathrm{~L}$ & 35,32 & 53,77 & 1,52 & $\mathrm{~B}$ & 45,69 & 47,91 & 10,90 & 35,65 \\
\hline & $40 x 40 \mathrm{~cm}$ & $\mathrm{~L}$ & $\mathrm{~h}=4,5$ & & $\mathrm{P}$ & 55,14 & & & $\mathrm{C}$ & 49,33 & & & \\
\hline & PILAR DE CANTO & $\mathrm{P}$ & $\mathrm{h}=65$ & & $\mathrm{P}$ & 51,70 & & & $\overline{\mathrm{A}}$ & 48,36 & & & \\
\hline $\begin{array}{c}\text { M V } \\
\text { áć }\end{array}$ & COM LAJE DE & $\mathrm{P}$ & $15 \times 15$ & 0 & $\mathrm{~L}$ & 43,34 & 53,82 & 1,24 & $\mathrm{~B}$ & 46,93 & 47,85 & 11,08 & 10,41 \\
\hline & $27,5 \times 27,5 \mathrm{~cm}$ & $\mathrm{~L}$ & $\mathrm{~h}=7,0$ & & $\mathrm{P}$ & 55,93 & & & $\mathrm{C}$ & 48,27 & & & \\
\hline & PILAR DE CANTO & $P$ & $\mathrm{~h}=65$ & & $\mathrm{P}$ & 60,58 & & & $\bar{D}$ & 37,47 & & & \\
\hline $\begin{array}{c}\text { M V } \\
\rho^{\text {a }} \text { SÉPIE }\end{array}$ & COM LAJE DE & $\mathrm{P}$ & $15 \times 15$ & 0 & $\mathrm{~L}$ & 32,67 & 60,58 & 1,85 & $E$ & 38,09 & 37,53 & 38,05 & 14,87 \\
\hline & $27,5 \times 27,5 \mathrm{~cm}$ & $\mathrm{~L}$ & $\mathrm{~h}=7,0$ & & $\mathrm{P}$ & 60,58 & & & $\mathrm{~F}$ & 37,02 & & & \\
\hline & PILAR DE CANTO & $P$ & $\mathrm{~h}=65$ & 0 & $\mathrm{P}$ & 53,68 & & & $\bar{A}$ & 45,56 & & & \\
\hline M VI & COM LAJE DE & $P$ & $15 \times 15$ & 0 & $\mathrm{~L}$ & 36,99 & 52,41 & 1,42 & $\mathrm{~B}$ & 44,58 & 45,63 & 12,93 & 23,36 \\
\hline & $27,5 \times 27,5 \mathrm{~cm}$ & $\mathrm{~L}$ & $\mathrm{~h}=7,0$ & $9 \times \phi 5 \mathrm{~mm}$ & $\mathrm{P}$ & 51,13 & & & $\mathrm{C}$ & 46,75 & & & \\
\hline & PILAR DE CANTO & $P$ & $\mathrm{~h}=65$ & I 12. & $\mathrm{P}$ & 56,67 & & & $\bar{A}$ & 45,73 & & & \\
\hline M VII & COM LAJE DE & $P$ & $15 \times 15$ & 0 & $\mathrm{~L}$ & 38,60 & 54,11 & 1,40 & $\bar{B}$ & 44,22 & 45,48 & 15,94 & 17,82 \\
\hline & $27,5 \times 27,5 \mathrm{~cm}$ & $\mathrm{~L}$ & $\mathrm{~h}=7,0$ & $3 \times \phi 5 \mathrm{~mm}$ & $\mathrm{P}$ & 51,54 & & & $\mathrm{C}$ & 46,49 & & & \\
\hline
\end{tabular}




\section{RESULTADOS DOS MODELOS CALCULADOS PELO MÉTODO DOS ELEMENTOS FINITOS}

Ao se modelar o pilar central com concreto de resistência característica à compressão $50 \mathrm{MPa}$ com laje de espessura de $4,5 \mathrm{~cm}$ e concreto de resistência característica à compressão $35 \mathrm{MPa}$ em um programa que utiliza o método dos elementos finitos, neste caso o programa ADINA, obteve-se os resultados apresentados a seguir. A figura 9.1 mostra o esquema de carregamento de pilares centrais e de canto. Cada caso tem um valor diferente de carregamento citado conforme a apresentação de cada um. As demais figuras mostram a região da laje e o trecho do pilar contido na espessura equivalente à laje somente, que é a região onde a distribuição de tensões é interessante ser observada para a análise em questão.
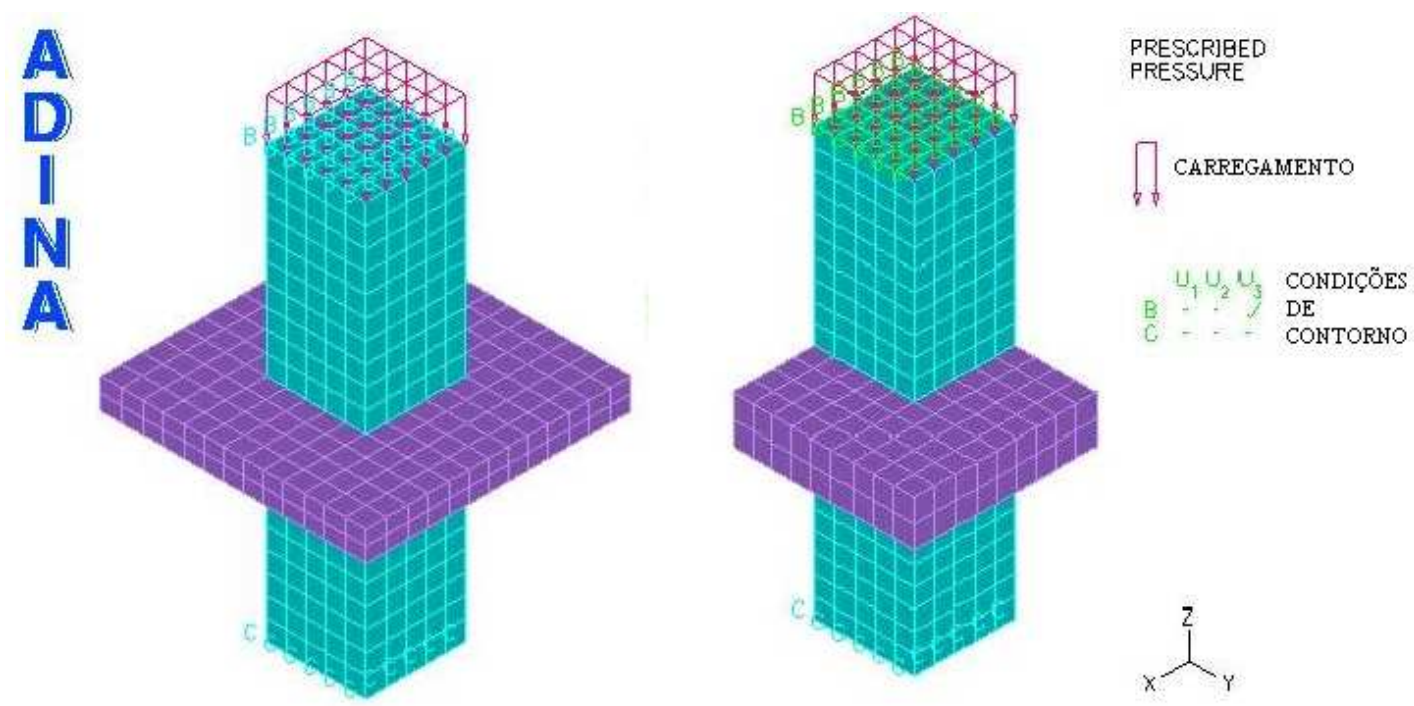

Figura 9.1 Esquema geral dos modelos com laje estudados pelo método dos elementos finitos 


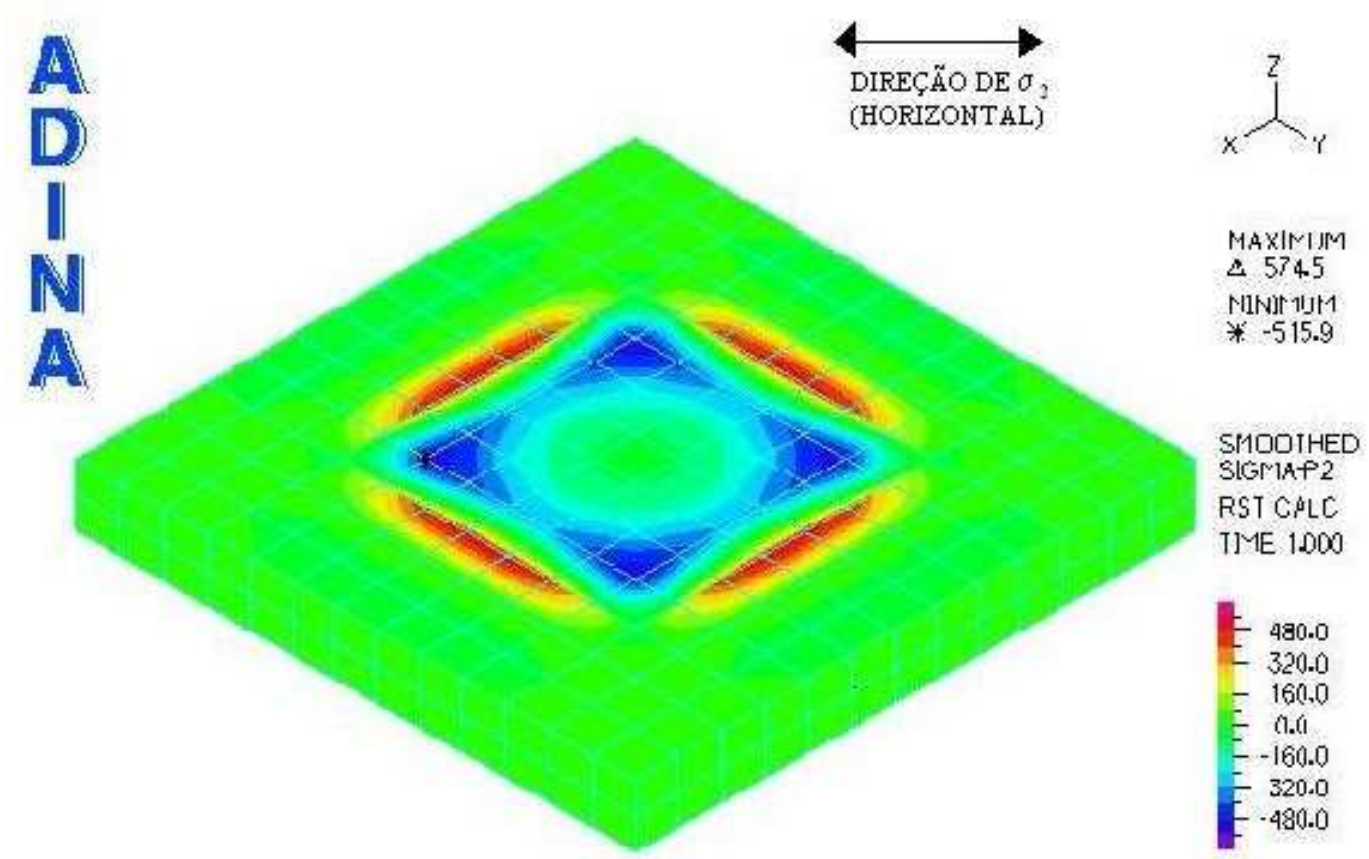

Figura 9.2 Tensões $\sigma_{2}$ na laje do modelo reduzido IV (pilar central com laje de 4,5 cm de espessura) com tensão axial aplicada de 47,91 MPa (tensões em tf/m²)
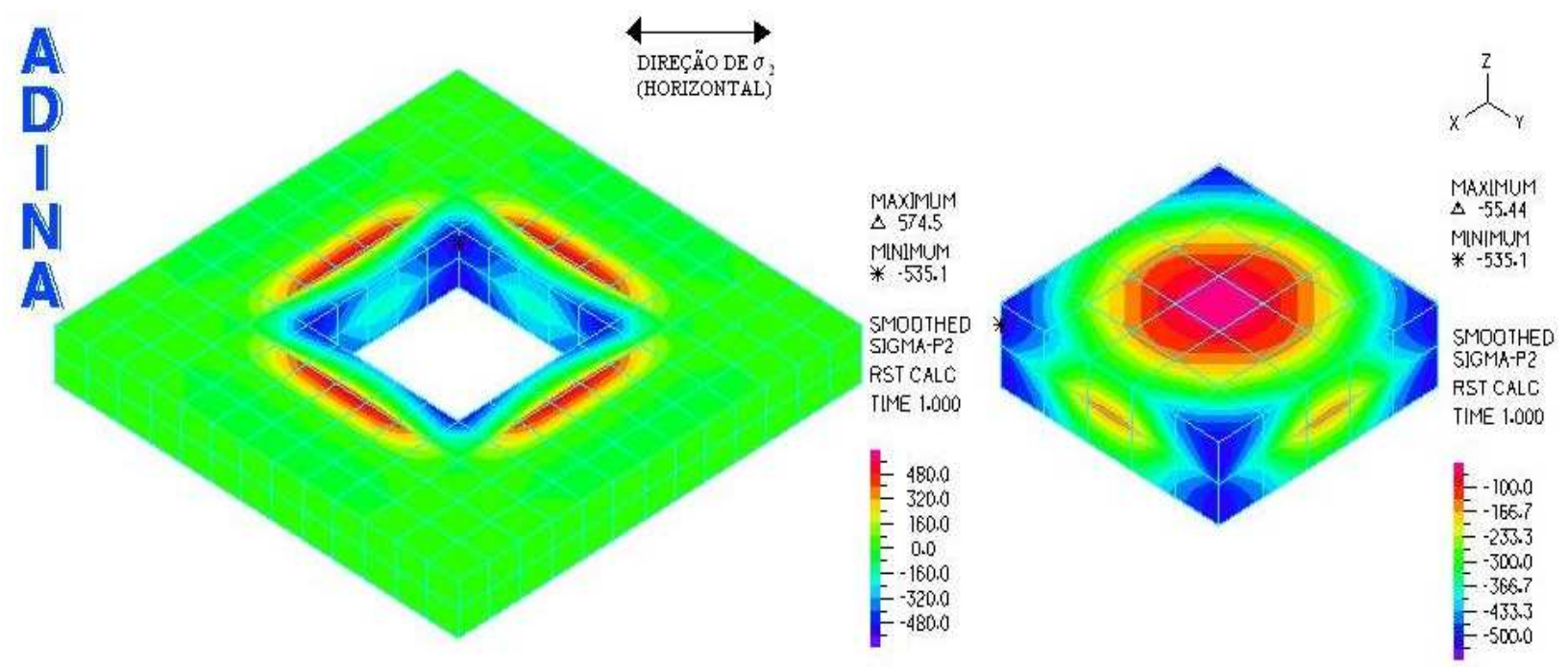

Figura 9.3 Recorte do trecho confinado do pilar contido na laje (tensões em tf/m²) 


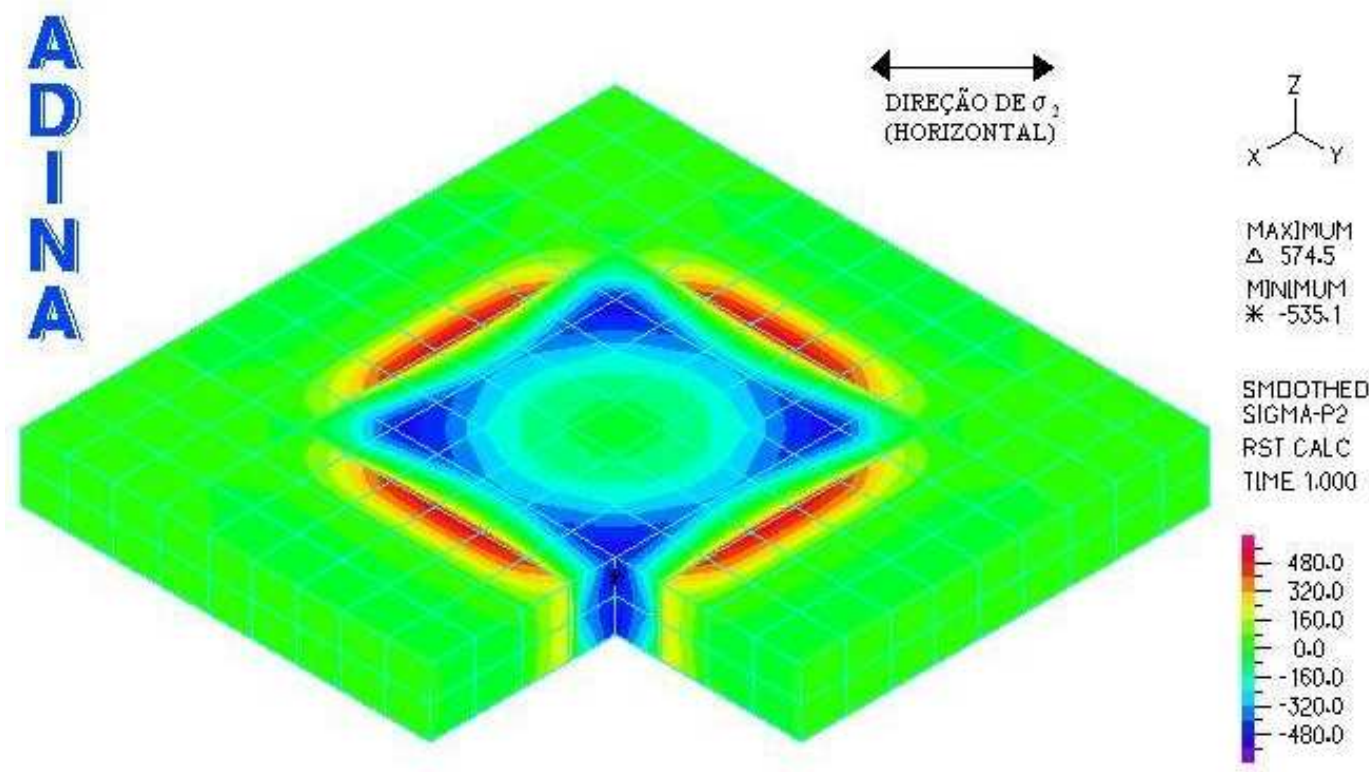

Figura 9.4 Recorte na laje para visualização das tensões próximas ao trecho confinado (tensões em tf//m²)

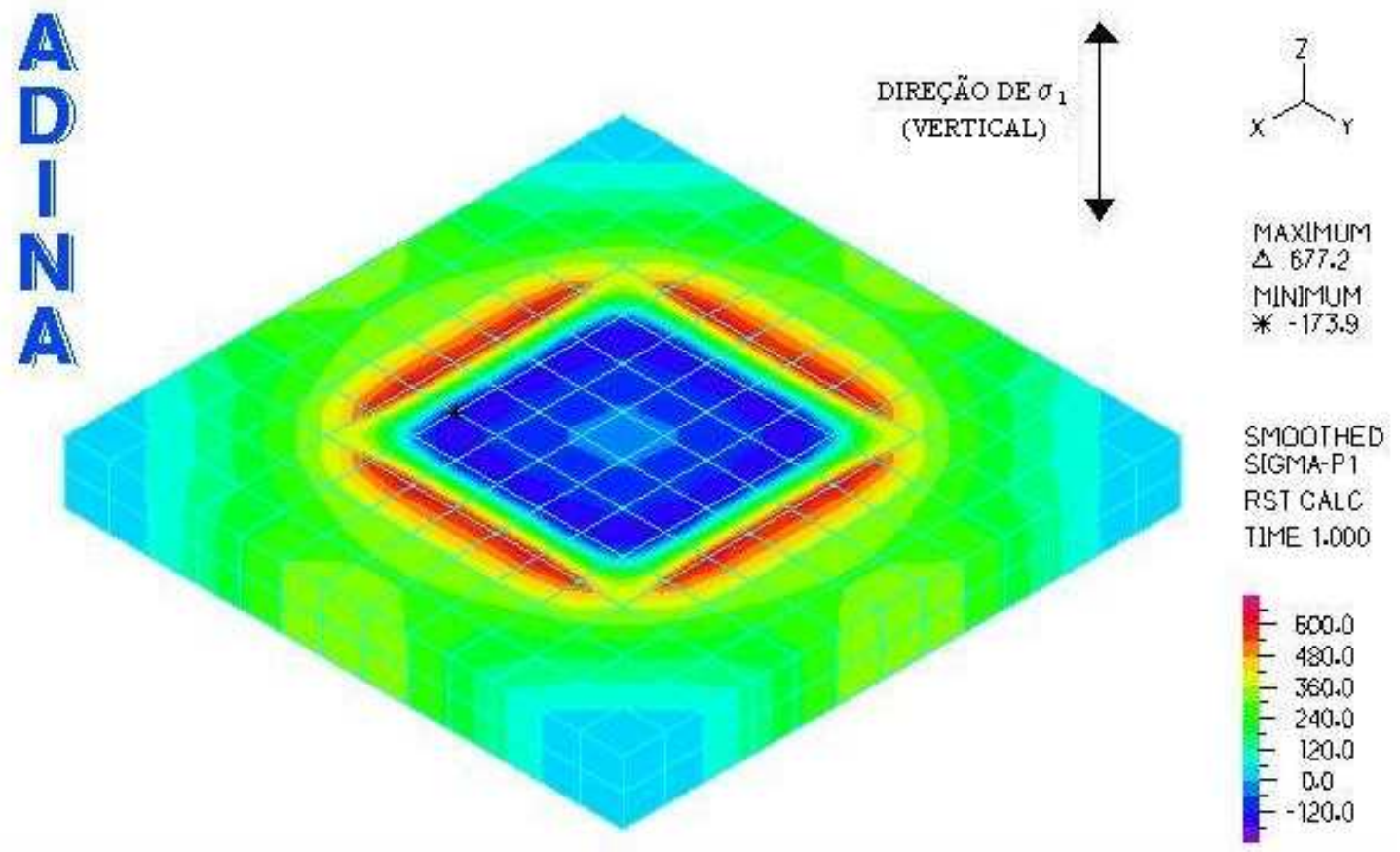

Figura 9.5 Tensões $\sigma_{1}$ na laje do modelo reduzido IV (pilar central com laje de 4,5 cm de espessura) com tensão axial aplicada de 47,91 MPa (tensões em tf $/ \mathrm{m}^{2}$ ) 

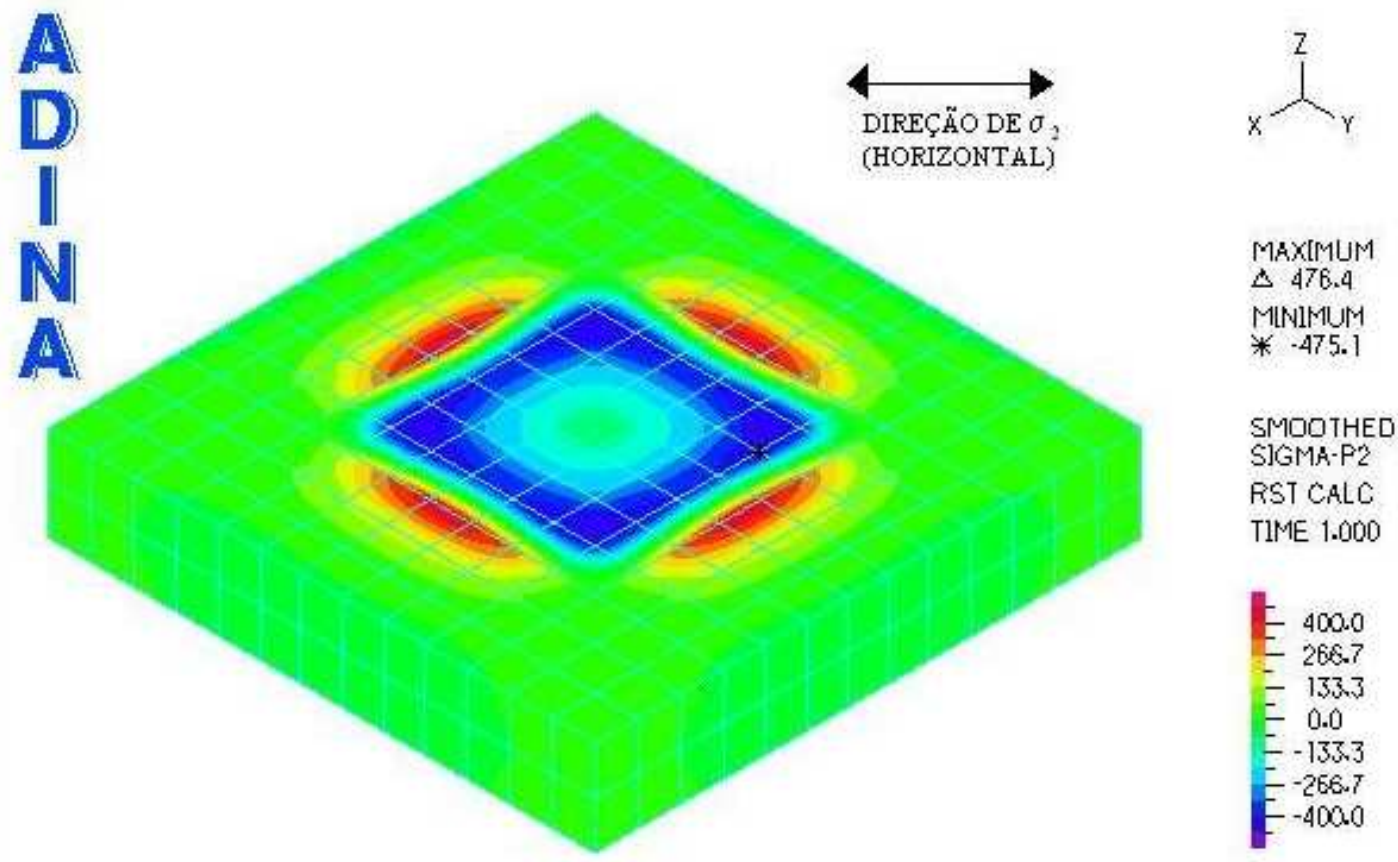

Figura 9.6 Tensões $\sigma_{2}$ na laje do modelo reduzido representando pilar central com laje de $7 \mathrm{~cm}$ de espessura com tensão axial aplicada de 49,20 MPa (tensões em tf/m Silveira dos Santos)

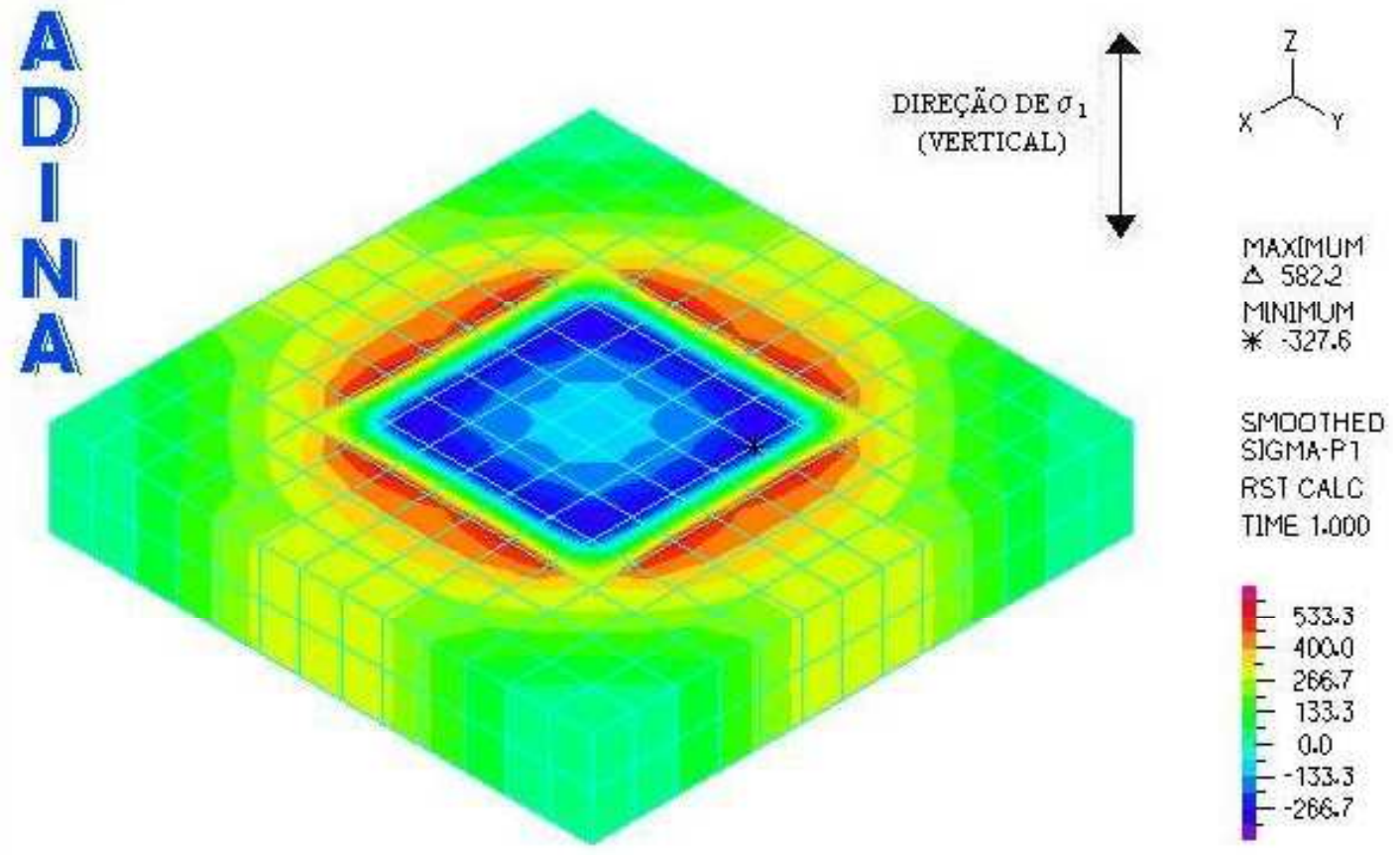

Figura 9.7 Tensões $\sigma_{1}$ na laje do modelo reduzido representando pilar central com laje de $7 \mathrm{~cm}$ de espessura com tensão axial aplicada de 49,20 MPa (tensões em tf/m Silveira dos Santos) 
$\mathrm{O}$ modelo reduzido $\mathrm{V}$, que representa um pilar de canto também foi modelado pelo método dos elementos finitos e apresentou os resultados que seguem.
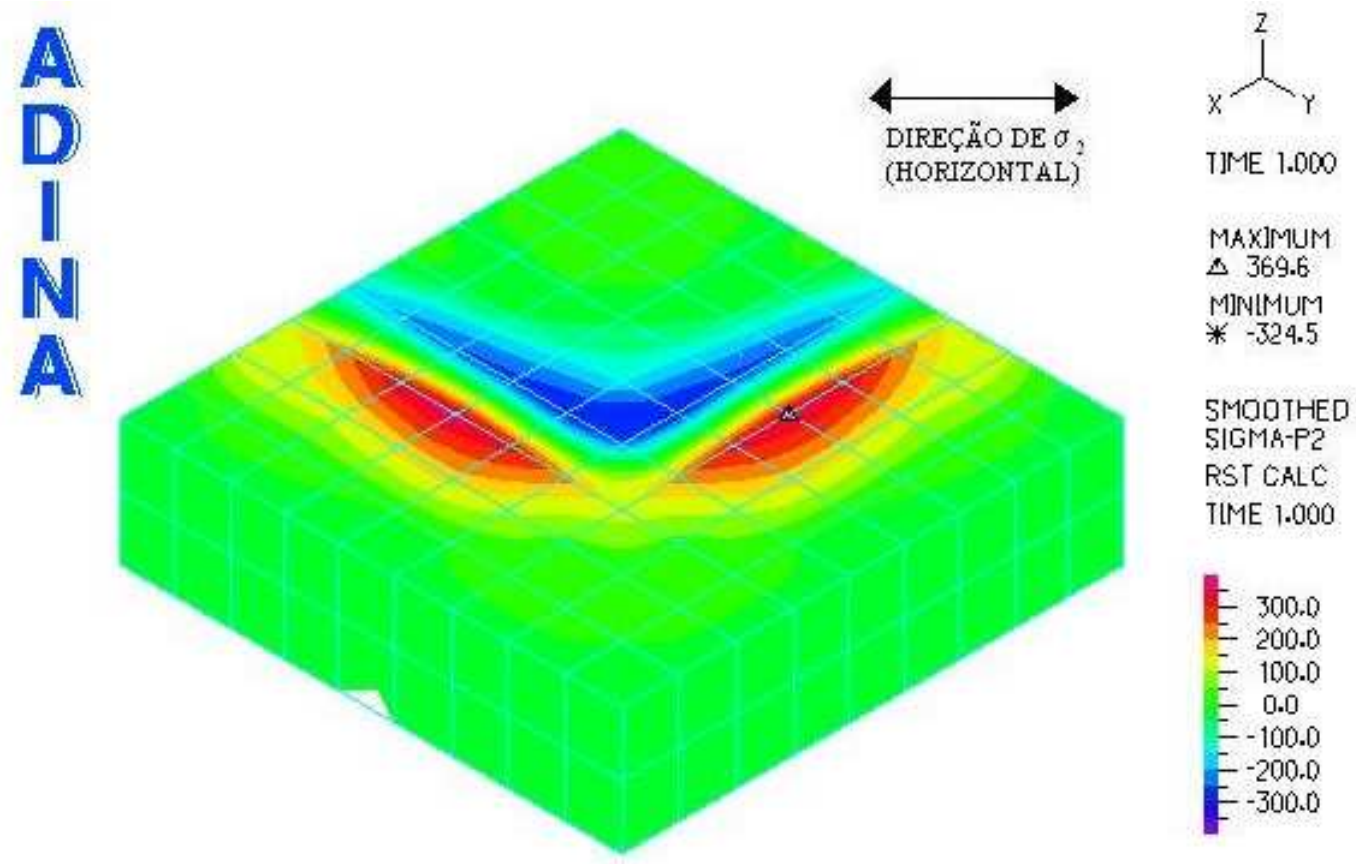

Figura 9.8. Tensões $\sigma_{2}$ na laje da $1^{a}$ série de exemplares do modelo reduzido $\mathrm{V}$ (pilar de canto com laje de $7 \mathrm{~cm}$ de espessura, exemplares V-A, V-B e V-C) com tensão axial aplicada de 47,85 MPa (tensões em $\mathrm{tf} / \mathrm{m}^{2}$ )

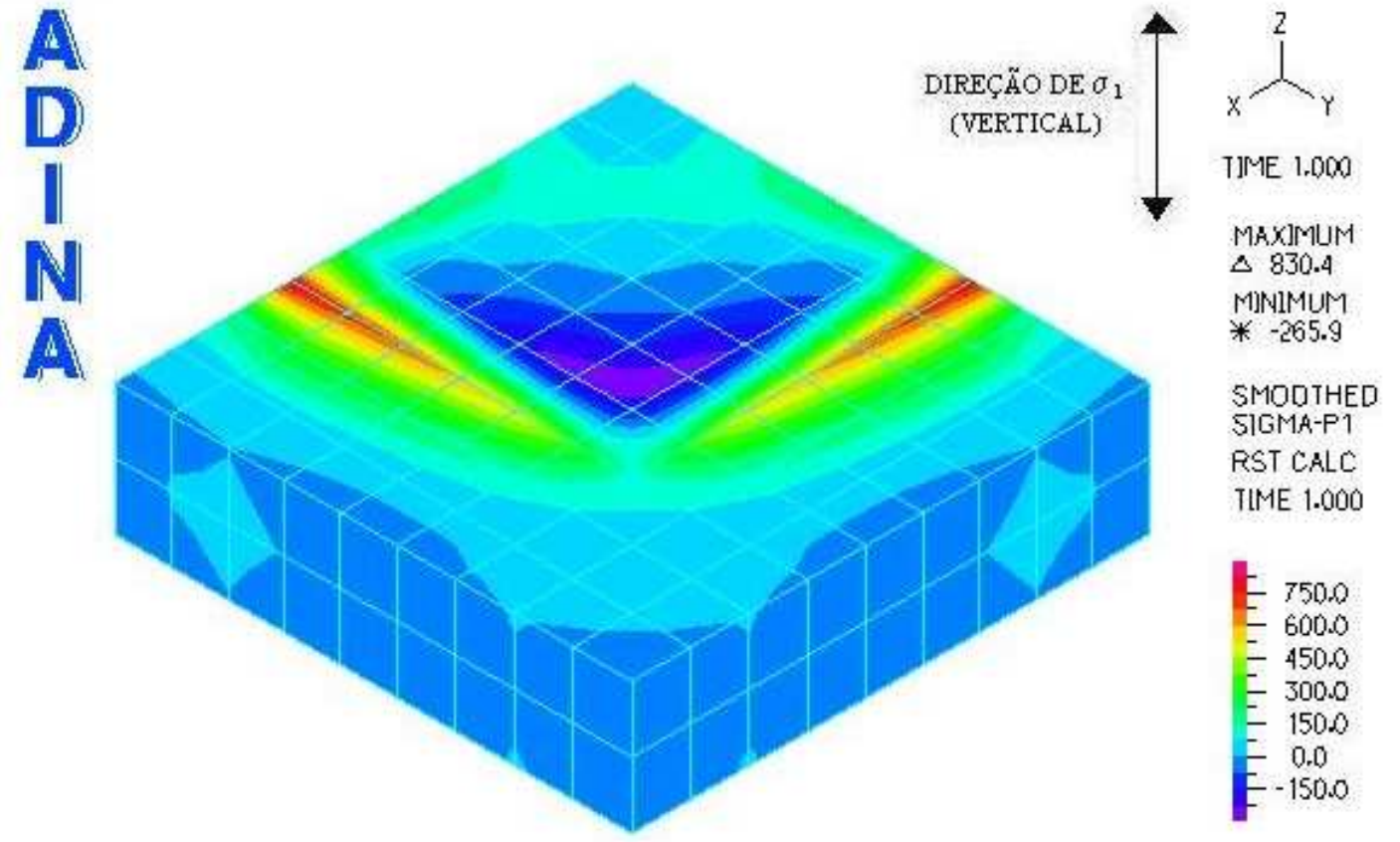

Figura 9.9 Tensões $\sigma_{1}$ na laje da $1^{\mathrm{a}}$ série de exemplares do modelo reduzido $\mathrm{V}$ (pilar de canto com laje de $7 \mathrm{~cm}$ de espessura, exemplares V-A, V-B e V-C) com tensão axial aplicada de 47,85 MPa (tensões em $\mathrm{tf} / \mathrm{m}^{2}$ ) 


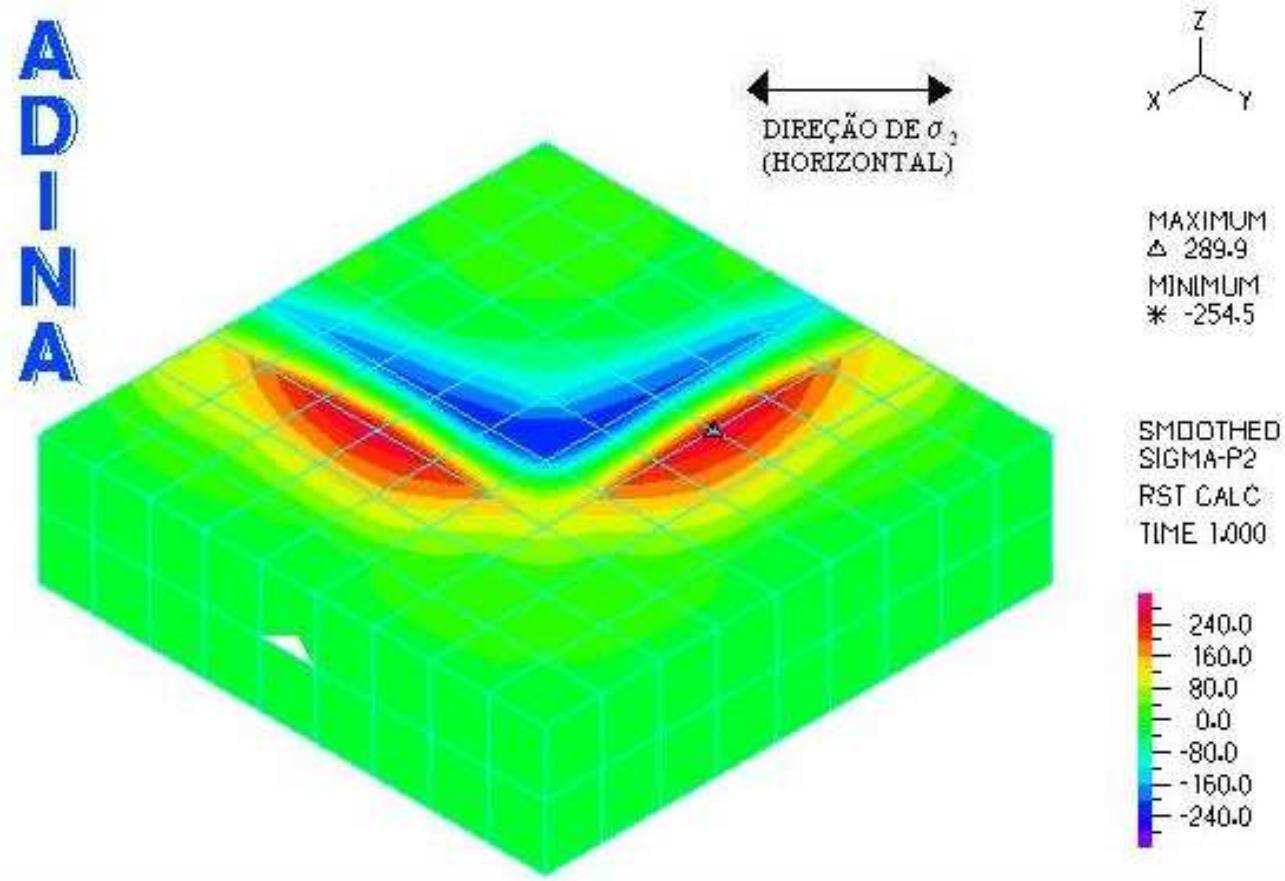

Figura 9.10 Tensões $\sigma_{2}$ na laje da $2^{\mathrm{a}}$ série de exemplares do modelo reduzido $\mathrm{V}$ (pilar de canto com laje de $7 \mathrm{~cm}$ de espessura, exemplares V-D, V-E e V-F) com tensão axial aplicada de 37,53 MPa (tensões em tf/m²)

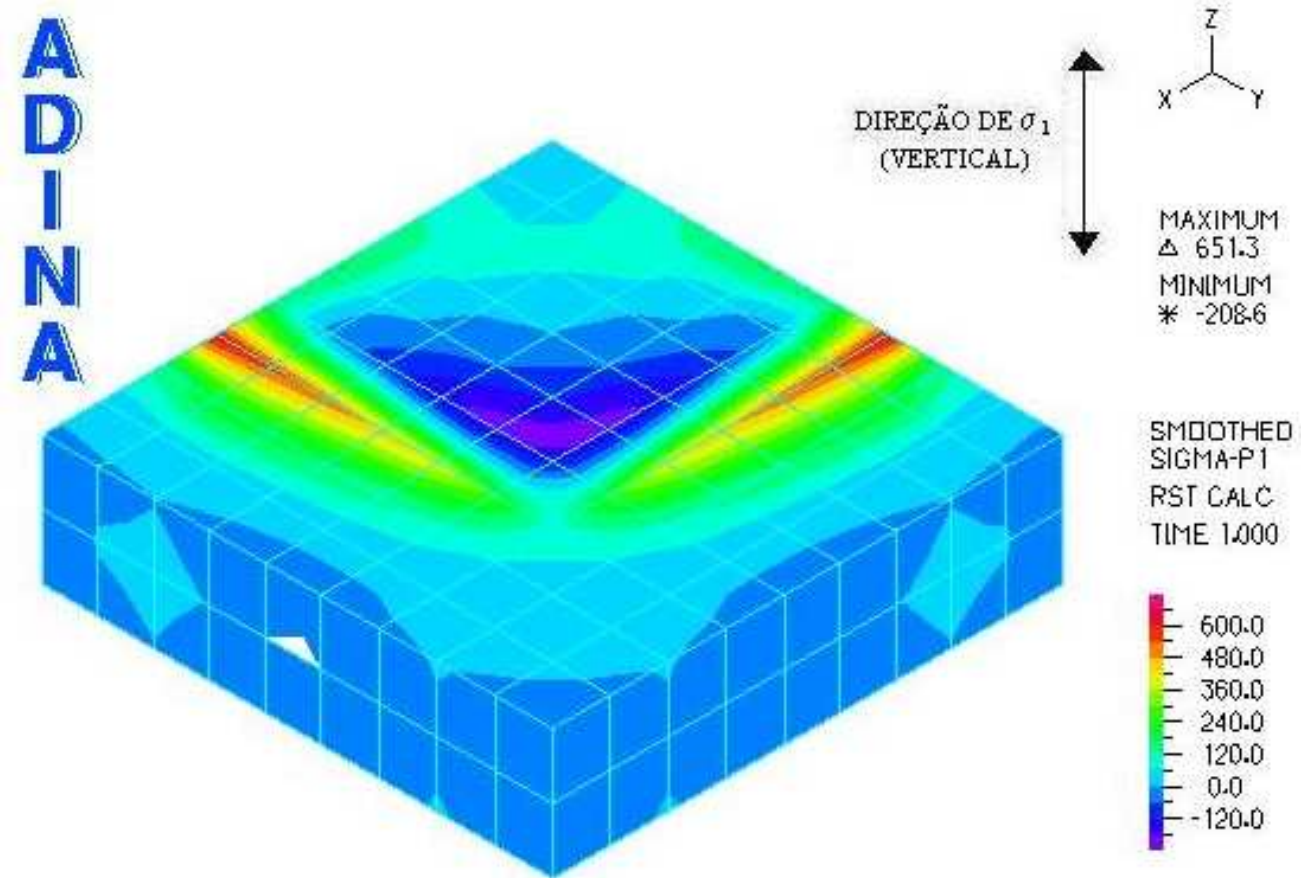

Figura 9.11. Tensões $\sigma_{1}$ na laje da $2^{\mathrm{a}}$ série de exemplares do modelo reduzido $\mathbf{V}$ (pilar de canto com laje de $7 \mathrm{~cm}$ de espessura, exemplares V-D, V-E e V-F) ) com tensão axial aplicada de $37,53 \mathrm{MPa}$ (tensões em $\mathrm{tf} / \mathrm{m}^{2}$ ) 
Os resultados dos modelos matemáticos mostrados acima foram comparados com os resultados experimentais e os valores obtidos para ambos foram muito próximos, comprovando que os parâmetros usados para a modelagem matemática estavam adequados. Este fato motivou uma extrapolação da modelagem pelo método dos elementos finitos para outros exemplos que não foram ensaiados nesta pesquisa a fim de investigar a distribuição de tensões para cada situação. É o caso de pilar central cercado somente por vigas de mesma altura, sem laje, por todos os lados. Foram estudadas duas variações: primeiro com vigas cuja largura é menor que a medida da face do pilar e uma segunda variação onde as vigas têm a mesma largura do pilar. Este modelo foi inspirado na recomendação do ACI-318 que define pilar interno, ou central, como cercado por lajes ou vigas com aproximadamente a mesma altura nos quatro lados.
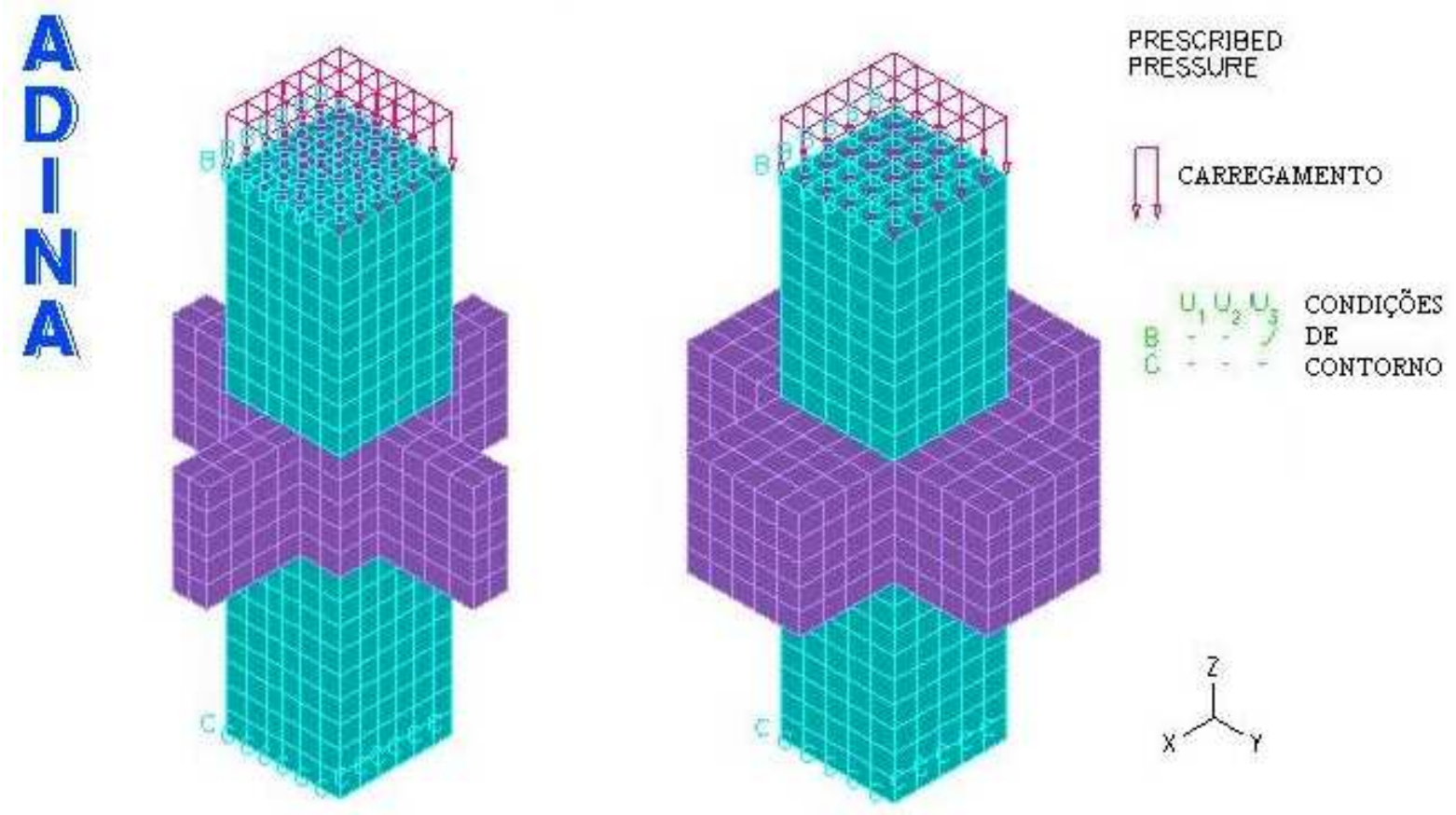

Figura 9.12 Esquema geral dos modelos com viga estudados pelo método dos elementos finitos 
Capítulo 9 - Resultados dos modelos calculados pelo método dos elementos finitos 101
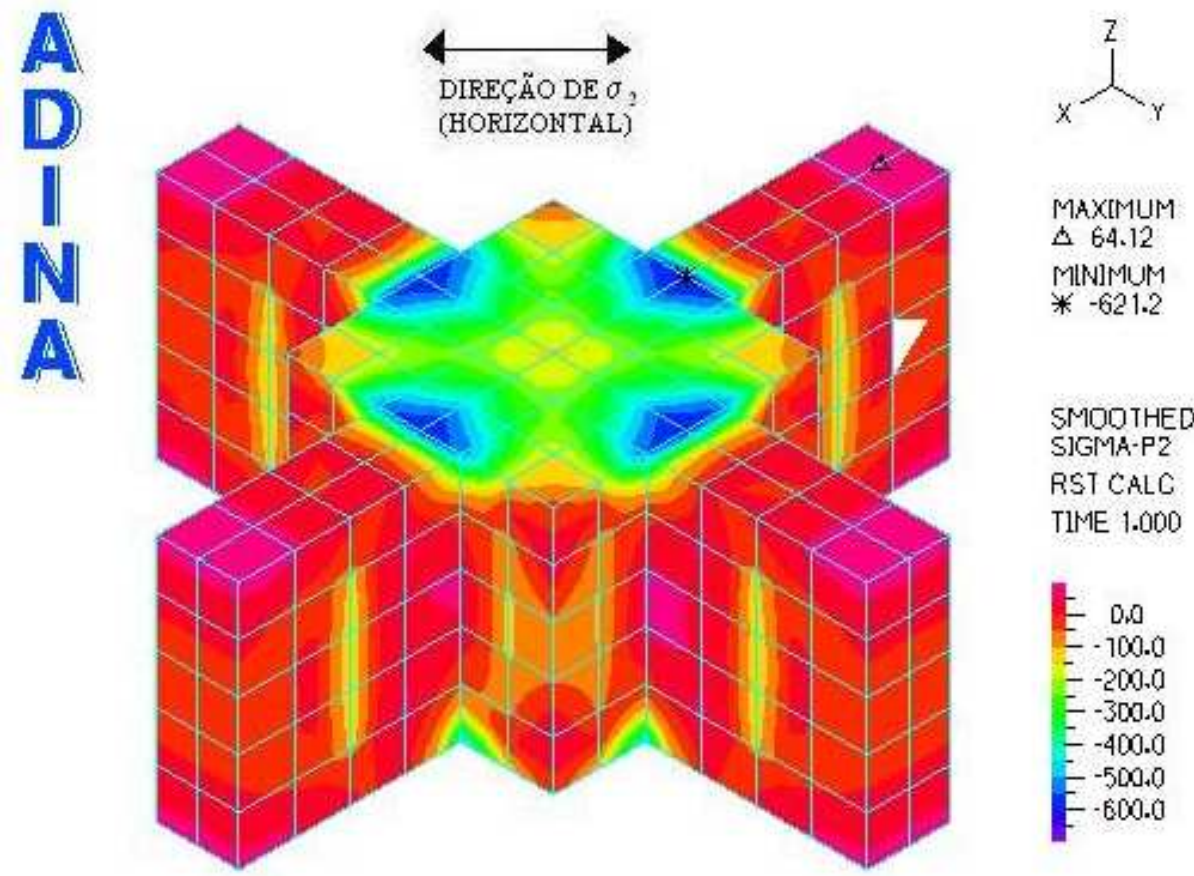

Figura 9.13 Tensões $\sigma_{2}$ na região de concreto com resistência menor do modelo matemático de pilar central com vigas estreitas e tensão axial aplicada de 40 MPa (tensões em tf/ $/ \mathbf{m}^{2}$ )
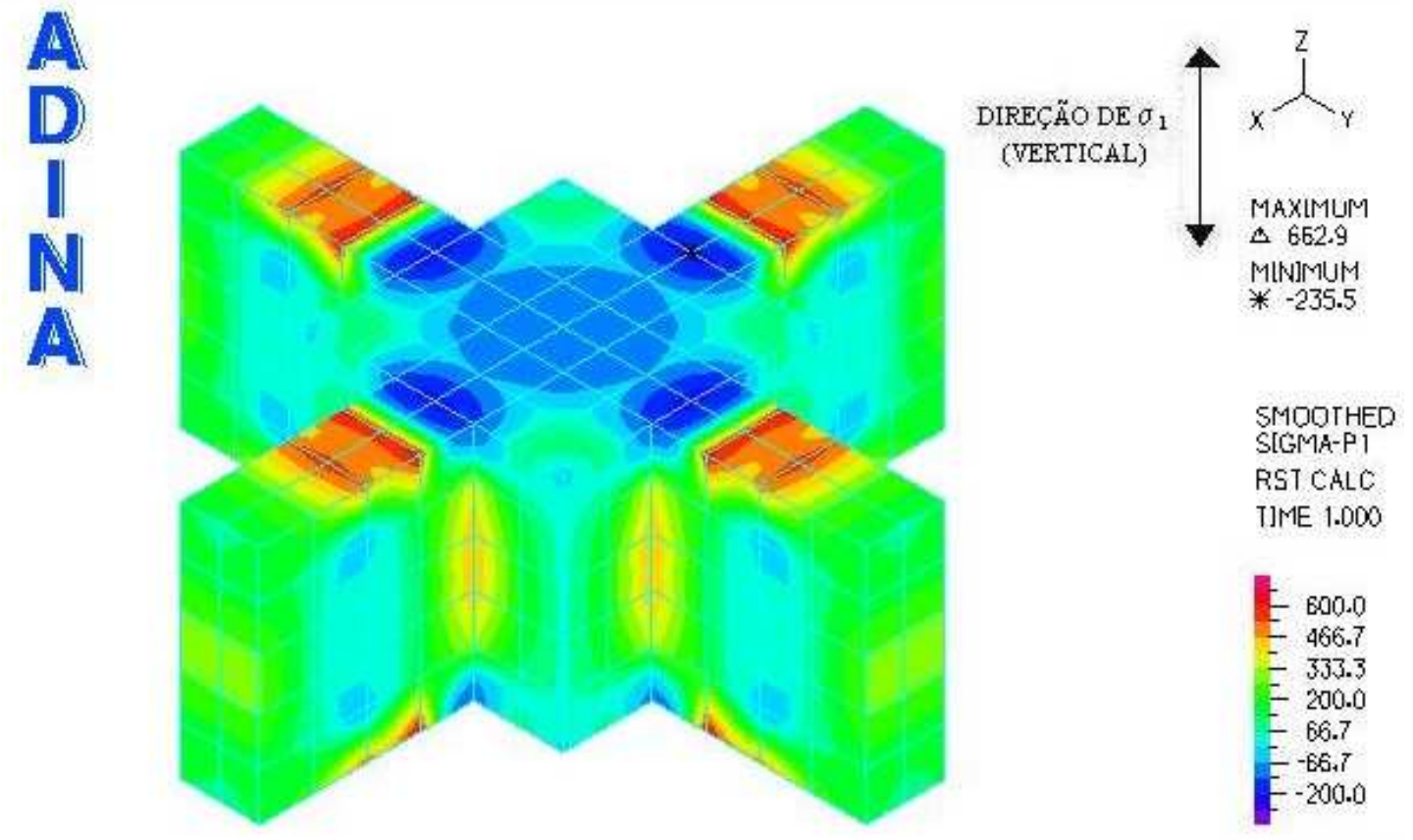

Figura 9.14 Tensões $\sigma_{1}$ na região de concreto com resistência menor do modelo matemático de pilar central com vigas estreitas e tensão axial aplicada de 40 MPa (tensões em tf//2 $\mathbf{m}^{2}$ 
Capítulo 9 - Resultados dos modelos calculados pelo método dos elementos finitos 102

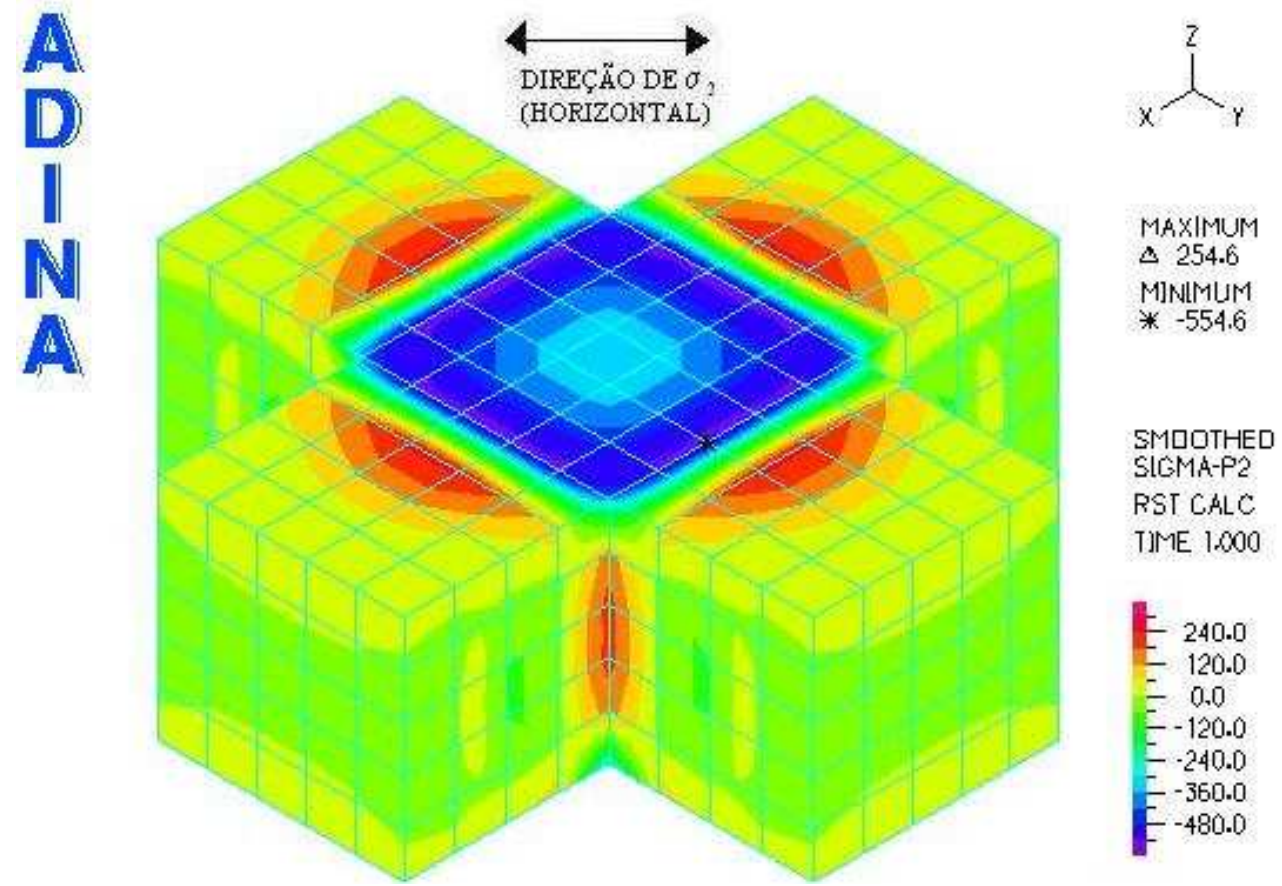

Figura 9.15 Tensões $\sigma_{2}$ na região de concreto com resistência menor do modelo matemático de pilar central com vigas largas e tensão axial aplicada de 40 MPa (tensões em tf $/ \mathbf{m}^{2}$ )
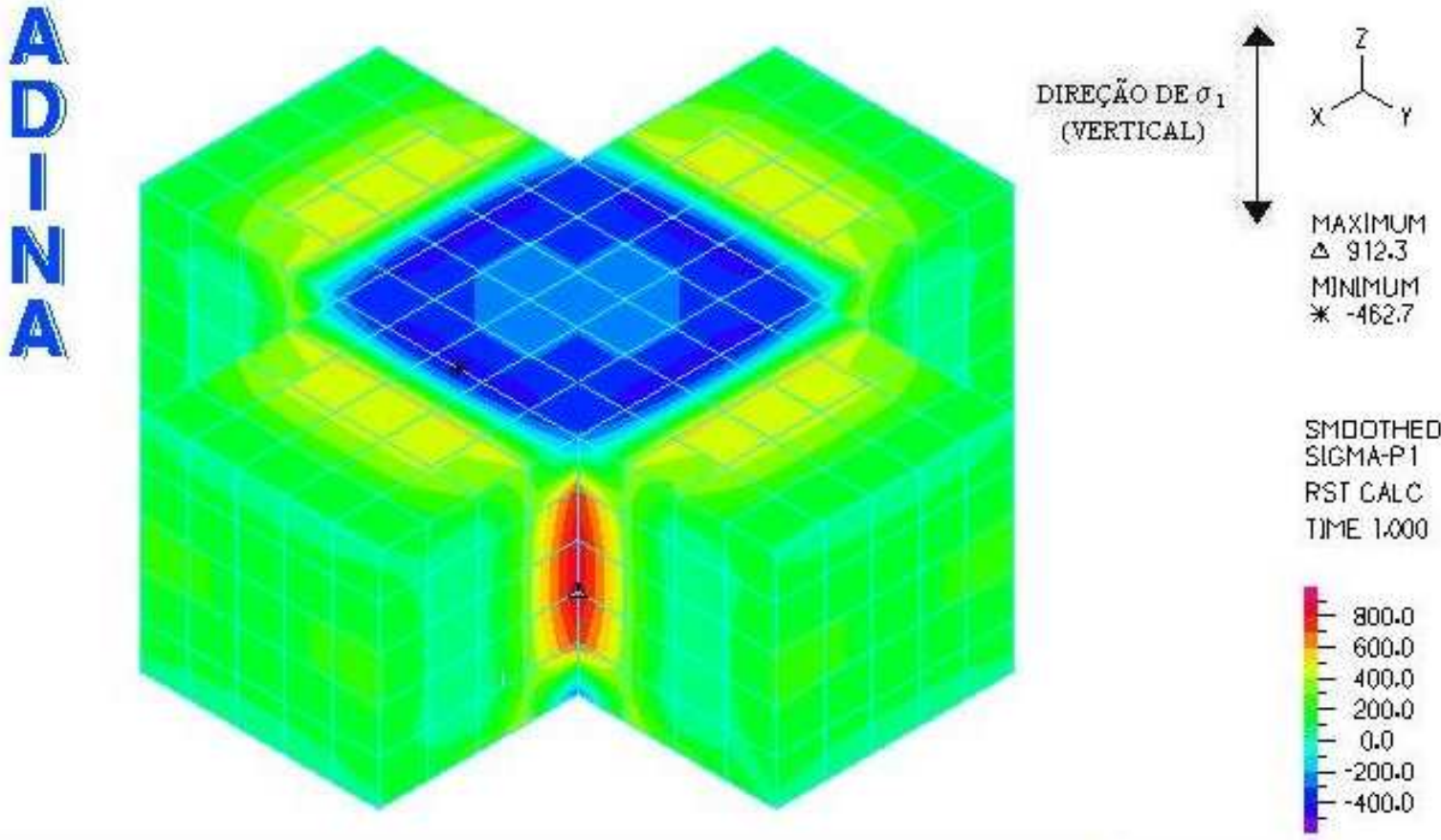

Figura 9.16 Tensões $\sigma_{1}$ na região de concreto com resistência menor do modelo matemático de pilar central com vigas largas e tensão axial aplicada de $40 \mathrm{MPa}$ (tensões em tf/ $/ \mathrm{m}^{2}$ ) 


\section{ANÁLISE DOS RESULTADOS EXPERIMENTAIS}

Analisando-se os resultados dos ensaios realizados neste trabalho e comparando com os resultados das soluções empíricas escolhidas podem-se tirar conclusões. Nessa análise as resistências médias dos concretos de cada betonada, obtidas aos 28 dias por meio de ruptura de corpos-de-prova cilíndricos de dimensões $10 \mathrm{~cm}$ x $20 \mathrm{~cm}$, foram corrigidas com 3\% de redução, ver capítulo 7, para compensar o efeito da geometria desses corpos-de-prova, quando comparado com os de dimensões de $15 \mathrm{~cm}$ x $30 \mathrm{~cm}$.

O modelo reduzido I, que representa um pilar isolado, apresentou resultados que demonstram uma perda de resistência à compressão do pilar quando comparada à resistência do concreto entre 5,84\% e 7,71\%. A perda observada se deve à geometria do pilar que, sendo mais esbelto que o corpo-de-prova cilíndrico, tem uma menor resistência à compressão. Avran, 1981 também sugere que para corpos-de-prova prismáticos com altura 4,3 vezes maior que a dimensão da base seja feita uma correção de até $15 \%$, portanto, pode-se concluir que os resultados obtidos estão dentro das expectativas. Silveira dos Santos, 2004, obteve como resultados de seus ensaios de compressão axial de pilares isolados perdas de resistência devido à geometria em torno de $22 \%$. É provável que a falta de capeamento tenha influenciado esse resultado e por isso foi observada uma maior perda da resistência efetiva do pilar.

Analisando-se os resultados obtidos para os pilares centrais, ou seja, rodeados por laje em todas as direções, pode-se compará-los com os critérios sugeridos por outros pesquisadores e normas.

Bianchini et al., 1960, segundo seus experimentos, sugeriu que para pilares centrais, quando a resistência do concreto do pilar superar em mais de $40 \%$ a resistência 
do concreto da laje, deve-se aplicar a fórmula a seguir para o cálculo da resistência do conjunto:

$$
f_{c_{\text {conjunto }}}=0,75 \times f_{c_{\text {pilar }}}+0,375 \times f_{\text {claje }}
$$

Os resultados do modelo reduzido IV apresentaram a proporção de resistências de concretos de 1,52, ou seja, a resistência do concreto do pilar central superou em 52\%, ou seja, mais de $40 \%$, a resistência do concreto da laje. Nota-se que as resistências dos concretos da parte inferior e da superior de cada pilar são diferentes, uma vez que, são provenientes de betonadas distintas, portanto, para analisar tais modelos utilizou-se a média entre essas resistências, $\mathrm{f}_{\mathrm{cpm}}$. Assim sendo, aplicando-se o critério em questão resulta, para o modelo reduzido IV:

$$
\begin{gathered}
f_{c p m}=(52,40+55,14) / 2=53,77 M P a \\
f_{c \bar{l}}=35,32 M P a \\
f_{c p m} / f_{c l}=1,52
\end{gathered}
$$

Substituindo-se os valores das equações acima na equação 10.1, tem-se:

$$
\begin{gathered}
f_{\text {c conjunto }}=0,75 \times 53,77+0,375 \times 35,32 \\
f_{\text {c conjunto }}=53,57
\end{gathered}
$$

Segundo o critério do ACI 318 e da norma canadense, CSA A23.3, 1984, quando a resistência do concreto do pilar central superar em mais de $40 \%$ a resistência do concreto da laje, a resistência final do conjunto deve ser calculada pela seguinte equação:

$$
f_{\text {c conjunto }}=0,75 \times f_{\text {c pilar }}+0,35 \times f_{\text {claje }}
$$

Equação 10.2

Para o modelo reduzido IV, substituindo-se os valores calculados para o modelo reduzido IV na equação 10.2 , tem-se:

$$
\begin{gathered}
f_{\text {c conjunto }}=0,75 \times 53,77+0,35 \times 35,32 \\
f_{c_{\text {conjunto }}}=52,69 \mathrm{MPa}
\end{gathered}
$$

A norma canadense, CSA A23.3, 1994, apresenta, para a mesma situação anterior, a seguinte expressão: 


$$
f_{\text {cconjunto }}=0,25 \times f_{\text {c pilar }}+1,05 \times f_{\text {claje }}
$$

Equação 10.3

Novamente, substituindo-se os valores calculados para o modelo IV na equação 10.3, tem-se:

$$
\begin{gathered}
f_{\text {c conjunto }}=0,25 \times 53,77+1,05 \times 35,32 \\
f_{\text {c conjunto }}=50,53 \mathrm{MPa}
\end{gathered}
$$

Seguindo a análise do mesmo caso agora sob o ponto de vista de Gamble e Klinar, 1991, que sugere que se calcule a resistência do conjunto de pilar de borda segundo a expressão:

$$
f_{\text {cconjunto }}=0,67 \times f_{\text {c pilar }}+0,47 \times f_{\text {claje }} \quad \text { Equação 10.4 }
$$

Substituindo-se os valores para o modelo IV na equação 10.4, que apesar de representar pilar central calcularemos segundo esse critério para comparação de resultados:

$$
\begin{gathered}
f_{\text {c conjunto }}=0,67 \times 53,77+0,47 \times 35,32 \\
f_{\text {c conjunto }}=52,63 \mathrm{MPa}
\end{gathered}
$$

Ospina e Alexander, 1998, concluíram que a expressão que melhor se aplica a este caso seria:

$$
f_{\text {cconjunto }}=(0,25 /(e / b)) \times f_{\text {cpilar }}+(1,4-0,35 /(e / b)) \times f_{\text {claje }} \quad \text { Equação } 10.5
$$

Apesar da condição que relação e/b deve ser maior ou igual ao valor de 0,33 e no caso do modelo reduzido IV esta relação ser de 0,3 avaliou-se esse modelo segundo esse critério, pois a diferença entre as relações é bastante pequena. Portanto, substituindo-se os valores do modelo IV na equação 10.5 , tem-se:

$$
\begin{gathered}
f_{\text {c conjunto }}=(0,25 /(4,5 / 15)) \times 53,77+(1,4-0,35 /(4,5 / 15)) \times 35,32 \\
f_{\text {c conjunto }}=53,05 \mathrm{MPa}
\end{gathered}
$$

Os resultados do modelo reduzido $\mathrm{V}$, que representa pilar de canto, mostram uma perda de resistência à compressão do conjunto em torno de $11 \%$, na primeira série de exemplares, quando comparado com a resistência do concreto do pilar, já feita a devida 
correção do corpo-de-prova, porém a relação entre os concreto do pilar e da laje foi $\mathrm{f}_{\mathrm{cp}} / \mathrm{f}_{\mathrm{cl}}=1,24$. A segunda série de exemplares, cuja relação citada foi de 1,85 mostrou uma perda de resistência efetiva quando comparada com a resistência do concreto do pilar de com valor próximo de $38 \%$.

Os modelos reduzidos VI e VII apresentaram um valor muito próximo de 1,4 para a relação $\mathrm{f}_{\mathrm{cpm}} / \mathrm{f}_{\mathrm{cl}}$, sendo que para o primeiro destes, este valor foi de 1,42 e para o modelo VII foi de exatamente 1,4. Assim sendo, pode-se desprezar esta diferença entre os dois modelos e compará-los diretamente entre si. Nota-se que houve uma perda de resistência à compressão do conjunto em torno de $13 \%$ e $16 \%$ respectivamente para os modelos reduzidos VI e VII, quando comparado com o valor médio da resistência do concreto do pilar. Observando-se os gráficos apresentados no capítulo 8, item 2.5, percebe-se que a armadura foi realmente solicitada e nota-se ainda um aumento dessa solicitação aparentando um patamar na curva força x deformação. Este aumento é em decorrência da fissuração do concreto a partir da qual a armadura é mais solicitada. Cabe ainda observar que o aço não escoou, como foi previsto e comentado no capítulo 6 ao se calcular a área de aço da armadura complementar da região da laje sem confinamento. Com isso conclui-se que a armadura colocada na região da laje na face do pilar onde não há confinamento pela mesma, proporcionou um efeito de confinamento que aumentou a resistência à compressão do conjunto. Pode-se assim sugerir uma determinada área de armadura que é calculada de acordo com os parâmetros adotados para cada caso, como mostrado no capítulo 6, que compense a falta da laje nesta região para efeito de confinamento.

Os resultados obtidos para módulo de elasticidade inicial, $\mathrm{E}_{\mathrm{c} i}$, e coeficiente de Poisson, $v$, foram bastante coerentes com cada um dos valores de resistência média à compressão aos 28 dias de idade, $\mathrm{f}_{\mathrm{cm} 28}$, dos concretos ensaiados, sendo que para $\mathrm{o}$ concreto de $\mathrm{f}_{\mathrm{cm} 28}=52,40 \mathrm{MPa}$ obteve-se $\mathrm{E}_{\mathrm{ci}}=25,2 \mathrm{GPa}$ e $v=0,24$ e para o concreto com $\mathrm{f}_{\mathrm{cm} 28}=35,32$ obteve-se $\mathrm{E}_{\mathrm{ci}}=21,0 \mathrm{GPa}$ e $v=0,18$.

O ensaio de determinação da resistência à tração por compressão diametral, $\mathrm{f}_{\mathrm{ctm} 28}$, do concreto com $\mathrm{f}_{\mathrm{cm} 28}=35,32 \mathrm{MPa}$ também obteve resultado bastante coerente. $\mathrm{O}$ 
valor obtido para este parâmetro foi de 3,45 MPa sendo que o esperado seria algo em torno de 3,53 MPa, ou seja, dez vezes menor que $\mathrm{f}_{\mathrm{cm} 28}$.

$\mathrm{O}$ aço foi ensaiado à tração e suas propriedades mecânicas foram obtidas por meio dos dados colhidos deste ensaio. Aqui também se obteve bastante coerência de resultados.

A tabela 10.1 e os gráficos 10.1 e 10.2 apresentam um resumo dos resultados discutidos neste capítulo. 
Tabela 10.1 Comparação de resultados

\begin{tabular}{|c|c|c|c|c|c|c|c|c|c|c|c|c|c|}
\hline \multirow{4}{*}{ MODELO } & \multirow{2}{*}{$\begin{array}{c}\text { BIANCHINI, } \\
1960\end{array}$} & \multirow{2}{*}{$\begin{array}{l}\text { ACI } 318, \\
2005\end{array}$} & \multirow{2}{*}{$\begin{array}{c}\text { CSA } \\
10.13 \\
1984\end{array}$} & \multirow{2}{*}{$\begin{array}{l}\text { CSA } \\
23.3 \\
1994\end{array}$} & \multirow{2}{*}{$\begin{array}{c}\text { GAMBLE } \\
\text { ET AL., } \\
1991\end{array}$} & \multirow{2}{*}{$\begin{array}{l}\text { OSPINA* } \\
\text { ET AL., } \\
1998\end{array}$} & \multicolumn{2}{|c|}{$\begin{array}{l}\text { SILVEIRA DOS } \\
\text { SANTOS, } 2004\end{array}$} & \multirow{2}{*}{$\begin{array}{l}\text { MODELO } \\
\text { IV } \\
\text { laje sem } \\
\text { armação }\end{array}$} & \multirow{2}{*}{$\begin{array}{c}\text { MODELO V } \\
1^{\text {a }} \text { SÉRIE } \\
\\
\text { laje sem } \\
\text { armação }\end{array}$} & \multirow{2}{*}{\begin{tabular}{|c} 
MODELO V 2a \\
SÉRIE \\
$\begin{array}{l}\text { laje sem } \\
\text { armação }\end{array}$
\end{tabular}} & \multirow{2}{*}{$\begin{array}{c}\text { MODELO } \\
\text { VI } \\
\text { laje } \\
\text { armada e } \\
\text { com arm. } \\
\text { adicional }\end{array}$} & \multirow{2}{*}{$\begin{array}{c}\begin{array}{c}\text { MODELO } \\
\text { VII }\end{array} \\
\text { laje armada } \\
\text { e com arm. } \\
\text { Adicional }\end{array}$} \\
\hline & & & & & & & $\begin{array}{l}\text { laje sem } \\
\text { armação }\end{array}$ & $\begin{array}{c}\text { laje } \\
\text { armada }\end{array}$ & & & & & \\
\hline & $\mathrm{f}_{\mathrm{cm}}$ & $\mathrm{f}_{\mathrm{cm}}$ & $\mathrm{f}_{\mathrm{cm}}$ & $\mathrm{f}_{\mathrm{cm}}$ & $\mathrm{f}_{\mathrm{cm}}$ & $\mathrm{f}_{\mathrm{cm}}$ & $\mathrm{f}_{\mathrm{cm}}$ & $\mathrm{f}_{\mathrm{cm}}$ & $\mathrm{f}_{\mathrm{cm}}$ & $\mathrm{f}_{\mathrm{cm}}$ & $\mathrm{f}_{\mathrm{cm}}$ & $\mathrm{f}_{\mathrm{cm}}$ & $\mathrm{f}_{\mathrm{cm}}$ \\
\hline & $\mathrm{MPa}$ & $\mathrm{MPa}$ & $\mathrm{MPa}$ & $\mathrm{MPa}$ & $\mathrm{MPa}$ & $\mathrm{MPa}$ & $\mathrm{MPa}$ & $\mathrm{MPa}$ & $\mathrm{MPa}$ & $\mathrm{MPa}$ & $\mathrm{MPa}$ & $\mathrm{MPa}$ & $\mathrm{MPa}$ \\
\hline $\begin{array}{c}\text { PILAR } \\
\text { CENTRAL } \\
\mathrm{f}_{\mathrm{cp}}>1,4 \mathrm{f}_{\mathrm{cl}}\end{array}$ & 53,57 & 52,69 & 52,69 & 50,53 & 52,63 & 53,05 & - & - & 47,91 & - & - & - & - \\
\hline $\begin{array}{c}\text { PILAR } \\
\text { CENTRAL } \\
\mathrm{f}_{\mathrm{cp}}>1,4 \mathrm{f}_{\mathrm{cl}}\end{array}$ & 54,63 & 53,72 & 53,72 & 51,74 & 53,69 & 52,87 & 49,20 & 50,07 & - & - & - & - & - \\
\hline $\begin{array}{l}\text { PILAR DE } \\
\text { CANTO f } \mathrm{f}_{\mathrm{cp}} \\
<1,4 \mathrm{f}_{\mathrm{cl}}\end{array}$ & 53,82 & 53,82 & 53,82 & 43,84 & $\begin{array}{c}53,82 \\
\text { (PILAR DE } \\
\text { BORDA) }\end{array}$ & - & - & - & - & 47,85 & - & - & - \\
\hline $\begin{array}{l}\text { PILAR DE } \\
\text { CANTO } \\
\mathrm{f}_{\mathrm{cp}}>1,4 \mathrm{f}_{\mathrm{cl}}\end{array}$ & 36,99 & 36,99 & 32,67 & 32,67 & $\begin{array}{c}55,94 \\
\text { (PILAR DE } \\
\text { BORDA) }\end{array}$ & - & - & - & - & - & 37,53 & - & - \\
\hline $\begin{array}{l}\text { PILAR DE } \\
\text { CANTO } \\
\mathrm{f}_{\mathrm{cp}}>1,4 \mathrm{f}_{\mathrm{cl}}\end{array}$ & 36,99 & 36,99 & 36,99 & 36,99 & $\begin{array}{c}52,50 \\
\text { (PILAR DE } \\
\text { BORDA) }\end{array}$ & - & - & - & - & - & - & 45,63 & - \\
\hline $\begin{array}{c}\text { PILAR DE } \\
\text { CANTO } \\
\mathrm{f}_{\mathrm{cp}}<1,4 \mathrm{f}_{\mathrm{cl}}\end{array}$ & 54,11 & 54,11 & 54,11 & 38,60 & $\begin{array}{c}54,11 \\
\text { (PILAR DE } \\
\text { BORDA) }\end{array}$ & - & - & - & - & - & - & - & 45,48 \\
\hline
\end{tabular}


SOLUÇÕES EMPÍRICAS PARA PILARES CENTRAIS QUADRADOS EM LAJES COGUMELOS

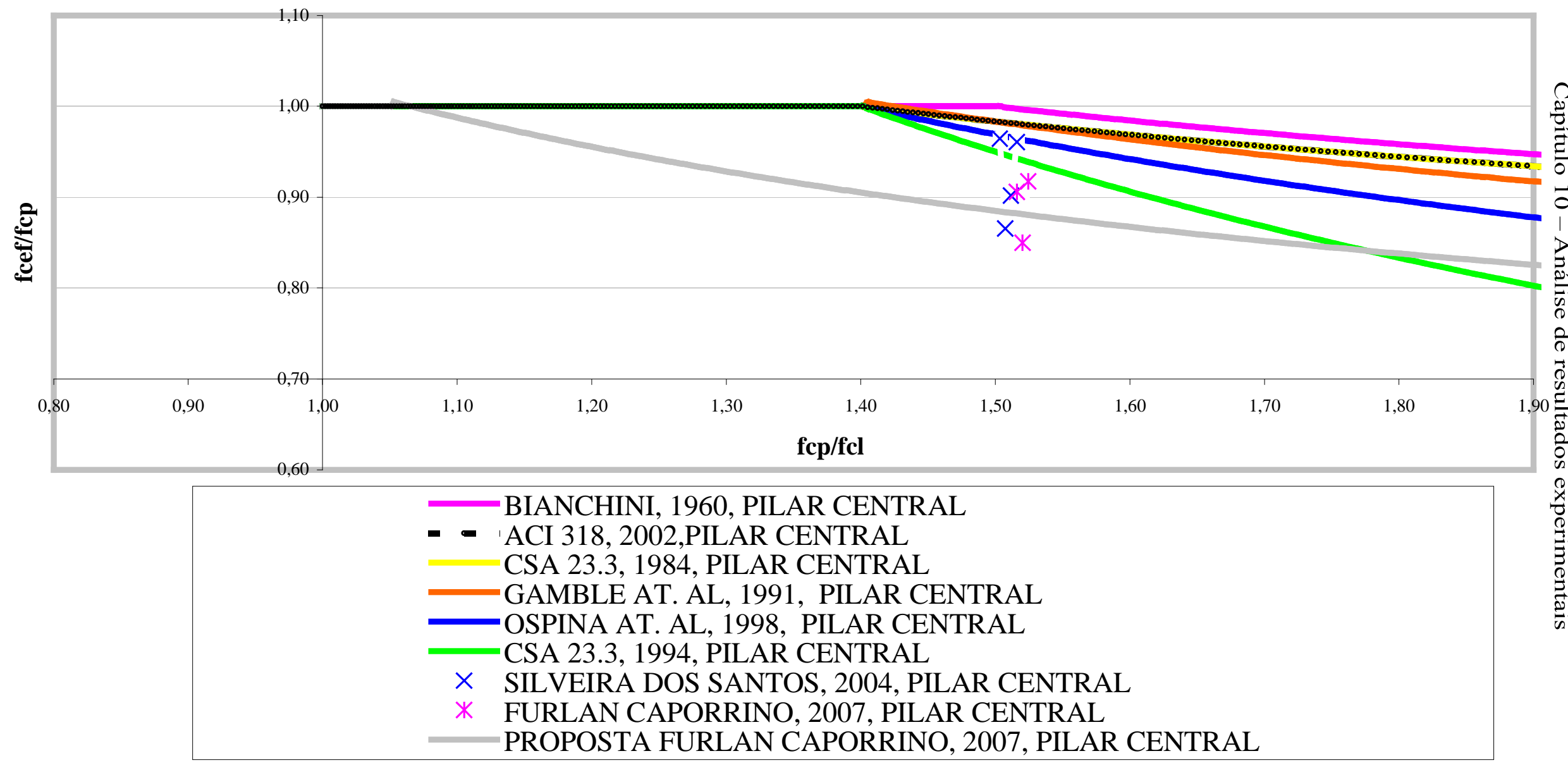

Gráfico 10.1 Gráfico comparativo para pilares centrais quadrados em lajes cogumelos 


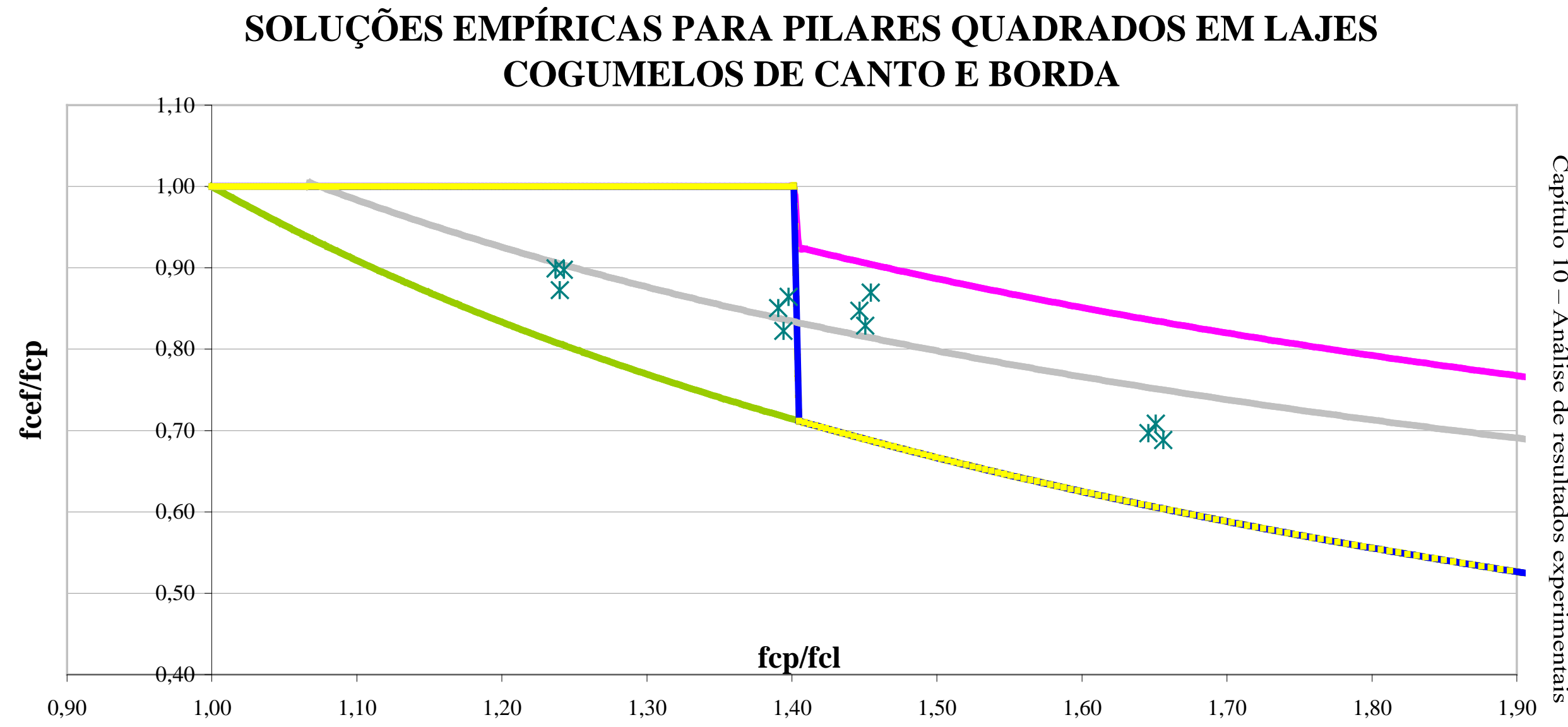

GAMBLE AT. AL, 1991, PILAR DE BORDA

BIANCHINI, 1960, PILAR DE CANTO

- ACI 318, 2002, PILAR DE CANTO

CSA 23.3, 1994, PILAR DE CANTO

CSA 23.3, 1984, PILAR DE CANTO

* FURLAN CAPORRINO, 2007, PILAR DE CANTO

PROPOSTA FURLAN CAPORRINO, 2007, PILAR DE CANTO

Gráfico 10.2 Gráfico comparativo para pilares de canto e borda quadrados em lajes cogumelos 
Analisando-se os gráficos anteriores nota-se que os resultados experimentais para pilares centrais obtidos nesta pesquisa assim como os resultados de Silveira dos Santos, 2004, estão abaixo das linhas que representam os valores propostos por outros pesquisadores e normas, ou seja, estes estão contra a segurança. Para o caso de pilares de canto a norma canadense CSA 23.3, 1994 é bem mais conservadora desde as menores relações entre os valores das resistências dos concretos do pilar e laje a ponto de não considerar contribuição alguma do confinamento para aumentar a resistência do conjunto, ou seja, considera a própria resistência do concreto da laje como sendo a efetiva. Os demais critérios para pilar de canto avaliados, que são Bianchini, 1960, ACI318 e CSA 23.3, 1984 estão se mostrando contra a segurança, para os resultados desta pesquisa, até a relação entre as resistências dos concretos atingir o valor de 1,4, após este limite também são bastante conservadores, adotando também a resistência do concreto da laje como efetiva do conjunto. Alguns critérios, como por exemplo, Bianchini, 1960, o ACI -318, 2002 e a norma canadense CSA 23.3, 1984, para pilares de canto, têm seus traçados coincidentes e por isso não estão visíveis no gráfico. $\mathrm{O}$ mesmo ocorre para pilares centrais com os critérios de Bianchini, 1960 e do ACI-318, 2002.

Com base nos resultados obtidos por essas pesquisas, nota-se que o critério que mais se aproxima destes é o de Gamble e Klinar, 1991, para pilares de borda e por este motivo estando contra a segurança quando comparado com os valores obtidos para pilares de canto. Portanto, pode-se sugerir um fator de redução para os valores calculados pelas equações propostas por estes pesquisadores.

Para tal, fez-se uma comparação e notou-se que em média os resultados experimentais desta pesquisa, estavam 90\% menores que os calculados pelo critério acima citado. Sendo assim, propõe-se que a resistência efetiva do conjunto seja calculada da seguinte maneira:

Para pilares centrais, ou seja, rodeado por laje em todas as direções:

$$
f_{\text {c conjunto }}=0,60 \times f_{\text {c pilar }}+0,42 \times f_{\text {claje }}
$$

Equação 10.6

Pilares de borda não foram pesquisados neste trabalho, porém, propõe-se ainda para pilares de canto, ou seja, com laje em apenas duas direções e com reforço de armadura transversal nas duas faces do pilar onde não existe a laje:

$$
f_{\text {c conjunto }}=0,29 \times f_{\text {c pilar }}+0,76 \times f_{\text {claje }}
$$




\section{ANÁLISE DOS RESULTADOS OBTIDOS PELO MÉTODO DOS ELEMENTOS FINITOS}

A figura 9.2 mostra uma tensão lateral $\sigma_{2}$ de confinamento, obtida pelo método dos elementos finitos, no valor de 4,00 MPa. Pode-se assim calcular a resistência efetiva do conjunto pelas equações 11.1 e 11.2 que são sugeridas pelo CM CEB-FIP e pelo Eurocode:

$$
f_{c k, c f}=f_{c k} \times\left(1+\frac{5 \times \sigma_{2}}{f_{c k}}\right)
$$

para $\sigma_{2}<0,05 f_{\text {ck }}$, onde $\sigma_{2}$ é a tensão lateral de confinamento,

$$
f_{c k, c f}=f_{c k} \times\left(1,125+\frac{2,5 \times \sigma_{2}}{f_{c k}}\right)
$$

$\operatorname{para} \sigma_{2}>0,05 f_{\text {ck. }}$

Nesse caso $\sigma_{2}>0,05 \mathrm{f}_{\mathrm{ck}}$ portanto deve-se utilizar a equação 11.2 que resulta:

$$
\begin{gathered}
f_{c k, c f}=35,32 \times\left(1,125+\frac{2,5 \times 4,00}{35,32}\right) \\
f_{c k, c f}=49,73 \mathrm{MPa}
\end{gathered}
$$

Comparando-se este valor com o resultado obtido no ensaio do modelo reduzido IV, nota-se coerência. O valor da resistência à compressão do conjunto ensaiado em laboratório foi:

$$
f_{\text {cefm, conjunto }}=47,91 \mathrm{MPa}
$$


Sendo:

$\mathrm{f}_{\text {cefm,conjunto: }}$ resistência à compressão efetiva média do conjunto.

A resistência efetiva média do conjunto foi calculada pela média entre os valores das resistências dos três exemplares ensaiados do modelo reduzido IV. A diferença entre o valor calculado pela equação e o valor resultante do ensaio é de 3,8\%.

Fazendo-se a mesma avaliação para o modelo reduzido ensaiado por Silveira dos Santos, 2004, chega-se ao seguinte valor:

$$
\begin{gathered}
f_{c k, c f}=36,25 \times\left(1,125+\frac{2,5 \times 3,6}{36,25}\right) \\
f_{c k, c f}=49,78 \mathrm{MPa}
\end{gathered}
$$

O seu valor de ensaio foi:

$$
f_{\text {cefm, }, \text { conjunto }}=49,20 \mathrm{MPa}
$$

Sendo, portanto, a diferença entre valores de 1,17\%. Isto vem demonstrar que os ensaios laboratoriais estão bem representados pelos modelos matemáticos estudados por meio do método dos elementos finitos. Verificaram-se também estes valores de tensões por equilíbrio na estrutura e mais uma vez constatou-se coerência nos resultados.

$\mathrm{O}$ estudo por este método do modelo reduzido $\mathrm{V}$, que representa um pilar de canto com laje de $7 \mathrm{~cm}$ e sem armadura na região sem confinamento, resultou nos valores apresentados nas figuras 9.8 e 9.10. Nota-se que o confinamento ocorre em apenas duas faces do pilar, as que têm laje, e que o valor da tensão lateral de confinamento é bem menor do que o valor observado nos casos de pilares centrais. Vale aqui ressaltar que não se deve tomar o maior valor de compressão registrado na laje, pois este ocorre apenas em uma região muito restrita. Deve-se portando considerar o valor médio que ocorre ao longo das quatro faces. Esse modelo foi ensaiado em duas séries, sendo a primeira constituída pelos exemplares A, B e C, cujo valor da resistência do concreto da laje foi de 43,34 MPa e a segunda D, E e F, com concreto da laje com resistência de 32,67 $\mathrm{MPa}$. Para se aplicar a equação proposta pelo CM CEB-FIP e 
Eurocode nesse modelo considerou-se para o valor de $\sigma_{2}$ a média das quatro faces, sendo que para as duas faces sem laje adotou-se o uma tensão nula. Assim tem-se:

- Modelo V primeira série

$$
\begin{gathered}
f_{c l m}=43,34 \mathrm{MPa} \\
\sigma_{2}=1,00 \mathrm{MPa} \\
f_{c k, c f}=43,34 \times\left(1+\frac{5 \times 1,0}{43,34}\right) \\
f_{c k, c f}=48,34 \mathrm{MPa}
\end{gathered}
$$

Sendo:

$\mathrm{f}_{\mathrm{clm}}$ : resistência à compressão do concreto da laje;

$\sigma_{2}:$ tensão lateral de confinamento;

$\mathrm{f}_{\text {ck,cf: }}$ resistência à compressão do pilar considerado o efeito do confinamento.

O valor da resistência efetiva obtido no ensaio de compressão axial foi de:

$$
f_{\text {cef }}=47,85 \mathrm{MPa}
$$

Portanto o valor calculado para a resistência do conjunto ficou $1 \%$ maior que o valor obtido no ensaio.

- Modelo V segunda série

$$
\begin{gathered}
f_{c l m}=32,67 \mathrm{MPa} \\
\sigma_{2}=0,80 \mathrm{MPa} \\
f_{c k, c f}=32,67 \times\left(1+\frac{5 \times 0,8}{32,67}\right) \\
f_{c k, c f}=36,67 \mathrm{MPa}
\end{gathered}
$$

Sendo:

$\mathrm{f}_{\text {clm: }}$ : resistência à compressão do concreto da laje;

$\sigma_{2}$ : tensão lateral de confinamento. 
$\mathrm{f}_{\mathrm{ck}, \mathrm{cf}}$ : resistência à compressão do pilar considerado o efeito do confinamento.

O valor da resistência efetiva obtido no ensaio de compressão axial foi de:

$$
f_{\text {cef }}=37,53 \mathrm{MPa}
$$

Portanto o valor calculado para a resistência do conjunto ficou 2,29\% maior que o valor obtido no ensaio.

Partindo-se agora para análise dos casos que foram estudados somente pelo método dos elementos finitos, iniciando com o pilar central com vigas estreitas, ou seja, cuja largura é menor que a face do pilar. A figura 9.13 apresenta os valores da tensão lateral de confinamento, $\sigma_{2}$. Apesar de o valor máximo de compressão na laje ser relativamente elevado, ao se comparar com os casos anteriores, observa-se, nesta figura, regiões sem nenhum confinamento, que são as regiões de concreto de resistência menor à compressão que não têm vigas nem laje ao seu redor.

Um segundo caso estudado foi o de pilar central com vigas cuja largura tem a mesma dimensão da face do pilar. O valor máximo da tensão lateral de confinamento é alto, porém, como fica evidenciado pela figura 9.15, existem regiões sem este confinamento lateral, que são exatamente os quatro cantos do pilar onde inexiste material confinante. Nota-se inclusive uma tensão de tração nestes pontos onde o concreto tem menor resistência à compressão e tende a se expandir. 


\section{CONCLUSÃO}

Seguindo a mesma seqüência na qual foram apresentados os casos da segunda etapa de ensaios, podem-se escrever as seguintes conclusões:

\subsection{Ensaios do modelo reduzido I, que representa um pilar isolado}

Moldado a partir de duas betonadas diferentes, este modelo, que foi analisado por quatro exemplares, A, B, C e D, apresentou uma resistência efetiva à compressão de $92 \%$ para os exemplares A e B e de $94 \%$ para C e D, quando comparada com a resistência média à compressão aos 28 dias de idade obtida no ensaio dos corpos-de-prova cilíndricos de dimensões $15 \mathrm{~cm}$ x $30 \mathrm{~cm}$. Conclui-se com isto que há uma perda devido apenas a diferença geométrica dos elementos ensaiados. Os modelos reduzidos por serem mais esbeltos apresentam uma perda de resistência com relação aos corpos-de-prova cilíndricos que têm uma geometria mais robusta. Lembrando que foi feita uma correção de valores para estes últimos de 97\%, segundo recomendação de Avran et al., 1981, que sugerem esse coeficiente de correção entre corpos-de-prova cilíndricos de $10 \mathrm{~cm}$ x $20 \mathrm{~cm}$ para $15 \mathrm{~cm}$ x $30 \mathrm{~cm}$. Outra sugestão destes autores é que para corpos-de-prova prismáticos com altura 4,3 vezes maior que a dimensão da base faça-se uma correção de $87 \%$ no valor da resistência efetiva.

Conclui-se assim que os resultados experimentais desta pesquisa para esse caso foram bem próximos aos previstos. A menor perda nesse caso e especialmente em relação aos modelos de Silveira dos Santos, 2004, que chegou a um fator de correção de aproximadamente $80 \%$, provavelmente se deve à cuidadosa execução do capeamento dos seus modelos. A falta desse capeamento também é a provável responsável pela 
excessiva variabilidade encontrada na primeira etapa dos ensaios que por isso foi eliminada.

\subsection{Ensaios do modelo reduzido II, que representa um pilar isolado com faixa de concreto de menor resistência}

O modelo reduzido II apresentou, como esperado, a maior perda de resistência à compressão quando comparada à resistência efetiva do modelo com a resistência à compressão aos 28 dias de idade dos corpos-de-prova cilíndricos de $15 \mathrm{~cm} \mathrm{x} 30 \mathrm{~cm}$. Isso se deve à presença de uma faixa de concreto de 4,5 $\mathrm{cm}$ de espessura de resistência menor, no caso 30,37 $\mathrm{MPa}$, enquanto a resistência média à compressão do concreto do pilar era de 53,77 MPa. Essa faixa representa uma laje de altura real de 19,35 cm de altura. No caso desse modelo não existe concreto confinado e conseqüentemente a ruptura se dá exatamente na região do concreto de menor resistência. Conclui-se assim que se não houver nenhum tipo de confinamento ou armadura a resistência efetiva do conjunto fica em torno de $30 \%$ menor quando comparada com a resistência dos corposde-prova cilíndricos.

\subsection{Ensaios do modelo reduzido IV, que representa um pilar central com laje de concreto de menor resistência com $4,5 \mathrm{~cm}$ de espessura}

O concreto do pilar desse modelo apresentou uma resistência média aos 28 dias de idade, ao se ensaiarem os corpos-de-prova cilíndricos, de 53,77 $\mathrm{MPa}$, enquanto o concreto da laje teve resistência de 35,32 MPa, ou seja, a resistência do concreto do pilar foi $52 \%$ maior que a do concreto da laje. A perda da resistência do conjunto, quando avaliada a resistência efetiva foi em torno de $10 \%$. Pode-se então concluir que com o efeito do confinamento, proporcionado pela laje, o conjunto recupera a resistência efetiva ficando muito próximo do valor obtido para o pilar isolado, com uma única resistência ao longo da altura. Silveira dos Santos, 2004, também chegou a essa 
constatação ao ensaiar um modelo reduzido de pilar central com laje de espessura de $7,0 \mathrm{~cm}$, que representava uma laje de altura real em torno de $30 \mathrm{~cm}$.

Comparando-se essas constatações com outros pesquisadores e normas concluise que os resultados experimentais realizados nesta pesquisa e na pesquisa de Silveira dos Santos, 2004, ficaram sempre um pouco abaixo dos demais. Assim sendo propôs-se uma correção nas equações sugeridas por Gamble at al., 1991, pois são as que apresentaram resultados mais próximos a estes, para se aplicar aos modelos brasileiros. Essa correção está apresentada no capítulo 10 pela equação 10.6 .

\subsection{Ensaios dos modelos reduzidos V, VI e VII que representam um pilar de canto com laje de concreto de menor resistência com $7 \mathrm{~cm}$ de espessura}

$\mathrm{O}$ modelo reduzido $\mathrm{V}$ foi ensaiado em duas séries de 3 exemplares cada uma. $\mathrm{Na}$ primeira série, contendo os exemplares V-A, V-B e V-C, o concreto do pilar apresentou uma resistência média à compressão aos 28 dias de idade em torno de $24 \%$ maior que a do concreto da laje, sendo estas, respectivamente, 53,82 $\mathrm{MPa}$ e 43,34 MPa. Os exemplares V-D, V-E e V-F, ensaiados na segunda série, apresentaram um concreto do pilar com resistência em torno de $85 \%$ maior quando comparado com a da laje que foram 60,58 MPa para o pilar e 32,67 MPa para a laje. A perda de resistência efetiva do conjunto foi para a primeira série em torno de $11 \%$ quando comparada com a resistência do concreto da laje e para a segunda série de $38 \%$.

Com o resultado da segunda série conclui-se que, quando não há nenhum tipo de armadura horizontal na região do pilar com concreto de resistência menor e sem o confinamento proporcionado pela laje em todo o contorno, o conjunto tem uma perda significativa de resistência.

A perda de $11 \%$ da primeira série está bem próxima da perda devida somente a esbeltez do corpo-de-prova, porém a diferença entre as resistências dos concretos do pilar e laje é pequena.

Aos modelos reduzidos VI e VII foi adicionada uma armadura na região do pilar com concreto de resistência menor e que não contava com o confinamento da laje. A 
resistência do concreto do pilar do modelo VI foi $42 \%$ maior que a da laje e do modelo VII $40 \%$ maior. O modelo VI teve nove barras de diâmetro 5,0 mm funcionando como armadura e o modelo VII um terço desta armação, ou seja, três barras de 5,0 $\mathrm{mm}$. Sendo assim o primeiro deles apresentou uma perda efetiva de resistência na casa de $13 \%$ e o modelo VII algo em torno de $16 \%$, bem abaixo da perda apresentada pela segunda série do modelo $\mathrm{V}$ de $38 \%$. Estas perdas, porém, são superiores àquela devida somente a esbeltez. Conclui-se, então, que mesmo com reforço de armadura compensando em parte a falta da laje, ainda assim, a perda efetiva é significativa quando inexiste confinamento do concreto em duas das faces do pilar na faixa que o mesmo apresenta concreto de resistência menor.

Pode-se concluir, portanto, que até um certo limite de resistência maior do pilar quando comparado à da laje, o confinamento dado pela laje presente em apenas duas faces do pilar seja suficiente, porém, com os resultados dos modelos reduzidos VI e VII nota-se que este limite é inferior ao de $40 \%$ proposto pela maioria das normas e pesquisadores.

Analogamente ao que foi feito para o pilar central sugere-se uma redução da curva proposta por Gamble e Klinar, 1991, que cubra esses resultados. Essa correção está mostrada no capítulo 10 pela equação 10.7 .

\subsection{Modelos estudados pelo método dos elementos finitos}

Foram analisados por este método os modelos reduzidos IV e V deste trabalho e ainda o modelo reduzido de pilar central com laje de 7,0 cm de espessura ensaiado por Silveira dos Santos, 2004. Por meio da equação proposta pelo CM CEB-FIP e pelo Eurocode EC2, compararam-se os resultados obtidos pelo programa ADINA, que utiliza o método em questão, com os resultados experimentais e a conclusão é que a modelagem feita é uma boa representação da realidade, tendo apresentado uma diferença em torno de $1,7 \%$. Dessa forma, partiu-se para uma extrapolação de estudo de outros modelos que não foram ensaiados, mas puderam ter seu comportamento previsto pela simulação. 
Nesse estudo foram analisados os casos de pilares internos rodeados apenas por vigas, ou seja, sem a presença de laje. Algumas normas e pesquisadores, como é o caso do ACI-318, sugerem que o modelo em questão seja tratado semelhantemente ao modelo com laje nas quatro faces, impondo apenas a condição que as vigas tenham aproximadamente a mesma altura. Contrariamente concluiu-se que as vigas, sendo largas ou estreitas, não proporcionam o mesmo confinamento que uma laje proporcionaria. Notam-se regiões, como nas figuras 9.13 e 9.15 , onde aparecem tensões de tração no pilar onde o concreto tem menor resistência que correspondem exatamente àquelas onde esse não está confinado por ausência de material ao redor. No caso de vigas estreitas essas regiões são maiores e no caso das vigas largas, com a largura igual à da face do pilar, essas regiões se encontram nos cantos do mesmo. Nesses dois casos a tensão média de confinamento resulta nula e o aumento de resistência por consequiência também. Uma estrutura composta por laje mais viga pode ter a resistência efetiva melhorada quando comparada com outra composta somente por laje, esse estudo, porém, não foi realizado nesta pesquisa.

\subsection{Sugestões para pesquisas futuras}

Este estudo abordou alguns casos de pilares sob parâmetros que foram fixados de forma a se aproximarem da realidade de projeto e viabilizarem esta pesquisa. Existem, porém, outras variáveis que também podem ser consideradas como, por exemplo: cargas excêntricas em pilares, solicitação à flexão do pilar, cargas aplicadas nas vigas e lajes que o rodeiam, variações na forma dos pilares, lajes e vigas e nos valores das resistências dos concretos utilizados, pilares de borda com apenas uma das faces sem confinamento, que sendo essa mais alongada pode reduzir significativamente a resistência final do conjunto, seções diversas de pilares, retangular ou circular; outros tipos de reforços de armadura, talvez em espiral, entre outros. Fica a sugestão para novos estudos sobre esse assunto ainda pouco pesquisado para se conhecer melhor o comportamento dessas interfaces com pilares. 


\section{REFERÊNCIAS BIBLIOGRÁFICAS}

AMERICAN CONCRETE INSTITUTE - Building Code Requirements for Reinforced Concrete (ACI 318-89) and Commentary. Detroit, revisado em 1992.

AMERICAN CONCRETE INSTITUTE - Building Code Requirements for Reinforced Concrete (ACI 318-99) and Commentary. Detroit, 1999.

AMERICAN CONCRETE INSTITUTE - Building Code Requirements for Reinforced Concrete (ACI 318-02) and Commentary. American Concrete Institute, Farmington Hills, Mich., 2002.

ASSOCIAÇÃO BRASILEIRA DE NORMAS TÉCNICAS - Concreto Determinação da consistência pelo abatimento do tronco de cone - Método de Ensaio - NBR-NM 67, 1998.

ASSOCIAÇÃO BRASILEIRA DE NORMAS TÉCNICAS - Determinação à tração por compressão diametral - Método de Ensaio - NBR-7222, 1983

ASSOCIAÇÃO BRASILEIRA DE NORMAS TÉCNICAS - Determinação dos módulos estáticos de elasticidade e de deformação e da curva tensãodeformação - Método de Ensaio - NBR-8522, 2003.

ASSOCIAÇÃO BRASILEIRA DE NORMAS TÉCNICAS - Concreto - Ensaio de compressão de corpos-de-prova cilíndricos - Método de Ensaio - NBR-5739, 1994. 
ASSOCIAÇÃO BRASILEIRA DE NORMAS TÉCNICAS -Materiais metálicos: Determinação das propriedades mecânicas à tração - Método de Ensaio - NBR6152, 1984.

ASSOCIAÇÃO BRASILEIRA DE NORMAS TÉCNICAS - Concreto - Procedimento para Moldagem e cura de corpos-de-prova - NBR-5738, 2003.

ASSOCIAÇÃO BRASILEIRA DE NORMAS TÉCNICAS - Projeto de estruturas de concreto - Procedimentos - NBR-6118. Rio de Janeiro, 2003.

AVRAN, C.; FACAOARU, I.; FILIMON, I.; MIRSU, O.;TERTEA, I., - Concrete Strength and Strains, Elsevier Scientific Publishing Company, Amsterdam, Oxford, New York, 1981.

BIANCHINI, A C.; WOODS, R, E.;E. KESLER, C. E., Effect of floor Concrete Strength on Column Strength, ACI Journal, Proceedings V. 31, No 11, 1960, pp. 1149-1169.

CANADIAN STANDARDS ASSOCIATION, Design of Concrete Structures for Buildings, CSA A10.13-84 Rexdale, Ontario, Canada, 1984.

CANADIAN STANDARDS ASSOCIATION, Design of Concrete Structures, CSA A23.3-94 Rexdale, Ontario, Canada, 1994.

CARRAZEDO, R; HANAI, J.B. \& TAKEUTI, A.R. Um estudo teórico-experimental sobre pilares de concretos encamisados por Polímero Reforçado com Fibras de Carbono (PRFC) submetidos à Compressão Axial. Trabalho apresentado nas Jornadas Sul-Americanas de Engenharia Estrutural, Brasília, 27 a 31 de maio de 2002. 
CM CEB-FIP, Model Code for Concrete Structures, Bulletin D'information $N^{0} 203$, capítulo 3, p. 29, julho, 1991.

EUROPEAN COMMITTEE FOR STANDARDATION 1991 EN 1992-1-1, EUROCODE 2: Design of Concrete Structures, Part 1: General rules and rules for buildings, item 3.1 .9 , p. 36 e 37.

FREIRE, L.; SHEHATA, L. C. D. Resistência de pilares interceptados por pisos de concreto de menor resistência. Trabalho apresentado no V Simpósio EPUSP sobre Estruturas de Concreto, São Paulo, junho de 2003.

GAMBLE, W.L.; KLINAR, J.D. Tests of high-strength concrete columns with intervening floor slabs. Journal of Structural Engineer. ASCE, V.5, No 117, 1991, pp. 1462-1476.

HELENE, P.R.L. \& TERZIAN, P.R., Manual de dosagem e controle do concreto. Ed. Pini, São Paulo, 1992.

MARTINS, Antonio Rodrigues, Técnicas Experimentais para Aplicação de Modelos de Microconcreto. 1990. 150p. Tese (Doutorado) - Escola Politécnica, Universidade de São Paulo. São Paulo, 1990.

OSPINA, C.E., ALEXANDER, S.D.B., Transmission of Interior Concrete Column Loads through Floors, Journal of Structural Engineering, ASCE, V. 124, № 6, 1998, pp.602-610.

SANTOS, Lauro Modesto dos, Simpósio EPUSP sobre estruturas de concreto, Anais, V. 1, São Paulo, 1989. 
SILVEIRA DOS SANTOS, A. P., Análise do confinamento dado por lajes em pilares com concretos de diferentes resistências ao longo da altura. Dissertação apresentada à Escola Politécnica da Universidade de São Paulo, para obtenção o título de Mestre em Engenharia, Orientador: Prof. Dr. Fernando Rebouças Stucchi, 2004.

TANGO, C.E.S. \& SAAD, V.M.K., Incrementos no Método de Dosagem IPT para concretos com amplo espectro de desempenho. Trabalho apresentado no $43^{\circ}$ Congresso Brasileiro do Concreto, 2001.

TUlA, L., HELENE, P., DIAZ, N., E BORTOLUCCI, A, Resistência à Compressão do Concreto Confinado, Anais, $42^{\circ}$ Congresso Brasileiro do Concreto, Fortaleza, IBRACON, Agosto, 2000.

PIMENTA, P. M., Fundamentos da Mecânica das Estruturas. Notas de aula para a disciplina de mesmo título do departamento de Estruturas e Fundações da Escola Politécnica da Universidade de São Paulo, 2003.

PLAZA, C. A. S., Análise Comparativa, pelo Método dos Elementos Finitos Bidimensional, das Tensões Geradas nas Estruturas de Suporte de Prótese Parcial Removível de Extremidade Livre Inferior, em Rebordo Horizontal e Descendente-Ascentente. Dissertação apresentada à Faculdade de Odontologia da Universidade de São Paulo, para obter o título de Mestre, Orientador: Prof. Dr. Hamilton Navarro, 2004.

WESTIN, M. F.; RIBEIRO, R. T. S., Método dos Elementos Finitos na Simulação de Tensão e Elasticidade em Placas. Trabalho apresentado nas disciplinas de Geometria Analítica e Álgebra Linear, 2002. 


\section{ANEXO A - Gráficos complementares}

\section{Aferição da Shimadzu}

A máquina SHIMADZU foi utilizada para todos os ensaios de compressão desta pesquisa e, portanto, aferida com a célula padrão. Por meio dessa afeição constatou-se um erro de $4 \%$ a mais nos valores por ela medidos. Esse erro, porém, tendeu a $4 \%$ conforme o aumento de carga, sendo que em cargas baixas não ultrapassou 6\%. Adotou-se desprezá-lo.

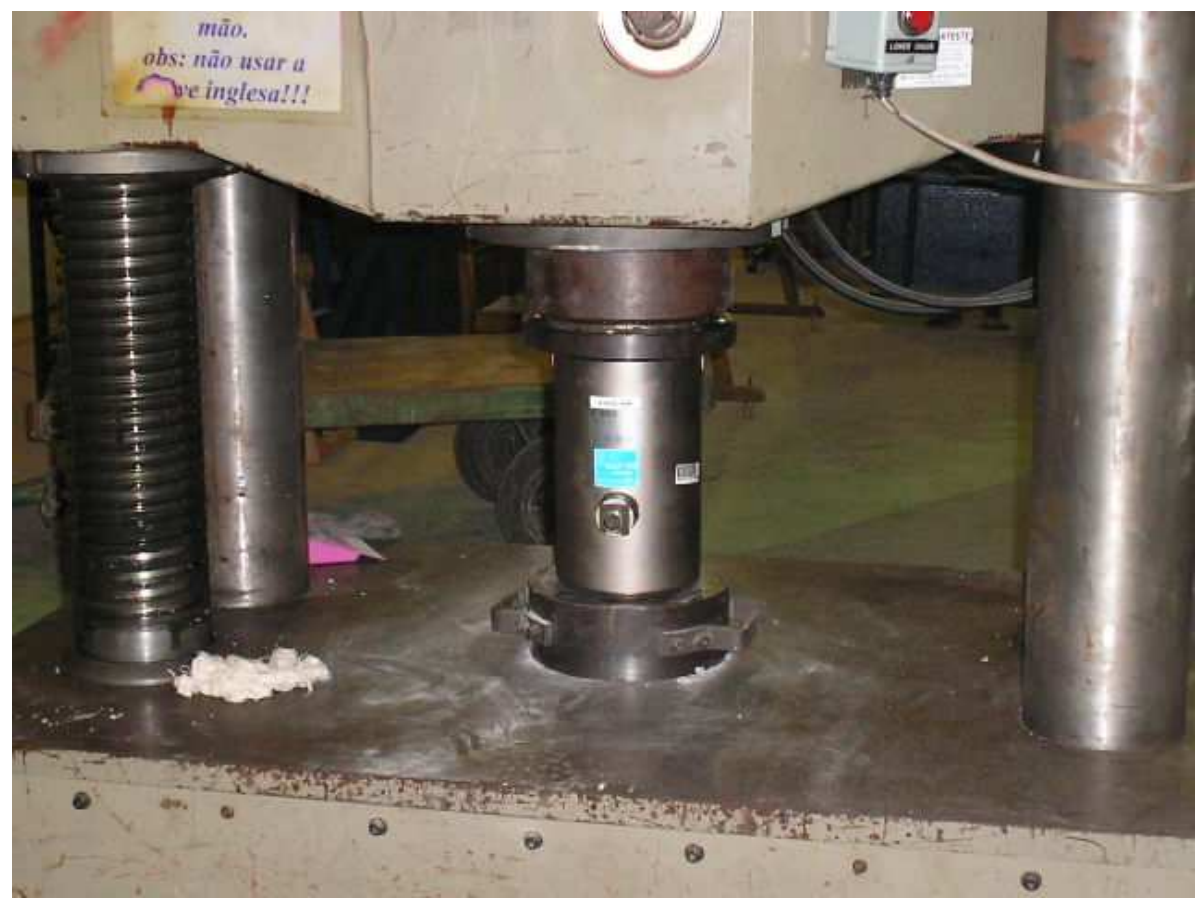

Figura 1 - Aferição da $S H I M A D Z U$ com célula padrão 
AFERIÇÕES DA SHIMADZU

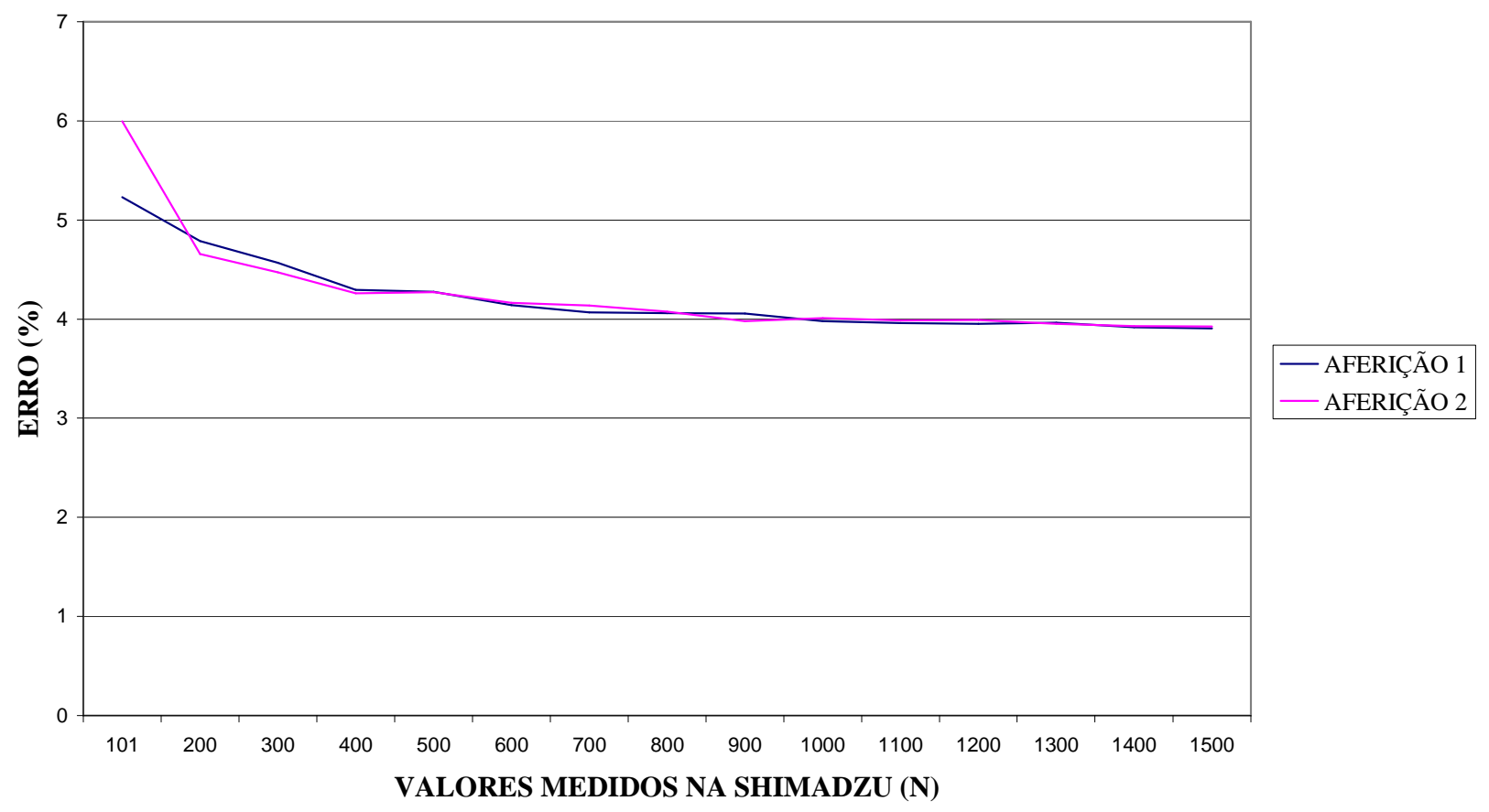

Gráfico 1 - Erro x força da máquina $S H I M A D Z U$ 


\section{Ensaios de tração no aço}

No capítulo 7 foram apresentados os gráficos de duas das nove barras de aço ensaiadas à tração. Os gráficos 2.A a 2.G referem-se às outras sete barras ensaiadas. As deformações foram medidas com clip gage, portanto, a curva é interrompida no momento da retirada do mesmo.

BARRA $1 \phi 5 \mathrm{~mm}$

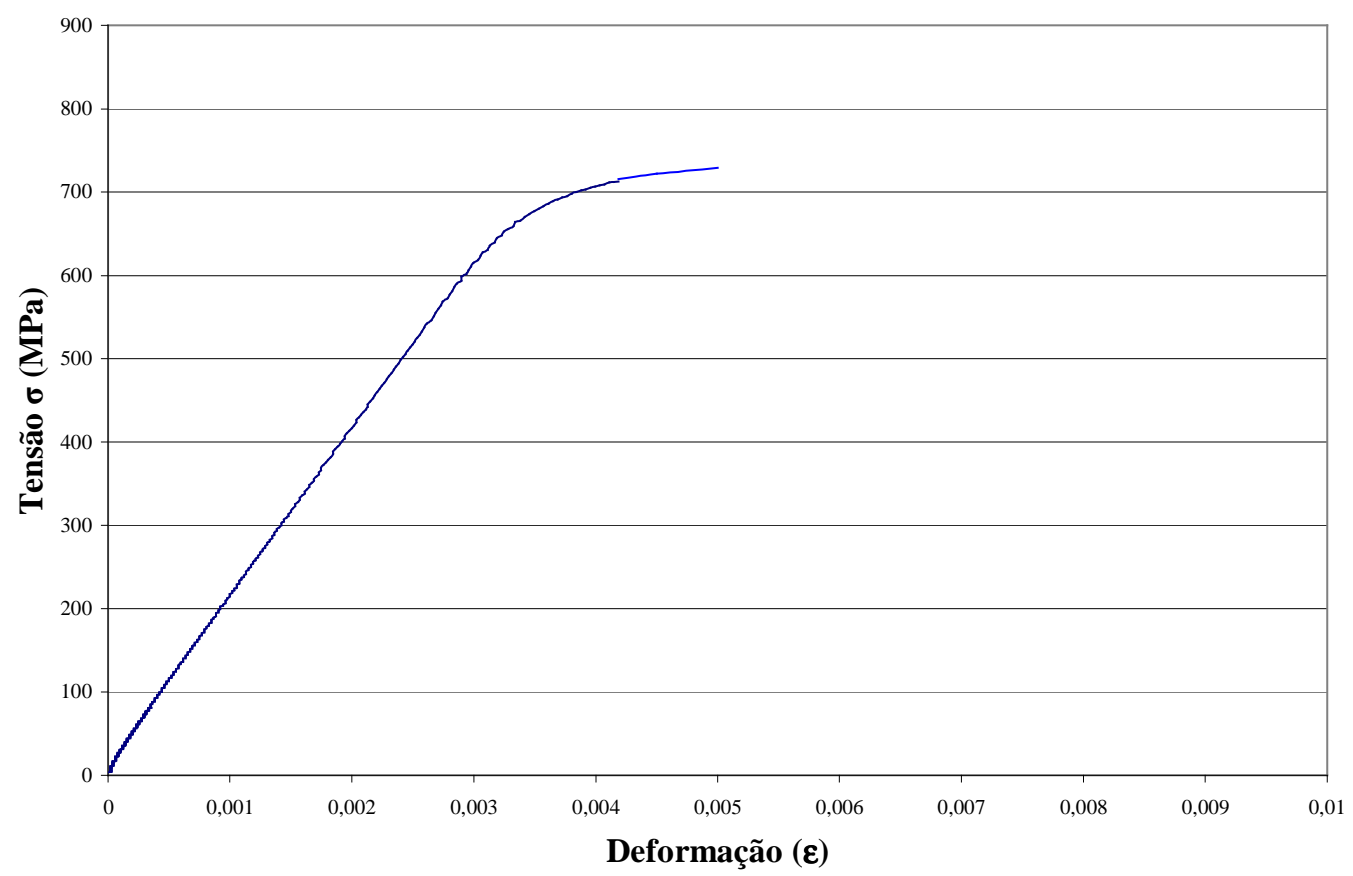

Gráfico.2 Ensaio de determinação da resistência à tração do aço de diâm. 5,0 mm, barra 1 


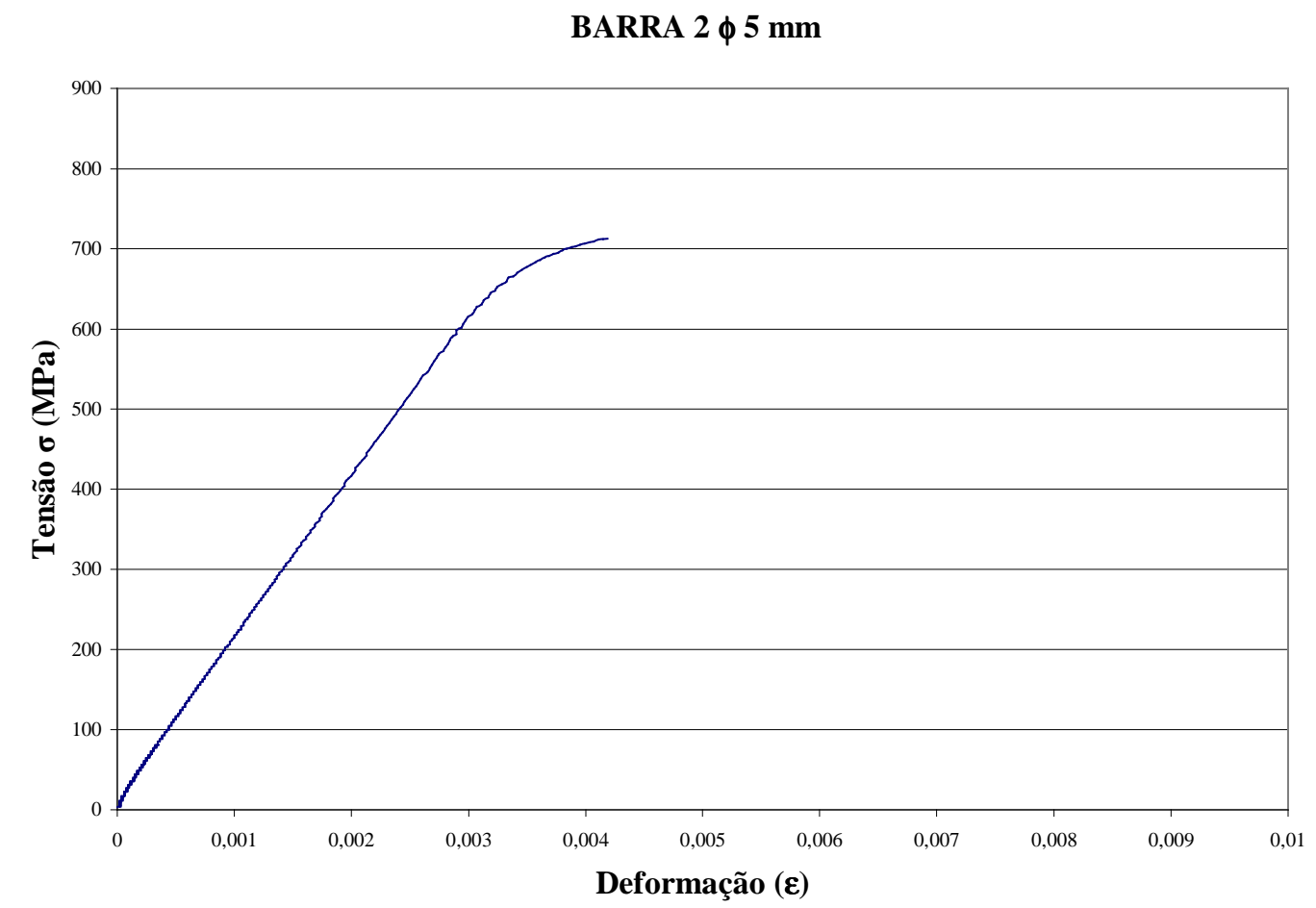

Gráfico.3 Ensaio de determinação da resistência à tração do aço de diâm. 5,0 mm, barra 2

BARRA $3 \phi 5 \mathrm{~mm}$

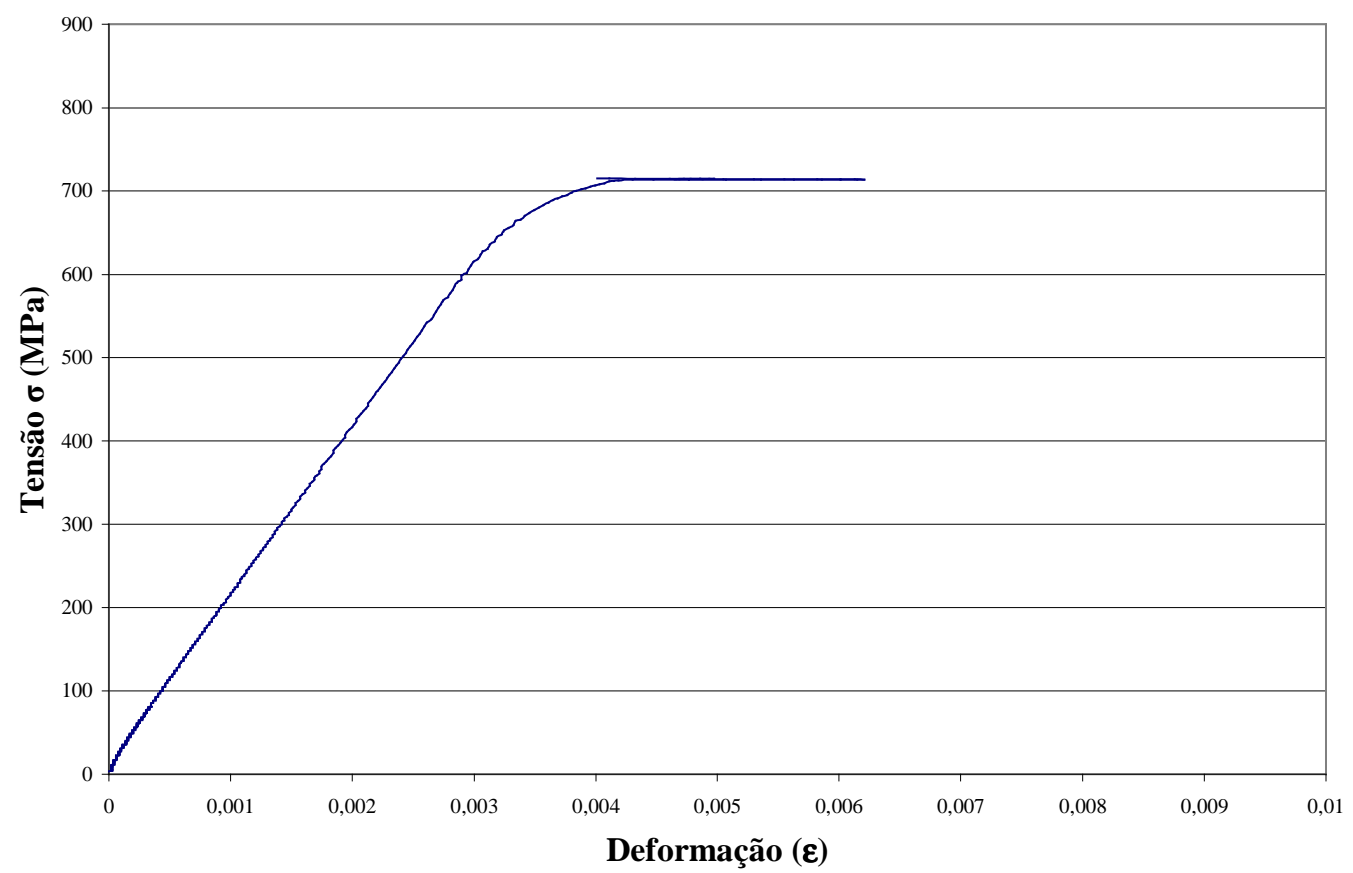

Gráfico.4 Ensaio de determinação da resistência à tração do aço de diâm. 5,0 mm, barra 3 
BARRA $5 \phi 5 \mathrm{~mm}$

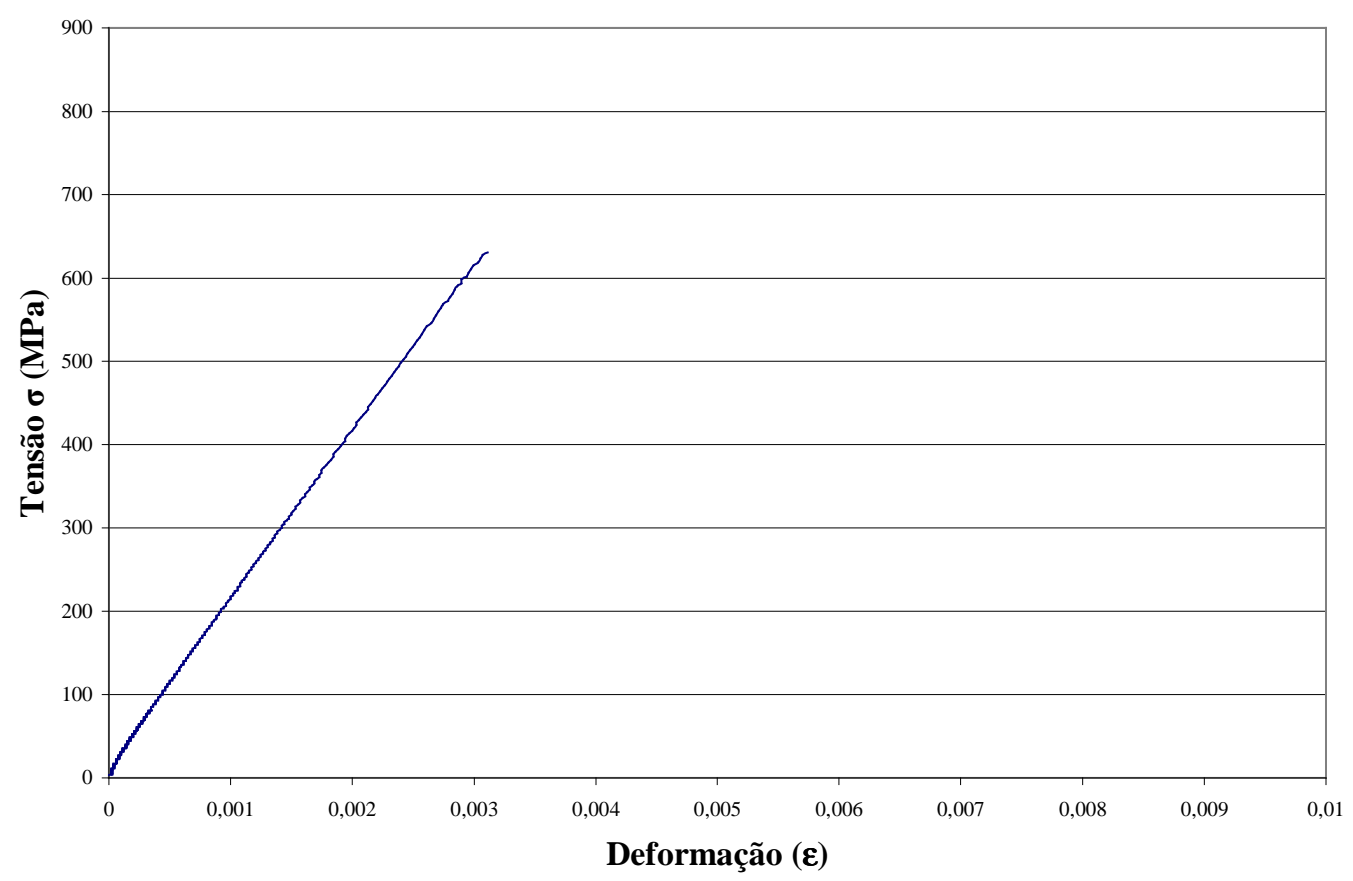

Gráfico.5 Ensaio de determinação da resistência à tração do aço de diâm. 5,0 mm, barra 5

BARRA $6 \phi 5 \mathrm{~mm}$

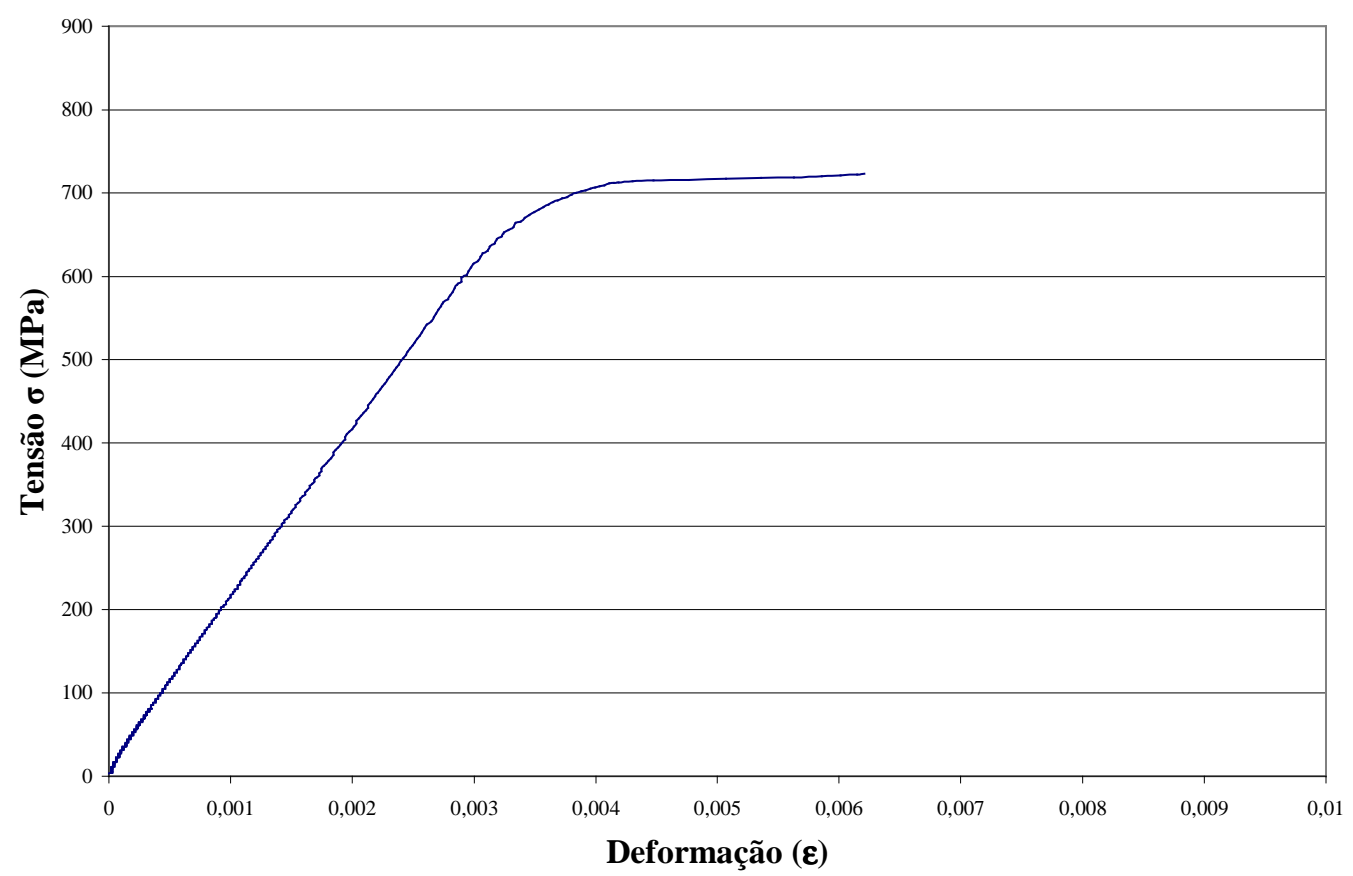

Gráfico.6 Ensaio de determinação da resistência à tração do aço de diâm. 5,0 mm, barra 6 
BARRA $8 \phi 4,2 \mathrm{~mm}$

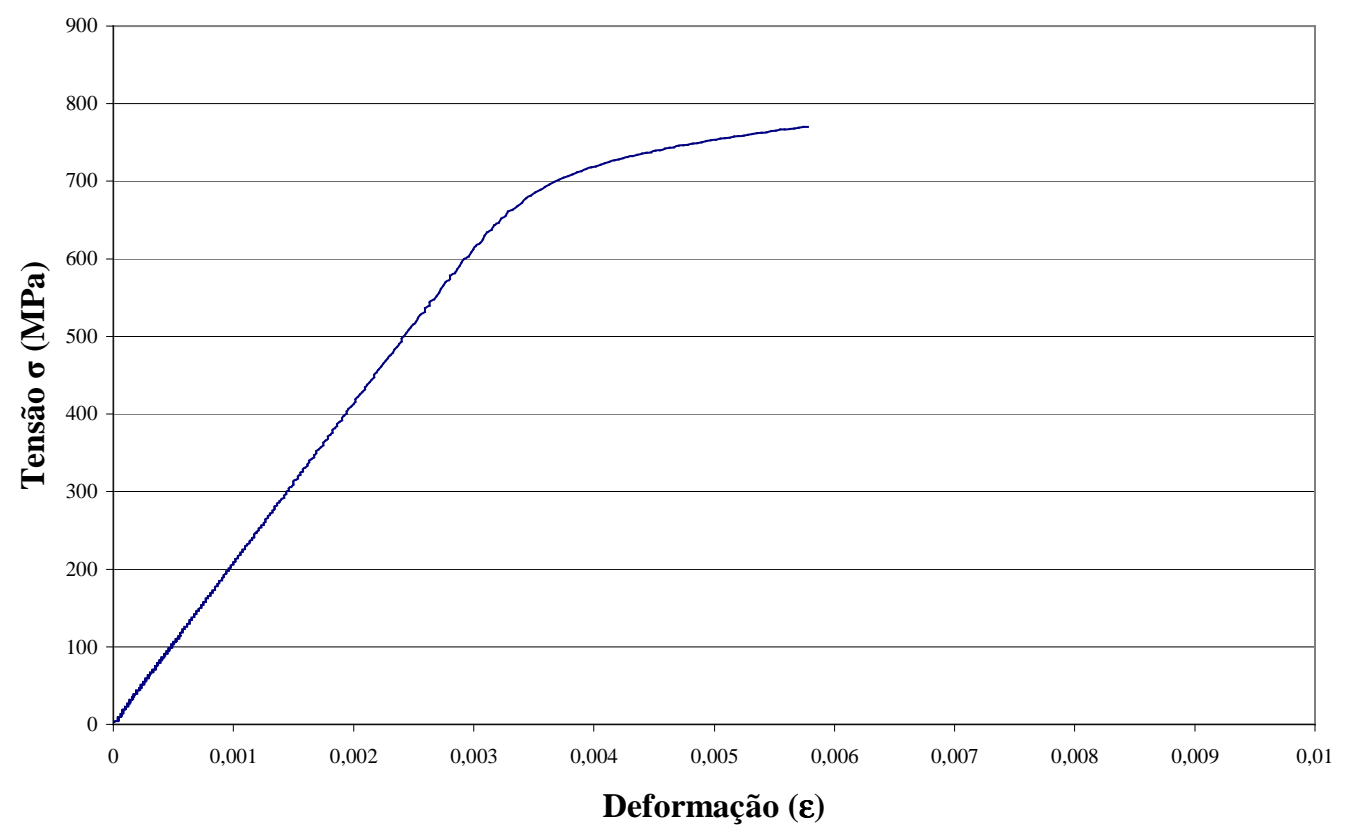

Gráfico 7 Ensaio de determinação da resistência à tração do aço de diâm. 4,2 mm, barra 8

BARRA $9 \phi 4,2 \mathrm{~mm}$

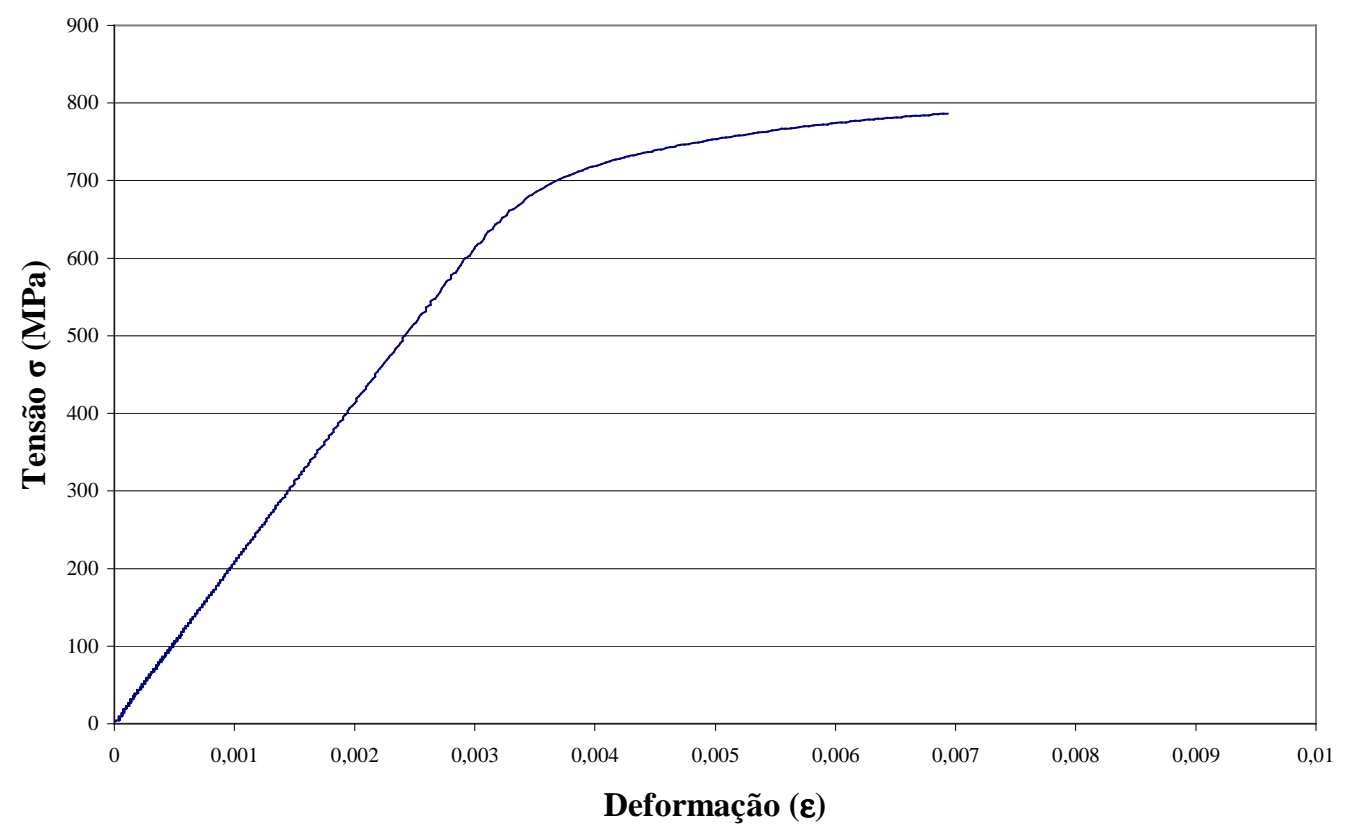

Gráfico.8 Ensaio de determinação da resistência à tração do aço de diâm. 4,2 mm, barra 9 


\section{ANEXO B - Fotos Adicionais}

Estão apresentadas aqui fotos que não foram incluídas no texto principal, detalhando mais os ensaios realizados. O motivo deste anexo foi de não sobrecarregar de figuras o citado texto.

\section{Abatimento do concreto}

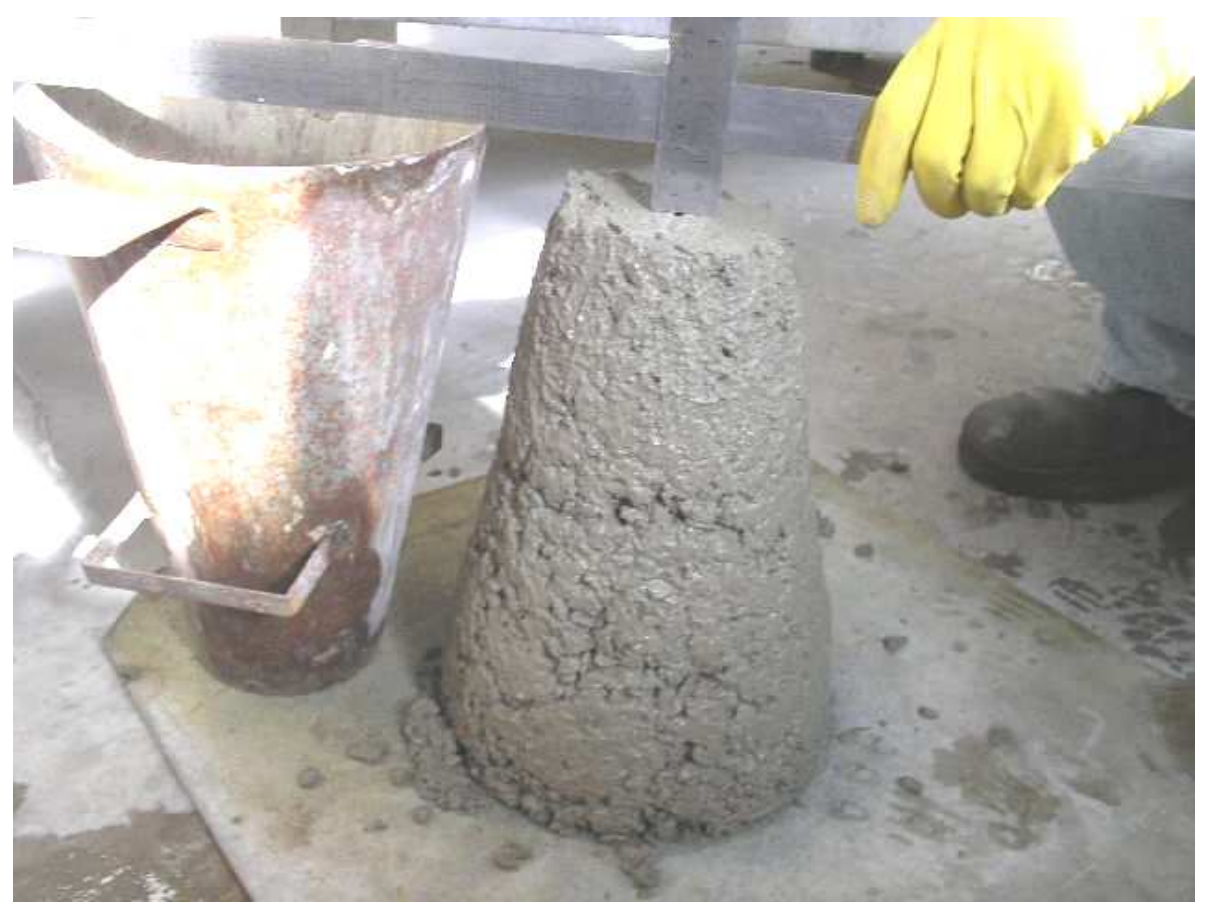

Figura.2 - Abatimento de $3 \mathrm{~cm}$ do concreto $\operatorname{com} \mathrm{f}_{\mathrm{c} 28} \approx 35 \mathrm{MPa}$ 


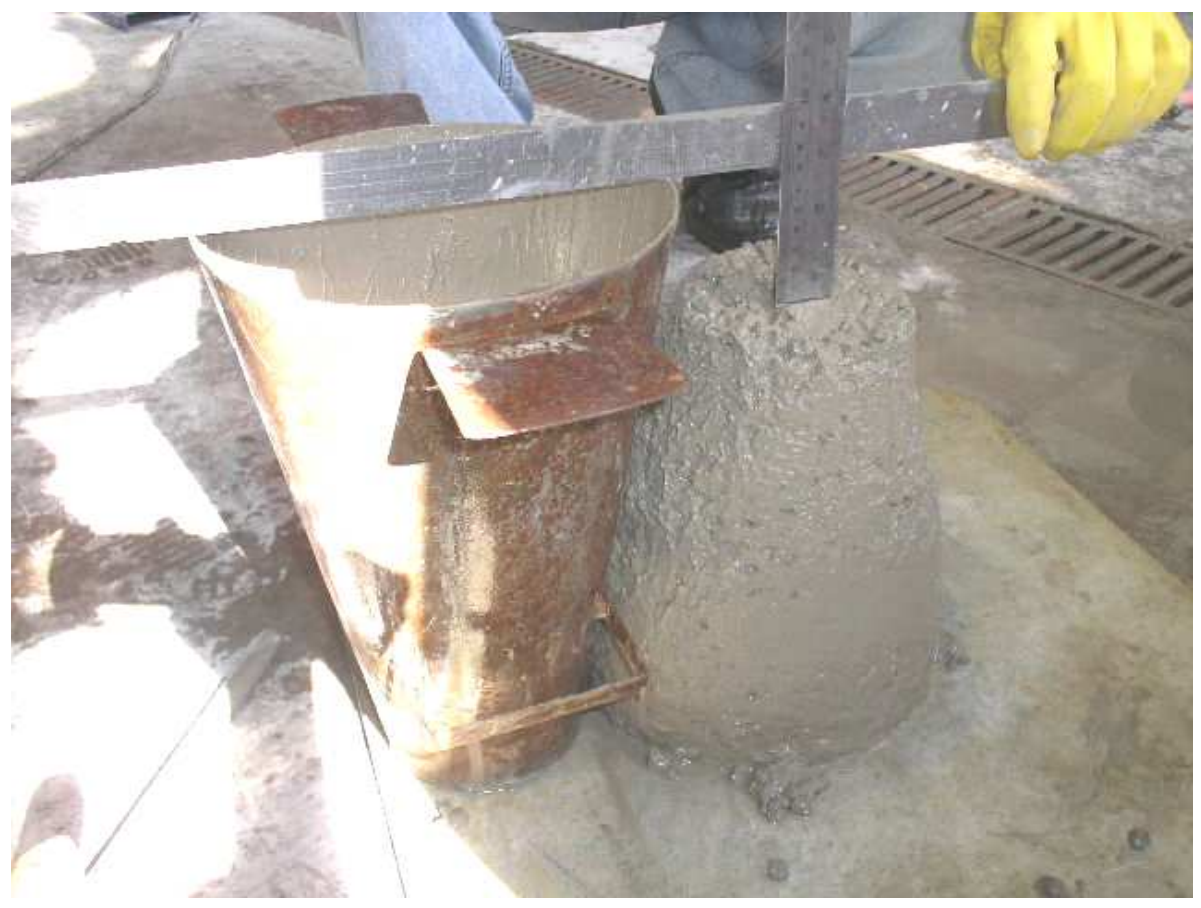

Figura.3 - Abatimento de $7 \mathrm{~cm}$ do concreto $\operatorname{com} \mathrm{f}_{\mathrm{c} 28} \approx 35 \mathrm{MPa}$

2. Cocretagem do modelo reduzido II
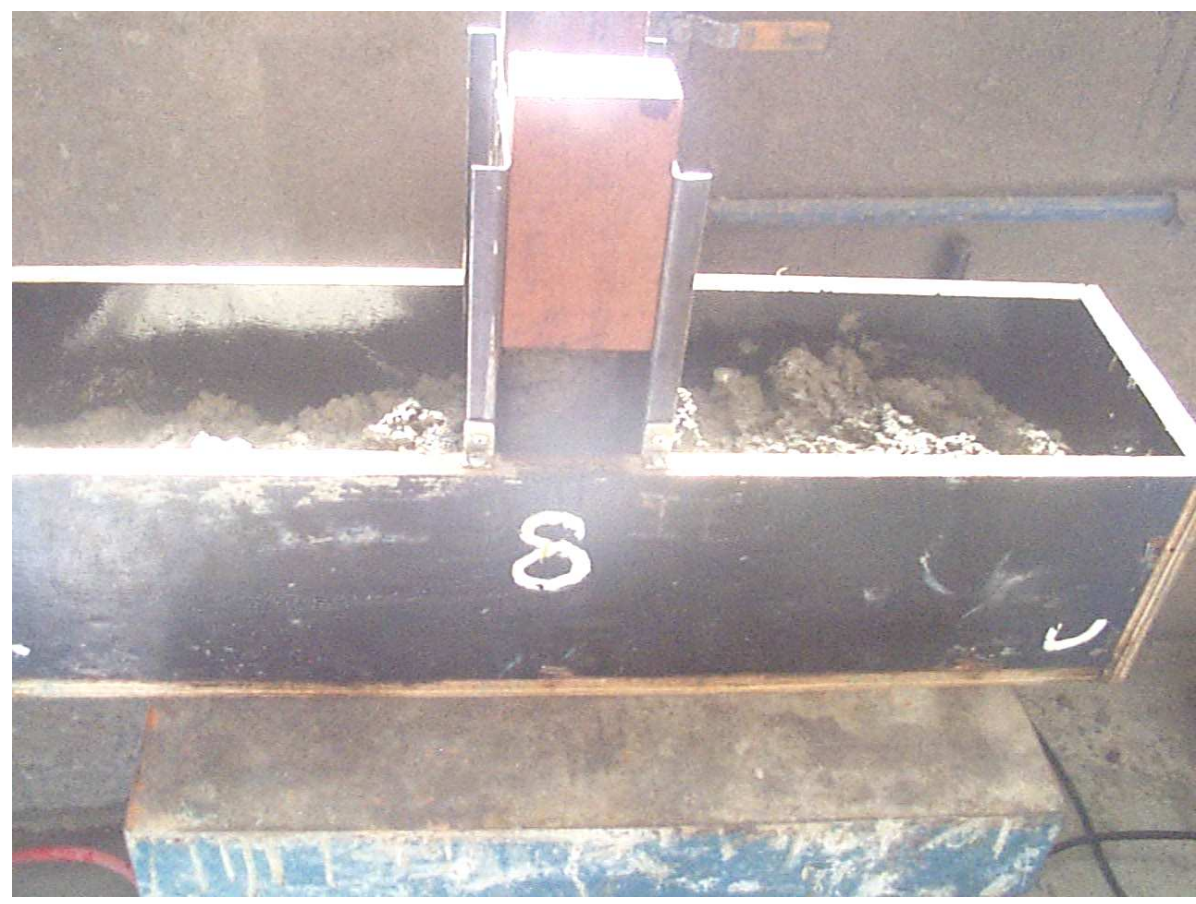

Figura.4 - Primeira etapa de concretagem do modelo reduzido II 


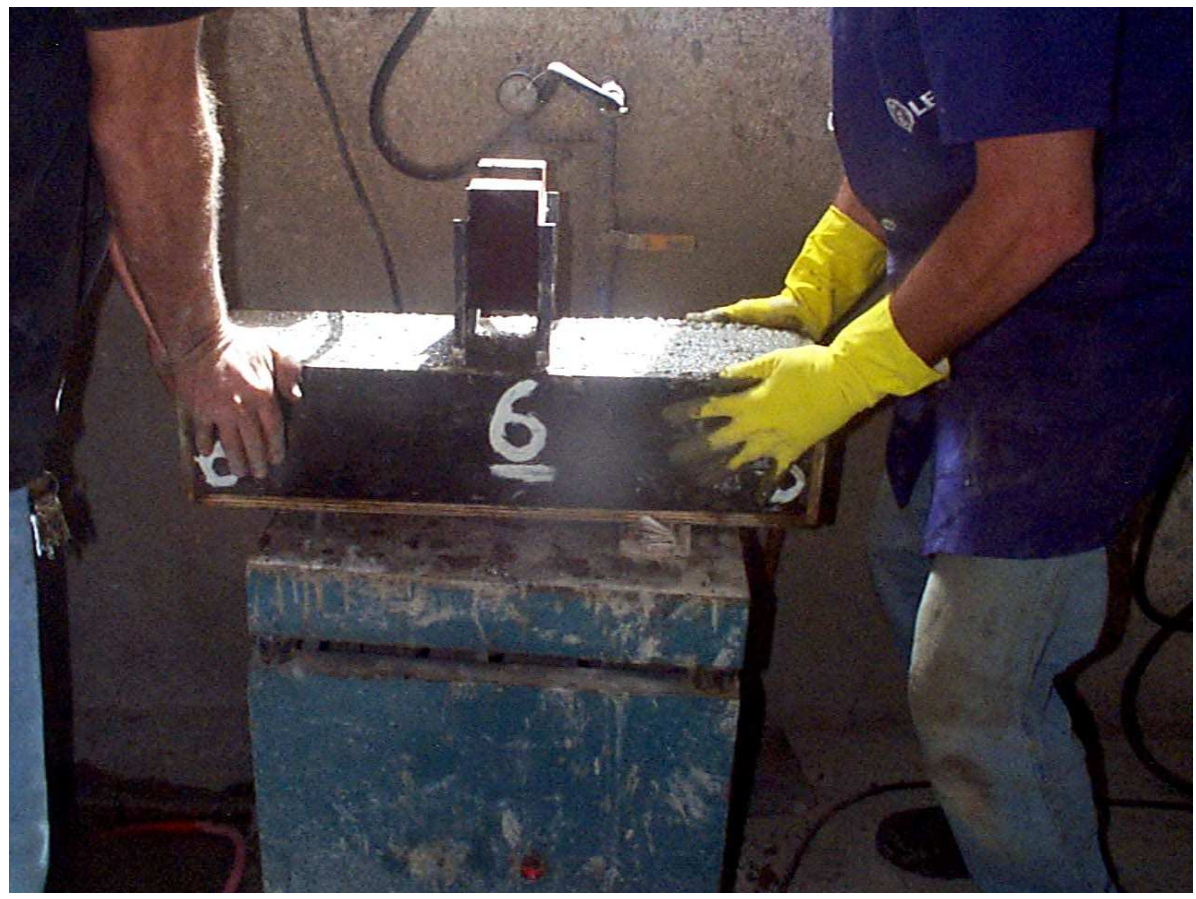

Figura.5 - Primeira vibração do modelo reduzido II

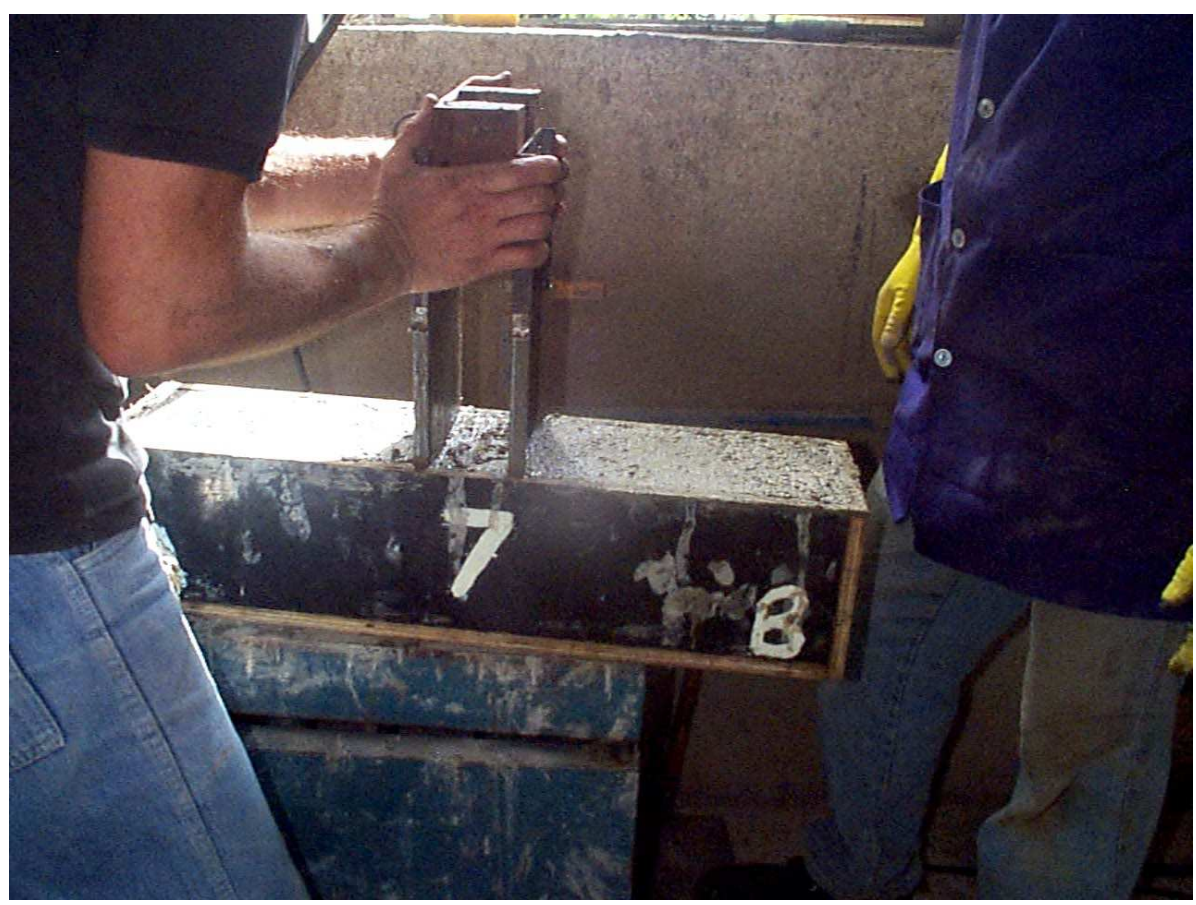

Figura.6 - Retirada do espaçador do modelo reduzido II 


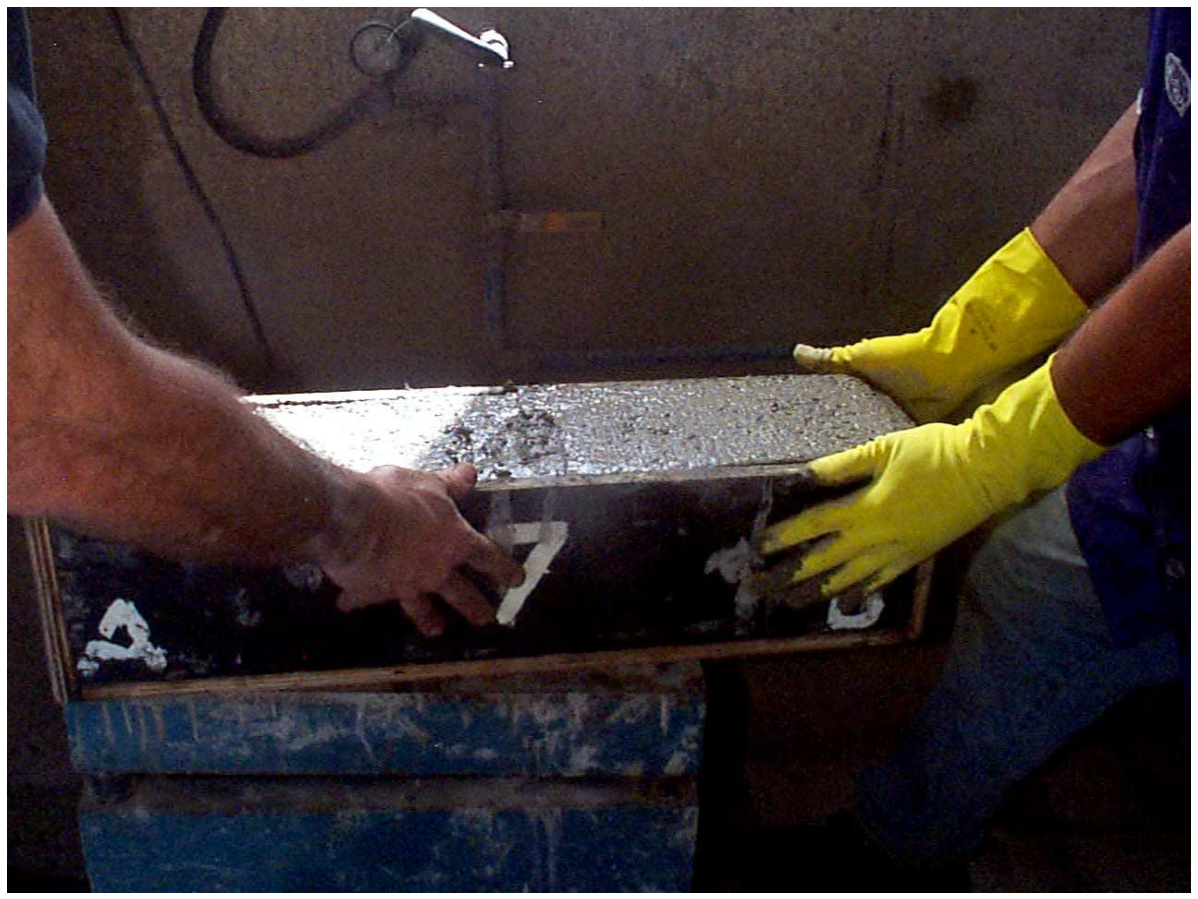

Figura.7 - Vibração final do modelo reduzido II

3. Cura dos modelos na câmara úmida

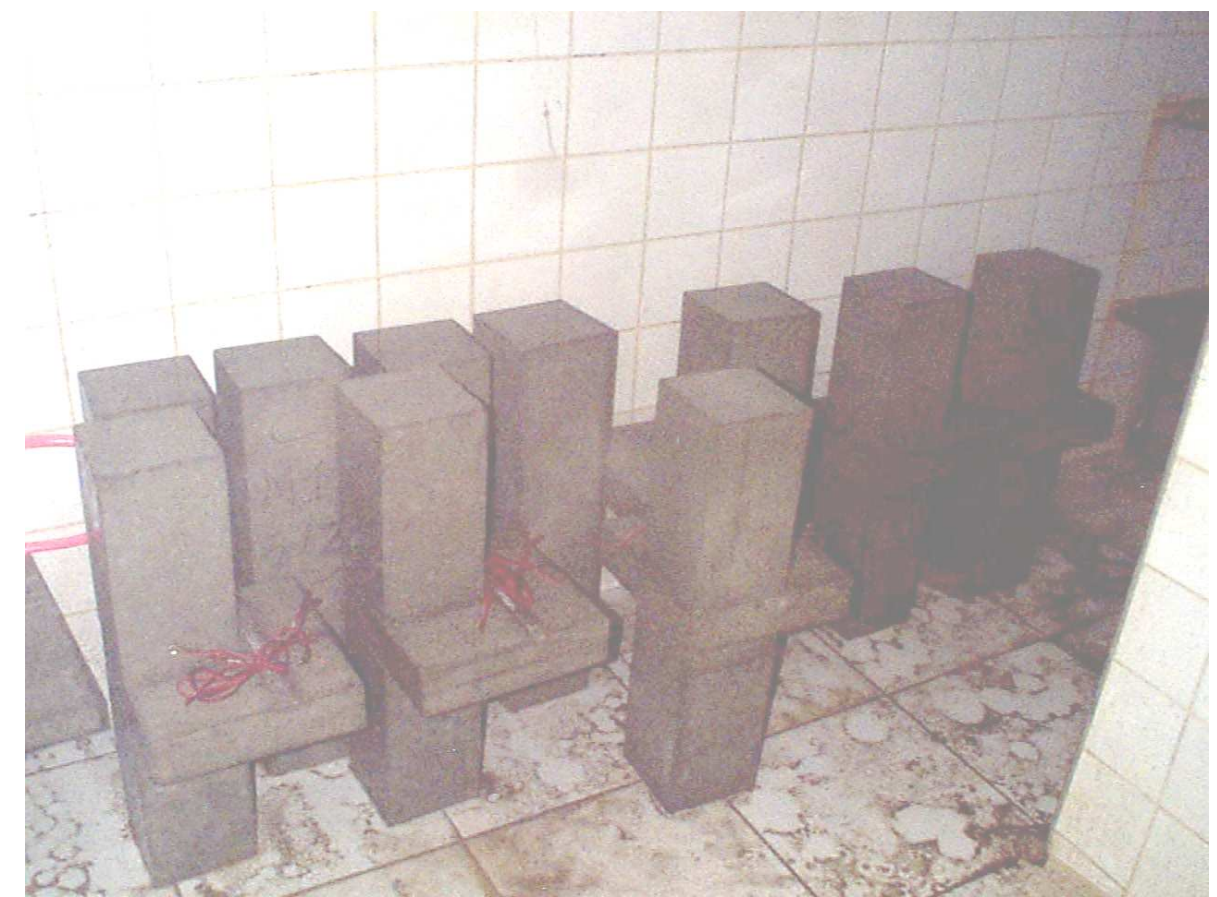

Figura.8 - Modelos reduzidos sendo curados na câmara úmida 
4. Cocretagem dos corpos de prova cilíndricos

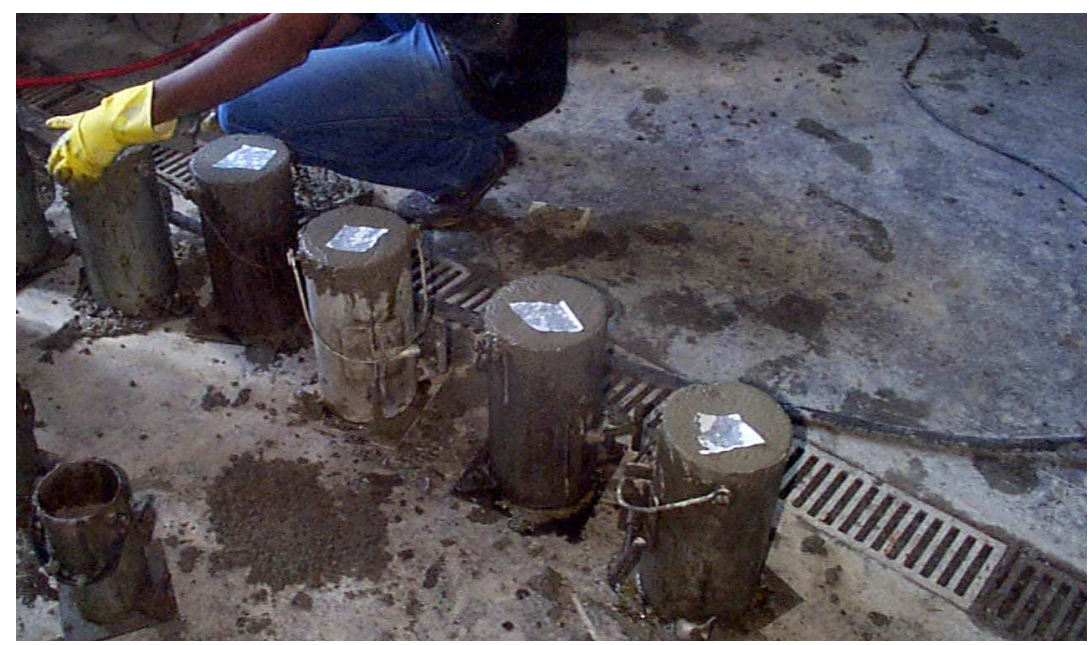

Figura.9 - Corpos-de-prova $15 \mathrm{~cm}$ x $30 \mathrm{~cm}$ identificados para serem levados para cura

5. Ensaio de tração do aço

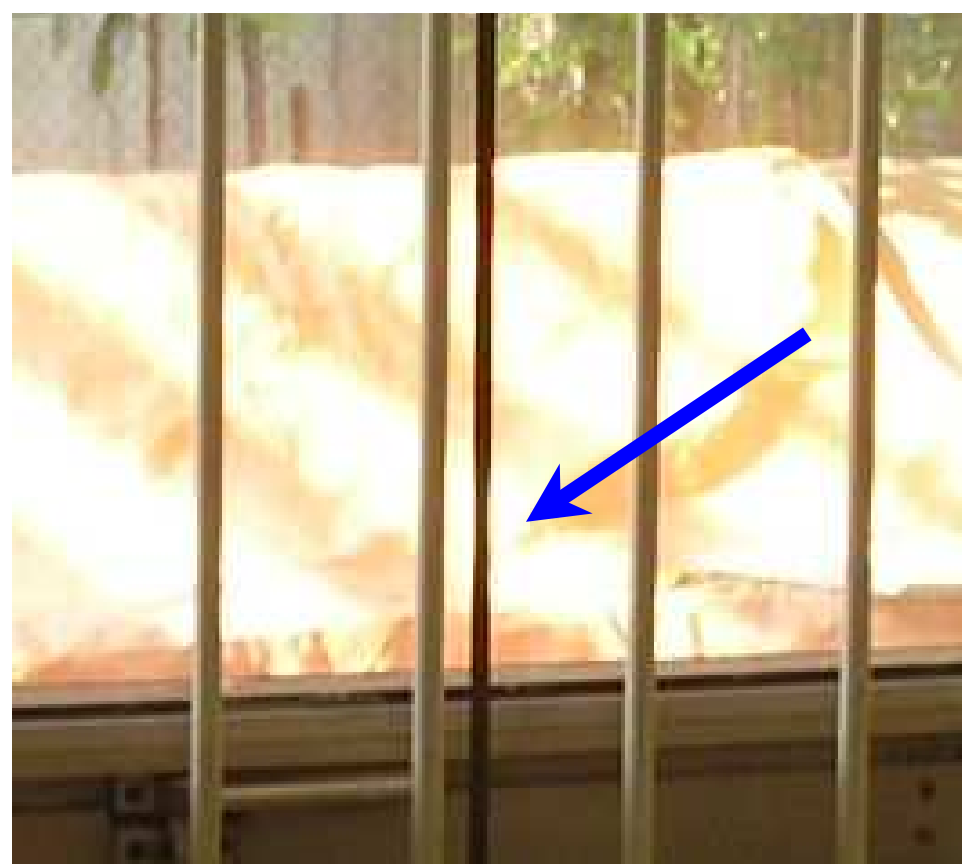

Figura 10 - Corpo-de-prova de aço momentos antes do rompimento 


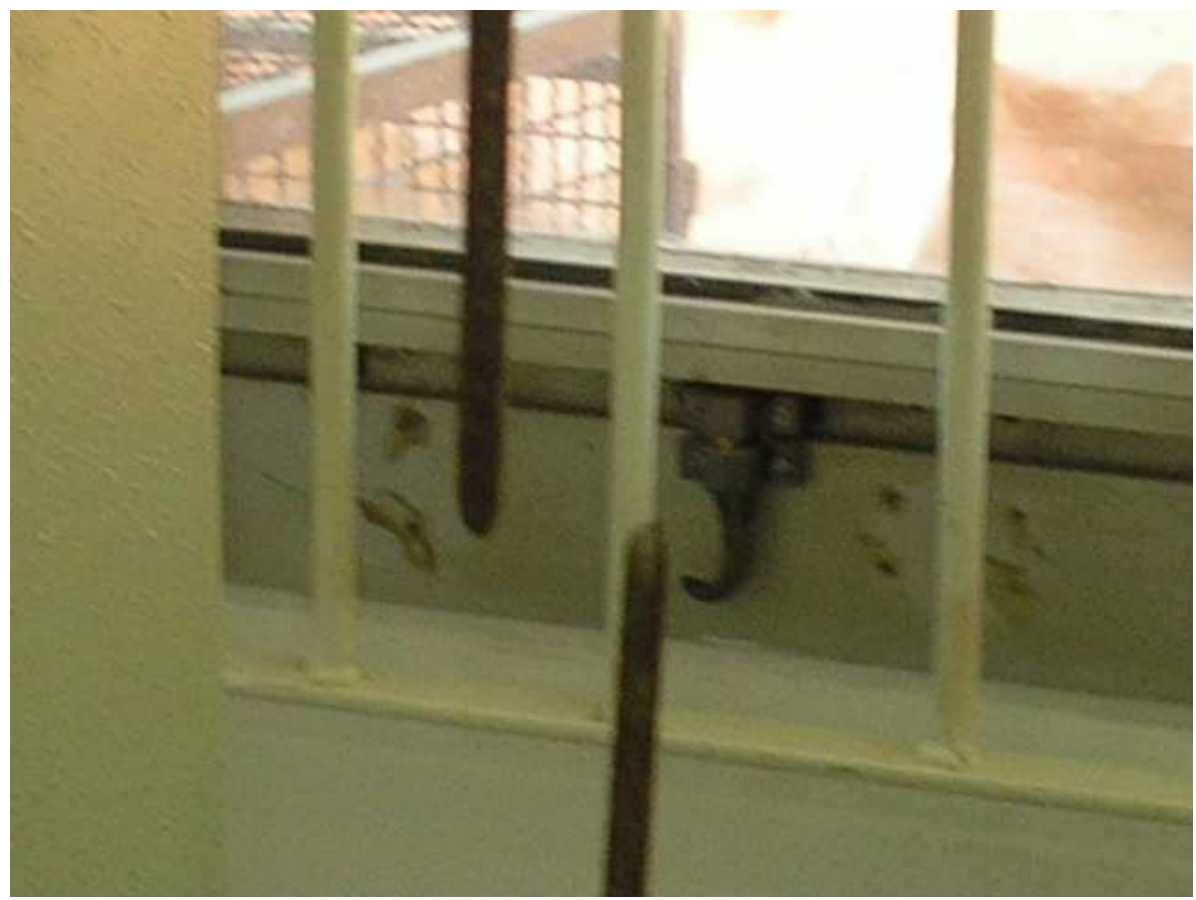

Figura 11 - Corpo-de-prova rompido

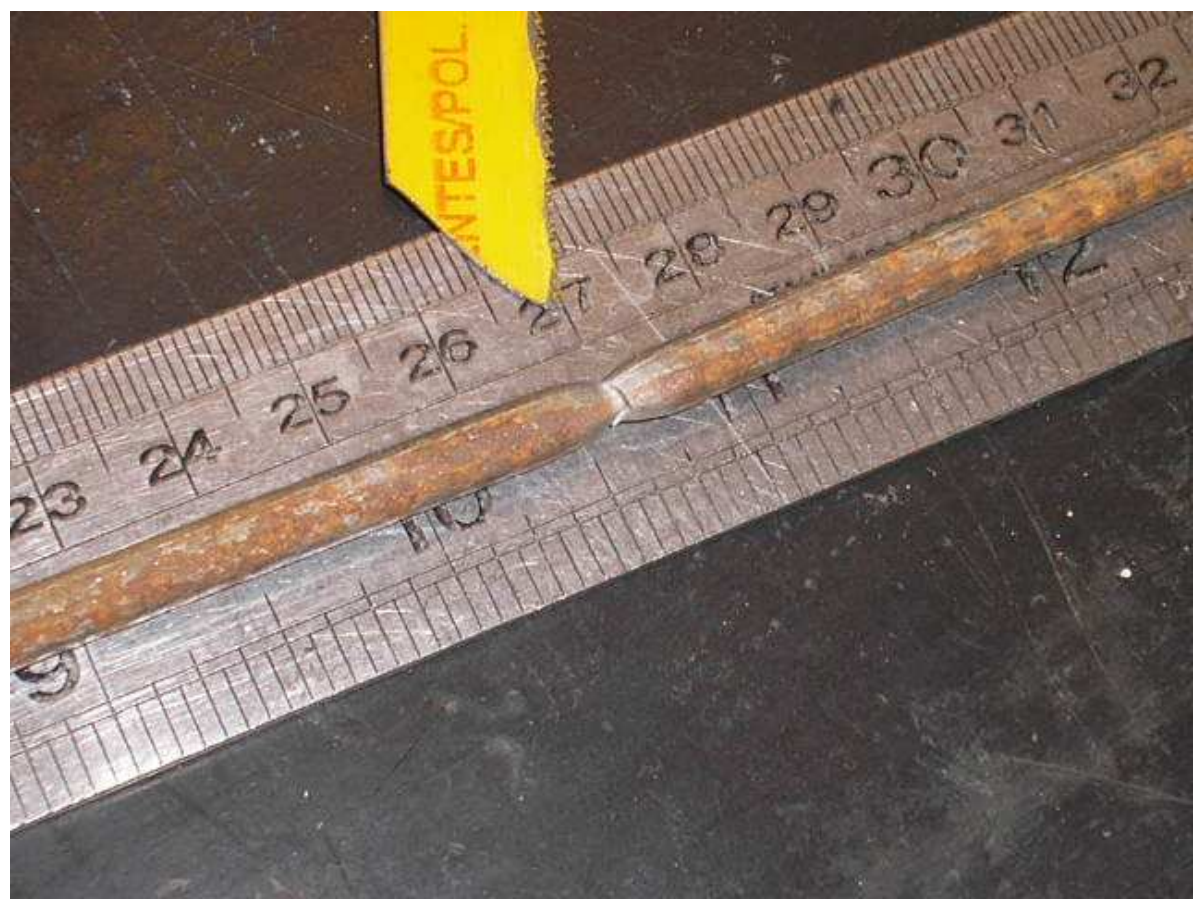

Figura 12 - Corpo-de-prova de aço rompido 
6. Ensaios dos modelos reduzidos da primeira etapa

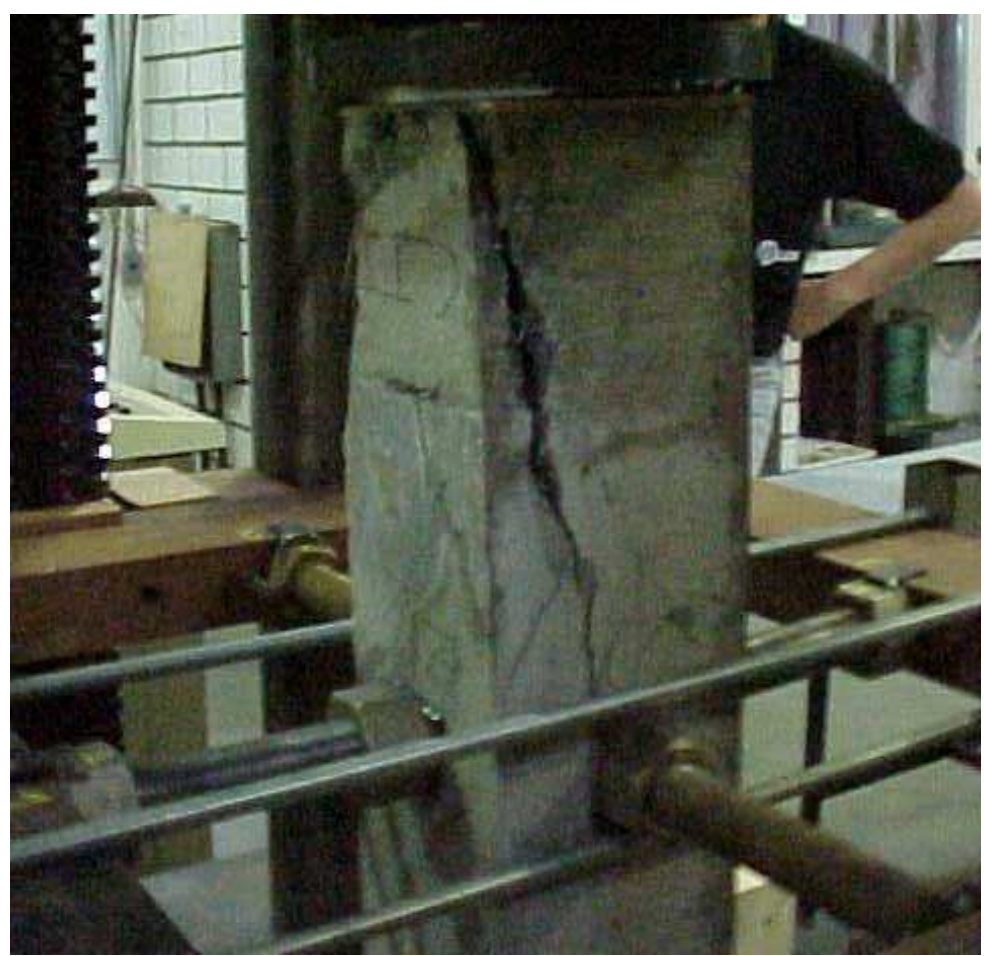

Figura 13 - Modelo reduzido 1, da primeira etapa de ensaios, rompido, nota-se ruptura apenas na região superior

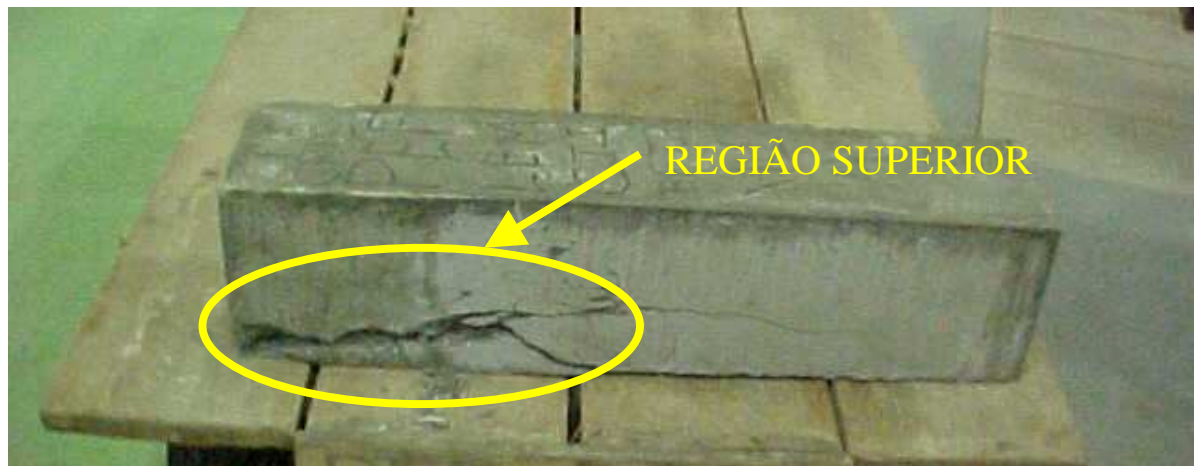

Figura 14 - Modelo reduzido 1, da primeira etapa de ensaios, rompido, nota-se ruptura apenas na região superior 


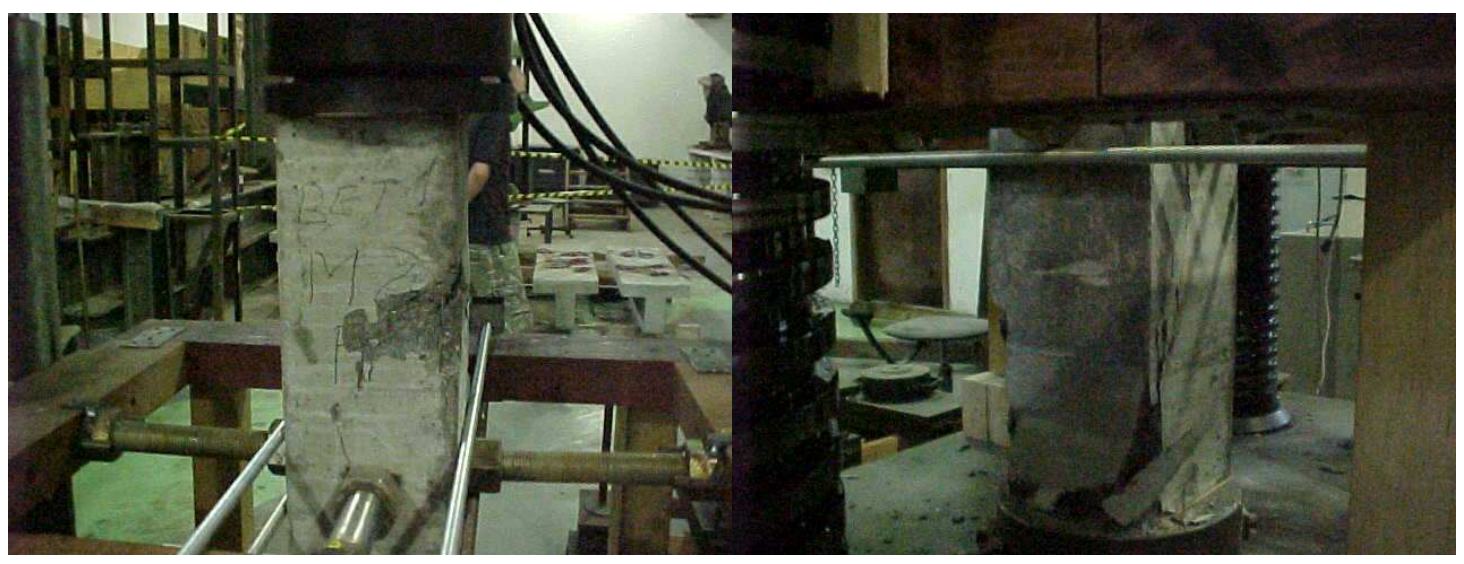

Figura 15 - Modelo reduzido 2, da primeira etapa de ensaios, rompido, nota-se ruptura apenas na região superior e esmagamento do concreto em uma das faces de contato com a prensa

6. Ensaios dos modelos reduzidos da segunda etapa

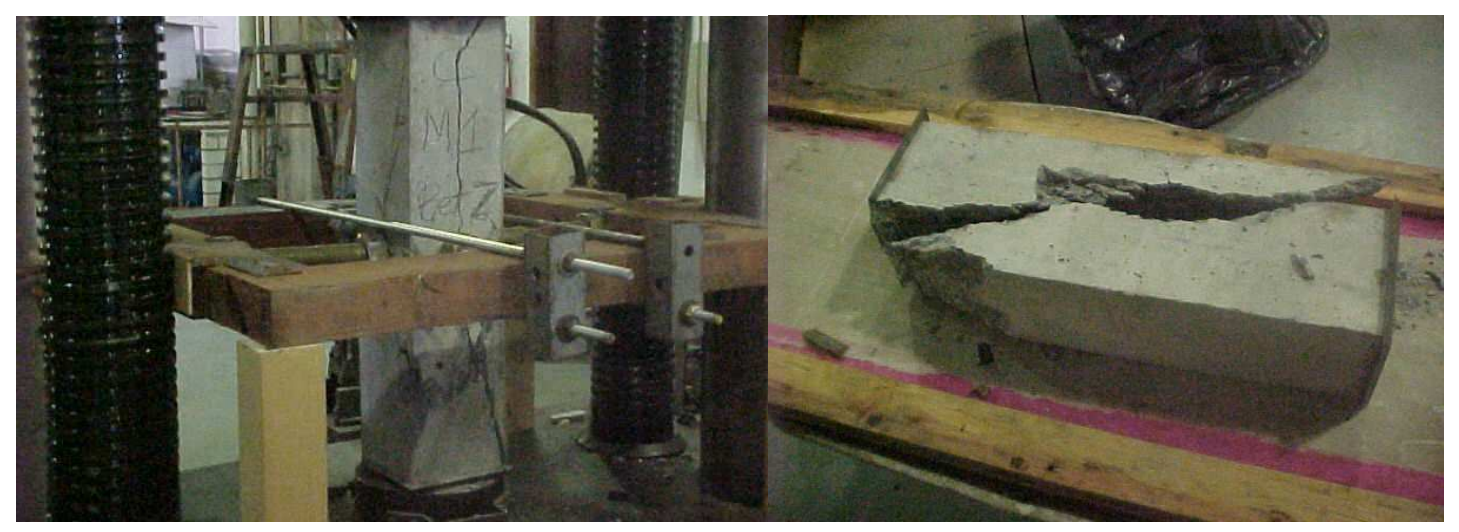

Figura 16 - Modelo reduzido I, da segunda etapa de ensaios, rompido, nota-se ruptura longitudinal em toda a altura do modelo 


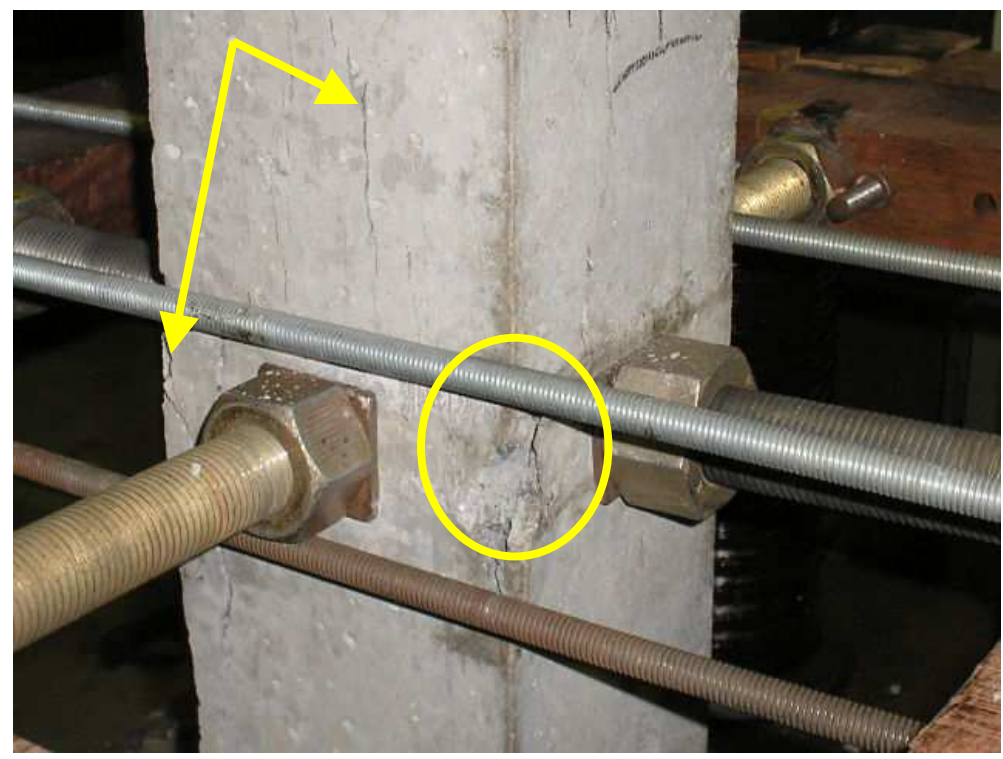

Figura 17 - Modelo reduzido II, da segunda etapa de ensaios, rompido, nota-se ruptura se propagando do pilar na região da laje, sendo que essa ruptura teve início na laje

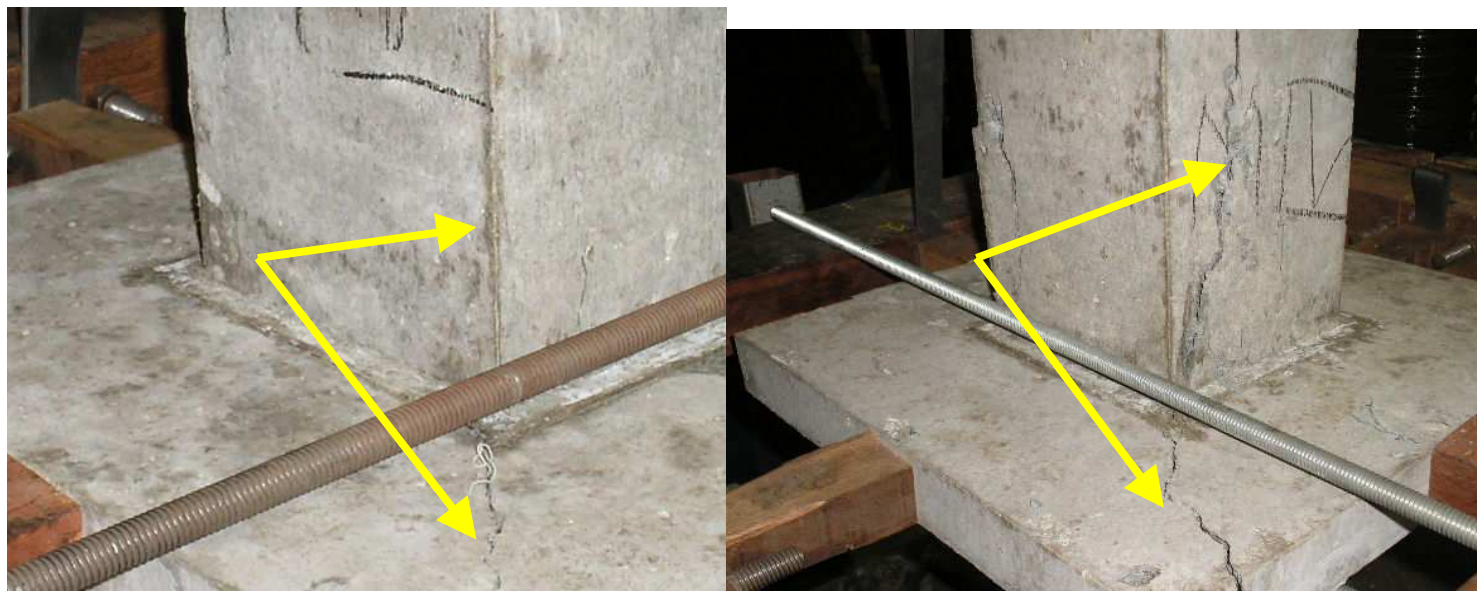

Figura 18 - Modelo reduzido IV, da segunda etapa de ensaios, rompido, nota-se a rachadura do pilar se propagando pela laje, ao contrário do modelo II a ruptura nesse ensaio teve início no pilar e depois se propagou pela laje. 


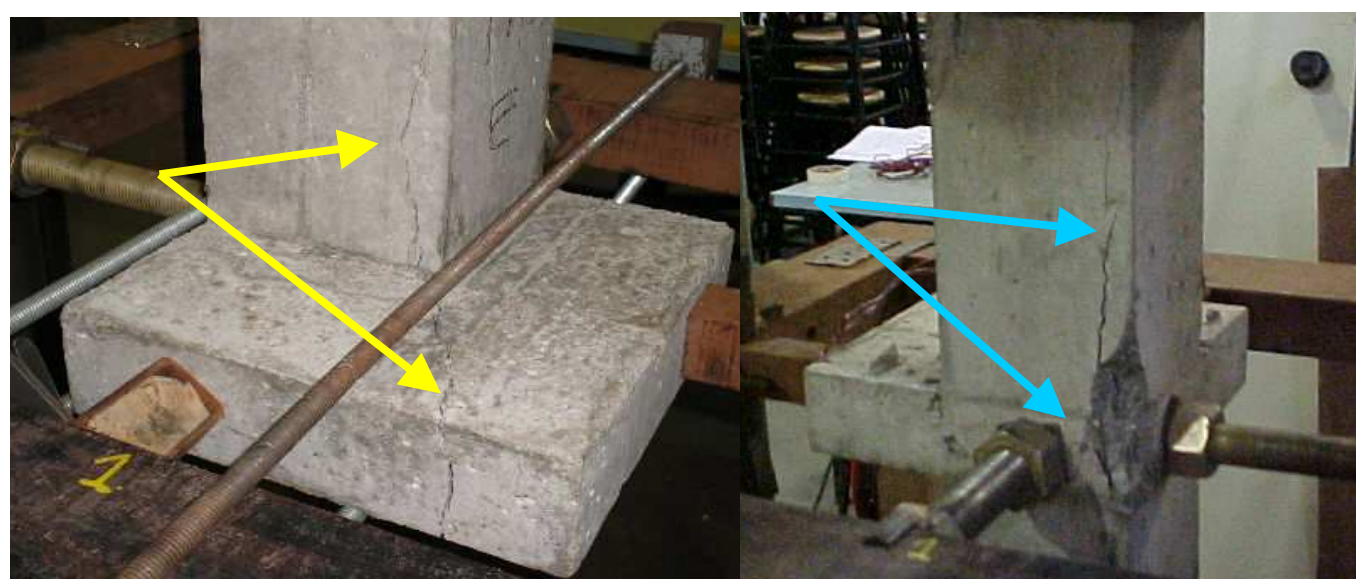

Figura 19 - Modelo reduzido $\mathrm{V}$, da segunda etapa de ensaios, rompido, nota-se a rachadura do pilar se propagando pela laje, setas amarelas, porém a ruptura inicial ocorreu na face que não tem laje, seta azul, iniciando pela região da laje e depois se propagando pela altura do pilar

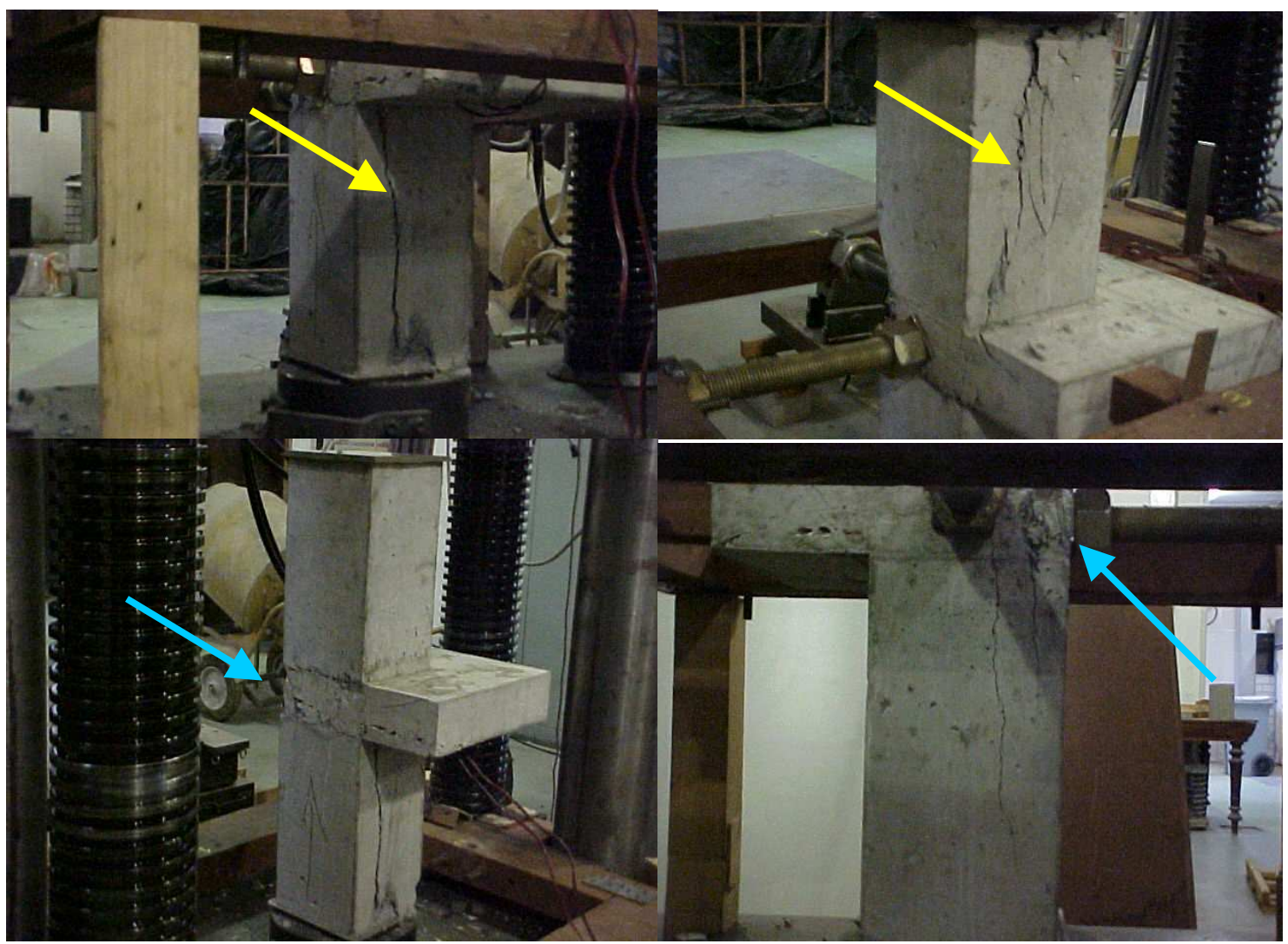

Figura 20 - Modelo reduzido VI, da segunda etapa de ensaios, nota-se a rachadura do pilar se propagando por toda a altura do pilar,setas amarelas, ficando porém intacta a região da laje, que está protegida pela armadura, setas azuis 


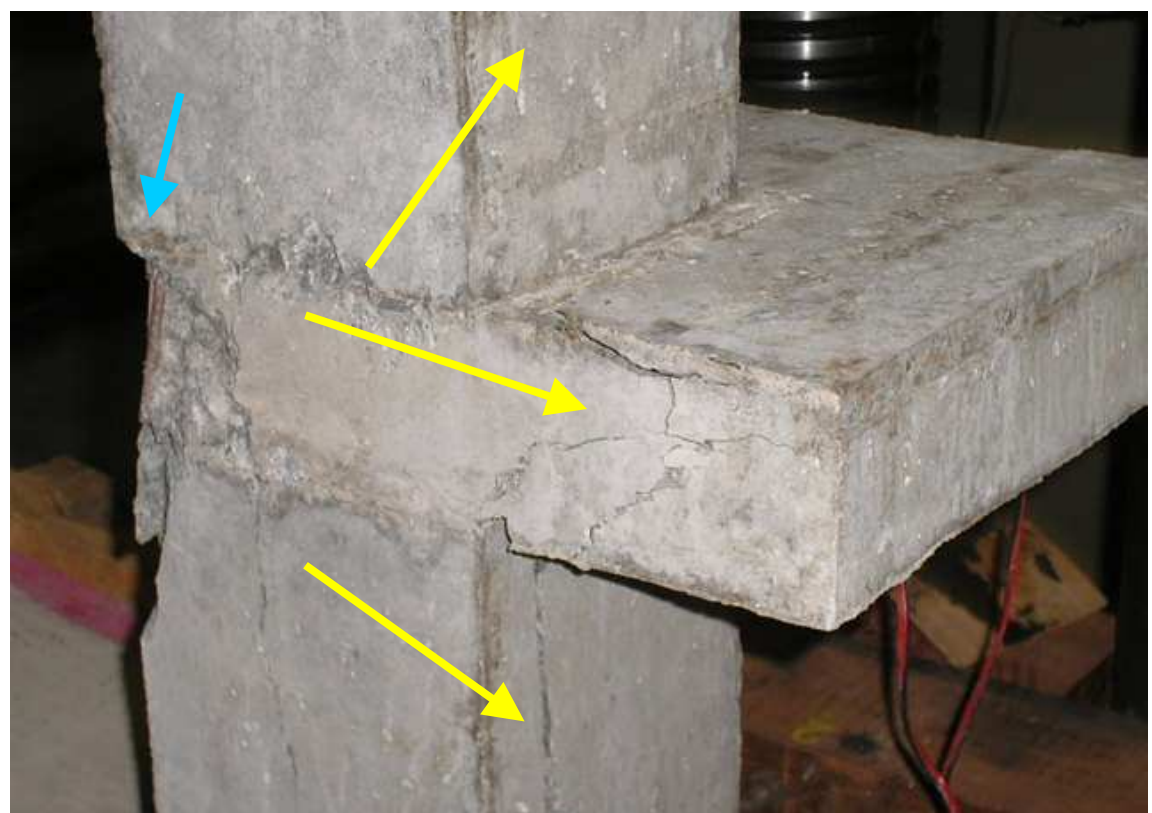

Figura 21 - Modelo reduzido VII, da segunda etapa de ensaios, rompido, nota-se, setas amarelas, a rachadura do pilar se propagando por toda a altura do pilar e “abrindo-se” na laje. Pode-se ainda notar, seta azul, que a região interna à armadura não se rompeu. 
ANEXO C - Medições

Este anexo destina-se a apresentar as medições realizadas para cada um dos modelos reduzidos, a partir das quais calcularam-se os valores médios que por sua vez foram utilizados nos cálculos apresentados anteriormente.

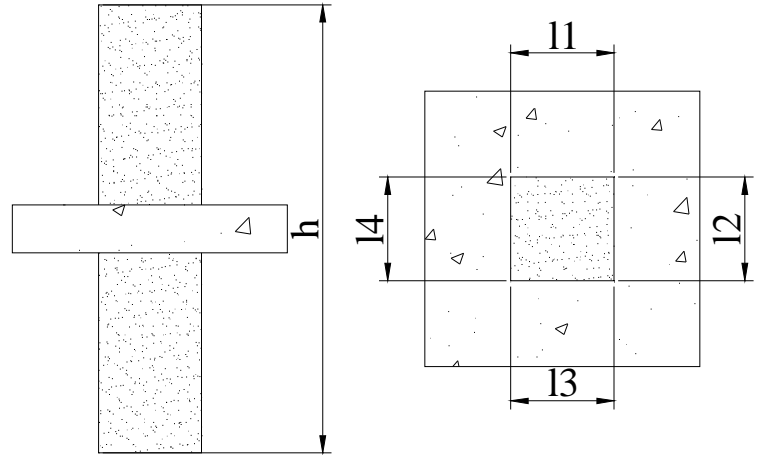

PILAR CENTRAL

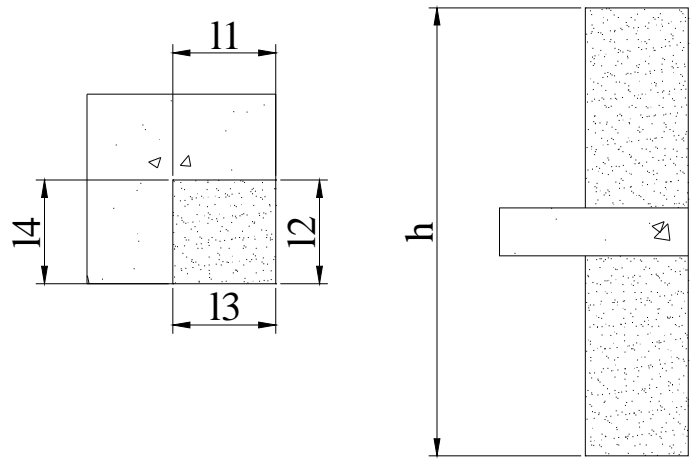

PILAR DE CANTO

Figura 1 - Medidas consideradas 


\begin{tabular}{|c|c|c|c|c|c|c|c|c|c|c|c|c|}
\hline \multirow[t]{2}{*}{ MODELO } & \multirow[t]{2}{*}{$\begin{array}{c}\text { EXEM- } \\
\text { PLAR }\end{array}$} & $\begin{array}{c}\text { VALORES } \\
\text { MEDIDOS } \\
(\mathrm{cm})\end{array}$ & $\begin{array}{l}\text { VALOR } \\
\text { MÉDIO } \\
(\mathrm{cm})\end{array}$ & $\begin{array}{c}\text { VALORES } \\
\text { MEDIDOS } \\
(\mathrm{cm})\end{array}$ & $\begin{array}{l}\text { VALOR } \\
\text { MÉDIO } \\
(\mathrm{cm})\end{array}$ & $\begin{array}{c}\text { VALORES } \\
\text { MEDIDOS } \\
(\mathrm{cm})\end{array}$ & $\begin{array}{c}\text { VALOR } \\
\text { MÉDIO } \\
(\mathrm{cm})\end{array}$ & $\begin{array}{c}\text { VALORES } \\
\text { MEDIDOS } \\
(\mathrm{cm})\end{array}$ & $\begin{array}{c}\text { VALOR } \\
\text { MÉDIO } \\
(\mathrm{cm})\end{array}$ & $\begin{array}{c}\text { ÁREA } \\
\left(\mathrm{cm}^{2}\right)\end{array}$ & $\begin{array}{l}\text { VALORES } \\
\text { MEDIDOS } \\
(\mathrm{cm})\end{array}$ & $\begin{array}{l}\text { VALOR } \\
\text { MÉDIO } \\
(\mathrm{cm})\end{array}$ \\
\hline & & \multicolumn{2}{|c|}{$l_{1}$} & \multicolumn{2}{|l|}{$l_{2}$} & \multicolumn{2}{|l|}{$l_{3}$} & \multicolumn{2}{|l|}{$\mathrm{l}_{4}$} & $\mathrm{a}$ & \multicolumn{2}{|l|}{$\mathrm{h}$} \\
\hline \multirow{12}{*}{ M I } & \multirow{3}{*}{ A } & 15,01 & \multirow{3}{*}{15,01} & 14,99 & \multirow{3}{*}{15,01} & 15,02 & \multirow{3}{*}{15,02} & 14,98 & \multirow{3}{*}{15,01} & \multirow{3}{*}{225,28} & 65,03 & \multirow{3}{*}{65,03} \\
\hline & & 14,99 & & 15,01 & & 14,99 & & 15,03 & & & 65,08 & \\
\hline & & 15,02 & & 15,02 & & 15,04 & & 15,01 & & & 64,99 & \\
\hline & \multirow{3}{*}{ B } & 15,07 & \multirow{3}{*}{15,06} & 15,10 & \multirow{3}{*}{15,05} & 14,98 & \multirow{3}{*}{15,00} & 14,99 & \multirow{3}{*}{14,98} & \multirow{3}{*}{225,67} & 64,98 & \multirow{3}{*}{65,00} \\
\hline & & 15,00 & & 15,00 & & 15,00 & & 14,98 & & & 64,99 & \\
\hline & & 15,10 & & 15,06 & & 15,02 & & 14,97 & & & 65,03 & \\
\hline & \multirow{3}{*}{$\mathrm{C}$} & 14,97 & \multirow{3}{*}{14,99} & 14,99 & \multirow{3}{*}{14,97} & 15,05 & \multirow{3}{*}{15,07} & 14,95 & \multirow{3}{*}{14,96} & \multirow{3}{*}{225,00} & 65,02 & \multirow{3}{*}{65,01} \\
\hline & & 15,02 & & 14,97 & & 15,07 & & 14,99 & & & 64,99 & \\
\hline & & 14,98 & & 14,96 & & 15,10 & & 14,95 & & & 65,01 & \\
\hline & \multirow{3}{*}{$\mathrm{D}$} & 14,99 & \multirow{3}{*}{14,99} & 15,00 & & 14,99 & & 15,02 & & & 64,97 & \\
\hline & & 15,00 & & 14,98 & 14,99 & 14,98 & 14,98 & 14,98 & 15,00 & 224,68 & 65,03 & 65,00 \\
\hline & & 14,98 & & 14,99 & & 14,96 & & 15,00 & & & 65,01 & \\
\hline & & 14,99 & & 15,03 & & 14,98 & & 14,98 & & & 65,06 & \\
\hline & A & 15,02 & 15,01 & 15,01 & 15,02 & 14,99 & 14,99 & 15,02 & 15,00 & 225,15 & 65,02 & 65,03 \\
\hline & & 15,01 & & 15,02 & & 15,00 & & 15,01 & & & 65,00 & \\
\hline & & 15,05 & & 15,00 & & 14,97 & & 15,04 & & & 65,01 & \\
\hline M II & B & 14,99 & 15,03 & 15,00 & 15,00 & 14,99 & 14,98 & 15,06 & 15,04 & 225,48 & 64,99 & 65,01 \\
\hline & & 15,06 & & 15,01 & & 14,99 & & 15,03 & & & 65,02 & \\
\hline & & 15,00 & & 14,99 & & 15,03 & & 15,00 & & & 65,05 & \\
\hline & $\mathrm{C}$ & 15,10 & 15,05 & 14,98 & 14,98 & 15,05 & 15,05 & 14,99 & 15,00 & 225,58 & 64,99 & 65,02 \\
\hline & & 15,05 & & 14,96 & & 15,08 & & 15,00 & & & 65,01 & \\
\hline
\end{tabular}




\begin{tabular}{|c|c|c|c|c|c|c|c|c|c|c|c|c|}
\hline \multirow[t]{2}{*}{ MODELO } & \multirow[t]{2}{*}{$\begin{array}{c}\text { EXEM- } \\
\text { PLAR }\end{array}$} & $\begin{array}{c}\text { VALORES } \\
\text { MEDIDOS } \\
(\mathrm{cm}) \\
\end{array}$ & $\begin{array}{c}\text { VALOR } \\
\text { MÉDIO } \\
(\mathrm{cm})\end{array}$ & $\begin{array}{c}\text { VALORES } \\
\text { MEDIDOS } \\
(\mathrm{cm}) \\
\end{array}$ & $\begin{array}{c}\text { VALOR } \\
\text { MÉDIO } \\
(\mathrm{cm}) \\
\end{array}$ & $\begin{array}{c}\text { VALORES } \\
\text { MEDIDOS } \\
(\mathrm{cm})\end{array}$ & $\begin{array}{l}\text { VALOR } \\
\text { MÉDIO } \\
(\mathrm{cm})\end{array}$ & $\begin{array}{l}\text { VALORES } \\
\text { MEDIDOS } \\
(\mathrm{cm}) \\
\end{array}$ & $\begin{array}{l}\text { VALOR } \\
\text { MÉDIO } \\
(\mathrm{cm})\end{array}$ & $\begin{array}{c}\text { ÁREA } \\
\left(\mathrm{cm}^{2}\right)\end{array}$ & $\begin{array}{c}\text { VALORES } \\
\text { MEDIDOS } \\
(\mathrm{cm})\end{array}$ & $\begin{array}{l}\text { VALOR } \\
\text { MÉDIO } \\
(\mathrm{cm})\end{array}$ \\
\hline & & \multicolumn{2}{|c|}{$l_{1}$} & \multicolumn{2}{|c|}{$1_{2}$} & \multicolumn{2}{|c|}{$1_{3}$} & \multicolumn{2}{|c|}{$1_{4}$} & $\mathrm{a}$ & \multicolumn{2}{|c|}{$\begin{array}{c}\mathrm{h} \\
\end{array}$} \\
\hline \multirow{9}{*}{ M IV } & \multirow{3}{*}{ A } & 15,01 & \multirow{3}{*}{15,01} & 15,04 & \multirow{3}{*}{15,03} & 14,99 & \multirow{3}{*}{14,99} & 14,99 & \multirow{3}{*}{15,02} & \multirow{3}{*}{225,35} & 65,00 & \multirow{3}{*}{65,04} \\
\hline & & 15,02 & & 15,01 & & 14,99 & & 15,02 & & & 65,05 & \\
\hline & & 14,99 & & 15,03 & & 15,00 & & 15,05 & & & 65,08 & \\
\hline & \multirow{3}{*}{ B } & 15,10 & \multirow{3}{*}{15,08} & 15,02 & \multirow{3}{*}{15,02} & 14,95 & \multirow{3}{*}{14,95} & 14,90 & \multirow{3}{*}{14,93} & \multirow{3}{*}{224,85} & 65,08 & \multirow{3}{*}{65,06} \\
\hline & & 15,08 & & 15,03 & & 14,93 & & 14,85 & & & 65,05 & \\
\hline & & 15,06 & & 15,01 & & 14,98 & & 15,03 & & & 65,06 & \\
\hline & \multirow{3}{*}{$\mathrm{C}$} & 14,99 & \multirow{3}{*}{15,03} & 15,10 & \multirow{3}{*}{15,09} & 14,99 & \multirow{3}{*}{14,98} & 14,98 & \multirow{3}{*}{14,97} & \multirow{3}{*}{225,55} & 65,06 & \multirow{3}{*}{65,03} \\
\hline & & 15,07 & & 15,07 & & 14,97 & & 14,99 & & & 65,00 & \\
\hline & & 15,04 & & 15,09 & & 14,98 & & 14,95 & & & 65,04 & \\
\hline \multirow{9}{*}{ M V } & \multirow{3}{*}{$\mathrm{A}$} & 14,98 & \multirow{3}{*}{14,99} & 15,08 & \multirow{3}{*}{15,08} & 14,98 & & 14,98 & & & 65,03 & \\
\hline & & 15,00 & & 15,10 & & 14,99 & 14,99 & 15,00 & 15,00 & 225,43 & 65,01 & 65,02 \\
\hline & & 14,99 & & 15,05 & & 14,99 & & 15,03 & & & 65,02 & \\
\hline & & 15,01 & & 15,00 & & 15,01 & & 15,00 & & & 65,07 & \\
\hline & B & 14,99 & 15,00 & 15,01 & 15,01 & 15,00 & 15,01 & 14,99 & 15,00 & 225,15 & 65,03 & 65,04 \\
\hline & & 14,99 & & 15,03 & & 15,02 & & 15,01 & & & 65,01 & \\
\hline & & 15,10 & & 15,02 & & 15,01 & & 15,00 & & & 65,01 & \\
\hline & $\mathrm{C}$ & 15,05 & 15,06 & 15,00 & 15,02 & 15,04 & 15,02 & 14,99 & 14,99 & 225,68 & 65,07 & 65,03 \\
\hline & & 15,04 & & 15,03 & & 15,00 & & 14,99 & & & 65,02 & \\
\hline
\end{tabular}

